\title{
Tradeoffs, Complementarities and Synergies between Different Agricultural Technologies: Insights from Maize Farmers in Kenya
}

\author{
Dissertation \\ to obtain the $\mathrm{Ph}$. D. degree \\ in the International Ph. D. Program for Agricultural Sciences in Goettingen (IPAG) \\ at the Faculty of Agricultural Sciences, \\ Georg-August-University Göttingen, Germany \\ presented by \\ Priscilla Wainaina \\ born in Kikuyu, Kenya
}

Göttingen, March 2016 
1. Name of supervisor: Prof. Dr. Matin Qaim

2. Name of co-supervisor: Prof. Dr. Bernhard Brümmer

Date of dissertation: $12^{\text {th }}$ May 2016 


\section{Summary}

Global demand for food and farm commodities continues to grow, while land and other natural resources are becoming increasingly scarce. In Sub-Saharan Africa (SSA), rising population, decreasing per capita arable land, soil degradation and changes in weather patterns are the major challenges affecting productivity and welfare of smallholder farmers. Existing agricultural practices may not be able to meet production needs in the face of these challenges. Sustainable intensification has been proposed as one way of increasing agricultural productivity in a socially and environmentally responsible way. This requires a broad portfolio of technologies, including input-intensive and various natural resource management (NRM) practices. However, while there is consensus that these agricultural technologies play an important role in improving the welfare of smallholder farmers, there are disagreements as to which type of technology is best suited for farmers in SSA. Some support input-intensive technologies while others support NRM technologies. In reality these technologies are not incompatible and there may even be synergies in combining them. We use nationally representative data from maize production systems in Kenya to understand tradeoffs, complementarities and synergies that exist between different input-intensive and NRM technologies. Maize is the most important crop in Kenya, providing much of the daily calorie requirements and is grown by the majority of smallholder farmers in almost all of the country's agroecological zones.

This dissertation comprises three essays. In the first essay, we analyze adoption as well as tradeoffs and complementarities that exist between different types of input-intensive and NRM technologies practiced by smallholder maize farmers in Kenya. There is a lively debate about which type of technology is the most appropriate to foster sustainable development. In the public debate, the two strategies are often perceived as incompatible. Environmental non-governmental organizations (NGOs) in particular consider NRM practices, which are mostly low-external input strategies as the only sustainable form of agriculture, a view that has considerable influence on policymakers and the international donor community. Most existing adoption studies have either looked at input-intensive technologies or at NRM techniques, using different data and methodologies, so that comparisons were not easily possible. We apply a multivariate probit in the analysis since it allows for correlation between the error terms in the adoption of these technologies. This enables us to analyze adoption of different technologies simultaneously. 
Specifically, we consider seven technologies; improved seeds, chemical fertilizers (input intensive), terracing, soil bunds, zero tillage, crop residue management and use of animal manure. Results indicate that NRM technologies and strategies that build on external inputs are not incompatible. Interesting complementarities exist, which are not yet sufficiently exploited, because many organizations promote either one type of technology or the other, but rarely a combination of both. NRM technologies are mostly promoted by the public extension service and NGOs, whereas for improved seeds and mineral fertilizer the private sector plays a larger role. While this view is short-sighted, it influences development programs and prevents more widespread implementation of combined approaches that can bring about important synergies.

In the second essay, we analyze income effects of various technologies and technology combinations. Possible synergies in smallholder environments are not yet sufficiently understood since most impact studies focus on the effects of single technologies. We compare income effects of various input-intensive technologies, NRM technologies, and selected combinations. We use propensity score matching to correct for selection bias. When adopted alone, some innovations produce positive effects, while others do not. Effects of certain technology combinations are larger. The largest income gains occur when improved seeds are adopted together with organic manure and zero tillage practices. This clearly underlines that there are important synergies between input-intensive and NRM technologies. However, the number of farmers that have adopted such promising technology combinations is relatively small, again implying that synergies are not yet fully exploited.

In the third essay, we estimate and make a distinction between technical efficiency (TE) and environmental gaps among maize farmers distributed across different agroecological zones (AEZs). Reducing inefficiencies among smallholder farmers is one way of sustainably increasing yields. While there are numerous studies on productivity in SSA, few make a distinction between TE and environmental gaps resulting from climatic differences. Not differentiating can contribute to misinformed policies, for instance when existing environmental gaps are falsely attributed to farmers' inefficiencies. The AEZs in Kenya differ substantially in their climatic conditions and other factors. We apply the stochastic meta-frontier production function framework, which allows distinguishing between TEs and meta-technology ratios (which capture environmental gaps). We further assess factors explaining inefficiencies among farmers in each of the AEZs as well as those associated with meta-technology ratios (MTRs). We find large 
deviations between TEs and MTRs across the AEZs. TEs relative to the group frontiers are relatively high; in some zones (mostly the drier zones) they are two to three times higher than the TEs relative to the meta-frontier. This suggests that farmers compare much more favorably with farmers in the same AEZ as opposed to the whole industry. In the same vein, results suggest that environmental gaps contribute more to observed yield differences than farmers' inefficiencies, implying that farmers have not been able to sufficiently adapt their agricultural practices to the constraints they face. This interpretation is supported by low magnitudes of MTRs coupled with wide variation across the AEZs. Environmental gaps can be explained by the amount of rainfall received, maximum daily temperatures, population pressure, access to infrastructure, incidences of maize lethal necrosis disease and technologies adopted. Efforts to narrow down environmental gaps among farmers are thus more urgent than efforts to reduce technical inefficiencies.

We draw several conclusions from the study. Synergistic income effects exist between input-intensive and NRM technologies. However, these synergistic relationships have not been fully exploited. Furthermore, some technology combinations which were shown to be beneficial in other places are rarely observed among Kenyan farmers. This may be due to the divide among different organizations on the type of technologies they promote. Some tend to focus on promoting specific seed varieties or techniques, rather than more holistic approaches to increasing yields while protecting the environment. To be able to exploit these synergies there is need for more integrated extension by different organizations. In addition, narrowing down environmental gaps among farmers in different AEZs should be a priority for increasing maize yields. This can be achieved through promotion of appropriate technologies necessary to adapt to environmental stresses, such as drought and heat tolerant varieties for the dry regions as well as proper infrastructure. Further research is also necessary to be able to understand more synergistic associations between different types of technologies. 


\section{Acknowledgments}

This dissertation and my $\mathrm{PhD}$ journey would not have been successfully complete without assistance from various people. First and foremost, my sincere gratitude goes to my supervisor Prof. Dr. Matin Qaim for funding my PhD position. I am also very grateful for his guidance throughout the entire work and for his valuable and timely feedbacks. Special thanks also go to Prof. Dr. Bernhard Brümmer for co-supervising my dissertation and for helpful insights in chapter 4 of this dissertation. I am also grateful to Prof. Dr. Meike Wollni for serving on my examination committee.

I also thank all my colleagues in Georg-August-University of Goettingen, Department of Agricultural Economics and Rural development, Chair of International Food Economics and Rural Development, for the intriguing interactions and brilliant conversations we shared. I am especially thankful to Dr. Vijesh Krishna and Dr. Theda Goedecke for taking time to read my papers and for the valuable comments and being there to answer further questions. I also acknowledge Ms. Ilona Hoepfner for her very efficient assistance in all the administrative aspects that led me to successfully complete my $\mathrm{PhD}$.

This research was conducted in collaboration with International maize and wheat improvement centre (CIMMYT). I am grateful for the much support I received from the entire socioeconomics team in CIMMYT, Kenya during data collection and entry. Much gratitude especially goes to Dr. Songporne Tongruksawattana (currently at Partnership for Economic Policy, Kenya) who worked directly with me and also gave me valuable insights while writing this dissertation. I also received much support from the staff in Kenya Agricultural Research Institute (KARI) offices in all the districts where the survey was conducted. I am especially greatly indebted to Zachary Gitonga (CIMMYT) and Charles Bett (KARI) for the much needed assistance during the survey. I am also grateful to the large team of supervisors, enumerators, drivers and data entry clerks who were very skilled and reliable and ensured the process though tough went well. Special thanks especially go to Nicholas Ngwili and Judy Mutuku who after the survey worked with me diligently in data cleaning and addressing follow-up questions to the farmers. Much gratitude goes to all the farmers we interviewed for their patience throughout the long questionnaire and for sharing information willingly and generously. I also acknowledge the 
CGIAR Research Program on Climate Change, Agriculture, and Food Security (CCAFS) for financially supporting this research.

Special thanks are due to my parents for supporting and encouraging me throughout my entire education process. Much gratitude also goes to my brothers, sisters, nephews and nieces for much encouragement throughout the entire process. Last but not least, I am grateful to all my friends in Germany, in Kenya and elsewhere in the world for intriguing conversations and beautiful moments we shared during this time. PhD process can be very lonely but all of you made it enjoyable. 


\section{Table of Contents}

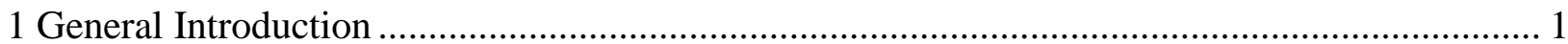

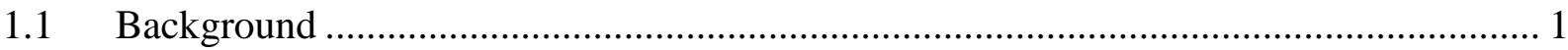

1.2 Problem statement and objectives ………………………………………………... 5

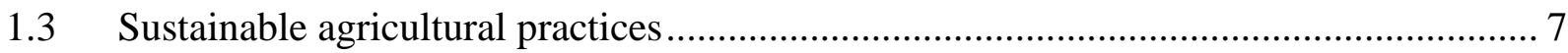

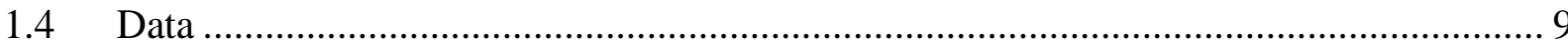

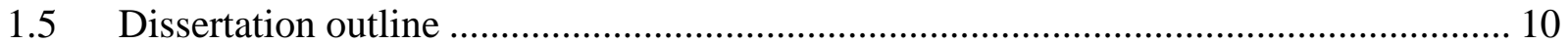

2 Tradeoffs and Complementarities in the Adoption of Improved Seeds, Fertilizer, and Natural Resource Management Technologies in Kenya........................................................................ 11

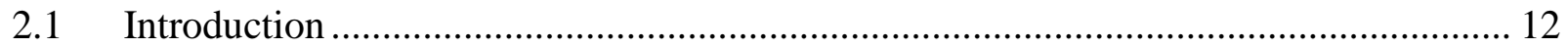

2.2 Types of technologies and factors influencing adoption............................................... 14

2.2.1. Input-intensive and NRM technologies ................................................................... 14

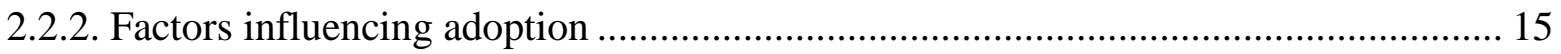

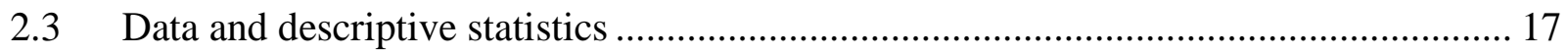

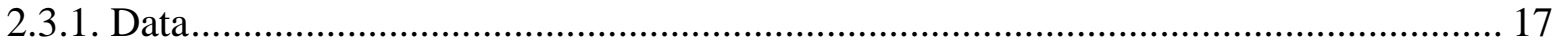

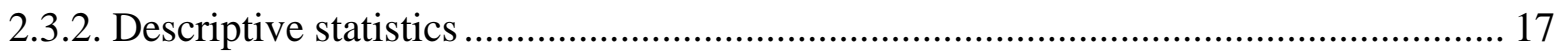

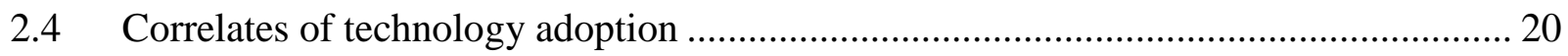

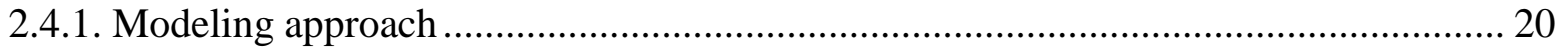

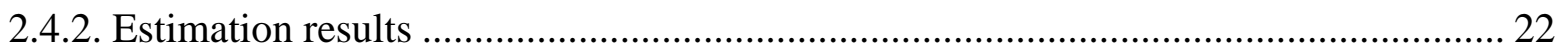

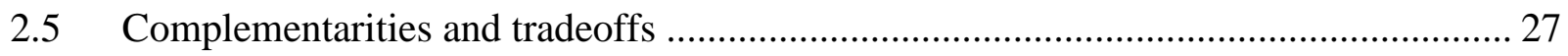

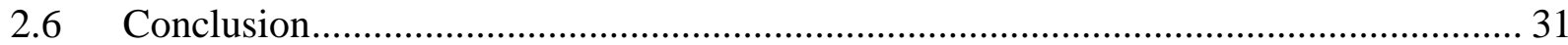

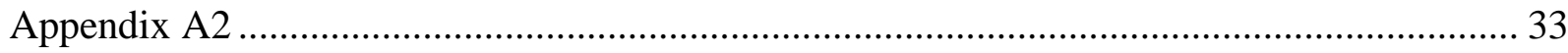

3 Synergies between Different Types of Agricultural Technologies: Insights from the Kenyan

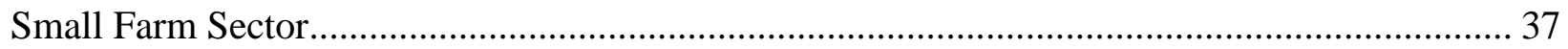

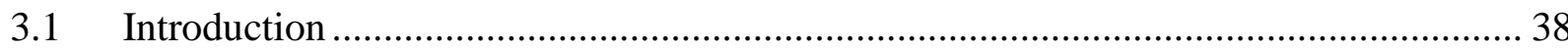

3.2 Data and technologies considered ............................................................................. 40

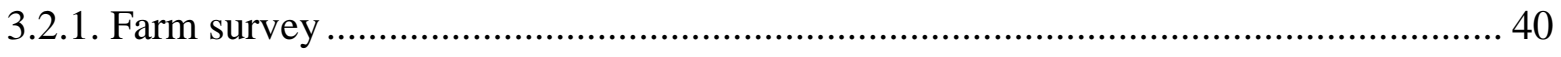

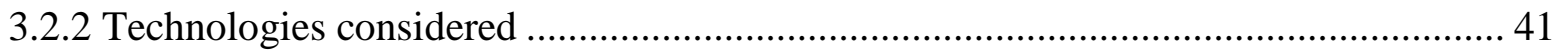

3.3 Methods ............................................................................................................ 42

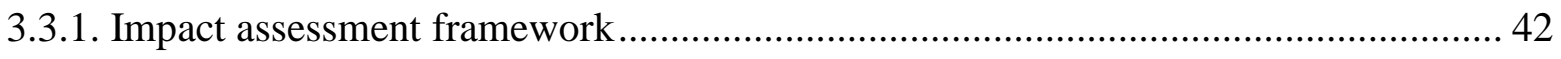




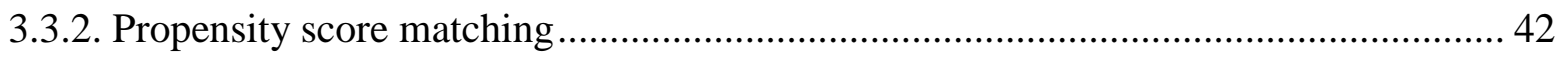

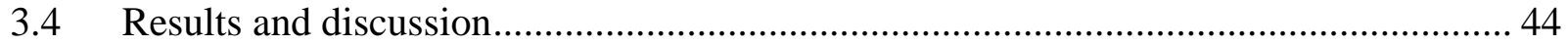

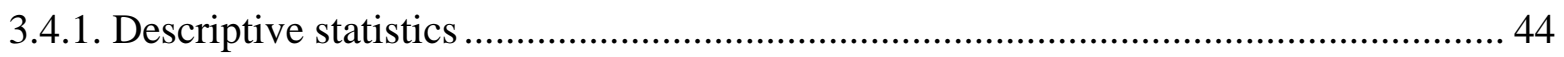

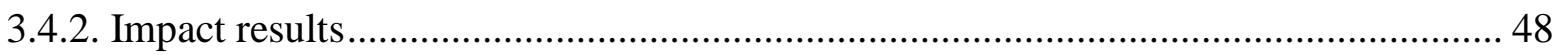

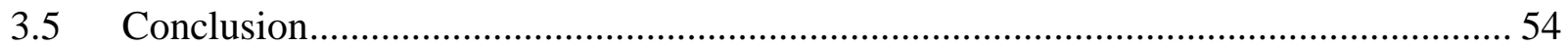

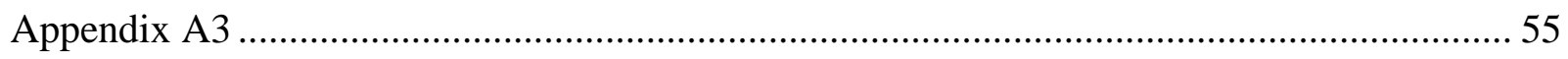

4 Technical Efficiency and Meta-technology Gap Ratios across Agroecological Zones among

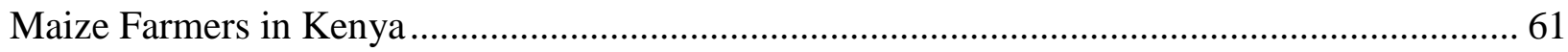

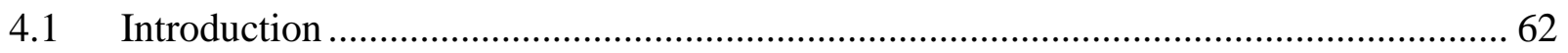

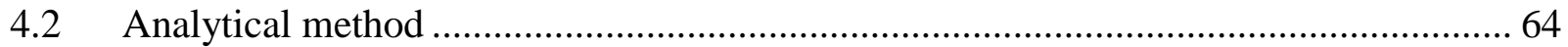

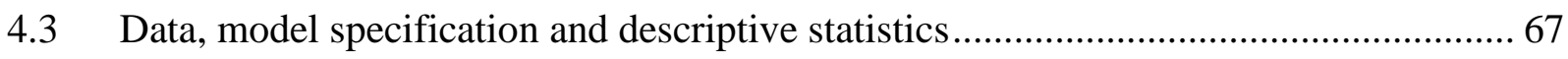

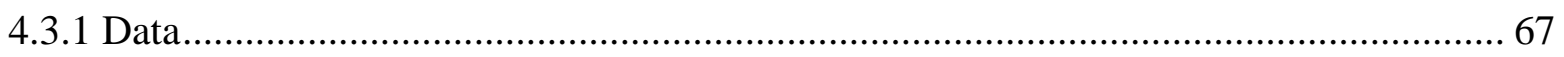

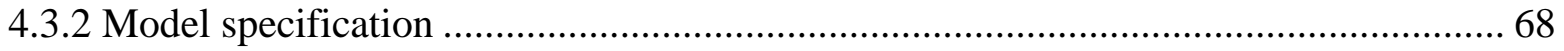

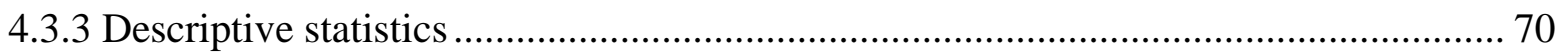

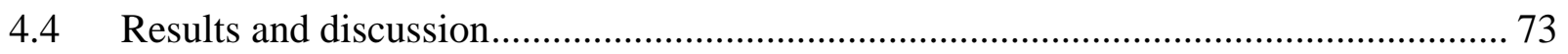

4.4.1 Results of the stochastic production function..................................................... 73

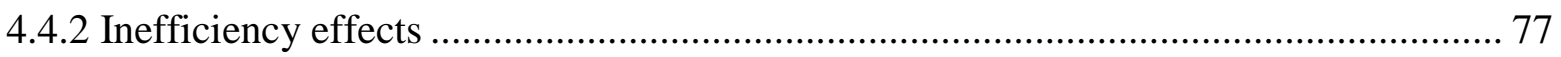

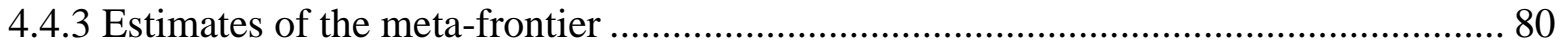

4.4.4 Summary estimates of meta-technology ratios and technical efficiencies across AEZs

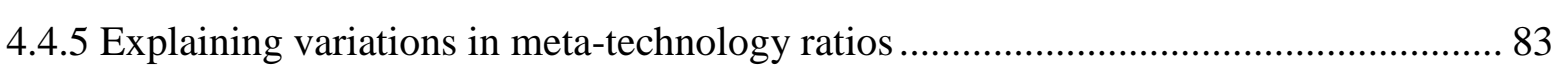

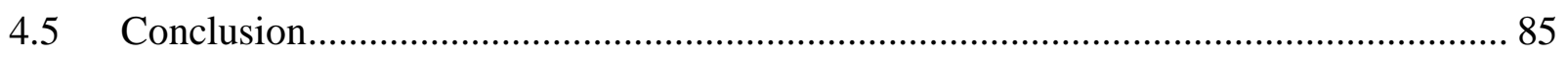

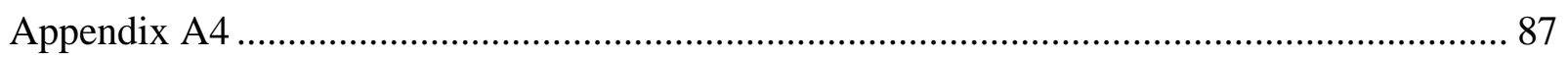

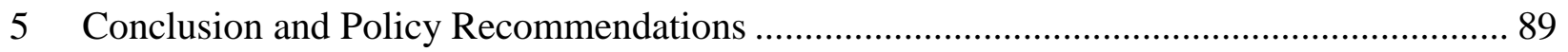

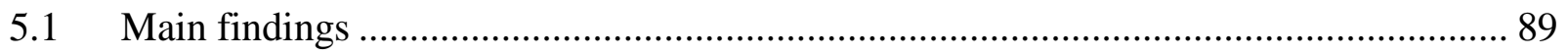

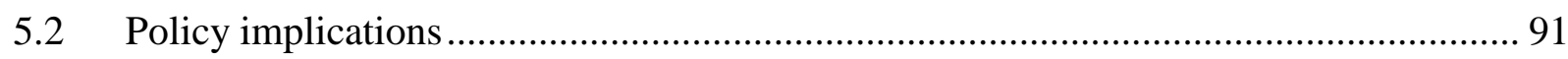

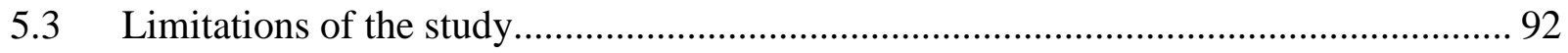

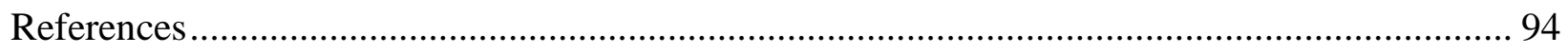

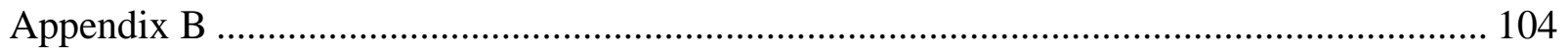




\section{List of Tables}

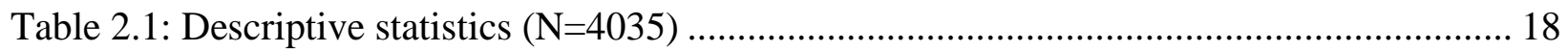

Table 2.2: Adoption rates and average yields by technology type ......................................... 19

Table 2.3: Characteristics of maize agroecological zones in Kenya ......................................... 20

Table 2.4: Results of the multivariate probit model ................................................................. 23

Table 2.5: Correlation matrix from the multivariate probit model ............................................ 28

Table 3.1: Agroecological zones in Kenya and regional distribution of sampled households ..... 40

Table 3.2: Summary statistics of outcome variables, technology adoption, and covariates......... 44

Table 3.3: Average structure of household income by status of technology adoption (income

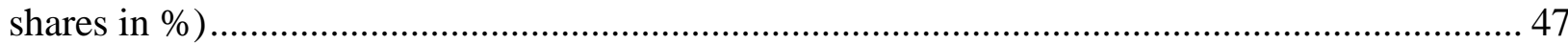

Table 3.4: Average household income levels by technology adoption status ........................... 48

Table 3.5: Impact of the adoption of technologies and technology combinations on household

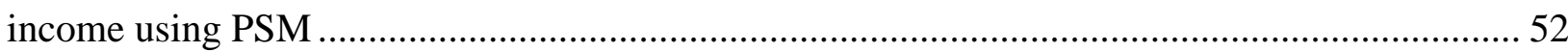

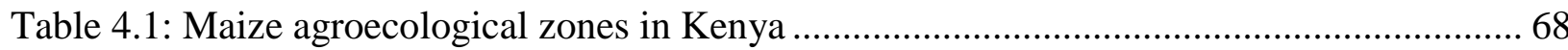

Table 4.2: Hypothesis testing for stochastic production frontier model ................................... 69

Table 4.3: Descriptive statistics of variables in the production frontier and inefficiency

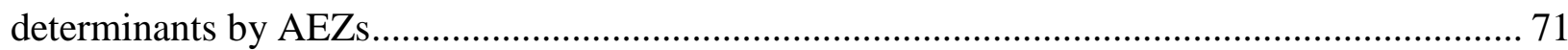

Table 4.4: Results of the stochastic production function ................................................... 75

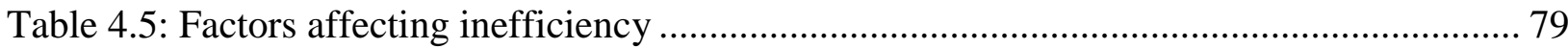

Table 4.6: Estimates of the meta-frontier, LP and QP .................................................. 81

Table 4.7: Summary statistics for the MTRs and the TEs relative to the pooled frontier, AEZs

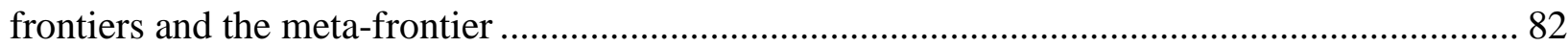

Table 4.8: Ordinary least squares regression of meta-technology ratios .................................. 84

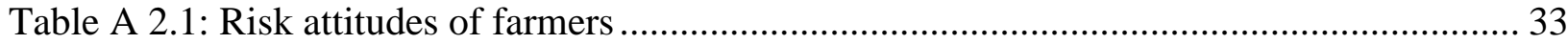

Table A2.2: Zero tillage adoption with plot ownership-farm size interaction term included...... 34

Table A2.3: Results of the multivariate probit model without AEZ dummies .......................... 35

Table A3.1: Logit models for estimating propensity scores ................................................. 55

Table A3.2: Balancing tests before and after matching ..................................................... 57

Table A3.3: Differences in attributes between matched and unmatched adopters of improved

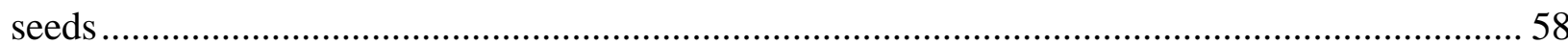

Table A 4.1: Summary statistics of variables explaining variation in MTRs ........................... 88 


\section{List of Figures}

Figure 1.1: Maize production and consumption in Kenya over the last decade ......................... 4

Figure 2.1: Farmers' sources of information for different technologies (proportions)................ 30

Figure 3.1: Average structure of household income by agroecological zones ........................ 46

Figure A 3.1: Propensity score histograms using radius matching showing common support

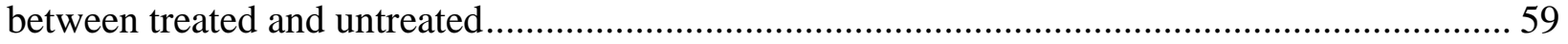

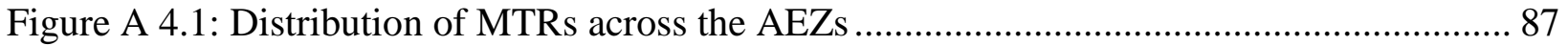




\begin{tabular}{|c|c|}
\hline \multicolumn{2}{|r|}{ Abbreviations } \\
\hline ATT & Average treatment effect on the treated \\
\hline CGIAR & Consultative Group for International Agricultural Research \\
\hline CIMMYT & International maize and wheat improvement centre \\
\hline AEZs & Agroecological zones \\
\hline FAO & Food and Agricultural Organization \\
\hline FAOSTAT & Food and Agricultural Organization Statistical Database \\
\hline KNBS & Kenya National Bureau of Statistics \\
\hline MFTE & Technical efficiency relative to the meta-frontier \\
\hline MLN & Maize lethal necrosis \\
\hline MTR & Meta-technology ratio \\
\hline MVP & Multivariate probit \\
\hline NRM & Natural resource management \\
\hline OLS & Ordinary least squares \\
\hline OPVs & Open pollinated varieties \\
\hline PSM & Propensity score matching \\
\hline PSU & Primary sampling units \\
\hline $\mathrm{TE}$ & Technical efficiency \\
\hline TGR & Technology gap ratio \\
\hline SSA & Sub-Saharan Africa \\
\hline SSU & Secondary sampling unit \\
\hline
\end{tabular}




\section{General Introduction}

\subsection{Background}

Across the world, continued population growth, rapidly changing consumption patterns and the impacts of climate change and environmental degradation are driving the limited resources towards critical thresholds. These pressures are more likely to be substantial across Africa (Reil and Smaling, 2008; DFID, 2009). Population is growing fastest in Sub-Saharan Africa (SSA) resulting in the steepest drop of per capita arable land in the world (Nkonya et al., 2011). Although at continent level Africa is characterized as the most land abundant having approximately half of the world's remaining arable land (Deininger et al., 2011), most of this land is concentrated in just eight countries while the remaining countries, such as Kenya, have large rural population densities (Chamberlin et al., 2014; Muyanga and Jayne, 2014). The problem is predicted to become worse since SSA's population which currently stands at 949 million people is expected to double by 2050 (Population Reference Bureau, 2015). Coupled with the increase in population, rising incomes and increasing urbanization are likely to further increase demand for food thus exerting even more pressure on the limited resources.

Soil degradation is another major concern in SSA - a substantial proportion of the arable land is degraded resulting in depleted and undernourished soils (The Montpellier panel, 2014). That a large proportion of people are relying on depleted soil to grow their food is a key reason why SSA lags behind other developing regions in meeting its agricultural productivity goals. The problem is especially severe in densely populated areas, where soils have been continuously cultivated and face fertility constraints that make them less responsive to chemical fertilizers (Marenya and Barrett, 2009; Sheahan et al., 2013). Climate change is also a growing concern in SSA mostly felt through increasing frequencies of drought and changes in the distribution of rainfall resulting in floods in some areas and no rainfall in others (Shiferaw et al., 2014a). Further still, rising temperatures in the decades ahead may lead to major disruptions in agriculture in these areas in form of crops failure due to little or too much rain as well as destruction by pests and diseases that thrive in the warmer climate. Effects of climate change are particularly severe in rain-fed agricultural systems that are common in most small farms in SSA. Lobell et al. (2011) estimated that, in Africa, each day the temperature was above $30^{\circ} \mathrm{C}$, maize 
yields were reduced by $1 \%$ under optimal rain-fed conditions and by $1.7 \%$ under drought conditions. Traditionally, African farmers were able to rely on more abundant land on which to farm and on more consistent weather to dictate planting and harvesting times. However, with a growing population, more competition for land, degraded soils and more variable and extreme weather, African farmers need to be equipped to deal with these new realities.

In the past decades since the 1960s, the green revolution produced success stories in Asia and Latin America where use of improved varieties, fertilizers, pesticides and irrigation resulted in large increases in food production thus reducing poverty and food insecurity amidst a growing population. Over-reliance on green revolution technologies has however been criticized due to environmental costs involved such as depletion of soil micronutrients, build-up of soil toxicity and a high incidence of pest and diseases (Jhamtani, 2010; FAO, 2011a). It has also been linked to contributing significantly to green-house gas emissions that are responsible for climate change (FAO, 2013; Tubiello et al., 2014). Against this background, simply copying the Asian green revolution model in SSA will not be sustainable.

Sustainable agricultural intensification ${ }^{1}$ has been proposed as one of the ways to sustainably feed the growing population without ignoring significant challenges of climate change and soil degradation (Godfray et al., 2010; Pretty, 2011; FAO, 2016). This entails producing more output from the same area of land while reducing the negative environmental impacts and at the same time increasing contributions to natural capital and the flow of environmental services (Royal Society, 2009; Godfray et al., 2010). Sustainable intensification involves employing better land management skills as well as more physical inputs; a combination of input-intensive technologies and natural resource management (NRM) technologies. Applied together, or in various combinations, these practices should contribute to important ecosystems services and work synergistically to produce positive outcomes. However, there is no consensus about which agricultural technologies and practices to deploy, since the suitability of technologies and technology combinations is context specific (Garnett et al., 2013). Sustainable agricultural intensification also include socio-economic aspects such as linking

\footnotetext{
${ }^{1}$ Sustainable agriculture is also part of Sustainable Development Goal 2- "End hunger, achieve food security and improve nutrition and promote sustainable agriculture".
} 
farmers with input and output markets, building human and social capital and so on (The Montpellier panel, 2013).

Additionally, one premise of sustainable intensification is that increased production must be met through higher yields since increasing the area of land under agriculture carries major environmental costs (Garnett et al., 2013). Hence, much of the expected increase in production in developing countries should come from increase in yield or crop intensities as opposed to arable land expansion. Recent studies however indicate that most production in SSA is below the potential yield and some countries even have experienced decreasing yields over the last years (Byerlee and Deininger, 2013; Ray et al., 2013). Maize yield gaps in SSA have been attributed to poor soils, drought, temperature stress, weeds and low use of fertilizer and other agricultural inputs (Gibbon et al., 2007). Thus there is potential to increase production in SSA by reducing yield gaps through efficient use of existing resources and use of technologies that can adapt to the particular stress.

Adoption of technological improvements is crucial to improving smallholder farmers' welfare, while sustaining the agro-ecosystems that support livelihoods. There is consensus that policies directed towards fighting hunger and poverty require a strong focus on the small farm sector, including the development and implementation of appropriate innovations (e.g., World Bank 2007, Oxfam 2011). Empirical studies show that agricultural technologies can help reduce poverty directly, by raising incomes of farm households, and indirectly, by raising employment and wage rates of functionally landless laborers, and by lowering the price of food staples (De Janvry and Sadoulet, 2001; Evenson and Gollin, 2003; Minten and Barrett, 2007; Becerril and Abdulai, 2010; Kabunga and Qaim, 2014).Agricultural technologies could also stimulate the transition from low productivity subsistence agriculture to a high productivity agro-industrial economy in Africa through increases in agricultural productivity (World Bank, 2007).

This study seeks to understand adoption and impacts of different sustainable agricultural practices (both input-intensive and NRM technologies) common among farmers in Kenya. Specifically, we seek to understand what associations in form of tradeoffs and complementarities exist in the adoption of these technologies. We also seek to assess synergistic impacts arising from adopting technologies in combination. In addition, we analyze the productivity of the farmers. We acknowledge that yield differences among farmers may result mainly from environmental gaps or farmers' inefficiencies. We distinguish between the two and assess factors 
associated with each. Environmental gaps are mainly as a result of environmental stresses and farmers inabilities to adapt their agricultural practices to the respective constraints. Where major environmental gaps exist between farmers in different regions, adoption of appropriate technologies and practices may play a vital role in narrowing down these gaps.

The empirical analysis is based on a survey among smallholder maize farmers from all maize producing regions in Kenya. A variety of crops are grown in Kenya, but maize is the most important crop with an average per capita consumption of approximately $88 \mathrm{Kgs}$ accounting for about one third of daily calories intake (Mohajan, 2014). It is grown on half of the cultivated land in almost all agroecological zones by $98 \%$ of the 3.5 million smallholder farmers who contribute at least $75 \%$ of national maize production (Kirimi et al., 2011). Almost all maize production in Kenya is rain-fed and is entirely dependent on bimodal rainfall in most parts of the country and this causes variation in yields from year to year. Whereas the demand for maize in the country has been consistent over the last decade there have been wide fluctuations in production resulting in substantial deficits in some years (Figure 1.1). In addition, despite the crop's importance, average maize yields in Africa are low - around 2 tonnes/ha, compared to a global average of over 5 tonnes/ha (FAOSTAT, 2012).

\section{Figure 1.1: Maize production and consumption in Kenya over the last decade}

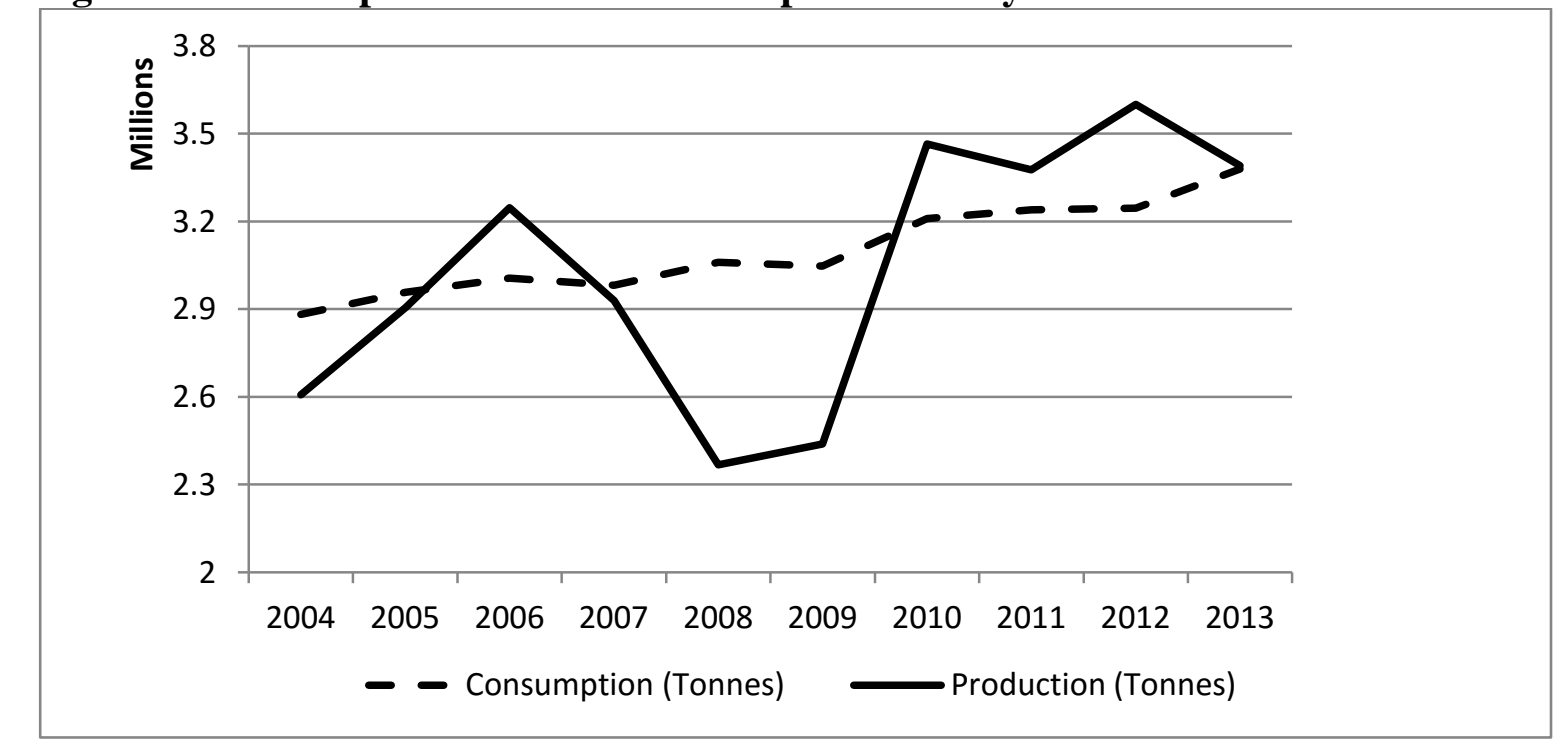

Constructed by author; data source FAOSTAT, accessed on 24/08/2015. 


\subsection{Problem statement and objectives}

Sub-Saharan Africa is the region with the highest rates of poverty and undernutrition, and the lowest rates of productivity growth in agriculture. Many of the poor and undernourished people live in rural areas and depend on smallholder agriculture as a source of income and employment. Thus to reduce poverty and increase food security, Sub-Saharan Africa will require substantial productivity and income growth in the small farm sector (Foresight, 2011). Sustainable agricultural practices- both input-intensive and NRM (low-external input) technologies have been proposed as one way of improving the welfare of these farmers while maintaining the environment.

There is however a lively debate about which type of technology is most appropriate to foster sustainable development in the small farm sector. While some consider low-external input (natural resource management) strategies as most suitable others suggest models of input intensification with a stronger role of the private sector. Advocates of low-external input strategies often argue that the use of high-yielding crop varieties and agrochemicals would destroy the environment and create farmer dependencies, with negative impacts on food security (Holt-Gimenez et al., 2012). On the other side of the debate, it is argued that improved seeds and higher rates of fertilizers are essential for food security, especially in Africa where the first green revolution did not take off to the same extent as elsewhere (Juma, 2011). This divide is particularly pronounced in the wider public where several NGOs equate low-external input technologies to sustainable agriculture. Sometimes these views are reflected in the design of development projects.

However, the use of NRM technologies and external inputs is not incompatible. There may even be important synergies. For instance, Sanchez (2002) argued that green revolution varieties could have been more successful in Africa if they had been adopted together with improved soil management practices. More research is needed to better understand which technologies, and combinations of technologies, are adopted in certain situations and what synergies exist between these technologies. Most existing studies focus on adoption and/or impact of one specific type of technology. The data and methodologies used are often different, so that results are not easily comparable. We use a nationally representative data set of maize farmers in Kenya to analyze what tradeoffs, complementarities and synergies exist among inputintensive and NRM technologies. 
In addition, one main premise of sustainable intensification is that increased production be met through increasing yields due to the environmental costs involved with land expansion. One way of sustainably increasing yields is by improving technical efficiency among small holder farmers. However, while there are many studies on efficiency and productivity in SSA, limited studies distinguish between technical efficiency and environmental gaps that may exist among different groups of farmers particularly differences due to climatic conditions. Farmers in different agroecological zones have diverse climatic conditions and are prone to different weather challenges, some regions are more prone to droughts or extreme heat and others to floods. Considering that most smallholder farming systems in SSA are rain-fed, climatic constraints influence production systems among these farmers such that assuming a single production function among these farmers will attribute environmental gaps to technical inefficiencies among farmers resulting in misinformed policies. Yield differences may result majorly from environmental gaps or farmers inefficiencies, hence distinguishing the two is essential for prioritizing policy actions. Using data collected in all the maize producing zones in Kenya, we make a distinction between the two and analyze factors associated with each.

Given these identified research gaps we seek to understand what associations and synergies exist between different input-intensive and NRM technologies. We also seek to differentiate technical efficiency and meta-technology ratios (capturing environmental gaps) between farmers in different agroecological zones. The specific objectives are as follows:

i. To assess tradeoffs and complementarities in the adoption of input-intensive and NRM technologies.

ii. To assess synergistic impacts on household income arising from the interrelations between different input-intensive and NRM technologies.

iii. To estimate and make a distinction between technical efficiency and meta-technology ratios among farmers in different agroecological zones and to assess factors associated with each. 


\subsection{Sustainable agricultural practices}

Sustainable agricultural intensification practices encompass both input-intensive and NRM technologies. Input-intensive technologies have driven a revolution of global cereal production since the mid-1960s leading to substantial yield gains (Foresight, 2011) while natural resource management (NRM) technologies have been proposed to improve the efficiency of cropping systems in a sustainable way (Altieri, 2002). NRM technologies build on integrated agronomic principles, responding to a wide range of challenges in different environments. They reduce the use of external inputs such as fertilizer by enhancing the potential of locally available resources through improved management practices (Altieri, 2002).

External input-intensive technologies considered in this study are use of improved maize varieties and chemical fertilizers. Improved maize varieties include hybrids and open pollinated varieties (OPVs) whose traits have been improved for selected characteristics such as disease resistance, short maturity rate, and increased yield per unit of land. Drought and heat tolerant maize varieties are however not widely available to these farmers. Several drought tolerant maize varieties have been released in SSA between 2007 and 2013 through the Drought Tolerant Maize for Africa (DTMA) project but the uptake is still very low in Kenya (Fisher et al., 2015). Chemical fertilizers are usually aimed at improving soil fertility. Expanded use of chemical fertilizers in SSA has also been stressed as one of the solutions to alleviate production shortfalls and land degradation in the region. Although fertilizer use in SSA lags far behind the rest of the world (Morris, 2007), Kenya has shown an increase in the use of chemical fertilizers between the1990s and 2010.

The NRM technologies considered include conservation agriculture, soil and water management practices and the use of organic manure. These NRMs are designed to address one of the major environmental problems of developing countries - land degradation in the form of soil erosion and nutrient depletion, both of which undermine land productivity (FAO, 2015). These NRM technologies also assist in reduction of green-house gases in the atmosphere through soil carbon sequestration- process of removing carbon from the atmosphere and storing it in the soil.

Soil and water management practices such as constructing terraces and soil/stone bunds are usually recommended to curb the problem of soil erosion. These alternative soil and water management practices contrasts in length of investment and effectiveness of erosion abatement. 
Stone terraces are constructed walls that retain embankments of soil. Their construction involves preparing a base for the wall, transporting construction rocks, and carefully layering the stones. Stone terraces are more effective than soil bunds in preventing soil erosion on steep slopes prone to heavy runoff. Soil bunds on the other hand are embankments made by ridging soil on the lower side of a ditch along a slope contour (Gebremedhin and Swinton, 2003). They can be constructed by hand digging or plowing and are usually cheaper and easier to establish than stone terraces.

Conservation agriculture involves decreased disturbance to the structure of the uppermost soil layers. This is achieved through combination adoption of three essential farm practices: a reduced tillage method of seedbed preparation (zero/minimum tillage), permanent soil cover through crop residue management (mulching) and crop rotation (Hobbs et al., 2008). For this study only zero tillage and crop residue management are considered. Zero tillage systems of production have been developed to address the problems caused by intensive cultivation of soils; damages to the soil structure and overuse of groundwater resources (Royal Society, 2009). It involves maintaining soil structure and soil organic matter by limiting mechanical soil disturbances in the process of crop production. Zero tillage sites have reported increased yields, as well as evidence of reduced green-house gas emissions, fewer weeds, more beneficial insects and improved water use efficiency (Hobbs et al., 2008). It however requires some machinery such as direct seeders as well as herbicides and pesticides. A shortcoming of zero tillage is that, in the absence of herbicides, weeds may overwhelm plots and may require additional labor to control (Giller et al., 2009).

Mulching has other beneficial effects such as reducing soil evaporation, improving water infiltration, reducing maximum temperatures in the soil surface layers, increasing aggregate stability and soil porosity. There are however tradeoffs in the use of crop residues particularly in the crop-livestock systems either as livestock fodder, mulch, for trading or for other purposes such as fuel or construction (Magnan et al., 2012; Valbuena et al., 2012; Berazneva, 2013). In crop-livestock systems, production of sufficient biomass for both mulch and forage without adequate fertility and water may be difficult (Valbuena et al., 2012).

Finally, use of animal manure as an NRM practice has great potential as a principal source of nutrients for soil fertility maintenance and crop production in developing countries. Use of manure also improves soil quality and texture as well as the water-holding capacity of the 
soil. Although some of these NRM technologies seem direct, they may involve radical changes in how farmers cultivate their crops and manage their livestock, water, soils, residues and waste. Some of these technologies may for some farmers be controversial and counterintuitive from technologies that were being promoted over the past few decades leading to low adoption rates.

\subsection{Data}

The data were collected in collaboration with CIMMYT, Nairobi, from 1344 households in all the maize growing areas in Kenya distributed over six major maize agroecological zones (AEZs) as defined by Hassan (1998). These AEZs vary depending on climatic conditions and other characteristics. Households to be surveyed were selected using a stratified two stage sampling technique. The strata were the six AEZs. The sublocations (Kenya's smallest administrative units) as determined in the 2009 Kenya National Bureau of Statistics (KNBS, 2010), census were the primary sampling units (PSU), households were the secondary sampling units (SSU). The number of PSU and SSU in each of the strata was first determined by optimizing the sample size needed to obtain a precision of at least 15\% in each stratum, and $8 \%$ overall (calculated for the variable "maize area") (De Groote, 1996). Based on the results, the required number of PSU was calculated at 120 sublocations, spread over the different zones.

Using maps, Geographic Information System (GIS) analysis and key informants, a list of all rural sublocations in each of the six zones was established, with the number of households in each obtained from the 2009 Kenya national census. For each zone, the required number of sublocations was selected with probability proportionate to size (using total area under maize). For each sublocation, 12 households were selected by random sampling except for the lowland tropics where six households were selected per sublocation due to budgetary constraints. The survey was conducted between December 2012 and February 2013 with a reference period of 2012 cropping year. Data were collected on socioeconomic characteristics of the household members, general risk preferences, maize plot level characteristics, maize plot level production data, asset ownership, annual income and expenditure among others. A map showing the study area, a list of sublocations surveyed by AEZs and the survey questionnaire are presented in Appendix B. 


\subsection{Dissertation outline}

The rest of the dissertation is organized as follows. Each of the subsequent chapters addresses one of the stated objectives, and chapter 5 concludes the dissertation. Chapter 2, addressing the first objective, seeks to find out tradeoffs and complementarities that exist between inputintensive and NRM technologies. Seven individual technologies are considered, including improved seeds, chemical fertilizers, crop residue management, zero tillage, terracing, soil bunds and use of animal manure. A multivariate probit (MVP) is applied since it allows for correlation of error terms between adoption of different technologies.

Chapter 3 presents an assessment of the impact of these input-intensive and NRM technologies and their combinations on income to find out whether there are synergy effects arising from their interrelations. Specifically, we assess the impact of each individual technology and that of several technology combinations to find out which technologies type and/or combinations have the highest payoff in terms of total household income. To correct for possible selection bias arising from adoption of these technologies propensity score matching (PSM) is used. Chapter 4 addresses the final objective which is distinguishing between technical efficiencies and meta-technology ratios among the farmers across different AEZs and assessing the determinants thereof. Farmers in our sample are distributed across six AEZs which are very diverse in their climatic conditions and as such a stochastic meta-frontier production frontier is applied. Finally, chapter 5 concludes the dissertation, also discussing a few policy recommendations and limitations of the study. 


\title{
2 Tradeoffs and Complementarities in the Adoption of Improved Seeds, Fertilizer, and Natural Resource Management Technologies in Kenya ${ }^{2}$
}

\begin{abstract}
There is widespread consensus that agricultural technology has an important role to play for poverty reduction and sustainable development. There is no consensus, however, about the types of technologies that are best suited for smallholder farmers in Africa. While some consider natural resource management (NRM) technologies as most appropriate, others propagate input intensification with a stronger role of the private sector. In the public debate, the two strategies are often perceived as incompatible. Environmental NGOs in particular consider low-external input strategies as the only sustainable form of agriculture, a view that has considerable influence on policymakers and the international donor community. Most existing research studies on smallholder innovation focus on the adoption of individual technologies, so that comparisons across technologies in the same context are not easily possible. We use representative data from maize-producing households in Kenya and a multivariate probit model to analyze the adoption of different types of technologies simultaneously. Results indicate that NRM technologies and strategies that build on external inputs are not incompatible. Interesting complementarities exist, which are not yet sufficiently exploited, because many organizations promote either one type of technology or the other, but rarely a combination of both.
\end{abstract}

\footnotetext{
${ }^{2}$ This chapter has been published in Agricultural Economics: Wainaina, P., Tongruksawattana, S., Qaim, M., 2016. Tradeoffs and complementarities in the adoption of improved seeds, fertilizer, and natural resource management technologies in Kenya. Agricultural Economics 47, 351-362.
} 


\subsection{Introduction}

Growth in the agricultural sector is key to alleviating poverty and food insecurity in developing countries (World Bank, 2007). In this connection, technological innovation plays an important role. Agricultural technologies can help to increase output and thus improve access to food, as experience with the green revolution has demonstrated (Evenson and Gollin, 2003). In addition, agricultural technologies can contribute to poverty reduction, by raising the incomes of farm households and, in some cases, providing new employment opportunities for landless laborers (Winters et al., 1998; De Janvry and Sadoulet, 2001; Minten and Barrett, 2008; Noltze et al., 2013). However, especially in the African small farm sector, adoption rates of agricultural technologies remain low.

There is also a lively debate about which type of technology is most appropriate to foster sustainable development in the small farm sector. While some consider low-external input strategies as most suitable (Altieri, 2002; FAO and Biodiversity International, 2007; IAASTD, 2009; Altieri and Toledo, 2011; De Schutter and Vanloqueren, 2011), others suggest models of input intensification with a stronger role of the private sector (Borlaug, 2007; Pingali, 2007; Stevenson et al., 2013). Low-external input strategies involve different agronomic practices, such as conservation tillage, other soil and water management techniques, and use of organic manure. Such improved agronomic practices are often referred to as natural resource management (NRM) technologies. These approaches can reduce the use of external inputs such as fertilizer by enhancing the potential of locally available resources through improved management practices (Altieri, 2002). Input intensification strategies, on the other hand, place higher emphasis on the use of improved seeds, mineral fertilizer, irrigation, and other productivity-enhancing external inputs. Advocates of low-external input strategies often argue that the use of high-yielding crop varieties and agrochemicals would destroy the environment and create farmer dependencies, with negative impacts on food security (Holt-Gimenez et al., 2012). On the other side of the debate, it is argued that improved seeds and higher rates of fertilizers are essential for food security, especially in Africa where the first green revolution did not take off to the same extent as elsewhere (Juma, 2011).

However, the use of NRM technologies and external inputs is not incompatible. There may even be important synergies. For instance, the adoption of conservation agriculture is facilitated by the use of chemical herbicides. And enhanced soil and water management 
techniques can complement the productivity gains from improved seeds and mineral fertilizers (Lee, 2005; Noltze et al., 2013; Kassie et al., 2013; Kassie et al., 2015a). Nevertheless, in the wider public debate a divide is often made between low-external input and high-external input strategies as two conflicting paradigms. This conflict became especially obvious in the controversies around the International Assessment of Agricultural Science and Technology for Development (IAASTD) (Stokstad, 2008). Non-governmental organizations (NGOs) in particular equate sustainable farming with low-external input systems (Oxfam, 2011; Via Campesina, 2015; Greenpeace Africa, 2015). Such NGOs arguments have considerable influence on public attitudes, as well as on the international donor community and on policymakers in Africa (Paarlberg, 2008; De Schutter, 2010). Prejudiced views are sometimes also reflected in the design of development projects that promote one or the other type of technology instead of suitable combinations of both.

Rather than searching for a general blueprint, appropriate strategies may differ from one situation to another, depending on local agroecological, socioeconomic, and market conditions. More research is needed to better understand which technologies, and combinations of technologies, are adopted in certain situations and how sustainable innovation could be promoted. Most existing studies focus on the adoption of one specific type of technology, such as improved seeds (Nkonya et al., 1997; Becerril and Abdulai, 2010; Smale and Olwande, 2014; Kathange et al., 2016), mineral fertilizer (Lambrecht et al., 2014), conservation agriculture (Kassie et al., 2010; Wollni et al., 2010), or other soil conservation techniques (Gebremedhin and Swinton, 2003). The data and methodologies used are often different, so that results are not easily comparable. While focusing on individual technologies is useful for many questions, studies that look across different types of technologies are also important to gain a broader picture, be able to compare, and identify complementarities and tradeoffs. Here, we intend to contribute in this direction by analyzing the adoption of multiple technologies among smallholder farmers in Kenya. By showing that input-intensive and NRM technologies are actually not incompatible, we also want to counter some widely-held public misconceptions.

The analysis builds on a large, nationally representative data set of maize-growing farms in Kenya. Maize is grown in almost all of the country's agroecological zones, primarily by smallholders (Smale and Olwande, 2014). We specify and estimate a multivariate probit model that accounts for the fact that farmers make multiple adoption decisions simultaneously 
(Dorfman, 1996). In addition to farm, household, and institutional variables, we include plotlevel variables, such as soil fertility and slope, as covariates in the adoption model. Finally, we analyze how the adoption of different technologies correlates and how such correlation, or lack thereof, can be explained.

\subsection{Types of technologies and factors influencing adoption}

\subsubsection{Input-intensive and NRM technologies}

There are two broad types of technologies that are promoted for use by farmers in Kenya and other developing countries. The first type are technologies that build on external inputs such as improved seeds, chemical fertilizer, pesticides, and irrigation. In the Kenyan small farm sector, irrigation and pesticides are rarely used for maize production, so we concentrate on improved maize seeds and mineral fertilizer. Improved maize seeds include maize hybrids and openpollinating varieties (OPVs) developed by private and public sector breeding programs. The second type of technologies are NRM practices, such as conservation agriculture, soil and water management techniques, and use of organic manure. The concrete NRM technologies included in this study are described in the following paragraphs.

NRM strategies are mainly developed to deal with and mitigate environmental stresses, such as land degradation and nutrient depletion. Soil and water management practices such as constructing terraces or soil bunds are promoted to curb problems of soil erosion. Terraces are constructed walls that retain embankments of soil. The construction involves preparing a base for the wall, transporting construction rocks, and carefully layering the stones. Soil bunds, on the other hand, are embankments made by ridging soil on the lower side of a ditch along a slope contour (Gebremedhin and Swinton, 2003). Soil bunds can be constructed by hand digging or plowing, which is cheaper than building stone terraces but usually also less effective in terms of reducing water erosion. We consider both technologies in the adoption analysis.

Conservation agriculture aims at decreasing disturbance of the soil structure to reduce erosion and improve water and nutrient management. Conservation agriculture involves three components, namely reduced tillage (zero/minimum tillage), permanent soil cover through crop residue management (mulching), and crop rotation (Hobbs et al., 2008). In practice, these three components are not always adopted in combination, so we consider zero tillage and crop residue 
management as two separate technologies in the adoption analysis. Adoption of zero tillage is facilitated by the use of inputs such as chemical herbicides and direct seeder equipment. Independent of tillage practices, mulching helps to reduce soil evaporation and maximum temperatures in the soil surface layers, and to increase water infiltration, soil porosity, and aggregate stability. ${ }^{3}$ Finally, we consider the use of animal manure as an additional technology to improve nutrient supply and organic matter in the soil.

\subsubsection{Factors influencing adoption}

The broad literature on agricultural technology adoption suggests that there are many socioeconomic, institutional, and agroecological factors that influence individual adoption decisions by farmers. However, as is also known, the importance of each factor and the direction of influence depend on the nature of the technology. In the following paragraphs, we discuss important groups of covariates that were shown to play a role in the existing literature about the adoption of input-intensive and NRM technologies (Gollin et al, 2005; Lee, 2005). This discussion will help in selecting covariates in the empirical sections below and in interpreting the estimation results.

We start the discussion with socioeconomic characteristics of the farm, the farmer, and the farming household. Farm size and other assets owned are often found to affect technology adoption in a positive way. This is especially true when adoption requires large investments (Feder et al., 1985). Risk aversion can lead to slow and low adoption of agricultural technologies, especially when inputs that need to be purchased are involved. Human capital is another factor that can influence adoption. Better-educated and more experienced farmers tend to adopt new technologies faster, especially when the technologies are knowledge-intensive and require changes in traditional cultivation practices (Kabunga et al., 2012). Moreover, the gender of the farmer may play an important role. Women farmers are often more constrained in their access to markets and finance, so that they adopt new technologies slower than their male counterparts (FAO, 2011b). Finally, household availability of other resources required for

\footnotetext{
${ }^{3}$ Depending on the concrete situation, there may be tradeoffs between mulching and using crop residues for other purposes, such as livestock fodder, fuel, or construction material (Magnan et al., 2012; Valbuena et al., 2012; Berazneva, 2013).
} 
adoption is important. NRM technologies are often more labor-intensive, so that their adoption depends on family labor availability (Lee, 2005; Wollni et al., 2010; Noltze et al., 2012). Livestock keeping facilitates the use of organic manure in crop production, but complicates mulching because crop residues may be required as fodder.

Beyond farm, farmer, and household characteristics, contextual factors can be important. Infrastructure and institutional variables, such as distance to markets and access to credit and agricultural extension, were shown to influence technology adoption in many empirical studies (Feder et al., 1985). Access to extension is particularly important for NRM technologies, as they often require experimentation and adaptation to the local context (Lee, 2005; Noltze et al., 2012). Furthermore, depending on the type of technology, agroecological factors such as climate and soil conditions can matter a lot. For instance, high rainfall can stimulate weed growth and increase water logging (Kassie et al., 2010), which may negatively influence the adoption of zero tillage. With frequent droughts and other extreme weather events, farmers tend to adopt practices that involve smaller cash outlays to reduce financial risks (Hintze et al., 2003).

Most technology adoption studies consider agroecological factors at the farm or regional level. However, relevant conditions may also vary within farms, which may explain why farmers adopt certain technologies on some plots but not on others. Important plot level characteristics include plot size, slope, soil conditions, and ownership status (Amsalu and De Graaff, 2006; Marenya and Barrett, 2007; Noltze et al., 2012). For instance, soil and water management practices (terracing and soil bunds) are more relevant for locations with slopes. Technologies that require investments with longer-term impacts, such as terracing, are more likely observed on owned as opposed to rented plots.

We will analyze the role that these factors play for technology adoption in the Kenyan context and pay particular attention to possible differences in the covariates between inputintensive and NRM technologies. Systematic differences would indicate that each type of technology is used under different conditions. Similarities in the covariates, on the other hand, would indicate that different types of technologies may be suitable in the same settings and that synergies could possibly be exploited through technology combinations. 


\subsection{Data and descriptive statistics}

\subsubsection{Data}

We use data that we collected through a nationally representative survey of maize-growing farms in Kenya. The data include 4035 plots from 1344 farm households distributed across all six maize agroecological zones (AEZs), as defined by Hassan (1998). Households to be surveyed were selected using a stratified, two-stage random sampling procedure. In all AEZs, we selected sublocations (Kenya's smallest administrative units) as primary sampling units (PSU) and households as secondary sampling units (SSU). Using maps, Geographic Information System (GIS) analysis and key informants, a list of all rural sublocations in each of the six zones was prepared. For each zone, the required number of sublocations was selected proportionate to the maize area in that zone. In total, we selected 120 sublocations. $^{4}$ In each sublocation, 12 households were randomly selected using census data (KNBS, 2010), except for the lowland tropics where we selected six households per sublocation due to budget constraints. The survey was conducted between December 2012 and February 2013, referring to the 2012 cropping year. Data were collected on technology adoption and various other farm, farmer, household, and contextual characteristics.

\subsubsection{Descriptive statistics}

Table 2.1 shows descriptive statistics for the main variables used in the empirical analysis. Farmers may adopt certain technologies on some of their plots but not on others. We therefore carry out the analysis at the plot level, with farm and household level variables referring to the farms and households that operate the respective plots. The upper part of Table 2.1 shows adoption rates for the input-intensive and NRM technologies considered in this study. Improved maize seeds, including hybrids and improved OPVs, were adopted on $72 \%$ of the plots. Mineral fertilizers were adopted on $54 \%$ of the plots. Some of the NRM technologies were also adopted quite widely. On more than $50 \%$ of the plots, farmers had constructed terraces, managed crop residues, and used organic manure. On the other hand, zero tillage was practiced on only $11 \%$ of the plots during the 2012 cropping year.

\footnotetext{
${ }^{4}$ The 120 sublocations were selected from the six AEZs as follows: 15 in the lowland tropics, 18 in the dry midaltitude, 17 in the dry transitional zone, 30 in the moist transitional zone, and 20 in the high tropics and moist midaltitude zones, respectively.
} 
Table 2.1: Descriptive statistics ( $\mathrm{N}=\mathbf{4 0 3 5}$ )

\begin{tabular}{|c|c|c|c|}
\hline Variable name & Variable description & Mean & $\begin{array}{l}\text { Std. } \\
\text { Dev. }\end{array}$ \\
\hline \multicolumn{4}{|c|}{ Technology adoption dummies } \\
\hline Improved seeds & $=1$ if maize seeds used are improved varieties, 0 otherwise & 0.72 & 0.45 \\
\hline Fertilizer & $=1$ if farmer applied mineral fertilizers, 0 otherwise & 0.54 & 0.50 \\
\hline Terraces & $=1$ if farmer practiced terracing on the plot, 0 otherwise & 0.52 & 0.50 \\
\hline Soil bunds & $=1$ if farmer had soil bunds on the plot, 0 otherwise & 0.17 & 0.37 \\
\hline Crop residues & $=1$ if farmer left any crop residues on the plot, 0 otherwise & 0.54 & 0.50 \\
\hline Zero tillage & $=1$ if farmer practiced zero tillage on the plot, 0 otherwise & 0.11 & 0.32 \\
\hline Manure & $=1$ if farmer used animal manure, 0 otherwise & 0.52 & 0.50 \\
\hline \multicolumn{4}{|l|}{ Plot level characteristics } \\
\hline Plot size & Size of plot in acres & 1.23 & 1.54 \\
\hline Plot ownership & $=1$ if farmer owns the plot, 0 if rented in & 0.88 & 0.33 \\
\hline Medium soil fertility ${ }^{a}$ & $=1$ if soil fertility was rated medium, 0 otherwise & 0.51 & 0.50 \\
\hline Good soil fertility ${ }^{\mathrm{a}}$ & $=1$ if soil fertility was rated good, 0 otherwise & 0.37 & 0.48 \\
\hline Gentle slope $^{\mathrm{b}}$ & $=1$ if plot slope is gentle, 0 otherwise & 0.43 & 0.50 \\
\hline Medium slope $^{\mathrm{b}}$ & $=1$ if plot slope is medium, 0 otherwise & 0.20 & 0.40 \\
\hline Steep slope ${ }^{b}$ & $=1$ if plot slope is steep, 0 otherwise & 0.05 & 0.22 \\
\hline \multicolumn{4}{|c|}{ Socioeconomic characteristics } \\
\hline Age & Age of farmer in years & 50.00 & 14.53 \\
\hline Male & $=1$ if farmer is male, 0 otherwise & 0.57 & 0.50 \\
\hline Education & Years of formal education of farmer & 7.54 & 3.89 \\
\hline HH size & Number of household members & 6.58 & 2.55 \\
\hline Farm size & Total land owned by household in acres & 5.59 & 9.11 \\
\hline TLU & Total livestock units & 5.85 & 7.88 \\
\hline Moderate risk aversion $^{c}$ & $=1$ if risk preference scale is 2,0 otherwise & 0.11 & 0.31 \\
\hline Low risk aversion $^{c}$ & $=1$ if risk preference scale is 3,0 otherwise & 0.31 & 0.46 \\
\hline Risk neutral $^{\mathrm{c}}$ & $=1$ if risk preference scale is 4,0 otherwise & 0.15 & 0.36 \\
\hline Risk loving $^{c}$ & $=1$ if risk preference scale is 5,0 otherwise & 0.23 & 0.42 \\
\hline \multicolumn{4}{|l|}{ Institutional variables } \\
\hline Info extension & $\begin{array}{l}=1 \text { if } \mathrm{HH} \text { received information from government extension } \\
\text { service or research centers, } 0 \text { otherwise }\end{array}$ & 0.51 & 0.50 \\
\hline Info NGOs & $=1$ if $\mathrm{HH}$ received information from NGOs, 0 otherwise & 0.12 & 0.33 \\
\hline Info farmer groups & $=1$ if $\mathrm{HH}$ received information from farmer groups, 0 otherwise & 0.19 & 0.39 \\
\hline Group membership & $=1$ if $\mathrm{HH}$ participates in any group, 0 otherwise & 0.87 & 0.33 \\
\hline Credit & $=1$ if $\mathrm{HH}$ received agricultural credit, 0 otherwise & 0.20 & 0.40 \\
\hline Market distance & Distance in walking hours to the closest market & 1.62 & 1.57 \\
\hline \multicolumn{4}{|l|}{ Weather extremes } \\
\hline Drought & Frequency of drought experienced between 2003-2012 & 2.21 & 2.07 \\
\hline Flooding & Frequency of flooding experienced between 2003-2012 & 0.56 & 1.73 \\
\hline \multicolumn{4}{|l|}{ AEZ dummies } \\
\hline Dry mid-altitude ${ }^{d}$ & $=1$ if $\mathrm{HH}$ is located in dry mid-attitude zone, 0 otherwise. & 0.16 & 0.37 \\
\hline Dry transitional ${ }^{\mathrm{d}}$ & $=1$ if $\mathrm{HH}$ is located in dry transitional zone, 0 otherwise & 0.15 & 0.36 \\
\hline Moist transitional ${ }^{\mathrm{d}}$ & $=1$ if $\mathrm{HH}$ is located in moist transitional zone, 0 otherwise & 0.26 & 0.44 \\
\hline High tropics ${ }^{\mathrm{d}}$ & $=1$ if $\mathrm{HH}$ is located in high tropics zone, 0 otherwise & 0.18 & 0.38 \\
\hline Moist mid-altitude ${ }^{\mathrm{d}}$ & $=1$ if $\mathrm{HH}$ is located in moist mid-attitude zone, 0 otherwise & 0.18 & 0.38 \\
\hline
\end{tabular}


Many farmers adopt various technologies. Three-quarters of the sample farmers have adopted both input-intensive and NRM technologies in combination. Table 2.2 shows mean yield levels of subsamples of farmers with different types of technologies expressed per acre of land and per labor-day. This comparison should not be misinterpreted as an impact assessment because we do not control for any confounding factors. Nevertheless, it is interesting to observe that mean yield levels are notably higher on plots where farmers adopted NRM and inputintensive technologies together than on plots where only NRM technologies were used. Yield levels are still higher on plots with only input-intensive technologies, but the number of observations in this category is small. These data suggest that complementarities in the adoption of different types of technologies exist.

Table 2.2: Adoption rates and average yields by technology type

\begin{tabular}{|c|c|c|c|}
\hline & $\begin{array}{l}\text { Adoption } \\
\text { rate }\end{array}$ & $\begin{array}{c}\text { Average maize } \\
\text { yield per acre }(\mathrm{kg})\end{array}$ & $\begin{array}{c}\text { Average maize yield } \\
\text { per labor day }(\mathrm{kg})\end{array}$ \\
\hline Input-intensive technologies only & 0.04 & 847.57 & 27.83 \\
\hline NRM technologies only & 0.19 & 355.67 & 10.21 \\
\hline Both input intensive and NRM & 0.76 & 722.46 & 22.09 \\
\hline None of the technologies & 0.01 & 351.02 & 9.50 \\
\hline
\end{tabular}

The lower part of Table 2.1 shows socioeconomic characteristics that are likely associated with technology adoption. We include age, education, and gender of the farmer in the adoption model. Unlike many other studies that focus on the household head, our human capital variables refer to the person in the household responsible for maize farming, which - in many cases - is the wife of the male household head. We include farm size (land owned) and total livestock units (TLU) owned as measures of asset ownership, and the number of household members as a proxy for family labor availability. Farmers' risk preferences, which we measure in terms of five dummy variables, were elicited through a lottery experiment adapted from Binswanger (1980). Details of this experiment are given in Table A2.1 in appendix A2. We also use a few institutional variables, such as access to agricultural information, whether a farmer received credit for agricultural production in 2012, and distance to the closest market measured in terms of walking hours required to reach the market place. Furthermore, we include a group membership dummy, capturing farmers' organizational capital and social connectedness. Several of these covariates may possibly be endogenous, hence parameter estimates should not be 
interpreted as causal. We are particularly interested here in the direction and significance of the associations.

Climatic shocks and weather extremes can also be associated with technology adoption behavior. We include drought and floods as covariates. Both variables are measured in terms of the farmer-reported frequency of events during a period of 10 years prior to the survey (20032012). Finally, we include dummies for the AEZs into the model, using the lowland tropics as the reference zone. Table 2.3 shows selected climatic and maize-growing characteristics of the six AEZs. The highland tropics, the moist transitional, and the moist mid-altitude zones receive higher levels of rainfall than the other three zones and together account for $75 \%$ of Kenya's total maize production. Table 2.3 also shows the distribution of sample households across AEZs.

Table 2.3: Characteristics of maize agroecological zones in Kenya

\begin{tabular}{|c|c|c|c|c|c|c|}
\hline Attribute & $\begin{array}{l}\text { Highland } \\
\text { tropics }\end{array}$ & $\begin{array}{l}\text { Moist tran- } \\
\text { sitional }\end{array}$ & $\begin{array}{l}\text { Moist mid- } \\
\text { altitude }\end{array}$ & $\begin{array}{l}\text { Dry tran- } \\
\text { sitional }\end{array}$ & $\begin{array}{l}\text { Dry mid- } \\
\text { altitude }\end{array}$ & $\begin{array}{c}\text { Lowland } \\
\text { tropics }\end{array}$ \\
\hline Elevation (meters) & $1600-2900$ & $1200-2000$ & $1100-1500$ & $1100-1700$ & $700-1400$ & $<700$ \\
\hline Annual rainfall(mm) & $>1800$ & $1000-1800$ & $800-1200$ & $<800$ & $400-800$ & $400-1400$ \\
\hline Average temperature $\left({ }^{\circ} \mathrm{C}\right)$ & 15.2 & 19.7 & 22.1 & 19.7 & 22 & 25.5 \\
\hline Maize area ('000 ha) & 307 & 461 & 118 & 118 & 118 & 33 \\
\hline $\begin{array}{l}\text { Share of national maize } \\
\text { production }(\%)\end{array}$ & 35 & 20 & 20 & 10 & 10 & 5 \\
\hline Potential yield (t/ha) & 6.7 & 5.2 & 5.2 & 4.5 & 2.7 & 3.3 \\
\hline Actual yield (t/ha) & 2.0 & 0.7 & 1.1 & 1.1 & 0.5 & 1.0 \\
\hline $\begin{array}{l}\text { Share of households } \\
\text { surveyed }(\%)\end{array}$ & 18 & 26 & 18 & 15 & 16 & 7 \\
\hline
\end{tabular}

Source: Adapted from Hassan (1998) and Jaetzold et al. (2005).

\subsection{Correlates of technology adoption}

\subsubsection{Modeling approach}

As the adoption of specific technologies is not independent of other technological choices on the same farm, we employ a multivariate probit (MVP) model that accounts for error term correlation. ${ }^{5}$ The MVP simultaneously models the relationship between a set of covariates and each of the different technologies, while allowing unobserved and unmeasured factors (error terms) to be correlated. Correlation between the different adoption decisions may be due to technological complementarities (positive correlation) or substitutabilities (negative correlation).

\footnotetext{
${ }^{5}$ A few previous technology adoption studies also used a multivariate probit model, such as Marenya and Barrett (2007) who analyzed the adoption of improved NRM practices in western Kenya.
} 
If such correlation exists, estimates of simple probit models would be biased and inefficient. Our MVP model consists of seven binary choice equations, namely use of improved maize seeds, mineral fertilizer, terracing, soil bunds, crop residues, zero tillage, and use of animal manure. We therefore have seven dependent binary variables $y_{i j}$ for household $i$ and plot $j$.

$$
\begin{gathered}
y_{i j m}^{*}=X^{\prime}{ }_{i j m} \beta_{m}+\varepsilon_{i j m} \quad m=1,2 \ldots . .7 \\
y_{i j m}=\left(\begin{array}{l}
1 \text { if } y_{i j m}^{*}>0 \\
0 \text { otherwise }
\end{array}\right)
\end{gathered}
$$

where $y_{i j m}^{*}$ is a latent variable that captures the degree to which a farmer views technology $m$ as beneficial. This latent variable is assumed to be a linear combination of observed plot and household characteristics, $X^{\prime}{ }_{i j m}$, and unobserved characteristics captured by the stochastic error term, $\varepsilon_{i j m}$. The vector of parameters to be estimated is denoted by $\beta_{m}$. Given the latent nature of $y_{i j m}^{*}$, estimation is based on observable binary variables $y_{i j m}$, which indicate whether or not a farmer used a particular technology in the reference year.

The error terms $\varepsilon_{i j m}(\mathrm{~m}=1,2 \ldots .7)$ are distributed multivariate normal each with mean 0 and a variance-covariance matrix $\mathrm{V}$, where $\mathrm{V}$ has 1 on the leading diagonal, and correlations $p_{j k}=p_{k j}$ as off-diagonal elements:

$$
\mathrm{V}=\left\{\begin{array}{cccccc}
1 & p_{12} & p_{13} & . & . & p_{1 k} \\
p_{21} & 1 & p_{23} & \cdot & \cdot & p_{2 k} \\
p_{31} & p_{32} & 1 & . & \cdot & p_{3 k} \\
\cdot & \cdot & \cdot & 1 & . & p_{4 k} \\
\cdot & \cdot & \cdot & \cdot & 1 & p_{5 k} \\
p_{j 1} & p_{j 2} & p_{j 3} & p_{j 4} & p_{j 5} & 1
\end{array}\right\}
$$

The computation of the maximum likelihood function based on a multivariate normal distribution requires multidimensional integration. Different simulation methods were proposed to approximate such a function (Train, 2002). The Geweke-Hajivassiliou-Keane (GHK) simulator is a particularly popular choice in empirical research (Hajivassiliou et al., 1996; Geweke et al., 1997). The GHK simulator exploits the fact that a multivariate normal distribution function can be expressed as the product of sequentially conditioned univariate normal distribution functions, which can be accurately evaluated (Cappellari and Jenkins, 2003). We use the GHK approach and employ a simulated maximum likelihood estimator that also offers possibilities of cross-equation tests. 


\subsubsection{Estimation results}

Table 2.4 presents results of the MVP adoption model. Based on a likelihood ratio test we reject the null hypothesis of zero correlation between the error terms $(p<0.0001)$, so that the MVP is preferred over single-equation probit models. In the Table we report coefficient estimates as well as marginal effects. The marginal effects indicate the strength of association between the covariates and technology adoption. For dummy variables, the marginal effect refers to a change in the variable from 0 to 1 .

Plot ownership has a significant association with adoption in most equations, but with different signs. Owning the plot is associated with a 10 percentage point higher probability of adopting stone terraces. The association with manure adoption is also positive and in the same magnitude. In contrast, owning the plot is associated with a lower probability of adopting mineral fertilizer and zero tillage. The positive association between plot ownership and some of the NRM technologies is plausible, especially when certain investments are required. If the plot does not belong to the farmer, or if tenure insecurity exists, farmers have lower incentives to invest in land-improvement technologies that may increase or sustain productivity in the long run (Feder et al., 1985). Against this background, the negative relationship between plot ownership and zero tillage may surprise, because zero tillage is also a technology that can increase productivity in the longer run. A possible reason for zero tillage to be observed more often on rented plots is that farmers who rent in land are wealthier, more commercialized, and less financially constrained. This was also observed by Kassie et al. (2013) in their study in Tanzania. The adoption of zero tillage is facilitated by the use of complementary inputs and certain machinery, especially direct seeder equipment. ${ }^{6}$

\footnotetext{
${ }^{6}$ In principle, farmers with rented-in land may also be poorer when they only have little or no own land. We further analyzed this possibility by interacting plot ownership with total land owned by the household in alternative MVP model estimates (see Table A2.2 in appendix A2). These estimates confirm that adoption of zero till is higher among wealthier households who rent in land.
} 
Table 2.4: Results of the multivariate probit model

\begin{tabular}{|c|c|c|c|c|c|c|c|c|c|c|c|c|}
\hline \multirow[t]{2}{*}{ Variables } & \multicolumn{3}{|c|}{ Improved seeds } & \multicolumn{3}{|c|}{ Fertilizer } & \multicolumn{3}{|c|}{ Terraces } & \multicolumn{3}{|c|}{ Soil bunds } \\
\hline & Coefficient & Std error & $\begin{array}{l}\text { Marginal } \\
\text { effect }\end{array}$ & Coefficient & Std error & $\begin{array}{l}\text { Marginal } \\
\text { effect }\end{array}$ & Coefficient & $\begin{array}{l}\text { Std } \\
\text { error }\end{array}$ & $\begin{array}{c}\text { Marginal } \\
\text { effect }\end{array}$ & Coefficient & Std error & $\begin{array}{c}\text { Marginal } \\
\text { effect }\end{array}$ \\
\hline \multicolumn{13}{|c|}{ Plot level characteristics } \\
\hline Plot size & 0.034 & 0.027 & 0.01 & -0.020 & 0.021 & -0.006 & $0.041 * *$ & 0.021 & 0.013 & -0.038 & 0.025 & -0.009 \\
\hline Plot ownership & -0.103 & 0.087 & -0.029 & $-0.269 * * *$ & 0.098 & -0.078 & $0.289 * * *$ & 0.093 & 0.095 & 0.162 & 0.112 & 0.038 \\
\hline Medium soil fertility & $0.201 *$ & 0.109 & 0.057 & -0.006 & 0.127 & -0.002 & $0.193^{*}$ & 0.115 & 0.063 & -0.065 & 0.130 & -0.015 \\
\hline Good soil fertility & $0.377 * * *$ & 0.109 & 0.107 & -0.184 & 0.126 & -0.053 & 0.157 & 0.118 & 0.051 & $-0.274 * *$ & 0.135 & -0.064 \\
\hline Gentle slope & 0.022 & 0.072 & 0.006 & 0.067 & 0.091 & 0.02 & $0.556^{* * *}$ & 0.086 & 0.182 & -0.163 & 0.100 & -0.038 \\
\hline Medium slope & 0.075 & 0.092 & 0.021 & $0.341 * * *$ & 0.108 & 0.099 & $0.914^{* * *}$ & 0.109 & 0.299 & -0.106 & 0.118 & -0.025 \\
\hline Steep slope & 0.097 & 0.161 & 0.027 & $0.644 * * *$ & 0.204 & 0.187 & $1.114^{* * *}$ & 0.183 & 0.365 & 0.107 & 0.194 & 0.025 \\
\hline \multicolumn{13}{|c|}{ Socioeconomic characteristics } \\
\hline Male & 0.102 & 0.073 & 0.029 & -0.135 & 0.092 & -0.039 & 0.065 & 0.084 & 0.021 & 0.138 & 0.092 & 0.032 \\
\hline Age & 0.019 & 0.014 & 0.005 & $9.26 \mathrm{e}-04$ & 0.017 & $2.69 \mathrm{e}-04$ & -0.006 & 0.016 & -0.002 & 0.006 & 0.019 & 0.001 \\
\hline Age squared & $-1.32 \mathrm{e}-04$ & $1.38 \mathrm{e}-04$ & $3.73 e-05$ & $6.86 \mathrm{e}-05$ & $1.67 \mathrm{e}-04$ & $1.99 \mathrm{e}-05$ & $9.28 \mathrm{e}-05$ & $1.51 \mathrm{e}-04$ & $3.04 \mathrm{e}-05$ & $-5.38 \mathrm{e}-05$ & $1.8 \mathrm{e}-04$ & $-1.26 \mathrm{e}-05$ \\
\hline Education & $0.040^{* * *}$ & 0.010 & 0.011 & $0.068^{* * *}$ & 0.013 & 0.02 & 0.011 & 0.011 & 0.004 & 0.011 & 0.013 & 0.003 \\
\hline Farm size & 0.008 & 0.006 & 0.002 & $8.65 e-04$ & 0.005 & $2.51 \mathrm{e}-04$ & $-6.76 e-04$ & 0.005 & 0.000 & $-0.015^{*}$ & 0.008 & -0.003 \\
\hline TLU & 0.009 & 0.006 & 0.002 & $-0.013^{* *}$ & 0.006 & -0.004 & -0.003 & 0.006 & -0.001 & 0.002 & 0.006 & 0.000 \\
\hline $\mathrm{HH}$ size & -0.003 & 0.014 & -0.001 & $-0.032 *$ & 0.018 & -0.009 & 0.002 & 0.015 & 0.001 & -0.009 & 0.019 & -0.002 \\
\hline Moderate risk aversion & $0.339 * *$ & 0.141 & 0.096 & 0.138 & 0.161 & 0.04 & -0.032 & 0.139 & -0.010 & -0.214 & 0.174 & -0.050 \\
\hline Low risk aversion & 0.107 & 0.103 & 0.03 & 0.076 & 0.134 & 0.022 & 0.049 & 0.124 & 0.016 & 0.131 & 0.146 & 0.031 \\
\hline Risk neutral & 0.124 & 0.134 & 0.035 & -0.021 & 0.167 & -0.006 & -0.068 & 0.150 & -0.022 & 0.040 & 0.176 & 0.009 \\
\hline Risk loving & 0.047 & 0.130 & 0.013 & -0.093 & 0.169 & -0.027 & -0.096 & 0.167 & -0.031 & 0.115 & 0.187 & 0.027 \\
\hline Risk*Drought a & $-0.021 * *$ & 0.010 & -0.006 & 0.006 & 0.015 & 0.002 & -0.022 & 0.014 & -0.007 & 0.006 & 0.015 & 0.001 \\
\hline Risk*Flooding a & 0.016 & 0.014 & -0.018 & 0.014 & 0.015 & 0.004 & -0.002 & 0.015 & -0.001 & 0.002 & 0.019 & 0.001 \\
\hline \multicolumn{13}{|l|}{ Institutional variables } \\
\hline Info extension & $0.200^{* * *}$ & 0.069 & 0.057 & 0.115 & 0.085 & 0.033 & 0.063 & 0.079 & 0.02 & 0.123 & 0.087 & 0.029 \\
\hline Info NGOs & 0.046 & 0.097 & 0.013 & $-0.219 *$ & 0.124 & -0.064 & -0.132 & 0.116 & -0.043 & $0.489 * * *$ & 0.123 & 0.114 \\
\hline Info farmer groups & 0.114 & 0.091 & 0.032 & $0.343^{* * *}$ & 0.113 & 0.1 & -0.051 & 0.100 & -0.017 & 0.107 & 0.111 & 0.114 \\
\hline Group membership & 0.067 & 0.106 & 0.019 & 0.041 & 0.122 & 0.012 & $0.225^{*}$ & 0.115 & 0.074 & 0.115 & 0.138 & 0.027 \\
\hline Market distance & $-0.042^{*}$ & 0.022 & -0.012 & -0.029 & 0.026 & -0.008 & 0.023 & 0.022 & 0.007 & -0.010 & 0.023 & -0.002 \\
\hline Credit & 0.139 & 0.087 & 0.039 & $0.242^{* *}$ & 0.108 & 0.07 & -0.021 & 0.099 & -0.007 & 0.116 & 0.116 & 0.027 \\
\hline \multicolumn{13}{|l|}{ Weather extremes } \\
\hline Drought & 0.035 & 0.033 & 0.01 & $-0.111 * *$ & 0.053 & -0.032 & $0.084^{*}$ & 0.050 & 0.027 & -0.037 & 0.055 & -0.009 \\
\hline Flooding & -0.064 & 0.053 & -0.018 & -0.025 & 0.055 & -0.007 & 0.046 & 0.054 & 0.015 & -0.067 & 0.070 & -0.016 \\
\hline
\end{tabular}


Table 2.4 (Continued)

\begin{tabular}{|c|c|c|c|c|c|c|c|c|c|c|c|c|}
\hline \multirow[t]{2}{*}{ Variables } & \multicolumn{3}{|c|}{ Improved seeds } & \multicolumn{3}{|c|}{ Fertilizer } & \multicolumn{3}{|c|}{ Terraces } & \multicolumn{3}{|c|}{ Soil bunds } \\
\hline & Coefficient & Std error & $\begin{array}{c}\text { Marginal } \\
\text { effect }\end{array}$ & Coefficient & Std error & $\begin{array}{c}\text { Marginal } \\
\text { effect }\end{array}$ & Coefficient & $\begin{array}{l}\text { Std } \\
\text { error }\end{array}$ & $\begin{array}{c}\text { Marginal } \\
\text { effect }\end{array}$ & Coefficient & Std error & $\begin{array}{l}\text { Marginal } \\
\text { effect }\end{array}$ \\
\hline \multicolumn{13}{|l|}{$A E Z$} \\
\hline Dry mid-altitude & -0.113 & 0.145 & -0.032 & -0.067 & 0.205 & -0.02 & $1.194 * * *$ & 0.178 & 0.391 & -0.005 & 0.233 & -0.001 \\
\hline Dry transitional & $0.285^{*}$ & $(0.148$ & 0.081 & $0.855^{* * *}$ & 0.201 & 0.249 & $1.211^{* * *}$ & 0.183 & 0.396 & -0.156 & 0.242 & -0.037 \\
\hline Moist transitional & $0.900 * * *$ & $0.148)$ & 0.255 & $1.430 * * *$ & 0.192 & 0.416 & $0.454 * * *$ & 0.168 & 0.149 & 0.118 & 0.222 & 0.027 \\
\hline High tropics & $0.945^{* * *}$ & 0.161 & 0.267 & $1.653^{* * *}$ & 0.203 & 0.48 & -0.010 & 0.177 & -0.003 & $0.502^{* *}$ & 0.225 & 0.117 \\
\hline Moist mid-altitude & $-0.310^{* *}$ & 0.143 & -0.088 & $0.416^{* *}$ & 0.194 & 0.121 & $0.400 * *$ & 0.175 & 0.131 & -0.231 & 0.232 & -0.054 \\
\hline Constant & $-0.990 * * *$ & 0.380 & & $-0.800^{*}$ & 0.479 & & $-1.840^{* * *}$ & 0.453 & & $-1.342^{* *}$ & 0.561 & \\
\hline
\end{tabular}

\begin{tabular}{|c|c|c|c|c|c|c|c|c|c|}
\hline \multirow[t]{2}{*}{ Variables } & \multicolumn{2}{|c|}{ Crop residues } & \multirow[b]{2}{*}{$\begin{array}{c}\text { Marginal } \\
\text { effect }\end{array}$} & \multicolumn{3}{|c|}{ Zero tillage } & \multicolumn{3}{|c|}{ Manure } \\
\hline & Coefficient & Std error & & Coefficient & Std error & $\begin{array}{c}\text { Marginal } \\
\text { effect }\end{array}$ & Coefficient & Std error & $\begin{array}{c}\text { Marginal } \\
\text { effect }\end{array}$ \\
\hline \multicolumn{10}{|c|}{ Plot level characteristics } \\
\hline Plot size & $0.074 * * *$ & 0.025 & 0.023 & 0.039 & 0.025 & 0.007 & $-0.057 * *$ & 0.025 & -0.021 \\
\hline Plot ownership & -0.081 & 0.093 & -0.025 & $-0.191 *$ & 0.109 & -0.033 & $0.268^{* * *}$ & 0.078 & 0.099 \\
\hline Medium soil fertility & 0.083 & 0.125 & 0.025 & $-0.373 * * *$ & 0.142 & -0.064 & 0.042 & 0.093 & 0.015 \\
\hline Good soil fertility & 0.103 & 0.126 & 0.031 & $-0.261 *$ & 0.139 & -0.045 & -0.074 & 0.099 & -0.027 \\
\hline Gentle slope & 0.107 & 0.090 & 0.033 & -0.074 & 0.104 & -0.013 & $0.120^{*}$ & 0.070 & 0.044 \\
\hline Medium slope & 0.095 & 0.110 & 0.029 & -0.065 & 0.141 & -0.011 & 0.087 & 0.085 & 0.032 \\
\hline Steep slope & 0.038 & 0.176 & 0.011 & $0.666^{* * *}$ & 0.216 & 0.114 & -0.073 & 0.160 & -0.027 \\
\hline \multicolumn{10}{|c|}{ Socioeconomic characteristics } \\
\hline Male & -0.041 & 0.093 & -0.013 & -0.043 & 0.107 & -0.007 & -0.022 & 0.069 & -0.008 \\
\hline Age & 0.024 & 0.018 & 0.007 & -0.013 & 0.019 & -0.002 & 0.020 & 0.014 & 0.007 \\
\hline Age squared & $-3.29 \mathrm{e}-04^{*}$ & $1.73 e-04$ & $-1.00 \mathrm{e}-04$ & $8.66 \mathrm{e}-05$ & $1.89 \mathrm{e}-04$ & $1.48 \mathrm{e}-05$ & $-1.09 \mathrm{e}-04$ & $1.35 \mathrm{e}-04$ & $-4.00 \mathrm{e}-05$ \\
\hline Education & -0.011 & 0.013 & -0.003 & -0.013 & 0.014 & -0.002 & -0.004 & 0.009 & -0.001 \\
\hline Farm size & $0.011 * *$ & 0.006 & 0.003 & $0.009 * *$ & 0.005 & 0.002 & $-0.013^{* * *}$ & 0.004 & -0.005 \\
\hline TLU & $-0.011 * *$ & 0.005 & -0.003 & $0.011 * *$ & 0.005 & 0.002 & $0.017 * * *$ & 0.004 & 0.006 \\
\hline HH size & $0.047 * *$ & 0.019 & 0.014 & 0.029 & 0.020 & 0.005 & $-0.041 * * *$ & 0.013 & -0.015 \\
\hline Moderate risk aversion & -0.126 & 0.169 & -0.038 & 0.048 & 0.190 & 0.008 & -0.186 & 0.118 & -0.068 \\
\hline Low risk aversion & -0.088 & 0.136 & -0.027 & $0.292^{*}$ & 0.158 & 0.050 & -0.002 & 0.101 & -0.001 \\
\hline Risk neutral & -0.250 & 0.174 & -0.076 & $0.371 *$ & 0.193 & 0.064 & 0.005 & 0.125 & 0.002 \\
\hline Risk loving & -0.162 & 0.177 & -0.049 & -0.100 & 0.211 & -0.017 & -0.034 & 0.132 & -0.013 \\
\hline Risk*Drought a & -0.010 & 0.016 & -0.003 & 0.005 & 0.020 & 0.001 & 0.011 & 0.011 & 0.004 \\
\hline
\end{tabular}


Table 2.4 (Continued)

\begin{tabular}{|c|c|c|c|c|c|c|c|c|c|}
\hline \multirow[t]{2}{*}{ Variables } & \multicolumn{3}{|c|}{ Crop residues } & \multicolumn{3}{|c|}{$\begin{array}{l}\text { Zero } \\
\text { tillage }\end{array}$} & \multicolumn{3}{|c|}{ Manure } \\
\hline & Coefficient & Std error & $\begin{array}{c}\text { Marginal } \\
\text { effect }\end{array}$ & Coefficient & Std error & $\begin{array}{c}\text { Marginal } \\
\text { effect }\end{array}$ & Coefficient & Std error & $\begin{array}{c}\text { Marginal } \\
\text { effect }\end{array}$ \\
\hline Risk $^{*}$ Flooding a & $0.035^{* *}$ & (0.017 & 0.011 & -0.005 & 0.018 & -0.001 & -0.010 & 0.014 & -0.004 \\
\hline \multicolumn{10}{|c|}{ Institutional variables } \\
\hline Info extension & 0.009 & 0.087 & 0.003 & $-0.187^{*}$ & 0.098 & -0.032 & -0.028 & 0.064 & -0.01 \\
\hline Info NGOs & 0.108 & 0.144 & 0.033 & 0.160 & 0.163 & 0.027 & -0.001 & 0.092 & $-4.90 \mathrm{e}-04$ \\
\hline Info farmer groups & 0.008 & 0.115 & 0.002 & -0.179 & 0.127 & -0.031 & 0.080 & 0.078 & 0.03 \\
\hline Group membership & 0.022 & 0.123 & 0.007 & 0.029 & 0.145 & 0.005 & $0.275^{* * *}$ & 0.106 & 0.101 \\
\hline Distance market & 0.025 & 0.026 & 0.008 & -0.008 & 0.029 & -0.001 & -0.032 & 0.020 & -0.012 \\
\hline Credit & 0.138 & 0.116 & 0.042 & $0.200^{*}$ & 0.117 & 0.034 & -0.109 & 0.081 & -0.04 \\
\hline \multicolumn{10}{|l|}{ Weather extremes } \\
\hline Drought & $0.062^{*}$ & 0.053 & 0.019 & -0.006 & 0.068 & -0.001 & -0.046 & 0.040 & -0.017 \\
\hline Flooding & $-0.096^{*}$ & 0.057 & -0.029 & 0.013 & 0.060 & 0.002 & 0.016 & 0.049 & 0.006 \\
\hline \multicolumn{10}{|l|}{$A E Z$} \\
\hline Dry mid-altitude & $-1.823^{* * *}$ & 0.216 & -0.555 & $-0.467 * *$ & 0.200 & -0.080 & $0.611 * * *$ & 0.144 & 0.225 \\
\hline Dry transitional & $-1.854 * * *$ & 0.218 & -0.565 & $-0.763^{* * *}$ & 0.215 & -0.131 & $0.488^{* * *}$ & 0.147 & 0.18 \\
\hline Moist transitional & $-0.787 * * *$ & 0.203 & -0.240 & -0.237 & 0.195 & -0.041 & -0.002 & 0.142 & -0.001 \\
\hline High tropics & $-0.828 * * *$ & $0.21)$ & -0.252 & -0.197 & 0.199 & -0.034 & -0.033 & 0.156 & -0.012 \\
\hline Moist mid-altitude & -0.102 & 0.218 & -0.031 & $-0.527 * * *$ & 0.204 & -0.090 & 0.204 & 0.141 & 0.075 \\
\hline Constant & 0.430 & 0.507 & & -0.365 & 0.543 & & $-0.936 * *$ & 0.395 & \\
\hline
\end{tabular}

Notes: $\mathrm{N}=4035 ; \log$ likelihood $=-11772.70 ;$ Wald $\mathrm{chi}^{2}=4169.45$; likelihood ratio test of rho chi $^{2}(21)=662.488 . * * *, * * *$ significant at $1 \%, 5 \%$, and $10 \%$ level, respectively. Standard errors are robust and clustered at household level.

${ }^{\mathrm{a}}$ For this interaction term, risk is expressed as a discrete variable with values between 1 and 5, where 1 represents high risk aversion, and 5 risk loving. 
The size of the plot is associated positively with adoption of terracing and crop residues, but negatively with the use of manure. As the construction of stone terraces requires significant fixed costs, such as contracting the delivery of stones and other building materials, adopting this technology on larger plots is more economical. In addition, some plots may simply be too small for terracing to make sense. We also find other plot characteristics to matter, yet without a clear distinction between input-intensive and NRM technologies. Good soil fertility seems to be associated with the adoption of improved seeds and stone terraces, which is consistent with higher expected returns on fertile land. On the other hand, technologies that help to improve soil fertility are adopted more on less-fertile land. The adoption of anti-erosion measures - such as terracing and zero tillage - is more likely on land with steep slopes, which is consistent with findings by Marenya and Barrett (2007). Use of mineral fertilizer is also more likely on steeper slopes, possibly to compensate for nutrient losses through soil erosion.

Among the socioeconomic characteristics, education of the farmer is positively associated with the adoption of improved seeds and fertilizer. These inputs are relatively easy to use, so this effect is unlikely due to the technologies' complexity. A more plausible explanation is that better-educated farmers have more lucrative income sources and thus fewer capital constraints to invest in external inputs. A larger number of livestock units on the farm is associated with a higher probability of manure use and with a lower probability of retaining crop residues in the field. In mixed crop-livestock systems, farmers often use crop residues as animal fodder. Livestock ownership is also associated with a lower probability of mineral fertilizer use, suggesting that farmers consider organic manure and mineral fertilizer as substitutes.

In terms of institutional variables, access to information from government extension officers or research centers is associated with a higher probability of improved seed adoption. Access to information from NGOs is associated with a higher probability of adopting soil bunds and with a lower probability of using mineral fertilizer. In contrast, information from farmer groups is positively associated with mineral fertilizer adoption, but not with any of the other technologies. These observations suggest that different types of organizations promote different types of technologies, a point that we discuss in more detail below. In terms of agroecological factors, weather extremes seem to matter. Farmers who experienced more frequent droughts in the past are less likely to adopt mineral fertilizer. It is commonly observed that smallholder farmers who operate under erratic weather conditions use fewer purchased inputs to minimize 
financial risks. On the other hand, more frequent droughts are associated with a higher adoption of stone terraces. Moreover, drought experience makes it more likely that farmers decide to retain crop residues in the field. These technologies help farmers to reduce production risks. As explained, terraces and mulching are mechanisms to reduce water losses through runoff and evaporation.

Beyond weather extremes, the AEZ dummies indicate that general climatic factors also play a significant role for technology adoption decisions. The lowland tropics, which we use as the base category, receive the lowest amount of rainfall. Improved seeds, mineral fertilizer, and organic manure are adopted more widely in regions with higher average rainfall. This is expected, because more favorable climatic conditions contribute to higher marginal returns to the use of these yield-enhancing inputs. Of course, this could be different for the adoption of drought-tolerant varieties, but such varieties are not yet widely available. Higher rainfall is also positively associated with the adoption of stone terraces. On the other hand, we observe lower adoption of zero tillage and crop residue management in AEZ with higher average rainfalls. This makes sense, because these technologies help to better cope with the stress of too little water.

Given that the AEZ dummies might also capture broader regional factors and thus possibly influence the effect of other socioeconomic and institutional variables, we also estimated the MVP model without the AEZ dummies (see Table A2.3 in appendix A2). While the estimation coefficients change slightly, the signs and significance levels are hardly affected. Some of the observed effects even get stronger in their absolute magnitude.

\subsection{Complementarities and tradeoffs}

In the previous section, we have analyzed factors associated with the adoption of different inputintensive and NRM technologies. The technologies are not mutually exclusive, that is, adoption of one technology does not mean that other technologies could not be adopted. In this section, we focus on complementarities and tradeoffs between the different technologies. To better understand which technologies are commonly adopted in combination we look at the correlation matrix from the MVP model, which is shown in Table 2.5. 
Table 2.5: Correlation matrix from the multivariate probit model

\begin{tabular}{|c|c|c|c|c|c|c|c|}
\hline & $\begin{array}{l}\text { Improved } \\
\text { seeds }\end{array}$ & Fertilizer & Terraces & Soil bunds & $\begin{array}{l}\text { Crop } \\
\text { residue }\end{array}$ & $\begin{array}{c}\text { Zero } \\
\text { tillage }\end{array}$ & Manure \\
\hline Improved seeds & 1 & & & & & & \\
\hline Fertilizer & $\begin{array}{c}0.395 * * * \\
(0.046)\end{array}$ & 1 & & & & & \\
\hline Terraces & $\begin{array}{c}0.050 \\
(0.040)\end{array}$ & $\begin{array}{c}0.152 * * * \\
(0.051)\end{array}$ & 1 & & & & \\
\hline Soil bunds & $\begin{array}{l}-0.024 \\
(0.046)\end{array}$ & $\begin{array}{l}-0.085 \\
(0.053)\end{array}$ & $\begin{array}{c}-0.698 * * * \\
(0.066)\end{array}$ & 1 & & & \\
\hline Crop residue & $\begin{array}{l}-0.023 \\
(0.044)\end{array}$ & $\begin{array}{c}-0.067 \\
(0.055)\end{array}$ & $\begin{array}{l}-0.065 \\
(0.050)\end{array}$ & $\begin{array}{l}0.101 * \\
(0.056)\end{array}$ & 1 & & \\
\hline Zero tillage & $\begin{array}{l}-0.028 \\
(0.050)\end{array}$ & $\begin{array}{c}0.046 \\
(0.064)\end{array}$ & $\begin{array}{l}-0.051 \\
(0.058)\end{array}$ & $\begin{array}{c}0.089 \\
(0.061)\end{array}$ & $\begin{array}{c}0.150 * * \\
(0.065)\end{array}$ & 1 & \\
\hline Manure & $\begin{array}{c}0.092 * * * \\
(0.034)\end{array}$ & $\begin{array}{l}-0.056^{*} \\
(0.042)\end{array}$ & $\begin{array}{c}0.055 \\
(0.038) \\
\end{array}$ & $\begin{array}{c}0.091 * * \\
(0.042)\end{array}$ & $\begin{array}{c}-0.089 * * \\
(0.041)\end{array}$ & $\begin{array}{c}-0.012 \\
(-0.049)\end{array}$ & 1 \\
\hline
\end{tabular}

Notes: Numbers in parentheses are standard errors. The likelihood ratio test of equal correlation coefficients is rejected ( $p<$ $0.001) . \mathrm{N}=4035 . * * *, * *, *$ significant at $1 \%, 5 \%$, and $10 \%$ level, respectively.

The negative correlation between some of the technologies indicates that farmers perceive tradeoffs or consider these technologies as substitutes. In certain cases, negative correlation may also simply indicate that different technologies are suitable for different plot conditions. The construction of stone terraces is negatively correlated with the use of soil bunds. This is expected, because both technologies serve the same purpose. We also observe a negative correlation between mineral fertilizer and organic manure adoption. Both technologies deliver nutrients to the soil. However, organic and mineral fertilizers have different advantages for soil fertility and texture, so that combining both could lead to positive synergies. Furthermore, there is a negative correlation between the use of animal manure and crop residue management. While these are not perfect substitutes, manure application is more common in crop-livestock systems, where crop residues are mostly used as livestock fodder.

There are also a number of positive correlations in Table 2.5, indicating technological complementarities. The adoption of improved seeds is positively correlated with the adoption of mineral fertilizer. The adoption of zero tillage is positively correlated with crop residue management. Similarly, the adoption of soil bunds is positively correlated with manure and crop residue management. Strikingly, most of these positive correlations occur either among the input-intensive or among the NRM technologies. There are only two cases of positive correlation across the two types of technologies, namely between improved seeds and manure and between 
mineral fertilizer and stone terraces. This suggests that many of the possible complementarities are not yet fully exploited. For instance, recent research has shown important synergies between conservation agriculture and other improved soil management techniques, improved seeds, and chemical inputs (Noltze et al., 2013; Kassie et al., 2015a).

What are reasons for the fact that comprehensive combinations of technologies are rarely observed? Based on the MVP model results, we hypothesize that this is partly related to different information flows. Figure 2.1 shows how farmers in our sample learned about different types of technologies. Significant differences in the sources of information can be identified. For NRM technologies, the government extension service is the most important source of information, followed by radio, other farmers, and NGOs. For improved seeds, the government extension service is also an important source of information, but the proportion of farmers who learn about new seeds from other sources is notably higher than for NRM technologies. Input traders and companies are important here, whereas they play no role as a source of information for NRM technologies. Radio and TV commercials are also more important for input-intensive technologies. This is not surprising, because private companies market their products in order to increase commercial sales. NGOs, on the other hand, are less important as a source of information for improved seeds and other input-intensive technologies. 
Figure 2.1: Farmers' sources of information for different technologies (proportions)

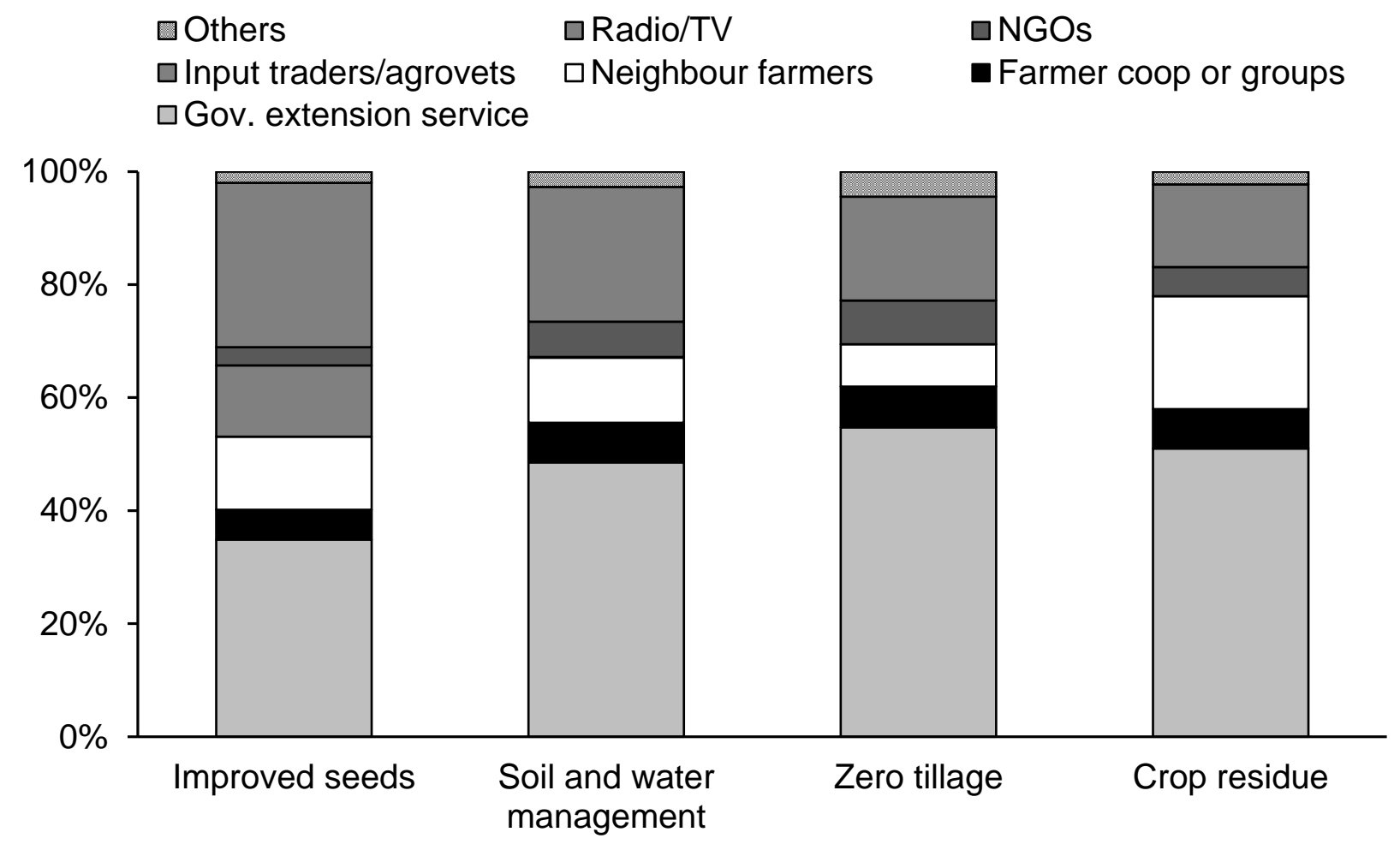

Note: Based on a chi-squared test the null hypothesis of equal proportions across technologies is rejected $(p=0.000)$.

One may consider this pattern of information flows as an efficient division of labor. Private companies market their products, whereas the public sector and NGOs focus on the promotion of NRM technologies for which private sector incentives are lower. This divide is also fostered by the bifurcated public debate. Some organizations that promote NRM technologies would not promote the use of external inputs at the same time, because of the perceived incompatibility. Getting information from different sources and then making informed decisions would not be a problem if farmers really had access to the different types of information. However, this is often not the case because of high transaction costs involved in obtaining information. When farmers happen to have access to only one type of information, the picture they get is incomplete, and synergies between different types of technologies cannot be fully exploited. This calls for more balanced extension approaches by all actors involved in farmer outreach activities. 


\subsection{Conclusion}

We have analyzed the adoption of different input-intensive and NRM technologies among maize farmers in Kenya, using data from a nationally representative survey. Most existing adoption studies have either looked at input-intensive technologies or at NRM techniques, using different data and methodologies, so that comparisons were not easily possible. We used a multivariate probit model to address this shortcoming. The input-intensive technologies considered in this study were improved maize seeds and mineral fertilizer. NRM technologies included in the analysis were zero tillage, management of crop residues, organic manure, and the construction of terraces and soil bunds. As covariates we included plot level, farm level, farmer, and household characteristics, as well as contextual factors characterizing infrastructure, institutional, and agroecological conditions. The estimation results show that the adoption covariates differ between technologies. For instance, improved seeds, mineral fertilizer, manure, and stone terraces are more adopted in regions with higher rainfalls, whereas zero tillage and crop residue management are more adopted under drier conditions. Education, farm size, market distance, credit, and several other variables also play significant roles, partly with differing signs across technologies. However, we did not find a clear divide in terms of adoption covariates between input-intensive and NRM technologies, suggesting that the two types of technologies can often be suitable in the same settings.

While a few technologies are indeed adopted in combination, many other combinations that were shown to be beneficial elsewhere are rarely observed among maize farmers in Kenya. This is due to the fact that input-intensive and NRM technologies are partly promoted by different organizations. NRM technologies are more promoted by the public extension service and NGOs, whereas for improved seeds and mineral fertilizer the private sector plays a larger role. This divide is fostered by the entrenched public debate about the most appropriate strategies. Outside of the academic community, many interest groups consider the use of external inputs and NRM techniques as two incompatible strategies. While this view is short-sighted, it influences development programs and prevents more widespread implementation of combined approaches that can bring about important synergies. NRM technologies can reduce the use of external inputs in situations where such inputs are excessively used. But this does not imply that optimal external input use is zero when NRM technologies are adopted. Especially in the African small farm sector, where little external inputs are used, a combination of improved NRM 
techniques, better seeds, and increased levels of other inputs could significantly contribute to sustainable productivity growth. This will require more integrated extension and farmer outreach approaches. More research on the concrete impacts of different types of technology combinations in specific contexts would be useful in guiding program design 


\section{Appendix A2}

Table A 2.1: Risk attitudes of farmers

\begin{tabular}{ccccc}
\hline \multirow{2}{*}{ Choice } & \multicolumn{2}{c}{ Payoff $(\text { Ksh })^{\text {a }}$} & & Risk preference \\
\cline { 2 - 3 }$(p=0.5)$ & $\begin{array}{c}\text { Blue stone } \\
(p=0.5)\end{array}$ & & Proportion of farmers \\
\hline 1 & 50 & 50 & High risk aversion & $19.9 \%$ \\
2 & 80 & 30 & Moderate risk aversion & $10.9 \%$ \\
3 & 100 & 20 & Low risk averse & $30.8 \%$ \\
4 & 120 & 10 & Risk neutral & $15.2 \%$ \\
5 & 150 & -20 & Risk loving & $23.1 \%$ \\
\hline
\end{tabular}

${ }^{\mathrm{a}} 10$ Kenyan Shilling $(\mathrm{Ksh})=0.012$ US Dollars (official exchange rate in early 2014).

Notes: To elicit risk preferences of farmers a simple lottery game was conducted. Each farmer was asked to choose one out of five possible options, each with two events of equal probability but different payoffs. For each individual choice, the amount that farmers won was randomly determined by drawing a stone from a blinded bag. The bag contained five blue and five yellow stones, so the farmers had an equal chance of drawing either color. The choice options and the actual distribution of choices are shown in the Table. Lower numbered choices indicate risk aversion, while the highest-numbered choice - which is five - represents risk-loving farmers. To normalize farmer's initial wealth and avoid possible financial losses, each farmer was given $50 \mathrm{Ksh}$ at the beginning of the lottery. Before playing with real money, the experiment was practiced with candies to ensure proper understanding of the rules and procedures. 
Table A2.2: Zero tillage adoption with plot ownership-farm size interaction term included Coefficient $\quad$ Standard error $\quad$ Marginal effect

\begin{tabular}{|c|c|c|c|}
\hline \multicolumn{4}{|l|}{ Plot level characteristics } \\
\hline Plot size & 0.035 & 0.026 & 0.006 \\
\hline Plot ownership & -0.058 & 0.126 & -0.010 \\
\hline Plot ownership*Farm size & $-0.033^{*}$ & 0.018 & -0.006 \\
\hline Medium soil fertility & $-0.344 * *$ & 0.141 & -0.059 \\
\hline Good soil fertility & $-0.228 *$ & 0.137 & -0.039 \\
\hline Gentle slope & -0.074 & 0.104 & -0.013 \\
\hline Medium slope & -0.059 & 0.141 & -0.010 \\
\hline Steep slope & $0.673 * * *$ & 0.216 & 0.115 \\
\hline \multicolumn{4}{|c|}{ Socioeconomic characteristics } \\
\hline Male & -0.045 & 0.107 & -0.008 \\
\hline Age & -0.013 & 0.019 & -0.002 \\
\hline Age squared & $8.88 \mathrm{e}-05$ & $1.89 \mathrm{e}-04$ & $1.52 \mathrm{e}-05$ \\
\hline Education & -0.014 & 0.014 & -0.002 \\
\hline Farm size & $0.041 * *$ & 0.018 & 0.007 \\
\hline TLU & $0.010^{* *}$ & 0.005 & 0.002 \\
\hline HH size & 0.030 & 0.020 & 0.005 \\
\hline Moderate risk aversion & 0.056 & 0.190 & 0.010 \\
\hline Low risk aversion & $0.303^{*}$ & 0.158 & 0.052 \\
\hline Risk neutral & $0.372 *$ & 0.193 & 0.064 \\
\hline Risk loving & -0.085 & 0.212 & -0.015 \\
\hline \multicolumn{4}{|l|}{ Institutional variables } \\
\hline Info extension & $-0.196 * *$ & 0.099 & -0.034 \\
\hline Info NGOs & 0.166 & 0.162 & 0.028 \\
\hline Info farmer group & -0.170 & 0.126 & -0.029 \\
\hline Group membership & 0.042 & 0.143 & 0.007 \\
\hline Market distance & -0.009 & 0.029 & -0.002 \\
\hline Credit & $0.202^{*}$ & 0.117 & 0.035 \\
\hline \multicolumn{4}{|l|}{ Weather extremes } \\
\hline Drought & -0.002 & 0.068 & -0.001 \\
\hline Flooding & 0.013 & 0.061 & 0.002 \\
\hline Risk $^{*}$ Drought $^{\text {a }}$ & 0.003 & 0.020 & 0.001 \\
\hline Risk*Flooding ${ }^{\text {a }}$ & -0.005 & 0.018 & -0.001 \\
\hline \multicolumn{4}{|l|}{ AEZ dummies } \\
\hline Dry mid-altitude & $-0.456 * *$ & 0.201 & -0.078 \\
\hline Dry transitional & $-0.762 * * *$ & 0.215 & -0.130 \\
\hline Moist transitional & -0.247 & 0.195 & -0.042 \\
\hline High tropics & -0.198 & 0.200 & -0.034 \\
\hline Moist mid-altitude & $-0.517 * *$ & 0.204 & -0.088 \\
\hline Constant & -0.507 & 0.548 & \\
\hline
\end{tabular}

Notes: Estimates are based on the MVP model for all 7 technologies, as shown in Table 4 of the article. The other six equations are not presented here for brevity. $\mathrm{N}=4035$. $* * * * *, *$ significant at $1 \%, 5 \%$, and $10 \%$ level, respectively. Standard errors are robust and clustered at household level. ${ }^{\text {a }}$ For this interaction term, risk is expressed as a discrete variable with values between 1 and 5, where 1 represents high risk aversion, and 5 risk loving. 
Table A2.3: Results of the multivariate probit model without AEZ dummies

\begin{tabular}{|c|c|c|c|c|c|c|c|c|c|c|c|c|}
\hline \multirow[t]{2}{*}{ Variables } & \multicolumn{3}{|c|}{ Improved seeds } & \multicolumn{3}{|c|}{ Fertilizer } & \multicolumn{3}{|c|}{ Terraces } & \multicolumn{3}{|c|}{ Soil bunds } \\
\hline & Coefficient & Std error & $\begin{array}{c}\text { Marginal } \\
\text { effect }\end{array}$ & Coefficient & Std error & $\begin{array}{c}\text { Marginal } \\
\text { effect }\end{array}$ & Coefficient & Std error & $\begin{array}{c}\text { Marginal } \\
\text { effect }\end{array}$ & Coefficient & Std error & $\begin{array}{c}\text { Marginal } \\
\text { effect }\end{array}$ \\
\hline \multicolumn{13}{|l|}{ Plot level characteristics } \\
\hline Plot size & 0.026 & 0.025 & 0.008 & -0.034 & 0.023 & -0.012 & $0.055^{* *}$ & 0.023 & 0.020 & -0.034 & 0.024 & -0.008 \\
\hline Plot ownership & $-0.269 * * *$ & 0.085 & -0.083 & $-0.485^{* * *}$ & 0.093 & -0.165 & $0.477 * * *$ & 0.090 & 0.171 & 0.076 & 0.111 & 0.018 \\
\hline Medium soil fertility & $0.230 * *$ & 0.104 & 0.071 & $-9.71 e-05$ & 0.117 & $-3.3 e-05$ & $0.225 * *$ & 0.113 & 0.081 & -0.025 & 0.129 & -0.006 \\
\hline Good soil fertility & $0.464 * * *$ & 0.104 & 0.144 & -0.056 & 0.116 & -0.019 & $0.208 *$ & 0.115 & 0.074 & -0.206 & 0.132 & -0.049 \\
\hline Gentle slope & 0.069 & 0.072 & 0.021 & 0.123 & 0.084 & 0.042 & $0.531 * * *$ & 0.085 & 0.190 & -0.125 & 0.100 & -0.030 \\
\hline Medium slope & 0.145 & 0.090 & 0.045 & $0.385 * * *$ & 0.104 & 0.131 & $0.905 * * *$ & 0.104 & 0.325 & -0.088 & 0.117 & -0.021 \\
\hline Steep slope & $0.287 *$ & 0.164 & 0.089 & $0.883 * * *$ & 0.210 & 0.301 & $1.182 * * *$ & 0.174 & 0.424 & 0.101 & 0.195 & 0.024 \\
\hline \multicolumn{13}{|c|}{ Socioeconomic characteristics } \\
\hline Male & 0.065 & 0.072 & 0.02 & $-0.139 *$ & 0.083 & -0.047 & -0.003 & 0.082 & -0.001 & 0.134 & 0.093 & 0.032 \\
\hline Age & $0.042 * * *$ & 0.014 & 0.013 & $0.029 *$ & 0.016 & 0.01 & -0.006 & 0.016 & -0.002 & 0.016 & 0.019 & 0.004 \\
\hline Age squared & $-3.5 \mathrm{e}-04 * * *$ & $1.35 \mathrm{e}-04$ & $-1.1 \mathrm{e}-04$ & $-1.91 e-04$ & $1.58 \mathrm{e}-04$ & $-6.5 e-05$ & $8.23 \mathrm{e}-05$ & $1.51 \mathrm{e}-04$ & $2.95 \mathrm{e}-05$ & $-1.49 \mathrm{e}-04$ & $1.74 \mathrm{e}-04$ & $-3.57 e-05$ \\
\hline Education & $0.045^{* * *}$ & 0.010 & 0.014 & $0.078 * * *$ & 0.012 & 0.027 & 0.015 & 0.011 & 0.005 & 0.009 & 0.013 & 0.002 \\
\hline Farm size & 0.007 & 0.005 & 0.002 & -0.006 & 0.005 & -0.002 & 0.001 & 0.005 & 0.000 & $-0.014 *$ & 0.007 & -0.003 \\
\hline TLU & 0.007 & 0.005 & 0.002 & -0.009 & 0.006 & -0.003 & -0.005 & 0.006 & -0.002 & 0.003 & 0.006 & 0.001 \\
\hline $\mathrm{HH}$ size & $-0.026^{*}$ & 0.014 & -0.008 & $-0.051 * * *$ & 0.016 & -0.017 & $-0.031 * *$ & 0.015 & -0.011 & -0.016 & 0.018 & -0.004 \\
\hline Moderate risk aversion & $0.299 * *$ & 0.134 & 0.093 & 0.062 & 0.157 & 0.021 & -0.054 & 0.139 & -0.019 & -0.222 & 0.177 & -0.053 \\
\hline Low risk aversion & 0.086 & 0.104 & 0.027 & 0.070 & 0.130 & 0.024 & 0.033 & 0.124 & 0.012 & 0.127 & 0.146 & 0.030 \\
\hline Risk neutral & 0.081 & 0.132 & 0.025 & -0.055 & 0.161 & -0.019 & -0.038 & 0.152 & -0.013 & 0.040 & 0.175 & 0.010 \\
\hline Risk loving & 0.057 & 0.129 & 0.018 & -0.082 & 0.167 & -0.028 & -0.073 & 0.164 & -0.026 & 0.126 & 0.187 & 0.030 \\
\hline \multicolumn{13}{|l|}{ Institutional variables } \\
\hline Info extension & $0.184 * * *$ & 0.067 & 0.057 & 0.098 & 0.080 & 0.033 & 0.052 & 0.076 & 0.019 & 0.131 & 0.088 & 0.031 \\
\hline Info NGOs & -0.096 & 0.097 & -0.03 & $-0.312 * * *$ & 0.114 & -0.106 & -0.117 & 0.111 & -0.042 & $0.427 * * *$ & 0.122 & 0.102 \\
\hline Info farmer group & $0.196 * *$ & 0.090 & 0.061 & $0.368 * * *$ & 0.104 & 0.125 & 0.003 & 0.099 & 0.001 & 0.139 & 0.111 & 0.033 \\
\hline Group membership & $0.184 * * *$ & 0.101 & -0.02 & 0.098 & 0.116 & -0.018 & 0.052 & 0.116 & 0.105 & 0.131 & 0.134 & 0.011 \\
\hline Market distance & $-0.043 * *$ & 0.021 & -0.013 & -0.038 & 0.023 & -0.013 & 0.016 & 0.022 & 0.006 & -0.001 & 0.022 & 0.000 \\
\hline Credit & 0.112 & 0.083 & 0.035 & 0.140 & 0.101 & 0.047 & 0.027 & 0.096 & 0.010 & 0.104 & 0.115 & 0.025 \\
\hline \multicolumn{13}{|l|}{ Weather extremes } \\
\hline Drought & -0.012 & 0.033 & -0.004 & $-0.193 * * *$ & 0.056 & -0.066 & $0.134 * * *$ & 0.048 & -0.048 & -0.053 & 0.055 & -0.013 \\
\hline Flooding & -0.023 & 0.048 & -0.007 & 0.028 & 0.052 & 0.01 & 0.035 & 0.058 & 0.012 & -0.063 & 0.071 & -0.015 \\
\hline Risk* $^{*}$ rought ${ }^{\text {a }}$ & $-0.016 *$ & 0.010 & -0.005 & 0.013 & 0.016 & 0.004 & -0.022 & 0.014 & -0.008 & 0.005 & 0.015 & 0.001 \\
\hline Risk $^{*}$ Flooding ${ }^{\text {a }}$ & 0.007 & 0.012 & 0.002 & 0.005 & 0.014 & 0.002 & -0.010 & 0.016 & -0.003 & 0.003 & 0.019 & 0.001 \\
\hline Constant & $-0.927 * *$ & & & -0.318 & & & $-1.313^{* * *}$ & & & $-1.405^{* * *}$ & & \\
\hline
\end{tabular}




\begin{tabular}{|c|c|c|c|c|c|c|c|c|c|}
\hline & \multicolumn{3}{|c|}{ Crop residues } & \multicolumn{3}{|c|}{ Zero tillage } & \multicolumn{3}{|c|}{ Manure } \\
\hline & Coefficient & Std error & Marginal effect & Coefficient & Std error & Marginal effect & Coefficient & Std error & Marginal effect \\
\hline \multicolumn{10}{|c|}{ Plot level characteristics } \\
\hline Plot size & 0.015 & 0.023 & 0.005 & 0.036 & 0.024 & 0.006 & $-0.041 *$ & 0.022 & -0.015 \\
\hline Plot ownership & $-0.300 * * *$ & 0.094 & -0.111 & $-0.266 * *$ & 0.106 & -0.047 & $0.395^{* * *}$ & 0.078 & 0.149 \\
\hline Medium soil fertility & -0.079 & 0.119 & -0.029 & $-0.362 * *$ & 0.141 & -0.063 & 0.067 & 0.094 & 0.025 \\
\hline Good soil fertility & -0.115 & 0.121 & -0.042 & $-0.259 *$ & 0.139 & -0.045 & -0.054 & 0.098 & -0.021 \\
\hline Gentle slope & 0.048 & 0.0850 & 0.018 & -0.072 & 0.102 & -0.013 & $0.120^{*}$ & 0.070 & 0.045 \\
\hline Steep slope & -0.236 & 0.177 & -0.087 & $0.547 * * *$ & 0.212 & 0.096 & -0.033 & 0.163 & -0.013 \\
\hline \multicolumn{10}{|c|}{ Socioeconomic characteristics } \\
\hline Male & 0.087 & 0.088 & 0.032 & -0.015 & 0.105 & -0.003 & -0.051 & 0.068 & -0.019 \\
\hline Age & 0.003 & 0.017 & 0.001 & -0.012 & $(0.019$ & -0.002 & 0.016 & 0.014 & 0.006 \\
\hline Age squared & $-9.72 \mathrm{e}-05$ & $1.66 \mathrm{e}-04$ & $-3.60 \mathrm{e}-05$ & $7.94 \mathrm{e}-05$ & $1.85 \mathrm{e}-04$ & $1.40 \mathrm{e}-05$ & $-8.42 \mathrm{e}-05$ & $1.31 \mathrm{e}-04$ & $-3.20 \mathrm{e}-05$ \\
\hline Education & -0.014 & 0.011 & -0.005 & -0.020 & 0.014 & -0.003 & -0.004 & 0.009 & -0.002 \\
\hline Farm size & 0.004 & 0.005 & 0.002 & $0.011 * *$ & 0.005 & 0.002 & $-0.011 * * *$ & 0.004 & -0.004 \\
\hline Moderate risk aversion & -0.022 & 0.159 & -0.008 & 0.052 & 0.187 & 0.009 & -0.196 & 0.121 & -0.074 \\
\hline Low risk aversion & -0.046 & 0.136 & -0.017 & $0.263^{*}$ & 0.158 & 0.046 & -0.002 & 0.102 & -0.001 \\
\hline Risk neutral & -0.215 & 0.167 & -0.080 & $0.333^{*}$ & 0.195 & 0.058 & 0.023 & 0.125 & 0.009 \\
\hline Risk loving & -0.144 & 0.175 & -0.053 & -0.105 & 0.211 & -0.018 & -0.027 & 0.134 & -0.01 \\
\hline \multicolumn{10}{|l|}{ Institutional variables } \\
\hline Info extension & -0.017 & 0.082 & -0.006 & $-0.189 *$ & 0.097 & -0.033 & -0.025 & 0.065 & -0.01 \\
\hline Info NGOs & 0.135 & 0.129 & 0.05 & 0.137 & 0.162 & 0.024 & 0.022 & 0.091 & 0.008 \\
\hline Info farmer group & -0.120 & 0.104 & -0.044 & -0.177 & 0.123 & -0.031 & 0.089 & 0.076 & 0.034 \\
\hline Group membership & -0.017 & 0.126 & 0.008 & $-0.189 *$ & 0.140 & -0.006 & -0.025 & 0.108 & 0.118 \\
\hline Market distance & 0.019 & 0.025 & 0.007 & -0.003 & 0.029 & -0.001 & -0.027 & 0.020 & -0.01 \\
\hline Credit & 0.049 & 0.106 & 0.018 & $0.201^{*}$ & 0.119 & 0.035 & -0.081 & 0.079 & -0.03 \\
\hline \multicolumn{10}{|l|}{ Weather extremes } \\
\hline Drought & -0.014 & 0.046 & -0.005 & -0.023 & 0.068 & -0.004 & -0.008 & 0.041 & -0.003 \\
\hline Flooding & -0.076 & 0.059 & -0.028 & 0.023 & 0.062 & 0.004 & 0.001 & 0.053 & 0.001 \\
\hline Risk*Drought a & -0.008 & 0.015 & -0.003 & 0.007 & 0.020 & 0.001 & 0.009 & 0.011 & 0.003 \\
\hline
\end{tabular}

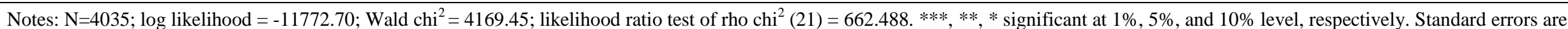

robust and clustered at household level. ${ }^{\mathrm{a}}$ For this interaction term, risk is expressed as a discrete variable with values between 1 and 5 , where 1 represents high risk aversion, and 5 risk loving. 


\title{
3 Synergies between Different Types of Agricultural Technologies: Insights from the Kenyan Small Farm Sector ${ }^{7}$
}

\begin{abstract}
Global demand for food and farm commodities continues to grow, while land and other natural resources are becoming increasingly scarce. Sustainable intensification is often seen as a new paradigm for increasing agricultural productivity in a socially and environmentally responsible way. Sustainable intensification requires a broad portfolio of technologies, including improved seeds, fertilizers, and various natural resource management (NRM) practices. However, possible synergies between different types of technologies are not yet sufficiently understood. Here, we address this knowledge gap. Using representative data from small farms in Kenya and a propensity score matching approach, we analyze income effects of various technologies and technology combinations. When adopted alone, some innovations produce positive effects, while others do not. Effects of certain technology combinations are larger. The largest income gains occur when improved seeds are adopted together with organic manure and zero tillage practices. This points at important synergies between input-intensive and NRM technologies. Yet, the number of farmers that have adopted such promising technology combinations is relatively small, implying that synergies are not yet fully exploited. More impact studies that explicitly account for possible synergies can add to the knowledge that is needed for designing and promoting technology combinations suitable for particular contexts.
\end{abstract}

\footnotetext{
${ }^{7}$ This chapter is co-authored with Songporne Tongruksawattana and Matin Qaim.
} 


\subsection{Introduction}

Global demand for food and farm commodities continues to grow, while land and other natural resources required for agricultural production are becoming increasingly scarce (Godfray et al., 2010; Hertel, 2015). In Sub-Saharan Africa, population growth is particularly strong and will likely remain so over the coming decades. Sub-Saharan Africa is also the region with the highest rates of poverty and undernutrition, and the lowest rates of productivity growth in agriculture. Many of the poor and undernourished people live in rural areas and depend on smallholder agriculture as a source of income and employment. To reduce poverty and increase food security in Sub-Saharan Africa will require substantial productivity and income growth in the small farm sector (Foresight, 2011). There is an urgent need for sustainable agricultural intensification, defined as producing more from the same area of land while reducing negative environmental impacts and increasing contributions to environmental services (Godfray et al., 2010; Pretty, 2011).

The development and use of improved seeds, chemical fertilizers, pesticides, and irrigation has contributed to large productivity gains in Asia and Latin America over the last few decades. These developments became widely known as the green revolution (Evenson and Gollin, 2003). In Africa, these input-intensive technologies have not been adopted to the same extent, due to various constraints. Wider use of improved seeds and agrochemicals will have an important role to play for increasing and stabilizing yields in the African small farm sector. However, in addition to the use of external inputs sustainable intensification will also require improved agronomy to conserve natural resources. Natural resource management (NRM) technologies build on integrated agronomic principles and include practices such as conservation tillage, intercropping, terracing of sloped land, and use of locally available organic inputs. NRM technologies can reduce farmers' reliance on external inputs and thus reduce the environmental footprint of agricultural production (Altieri, 2002; Hobbs et al., 2008). NRM practices can also help to reduce resource degradation and make farming more resilient to varying climatic shocks (Sanchez, 2002; Di Falco and Veronesi, 2013).

While in the wider public debate, input-intensive technologies and NRM practices are often depicted as two conflicting approaches (Greenpeace Africa, 2015), recent evidence shows that farmers sometimes adopt combinations of both types of technologies (Wainaina et al., 2014; Kassie et al., 2015a). Synergistic relationships may contribute positively to agricultural 
production and incomes. For instance, Sanchez (2002) argued that green revolution varieties could have been more successful in Africa if they had been adopted together with improved soil management practices. While this is plausible, there is little concrete evidence about synergistic relationships in smallholder environments. This is mainly due to the fact that available impact studies primarily focus on single technologies or compare effects of similar types of technologies. For instance, recent studies have analyzed productivity and income effects of improved seeds, sometimes in combination with chemical inputs (Becerril and Abdulai, 2010; Asfaw et al., 2012; Kabunga et al., 2014; Mathenge et al., 2014; Shiferaw et al., 2014b). Other studies have looked at the impact of organic manure, conservation agriculture, and related soil and water management practices (Pender and Gebremedhin, 2007; Kassie et al., 2010; Wollni et al., 2010; Kassie et al., 2015b). We are not aware of studies that have explicitly analyzed the impacts of adopting combinations of input-intensive and NRM technologies.

We address this research gap, using representative survey data from maize farmers in Kenya. In particular, we analyze and compare the impacts of different types of technologies such as improved seeds, chemical fertilizers, organic manure, zero tillage, and crop residue management - as well as various technology combinations on farm household income. Household income is chosen as a comprehensive welfare measure, as looking at crop yields alone may be misleading. A propensity score matching approach is used to reduce problems of selection bias. As the analysis builds on data collected in one single year and the number of adopters for certain technology combinations is relatively small, our intention is not to provide conclusive evidence about impacts and synergies. Rather, we want to highlight that important synergistic relationships exist, which should be accounted for more explicitly in future technology adoption and impact studies.

The rest of this article is structured as follows. Section 2 provides an overview of the survey data and the technologies considered in the impact analysis, while section 3 introduces the statistical methods. Results are presented and discussed in section 4 . Section 5 concludes. 


\subsection{Data and technologies considered}

\subsubsection{Farm survey}

A representative survey of maize-producing farm households was conducted in Kenya, covering all of the country's six agroecological zones (AEZs) as defined by Hassan (1998). Maize is the main staple food crop in Kenya and is produced by almost all farm households for home consumption; surplus quantities are sold in local markets. To select households, we used a multistage random sampling technique, building on official statistics and census data (KNBS, 2010). In each AEZ, we randomly selected sub-locations (Kenya's smallest administrative units). The appropriate number of sub-locations was determined proportional to the maize area in each AEZ. In total, 120 sub-locations were sampled. In each sub-location, 12 households were randomly selected, except for the coastal lowlands where only six households were selected per sublocation due to budgetary constraints. The total sample includes 1344 farm household observations. Table 3.1 shows a few general characteristics of the six AEZ and the regional distribution of the sampled households.

Table 3.1: Agroecological zones in Kenya and regional distribution of sampled households

\begin{tabular}{|c|c|c|c|c|c|c|}
\hline & $\begin{array}{l}\text { Highland } \\
\text { tropics }\end{array}$ & $\begin{array}{l}\text { Moist tran- } \\
\text { sitional }\end{array}$ & $\begin{array}{l}\text { Moist mid- } \\
\text { altitude }\end{array}$ & $\begin{array}{c}\text { Dry tran- } \\
\text { sitional }\end{array}$ & $\begin{array}{l}\text { Dry mid- } \\
\text { altitude }\end{array}$ & $\begin{array}{c}\text { Lowland } \\
\text { tropics }\end{array}$ \\
\hline Elevation (meters) & $1600-2900$ & $1200-2000$ & $1100-1500$ & $1100-1700$ & $700-1400$ & $<700$ \\
\hline Annual rainfall(mm) & $>1800$ & $1000-1800$ & $800-1200$ & $<800$ & $400-800$ & $400-1400$ \\
\hline Average temperature $\left({ }^{\circ} \mathrm{C}\right)$ & 15.2 & 19.7 & 22.1 & 19.7 & 22 & 25.5 \\
\hline Maize area (‘000 ha) & 307 & 461 & 118 & 118 & 118 & 33 \\
\hline $\begin{array}{l}\text { Share of national maize } \\
\text { production }(\%)\end{array}$ & 35 & 20 & 20 & 10 & 10 & 5 \\
\hline $\begin{array}{l}\text { Potential maize yield } \\
(\mathrm{t} / \mathrm{ha})\end{array}$ & 6.7 & 5.2 & 5.2 & 4.5 & 2.7 & 3.3 \\
\hline Actual maize yield (t/ha) & 2.0 & 0.7 & 1.1 & 1.1 & 0.5 & 1.0 \\
\hline $\begin{array}{l}\text { Share of households } \\
\text { surveyed (\%) }\end{array}$ & 18 & 26 & 18 & 15 & 16 & 7 \\
\hline
\end{tabular}

Source: Adapted from Hassan (1998) and Jaetzold et al. (2005).

The survey was implemented between December 2012 and February 2013. Face-to-face interviews were conducted by a local team of enumerators who were supervised by the researchers. The structured questionnaire focused on maize production aspects at the individual plot level, technology adoption, other farm and non-farm economic activities of the household, 
as well as broader socioeconomic household and contextual characteristics. The reference period for all income and expenditure data was the calendar year of 2012. The average farm size in the sample is 5.6 acres. Households are relatively poor with a mean per capita annual income of 460 US dollars. Further descriptive statistics are presented in section 3.4.

\subsubsection{Technologies considered}

We analyze the impact of seven different technologies and selected technological combinations that have been adopted by maize farmers in Kenya to varying extents. Out of the seven technologies, two can be classified as input-intensive technologies, namely improved maize seeds and chemical fertilizers. Improved seeds, which were adopted by $85 \%$ of the farmers in our sample, include both hybrids and open-pollinated varieties (OPVs). Improved hybrids and OPVs that are available in Kenya have higher yield potentials than traditional landraces under favorable environments. While breeders are currently also developing more stress-tolerant improved varieties of maize, such seeds are not yet commercially available in Kenya. The other five technologies considered can be classified as NRM technologies, namely terracing, soil bunds, crop residue management, zero tillage, and use of organic manure.

Terraces and soil bunds are both practices intended to reduce the problem of soil erosion, especially on sloped land (Gebremedhin and Swinton, 2003). These two practices differ in terms of investment costs, durability, and effectiveness of erosion abatement. Stone terraces are constructed walls that retain embankments of soil. Their construction involves preparing a base for the wall, transporting construction rocks, and carefully layering the stones. Stone terraces are more effective than soil bunds in preventing soil erosion on steep slopes prone to heavy runoff. More than $50 \%$ of the farmers in the sample have actually constructed stone terraces. Soil bunds, on the other hand, are embankments made by ridging soil on the lower side of a ditch along a slope contour (Gebremedhin and Swinton, 2003). They can be constructed by hand digging or plowing and are cheaper and easier to establish than stone terraces. Soil bunds are used by $20 \%$ of the sample farms.

Crop residue management and zero tillage are both important elements of conservation agriculture (Hobbs et al., 2008), which however are not always adopted together. In our sample, crop residue management is practiced by $60 \%$ of the farmers, whereas zero tillage was adopted by only $13 \%$. Both practices help to conserve the structure of the uppermost soil layers, thus 
reducing erosion and water evaporation. Crop residue management (mulching) also improves water infiltration and reduces maximum temperatures in the soil surface layers. Finally, livestock manure, which is used by $65 \%$ of the sample farmers, adds nutrients and organic matter to the soil.

\subsection{Methods}

\subsubsection{Impact assessment framework}

We analyze the impact of technology adoption on farm household income. Income does not only refer to cash income but also includes the value of subsistence production. Agricultural technologies can affect income through various pathways, such as higher yields, lower production costs, or changes in household labor requirements that may entail time reallocation and higher or lower incomes from alternative economic activities. As different technologies can involve different pathways, we use income as a comprehensive indicator of living standard.

The analysis is based on observational data, that is, the technologies considered were not assigned randomly. Instead, farmers chose themselves which particular innovations to adopt. Therefore, adopters and non-adopters are likely different in terms of various characteristics, and we cannot simply interpret observed income disparities as impacts of the technology without controlling for confounding factors. One common approach to deal with possible selection bias in impact assessment is to use instrumental variable (IV) regression techniques (Heckman and Vytlacil, 2005; Imbens and Wooldridge, 2009). However, IV methods require at least one valid instrument that is correlated with technology adoption but not correlated with income. We were unable to identify suitable instruments for all seven technologies and additional technology combinations, which is why we decided to use propensity score matching (PSM) techniques, another common approach to reduce selection bias in impact assessment (Rosenbaum and Rubin, 1983; Dehejia and Wahba, 2002; Abadie and Imbens, 2006).

\subsubsection{Propensity score matching}

PSM reduces selection bias by only comparing groups of adopters and non-adopters ("treated" and "untreated" subjects in the terminology of the impact evaluation literature) that are sufficiently similar based on observable characteristics. We follow five steps involved in applying PSM, as outlined by Baker (2000) and Caliendo and Kopeinig (2008). First propensity 
scores are estimated for each farm household using a discrete choice model. We use a logit regression model that leads to consistent parameter estimates (Baker, 2000; Ravallion, 2001). Propensity scores describe the likelihood of adopting a certain technology based on a set of covariates. Second, the matching algorithm is selected. Matching is the technique to select treated and untreated subjects that are similar in terms of their propensity score.

We use kernel based matching (KBM) and radius matching (RM) methods. KBM is a non-parametric matching method that uses the weighted average of the outcome variable (household income) for all non-adopters to construct the counterfactual outcome, attributing a higher weight to those observations that provide a better match. This weighted average is then compared with the outcome variable for the group of adopters. The difference in mean outcomes provides an estimate of the average treatment effect on the treated (ATT). For KBM, we use a bandwidth of 0.1. RM is a variant of caliper matching (Dehejia and Wahba, 2002). Applying caliper matching means that an individual from the group of non-adopters is chosen as a matching partner for an adopter that lies within the caliper (propensity range) and is closest in terms of propensity score (Caliendo and Kopeinig, 2008). RM as a variant of caliper matching implies that not only the nearest neighbor within each caliper is used as a match, but all of the comparison members within the caliper. A benefit of this approach is that it uses only as many comparison units as are available within the caliper and therefore allows for usage of extra (fewer) units when good matches are (not) available. For RM we use a radius caliper of 0.1. A balancing test is then conducted after matching to ascertain that the differences in covariates between adopters and non-adopters have been eliminated, such that the matched comparison group can be considered as a credible counterfactual (Caliendo and Kopeinig, 2008).

Third, the common support (overlap) condition is identified. Common support is the area where the balancing score has positive density for both treated and untreated units. No matches can be made to estimate average treatment effects when there is no overlap. Fourth, the ATT is estimated in the common support region based on the selected matching algorithm. Fifth, sensitivity analysis is undertaken to test the robustness of the results. In particular, PSM assumes that treated and untreated subjects differ only in terms of observed factors, which is referred to as the conditional independence assumption. Since with PSM it is not possible to estimate the magnitude of unobserved selection bias, Aakvix (2001) suggested the use of Rosenbaum bounds to test the null hypothesis of zero change in the ATT when different values of unobserved 
selection bias are introduced. This test shows how hidden bias - if relevant - might alter inferences about the ATT, but it does not indicate whether hidden bias is actually an issue.

\subsection{Results and discussion}

\subsubsection{Descriptive statistics}

Table 3.2 presents a summary of the key variables used in this analysis. As explained above, the outcome variable for the impact evaluation is household income. We look at total household income as well as income in per capita terms. The treatment variables are technology adoption, referring to the seven technologies described above plus selected combinations. In principle, 120 different combinations are possible, but many of these combinations are not observed in reality. We focus on those that are more common so that a sufficient number of adopters is available for the statistical analysis. It should be mentioned that data on technology adoption were collected at plot level, even though the impact evaluation is done at household level. We define a household as adopter if it adopted the particular technology on at least one of the plots. The covariates used to explain adoption are also shown in Table 3.2. They comprise a set of socioeconomic, institutional, farm, and agroecological characteristics. We also use two variables related to climatic shocks, namely drought and flooding events experienced by farmers during a period of 10 years prior to the survey.

Table 3.2: Summary statistics of outcome variables, technology adoption, and covariates

\begin{tabular}{|c|c|c|c|}
\hline Variable name & Description of the variable & Mean & Std Dev \\
\hline \multicolumn{4}{|l|}{ Outcome variables } \\
\hline Household income & Total annual income generated by the household in $\mathrm{KES}^{\mathrm{a}}$ & 257,643 & 323,721 \\
\hline Per capita income & Total household income per person in KES & 45,791 & 70,582 \\
\hline \multicolumn{4}{|l|}{ Technologies } \\
\hline Improved seeds & $=1$ if seeds are improved maize varieties, 0 otherwise & 0.85 & 0.36 \\
\hline Fertilizer & $=1$ if farmer applied chemical fertilizers, 0 otherwise & 0.60 & 0.49 \\
\hline Terraces & $=1$ if farmer has constructed terraces, 0 otherwise & 0.55 & 0.50 \\
\hline Soil bunds & $=1$ if farmer had soil bunds on the plot, 0 otherwise & 0.20 & 0.40 \\
\hline Crop residues & $=1$ if farmer left any crop residues on the plot, 0 otherwise & 0.60 & 0.49 \\
\hline Zero tillage & $=1$ if farmer practiced zero tillage, 0 otherwise & 0.13 & 0.33 \\
\hline Manure & $=1$ if farmer used animal manure, 0 otherwise & 0.65 & 0.48 \\
\hline \multicolumn{4}{|l|}{ Covariates } \\
\hline \multicolumn{4}{|c|}{ Socioeconomic characteristics } \\
\hline Age & Age of the household head in years & 53.96 & 13.86 \\
\hline Male & $=1$ if the household head is male, 0 otherwise & 0.81 & 0.39 \\
\hline Education & Years of formal education of the household head & 7.71 & 4.48 \\
\hline Household size & Number of household members. & 6.46 & 2.56 \\
\hline
\end{tabular}




\begin{tabular}{|c|c|c|c|}
\hline Farm size & Total land owned by the household in acres. & 5.59 & 9.12 \\
\hline TLU & Total livestock units & 5.57 & 7.46 \\
\hline Occupation & $\begin{array}{l}=1 \text { if farming is the main occupation of the household head, } 0 \\
\text { otherwise }\end{array}$ & 0.76 & 0.42 \\
\hline Productive assets & Total value of non-land productive assets in KES & 42,552 & 173,962 \\
\hline Off-farm income & Proportion of off-farm income in total income & 0.47 & 0.31 \\
\hline \multicolumn{4}{|l|}{ Institutional variables } \\
\hline Credit & $=1$ if household took any credit in the previous year, 0 if not & 0.20 & 0.40 \\
\hline Group membership & $=1$ if household participates in any group and 0 otherwise. & 0.87 & 0.33 \\
\hline Market distance & Distance in walking hours to the nearest main market & 1.62 & 1.57 \\
\hline Info improved seeds & $\begin{array}{l}=1 \text { if household got extension information on improved maize } \\
\text { varieties, } 0 \text { otherwise }\end{array}$ & 0.65 & 0.48 \\
\hline Info on zero tillage & $\begin{array}{l}=1 \text { if household got extension information on zero tillage, } 0 \\
\text { otherwise }\end{array}$ & 0.14 & 0.34 \\
\hline Info on crop residue & $\begin{array}{l}=1 \text { if household got extension information on crop residues, } 0 \\
\text { otherwise }\end{array}$ & 0.33 & 0.47 \\
\hline Info on soil management & $\begin{array}{l}=1 \text { if household got extension information on soil and water } \\
\text { conservation practices, } 0 \text { otherwise }\end{array}$ & 0.47 & 0.50 \\
\hline \multicolumn{4}{|l|}{ Farm characteristics } \\
\hline Slopy land & Proportion of slopy land & 0.69 & 0.44 \\
\hline Fertile land & Proportion of fertile land & 0.38 & 0.46 \\
\hline Own land & Proportion of owned land out of all land under cultivation & 0.88 & 0.25 \\
\hline \multicolumn{4}{|l|}{ Climatic shocks } \\
\hline Drought & Frequency of drought experienced between $2003-2012$ & 4.06 & 4.35 \\
\hline Flooding & Frequency of flooding experienced between $2003-2012$ & 1.10 & 1.60 \\
\hline \multicolumn{4}{|l|}{ AEZ dummies ${ }^{b}$} \\
\hline Dry mid-altitude & $=1$ if $\mathrm{HH}$ is located in the dry mid altitude, 0 otherwise. & 0.16 & 0.37 \\
\hline Dry transitional & $=1$ if $\mathrm{HH}$ located in the dry transitional zone, 0 otherwise & 0.15 & 0.36 \\
\hline Moist transitional & $=1$ if $\mathrm{HH}$ located in the moist transitional zone, 0 otherwise & 0.26 & 0.44 \\
\hline High tropics & $=1$ if $\mathrm{HH}$ is located in the high tropics, 0 otherwise & 0.18 & 0.38 \\
\hline Moist mid-altitude & $=1$ if $\mathrm{HH}$ is located in the moist mid altitude, 0 otherwise. & 0.18 & 0.38 \\
\hline
\end{tabular}

The number of observations is $n=1337$ (seven observations had to be dropped due to missing values). ${ }^{a}$ KES, Kenyan Shilling; 1 US dollar $=100 \mathrm{KES} .^{\mathrm{b}}$ For the AEZ, the lowland tropics are defined as base category.

Figure 3.1 provides an overview of the structure of household incomes by agroecological zone. In spite of some regional differences, maize production accounts for $10-20 \%$ of total incomes in all zones. Other crops and livestock together account for another $30-40 \%$, implying that off-farm activities account for $40-60 \%$ of total incomes. Among the off-farm activities, employed labor is the most important source of income, followed by self-employed trade and business activities. Table 3.3 compares income structures between farmers who did and did not adopt certain technologies. Various significant differences can be observed, underlining that the sub-groups are not identical and pursue different economic strategies. 
Figure 3.1: Average structure of household income by agroecological zones

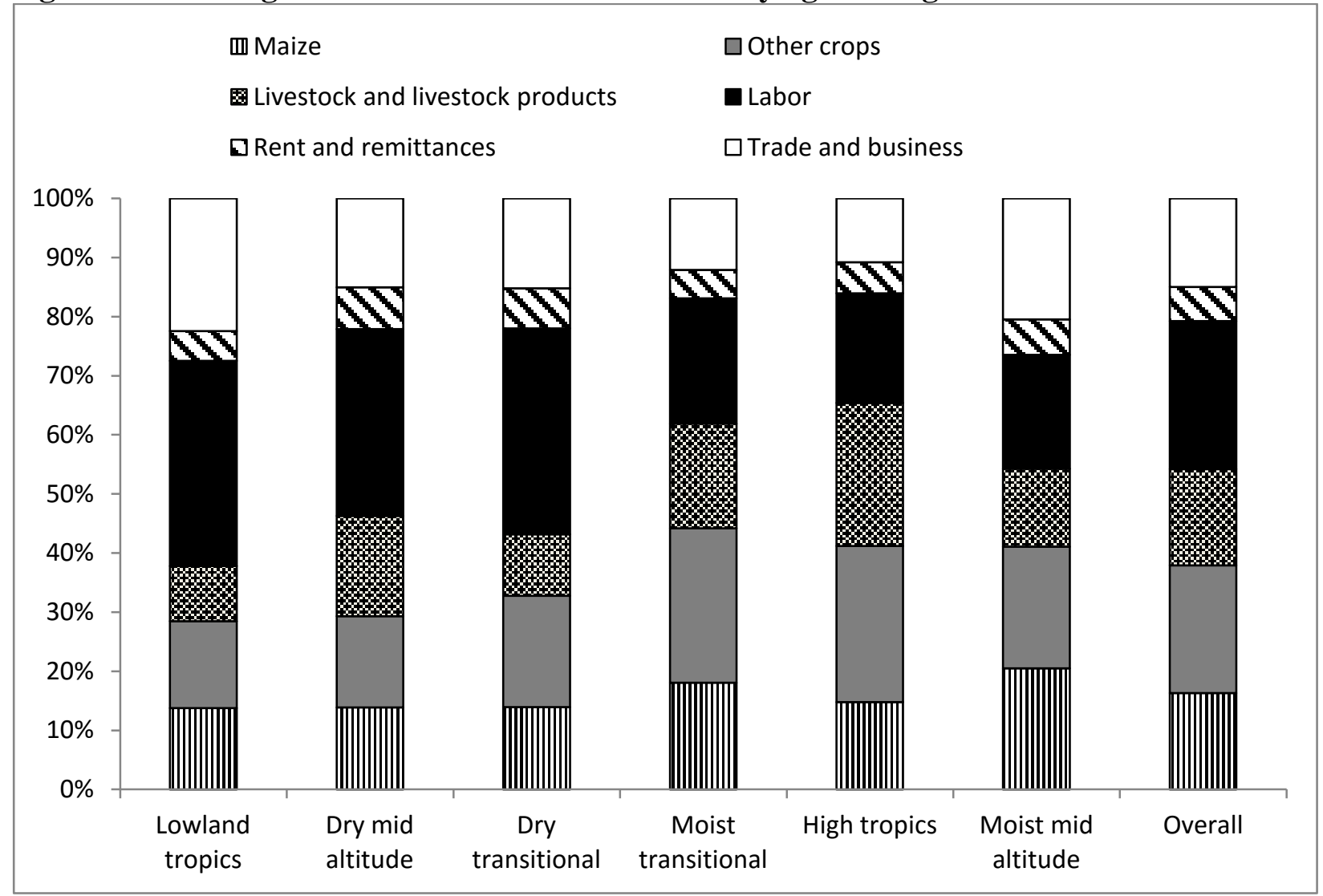


Table 3.3: Average structure of household income by status of technology adoption (income shares in \%)

\begin{tabular}{|c|c|c|c|c|c|c|c|c|c|c|c|c|}
\hline & \multicolumn{2}{|c|}{ Maize } & \multicolumn{2}{|c|}{ Other crops } & \multicolumn{2}{|c|}{ Livestock } & \multicolumn{2}{|c|}{ Labor } & \multicolumn{2}{|c|}{ Rent and remittances } & \multicolumn{2}{|c|}{ Trade and businesses } \\
\hline & Adopters & $\begin{array}{c}\text { Non- } \\
\text { adopters }\end{array}$ & Adopters & $\begin{array}{c}\text { Non- } \\
\text { adopters }\end{array}$ & Adopters & $\begin{array}{c}\text { Non- } \\
\text { adopters }\end{array}$ & Adopters & $\begin{array}{c}\text { Non- } \\
\text { adopters }\end{array}$ & Adopters & $\begin{array}{c}\text { Non- } \\
\text { adopters }\end{array}$ & Adopters & $\begin{array}{c}\text { Non- } \\
\text { adopters }\end{array}$ \\
\hline Improved seeds & $16.64 *$ & 14.51 & $22.51 * * *$ & 16.61 & $17.09 * * *$ & 11.64 & $23.82 * * *$ & 31.84 & $5.22 * * *$ & 8.80 & 14.71 & 16.59 \\
\hline Fertilizers & $17.63 * * *$ & 14.32 & $23.49 * * *$ & 18.73 & 16.99 & 15.13 & $21.85 * * *$ & 29.92 & $5.09 * *$ & 6.82 & 14.96 & 15.07 \\
\hline Terracing & 15.84 & 16.89 & 21.71 & 21.48 & $14.70 * * *$ & 18.13 & 25.89 & 24.03 & 6.06 & 5.43 & 15.79 & 14.05 \\
\hline Soil bunds & 16.03 & 16.39 & $24.46^{* *}$ & 20.88 & $18.38 * *$ & 15.71 & $21.49 * *$ & 25.95 & 6.32 & 5.63 & 13.32 & 15.43 \\
\hline Crop residues & $18.63 * * *$ & 12.91 & 21.92 & 21.14 & $15.16^{* *}$ & 17.88 & $23.84 *$ & 26.84 & $4.82 * * *$ & 7.20 & 15.65 & 14.05 \\
\hline Zero tillage & 15.61 & 16.42 & 23.89 & 21.27 & 15.44 & 16.37 & 23.20 & 25.32 & 6.57 & 5.66 & 15.29 & 14.96 \\
\hline Manure & $15.29 * * *$ & 18.15 & 21.87 & 21.13 & 16.67 & 15.50 & 25.02 & 25.10 & 5.97 & 5.43 & 15.17 & 14.69 \\
\hline Overall & \multicolumn{2}{|c|}{16.32} & \multicolumn{2}{|c|}{21.60} & \multicolumn{2}{|c|}{16.25} & \multicolumn{2}{|c|}{25.05} & \multicolumn{2}{|c|}{5.77} & \multicolumn{2}{|c|}{15.00} \\
\hline
\end{tabular}


Table 3.4 compares mean household incomes between adopters and non-adopters of each of the seven technologies. Adopters of input-intensive technologies have significantly higher incomes than non-adopters. In comparison, income differences between adopters and non-adopters of NRM technologies are less pronounced. However, as was discussed previously, these comparisons cannot be interpreted as impacts of technology adoption because of systematic differences between adopters and non-adopters. PSM results that account for confounding factors are presented in the following section.

Table 3.4: Average household income levels by technology adoption status

\begin{tabular}{|c|c|c|c|c|}
\hline & \multicolumn{2}{|c|}{ Household income } & \multicolumn{2}{|c|}{ Per capita income } \\
\hline & Adopters & Non-adopters & Adopters & Non-adopters \\
\hline Improved seeds & $\begin{array}{c}274,379 * * * \\
(341,817)\end{array}$ & $\begin{array}{c}165,227 \\
(168,528)\end{array}$ & $\begin{array}{c}48,886^{* * * *} \\
(75,198)\end{array}$ & $\begin{array}{c}28,700 \\
(30,484)\end{array}$ \\
\hline Fertilizer & $\begin{array}{c}281,019 * * * \\
(343,532)\end{array}$ & $\begin{array}{c}229,049 \\
(287,662)\end{array}$ & $\begin{array}{c}52,461 * * * \\
(81,977)\end{array}$ & $\begin{array}{c}35,635 \\
(46,600)\end{array}$ \\
\hline Terracing & $\begin{array}{c}254,066 \\
(297,444)\end{array}$ & $\begin{array}{c}261,958 \\
(353,028)\end{array}$ & $\begin{array}{c}45,765 \\
(63,737)\end{array}$ & $\begin{array}{c}45,823 \\
(78,100)\end{array}$ \\
\hline Soil bunds & $\begin{array}{c}272,661 \\
(409,995)\end{array}$ & $\begin{array}{c}253,843 \\
(298,074)\end{array}$ & $\begin{array}{c}52,026 \\
(102,419)\end{array}$ & $\begin{array}{c}44,213 \\
(59,870)\end{array}$ \\
\hline Crop residues & $\begin{array}{c}257,391 \\
(341,788)\end{array}$ & $\begin{array}{c}258,015 \\
(295,352)\end{array}$ & $\begin{array}{c}41,900 * * \\
(71,763)\end{array}$ & $\begin{array}{c}51,533 \\
(68,466)\end{array}$ \\
\hline Zero tillage & $\begin{array}{c}316,030 * * \\
(369,461)\end{array}$ & $\begin{array}{c}249,195 \\
(315841)\end{array}$ & $\begin{array}{c}53,214 \\
(80,556)\end{array}$ & $\begin{array}{c}44,717 \\
(68,993)\end{array}$ \\
\hline Manure & $\begin{array}{c}265,995 \\
(352,262)\end{array}$ & $\begin{array}{c}242,681 \\
(264,715)\end{array}$ & $\begin{array}{c}48,922 * * \\
(80,658)\end{array}$ & $\begin{array}{c}40,183 \\
(47,024)\end{array}$ \\
\hline
\end{tabular}

***,**, and * indicate significant differences in incomes between adopters and non-adopters at the $1 \%, 5 \%$, and $10 \%$ level, respectively ( $t$-test results). Incomes are measured in Kenyan Shilling (KES per year); 1 US dollar $=100$ KES. Standard deviations are shown in parentheses.

\subsubsection{Impact results}

PSM involves estimating propensity scores for each of the technologies using logit models. The logit model results for the seven technologies considered in this study are shown in appendix A3, Table A3.1. Using the same covariates we also estimated logit models to explain the adoption of relevant technology combinations and to calculate propensity scores. The propensity scores for adopters and non-adopters were then matched and balanced to find credible counterfactuals. Evidence of successful matching is presented in appendix A3, Table A3.2 in terms of reduced 
bias, low pseudo- $\mathrm{R}^{2}$, and insignificant log-likelihood values after matching. Successful bias reduction was achieved for all technologies except for improved seeds. To achieve successful matching, the number of available untreated controls should be greater than the number of treated subjects (Lunt, 2014). Due to the high share of adopters of improved seeds in our sample, this condition could not be fulfilled for this particular technology. To enable balancing, we had to reduce the number of covariates in the logit model for improved seeds. Also, we used a tighter caliper and kernel bandwidth of 0.05 for improved seeds (as compared to 0.1 for the other technologies) to reduce bias as much as possible.

Similarly, the common support condition was fulfilled for all technologies except for improved seeds (propensity score histograms are shown in appendix A3, Figure A3.1). For improved seeds, we could not find suitable matches for 156 adopters and therefore the ATT estimates for this technology should be interpreted with caution; it only represents the impact on the income of those adopters for whom suitable matches were found. We present differences in important covariates between matched and unmatched adopters in appendix A3, Table A3.3. Matched adopters are less wealthy and have lower propensity scores than unmatched adopters, meaning that the ATT results are more relevant for the lower part of the income distribution. Problems with successful matching and common support relate to the high adoption rates of improved seeds in three of the AEZs, namely the moist transitional zone (97\%), the highland tropics (94\%), and the dry transitional zone (87\%). As an additional robustness check, we exclude these three AEZs and estimate the impact of improved seeds in the remaining three AEZs (moist mid altitude, dry mid altitude, and lowland tropics), where adoption rates were lower and matching was successful.

Table 3.5 presents the estimated ATTs for the seven technologies and relevant combinations, with total household income and per capita income as outcome variables. Also shown are the critical gamma levels that indicate how hidden bias - if present - might affect the estimated impact. The gamma level is defined as the odds ratio of differential treatment assignment due to an unobserved covariate. For instance, a gamma level of 1.50 would imply that matched subjects would have to differ by a factor of $50 \%$ in terms of unobserved characteristics in order to render the estimated ATT insignificant. We only report gamma levels for significant ATT estimates. For estimates with low gamma levels more caution is warranted. 
The impact magnitudes and significance levels are quite robust to the chosen matching method. In the following paragraphs we concentrate on discussing results obtained with radius matching.

For terracing, crop residue management, and soil bunds we do not observe any significant impact on household income. In comparison, for the other two NRM technologies, zero tillage and use of manure, significantly positive income effects are observed. Adoption of zero tillage increases household income by 51,527 Kenyan Shillings (KES), which is equivalent to a gain of approximately $16 \%$. The effect of zero tillage on per capita income is positive but insignificant. Manure adopters increase their total household income by KES 36,444 (14\%) and their per capita income by KES 10,000 (20\%).

Turning to the input-intensive technologies, adoption of improved maize seeds contributes to an increase in household income by almost $15 \%$, when observations from all six AEZ are included. When only looking at the three AEZ with somewhat lower adoption rates, the ATT gets even larger, indicating that improved seeds help to raise household living standards. Somewhat strikingly, however, the use of chemical fertilizer does not contribute to household income gains. The estimated effect for fertilizer is even negative, albeit not statistically significant. This is in spite of the fact that fertilizer adopters are significantly richer than nonadopters, as was shown above in Table 3.4.

What are reasons for the insignificant effect of fertilizer adoption? Average fertilizer rates used in the Kenyan small farm sector are low and many of the soils are nutrient-depleted, hence positive yield and income effects of fertilization should actually be expected. However, many of the farmers use fertilizers that only contain nitrogen $(\mathrm{N})$, phosphorus $(\mathrm{P})$, and potassium $(\mathrm{K})$. While these are the key macronutrients that plants need for healthy growth, several micronutrients - such as sulfur $(\mathrm{S})$, boron $(\mathrm{B})$, zinc $(\mathrm{Zn})$, copper $(\mathrm{Cu})$, or manganese $(\mathrm{Mn})-$ are also required (Ryan et al., 2013). Many of the African soils are micronutrient depleted, so that using NPK fertilizers alone may not always result in expected yield gains (Chianu et al., 2012). This could also explain the notable differences in impacts between chemical fertilizers and manure, because manure contains micronutrients as well. When we confine the group of chemical fertilizer adopters to those that used fertilizers with micronutrients, the negative ATT estimate turns positive, even though it remains insignificant due to large standard errors (Table 3.5). It should be mentioned that water constraints may also limit the effectiveness of chemical 
fertilizers. Since we only have data from 2012, which happened to be relatively dry in some parts of Kenya, the estimated effects should not be over-interpreted.

We now look at the effects for technology combinations in Table 3.5. The adoption of improved seeds together with chemical fertilizers does not lead to a significant ATT, which is related to the disappointing fertilizer effect discussed previously. However, combining improved seeds with manure results in highly significant impacts on household (15\%) and per capita incomes (18\%). The combination of improved seeds with zero tillage also increases household income beyond what both technologies achieve when adopted alone. And the largest positive income effects are observed when improved seeds are combined with manure and zero tillage. On average, this combination of three technologies produces household income gains of KES $150,150(35 \%)$ and per capita income gains of KES 25,669 (35\%). These results clearly underline that important synergies exist between input-intensive and NRM technologies. On the other hand, we also see in Table 3.5 that the number of adopters of such promising technology combinations is relatively low, suggesting that the synergies are not yet fully exploited. 
Table 3.5: Impact of the adoption of technologies and technology combinations on household income using PSM

\begin{tabular}{|c|c|c|c|c|c|c|c|}
\hline & & \multicolumn{3}{|c|}{ Radius matching (RM) } & \multicolumn{3}{|c|}{ Kernel based matching (KBM) } \\
\hline & Impact on & ATT & Std error & Gamma level & ATT & Std error & Gamma level \\
\hline \multirow{2}{*}{$\begin{array}{l}\text { Improved seeds } \\
\text { (treated } n=1,132 \text { ) }\end{array}$} & Household income & $39,885 * *$ & 20,371 & $1.20-1.25$ & $38,811 * *$ & 20,562 & $1.20-1.25$ \\
\hline & Per capita income & 5,668 & 3,73 & & 5,454 & 3,766 & \\
\hline \multirow{2}{*}{$\begin{array}{l}\text { Improved seeds for } 3 \mathrm{AEZ}^{\mathrm{a}} \\
\text { (treated } \mathrm{n}=388 \text { ) }\end{array}$} & Household income & $65,184 * * *$ & 22,635 & $1.20-1.25$ & $64,445 * * *$ & 22,976 & $1.20-1.25$ \\
\hline & Per capita income & $10,813 * * *$ & 3,449 & $1.20-1.25$ & $10,737 * * *$ & 3,496 & $1.20-1.25$ \\
\hline \multirow{2}{*}{$\begin{array}{l}\text { Fertilizer } \\
\text { (treated } n=807)\end{array}$} & Household income & $-10,679$ & 24,738 & & $-13,280$ & 24,957 & \\
\hline & Per capita income & 98 & 4,477 & & 638 & 4,509 & \\
\hline \multirow{2}{*}{$\begin{array}{l}\text { Fertilizer (incl. micronutrients) } \\
\text { (treated } n=444 \text { ) }\end{array}$} & Household income & 28,266 & 22,137 & & 26,771 & 22,200 & \\
\hline & Per capita income & 2,391 & 4,774 & & 2,037 & 4,789 & \\
\hline \multirow{2}{*}{$\begin{array}{l}\text { Terraces } \\
(\text { treated } n=731)\end{array}$} & Household income & $-11,162$ & 22,456 & & $-9,457$ & 22,769 & \\
\hline & Per capita income & 2,140 & 4,970 & & 2,526 & 5,041 & \\
\hline \multirow{2}{*}{$\begin{array}{l}\text { Soil bunds } \\
(\text { treated } n=270)\end{array}$} & Household income & 22,171 & 26,802 & & 21,466 & 26,916 & \\
\hline & Per capita income & 6,679 & 6,546 & & 6,343 & 6,566 & \\
\hline \multirow{2}{*}{$\begin{array}{l}\text { Crop residue } \\
\text { (treated } n=797 \text { ) }\end{array}$} & Household income & 10,859 & 23,699 & & 10,325 & 24,112 & \\
\hline & Per capita income & -858 & 5,365 & & -657 & 5,463 & \\
\hline \multirow{2}{*}{$\begin{array}{l}\text { Zero tillage } \\
(\text { treated } n=169)\end{array}$} & Household income & $51,257^{*}$ & 31,093 & $1.70-1.75$ & $52,821 *$ & 31,265 & $1.70-1.75$ \\
\hline & Per capita income & 8,080 & 6,799 & & 8,765 & 6,838 & \\
\hline \multirow{2}{*}{$\begin{array}{l}\text { Manure } \\
\text { (treated } n=858 \text { ) }\end{array}$} & Household income & $36,644^{*}$ & 19,234 & $1.55-1.60$ & $35,595^{*}$ & 19,422 & $1.55-1.60$ \\
\hline & Per capita income & $10,000 * * *$ & 3,854 & $1.45-1.50$ & $9,704 * *$ & 3,883 & $1.45-1.50$ \\
\hline \multirow{2}{*}{$\begin{array}{l}\text { Improved seeds }+ \text { fertilizer } \\
\text { (treated } n=759)\end{array}$} & Household income & $-7,996$ & 23,313 & & $-10,314$ & 23,370 & \\
\hline & Per capita income & 991 & 4,449 & & 140 & 4,457 & \\
\hline \multirow{2}{*}{$\begin{array}{l}\text { Improved seeds }+ \text { manure } \\
\text { (treated } n=711)\end{array}$} & Household income & $41,947 * *$ & 17,366 & $1.50-1.55$ & $41,026^{* *}$ & 17,494 & $1.50-1.55$ \\
\hline & Per capita income & $9,576 * * *$ & 3,343 & $1.45-1.50$ & $9,423 * * *$ & 3,364 & $1.45-1.50$ \\
\hline \multirow{2}{*}{$\begin{array}{l}\text { Improved seeds }+ \text { fertilizer + manure } \\
\text { (treated } n=449)\end{array}$} & Household income & 7,514 & 20,089 & & 4,141 & 20,249 & \\
\hline & Per capita income & 3,817 & 4,121 & & 3,203 & 4,144 & \\
\hline \multirow{2}{*}{$\begin{array}{l}\text { Improved seeds + zero tillage } \\
\text { (treated } n=146)\end{array}$} & Household income & $57,308 *$ & 34,530 & $1.85-1.90$ & $57,001 *$ & 34,562 & $1.80-1.85$ \\
\hline & Per capita income & 8,900 & 7,578 & & 8,858 & 7,585 & \\
\hline \multirow{2}{*}{$\begin{array}{l}\text { Zero tillage }+ \text { crop residues } \\
\text { (treated } n=121 \text { ) }\end{array}$} & Household income & 31,721 & 36,449 & & 30,739 & 36,600 & \\
\hline & Per capita income & 1,704 & 6,940 & & 1,816 & 6,980 & \\
\hline \multirow{2}{*}{$\begin{array}{l}\text { Zero tillage }+ \text { manure } \\
(\text { treated } n=99)\end{array}$} & Household income & $129,188 * * *$ & 45,518 & $1.10-1.15$ & $128,618 * * *$ & 45,515 & $1.10-1.15$ \\
\hline & Per capita income & $22,514 * *$ & 10,375 & $1.40-1.45$ & $22,192 * *$ & 10,374 & $1.45-1.50$ \\
\hline \multirow{2}{*}{$\begin{array}{l}\text { Zero tillage+ fertilizer } \\
\text { (treated } n=101 \text { ) }\end{array}$} & Household income & 63,133 & 41,987 & & 61,269 & 42,425 & \\
\hline & Per capita income & 9,160 & 8,994 & & 9,237 & 9,093 & \\
\hline
\end{tabular}




\begin{tabular}{|c|c|c|c|c|c|c|}
\hline \multirow{2}{*}{$\begin{array}{l}\text { Improved seeds }+ \text { zero tillage }+ \text { manure } \\
\text { (treated } n=81 \text { ) }\end{array}$} & Household income & $150,150 * * *$ & 53,851 & $1.15-1.20$ & $148,858 * * *$ & 53,941 \\
\hline & Per capita income & $25,669 * *$ & 12,356 & $1.35-1.40$ & $25,697 * *$ & 53,941 \\
\hline \multirow{2}{*}{$\begin{array}{l}\text { Terracing }+ \text { manure } \\
\text { (treated } n=510 \text { ) }\end{array}$} & Household income & 10,138 & 22,163 & & 6,566 & 22,488 \\
\hline & Per capita income & 5,945 & 4,867 & & 5,684 & 4,936 \\
\hline \multirow{2}{*}{$\begin{array}{l}\text { Improved seeds }+ \text { terracing }+ \text { manure } \\
\text { (treated } n=429)\end{array}$} & Household income & 22,169 & 22,238 & & 20,244 & 22,476 \\
\hline & Per capita income & 7,574 & 4,930 & & 7,391 & 4,969 \\
\hline \multirow{2}{*}{$\begin{array}{l}\text { Improved seeds }+ \text { terracing }+ \text { manure }+ \\
\text { fertilizer }(\text { treated } n=281)\end{array}$} & Household income & 16,296 & 25,175 & & 18,208 & 25,476 \\
\hline & Per capita income & 6,990 & 5,765 & & 7,273 & 5,825 \\
\hline
\end{tabular}

fertilizer (treated $\mathrm{n}=281$ )

***, **, and * significant at 1\%,5\%, and 10\% level, respectively. ATT, average treatment effect on the treated. Results are reported in Kenyan Shillings (KES) per year; I US dollar $=100$ KES. ${ }^{a}$ This refers to the three AEZ moist mid-altitude, dry mid-altitude, and lowland tropics where a sufficient number of non-adopters was found for robust impact assessment. 


\subsection{Conclusion}

Sustainable intensification is seen by many as the new paradigm for increasing agricultural productivity and incomes in the African small farm sector while conserving natural resources and reducing negative environmental externalities. Sustainable intensification requires a broad portfolio of innovations and technologies, including improved seeds, fertilizers, as well as various natural resource management $(\mathrm{NRM})$ practices. While in the public debate technologies that rely on external inputs are sometimes depicted as being incompatible with NRM technologies, in reality there may be interesting synergistic relationships when elements of both types of technologies are combined. Possible synergies in smallholder environments are not yet sufficiently understood. Most impact studies focus on the effects of single technologies. In this article, we have used representative data from smallholder farmers in Kenya to compare the effects of various inputintensive technologies, NRM technologies, and selected combinations.

In particular, we have used propensity score matching methods to analyze impacts of technology adoption on household income. The estimation results show that - when adopted alone - some technologies produce positive income effects, while other technologies do not. At the same time, some of the technology combinations lead to higher positive impacts. The largest positive income effects are observed when improved seeds are adopted together with organic manure and zero tillage practices. This clearly underlines that there are important synergies between inputintensive and NRM technologies. On the other hand, the number of farmers adopting such promising technology combinations is relatively low, suggesting that the synergies are not yet fully exploited. More impact studies that explicitly account for possible synergies can help to improve the knowledge that is needed for designing and promoting suitable technology combinations in particular settings.

Our analysis has a few limitations. First, we used cross-section data from only one year, even though impacts of technologies may vary over time due to climatic variability and other factors. Second, while propensity score matching helps to control selection bias due to observable factors, unobserved heterogeneity may still lead to hidden bias. Third, we could only analyze a few technology combinations, because for other combinations we did not have sufficient adoption observations for meaningful impact assessment. Against this background the exact numerical results should be interpreted with caution. However, our intention was not to provide conclusive evidence. Rather, we wanted to show that important synergies between different types of technologies exist, which were often neglected in previous impact studies. Follow-up research is needed for a more comprehensive understanding. 
Appendix A3

Table A3.1: Logit models for estimating propensity scores

\begin{tabular}{|c|c|c|c|c|c|c|c|c|}
\hline & $\begin{array}{c}\text { Improved } \\
\text { seeds }\end{array}$ & $\begin{array}{c}\text { Improved } \\
\text { seeds (3 } \\
\text { AEZs) }\end{array}$ & Fertilizer & Terracing & Soil bunds & Crop residue & Zero tillage & Manure \\
\hline Male & & $\begin{array}{l}-0.377 \\
(0.308)\end{array}$ & $\begin{array}{l}-0.085 \\
(0.189)\end{array}$ & $\begin{array}{l}0.288^{*} \\
(0.167)\end{array}$ & $\begin{array}{c}-0.135 \\
(0.183)\end{array}$ & $\begin{array}{c}-0.075 \\
(0.171)\end{array}$ & $\begin{array}{l}-0.035 \\
(0.241)\end{array}$ & $\begin{array}{c}-0.282 \\
(0.179)\end{array}$ \\
\hline Age & $\begin{array}{l}-0.002 \\
(0.007)\end{array}$ & $\begin{array}{c}0.001 \\
(0.009)\end{array}$ & $\begin{array}{c}0.003 \\
(0.005)\end{array}$ & $\begin{array}{c}-0.004 \\
(0.005)\end{array}$ & $\begin{array}{l}-0.008 \\
(0.006)\end{array}$ & $\begin{array}{c}-0.021 * * * \\
(0.005)\end{array}$ & $\begin{array}{c}-0.012 * \\
(0.007)\end{array}$ & $\begin{array}{c}0.011 * * \\
(0.005)\end{array}$ \\
\hline Education & $\begin{array}{c}0.142 * * * \\
(0.024)\end{array}$ & $\begin{array}{c}0.180 * * * \\
(0.037)\end{array}$ & $\begin{array}{c}0.090^{* * *} \\
(0.020)\end{array}$ & $\begin{array}{l}-0.015 \\
(0.019)\end{array}$ & $\begin{array}{c}0.011 \\
(0.017)\end{array}$ & $\begin{array}{c}0.005 \\
(0.016)\end{array}$ & $\begin{array}{c}-0.052 * * \\
(0.025)\end{array}$ & $\begin{array}{c}0.011 \\
(0.017)\end{array}$ \\
\hline Household size & $\begin{array}{c}0.041 \\
(0.036)\end{array}$ & $\begin{array}{c}0.004 \\
(0.048)\end{array}$ & $\begin{array}{c}-0.035 \\
(0.028)\end{array}$ & $\begin{array}{c}0.026 \\
(0.025)\end{array}$ & $\begin{array}{c}-0.026 \\
(0.028)\end{array}$ & $\begin{array}{c}0.105^{* * * *} \\
(0.031)\end{array}$ & $\begin{array}{c}0.037 \\
(0.037)\end{array}$ & $\begin{array}{c}-0.028 \\
(0.024)\end{array}$ \\
\hline Farms size & & $\begin{array}{c}0.019 \\
(0.016)\end{array}$ & $\begin{array}{l}-0.002 \\
(0.008)\end{array}$ & $\begin{array}{c}-8.36 \mathrm{E}-04 \\
(0.007)\end{array}$ & $\begin{array}{c}-0.033 * * \\
(0.015)\end{array}$ & $\begin{array}{c}0.032 * * * \\
(0.019)\end{array}$ & $\begin{array}{c}0.024 * * * \\
(0.008)\end{array}$ & $\begin{array}{c}-0.039 * * * \\
(0.008)\end{array}$ \\
\hline TLU & & $\begin{array}{c}0.024 \\
(0.020)\end{array}$ & $\begin{array}{c}-0.039 * * \\
(0.016)\end{array}$ & $\begin{array}{c}-0.008 \\
(0.011)\end{array}$ & $\begin{array}{c}0.009 \\
(0.013)\end{array}$ & $\begin{array}{c}0.005 \\
(0.011)\end{array}$ & $\begin{array}{l}-0.007 \\
(0.016)\end{array}$ & $\begin{array}{c}0.041 * * * \\
(0.014)\end{array}$ \\
\hline Occupation & & $\begin{array}{l}-0.352 \\
(0.283)\end{array}$ & $\begin{array}{c}0.051 \\
(0.176)\end{array}$ & $\begin{array}{c}0.231 \\
(0.161)\end{array}$ & $\begin{array}{l}-0.018 \\
(0.189)\end{array}$ & $\begin{array}{l}-0.114 \\
(0.164)\end{array}$ & $\begin{array}{c}0.229 \\
(0.240)\end{array}$ & $\begin{array}{c}0.178 \\
(0.162)\end{array}$ \\
\hline Productive assets & $\begin{array}{c}0.199 * * * \\
(0.067)\end{array}$ & $\begin{array}{c}0.109 \\
(0.110)\end{array}$ & $\begin{array}{c}0.184 * * * \\
(0.050)\end{array}$ & $\begin{array}{c}0.083 * * \\
(0.040)\end{array}$ & $\begin{array}{c}-0.006 \\
(0.048)\end{array}$ & $\begin{array}{c}-0.101 * * \\
(0.042)\end{array}$ & $\begin{array}{c}-0.012 \\
(0.056)\end{array}$ & $\begin{array}{c}0.062 \\
(0.043)\end{array}$ \\
\hline Off farm income & $\begin{array}{c}-1.508 * * * \\
(0.328)\end{array}$ & $\begin{array}{c}-1.795 * * * \\
(0.422)\end{array}$ & $\begin{array}{c}-0.536 * * \\
(0.249)\end{array}$ & $\begin{array}{c}0.273 \\
(0.216)\end{array}$ & $\begin{array}{l}-0.399 \\
(0.255)\end{array}$ & $\begin{array}{l}-0.254 \\
(0.238)\end{array}$ & $\begin{array}{c}0.183 \\
(0.334)\end{array}$ & $\begin{array}{l}-0.245 \\
(0.227)\end{array}$ \\
\hline Group membership & & $\begin{array}{c}0.052 \\
(0.311)\end{array}$ & $\begin{array}{c}0.056 \\
(0.198)\end{array}$ & $\begin{array}{l}0.307 * \\
(0.182)\end{array}$ & $\begin{array}{c}0.309 \\
(0.255)\end{array}$ & $\begin{array}{c}0.154 \\
(0.196)\end{array}$ & $\begin{array}{c}-0.249 \\
(0.259)\end{array}$ & $\begin{array}{c}0.613 * * * \\
(0.185)\end{array}$ \\
\hline Market distance & $\begin{array}{c}-0.107 * * \\
(0.048)\end{array}$ & $\begin{array}{c}-0.174 * * * \\
(0.060)\end{array}$ & $\begin{array}{c}-0.005 \\
(0.040)\end{array}$ & $\begin{array}{c}0.027 \\
(0.038)\end{array}$ & $\begin{array}{c}-0.010 \\
(0.042)\end{array}$ & $\begin{array}{c}0.054 \\
(0.041)\end{array}$ & $\begin{array}{c}0.053 \\
(0.055)\end{array}$ & $\begin{array}{c}-0.057 \\
(0.038)\end{array}$ \\
\hline Credit & & $\begin{array}{c}0.277 \\
(0.296)\end{array}$ & $\begin{array}{c}0.422 * * \\
(0.178)\end{array}$ & $\begin{array}{c}0.024 \\
(0.160)\end{array}$ & $\begin{array}{c}-0.009 \\
(0.181)\end{array}$ & $\begin{array}{c}0.126 \\
(0.176)\end{array}$ & $\begin{array}{l}0.386^{*} \\
(0.213)\end{array}$ & $\begin{array}{c}-0.207 \\
(0.161)\end{array}$ \\
\hline Info on zero tillage & & & & & & & $\begin{array}{c}1.547 * * * \\
(0.189)\end{array}$ & \\
\hline Info on crop residues & & & & & & $\begin{array}{c}0.426 * * * \\
(0.135)\end{array}$ & & \\
\hline Info on soil management & & & & $\begin{array}{c}0.421 * * * \\
(0.146)\end{array}$ & $\begin{array}{c}0.438 * * \\
(0.184)\end{array}$ & & & \\
\hline Info improved seeds & $\begin{array}{c}0.787 * * * \\
(0.241)\end{array}$ & $\begin{array}{c}1.383 * * * \\
(0.333)\end{array}$ & & & & & & \\
\hline
\end{tabular}




\begin{tabular}{|c|c|c|c|c|c|c|c|c|}
\hline & $\begin{array}{l}\text { Improved } \\
\text { seeds }\end{array}$ & $\begin{array}{c}\text { Improved } \\
\text { seeds (3 } \\
\text { AEZs) }\end{array}$ & Fertilizer & Terracing & Soil bunds & Crop residue & Zero tillage & Manure \\
\hline Own land & & -0.905 & $\begin{array}{l}-0.433 \\
(0.353)\end{array}$ & 0.101 & 0.024 & -0.213 & -0.218 & 0.323 \\
\hline Fertile land & & $\begin{array}{c}(0.515) \\
0.260 \\
(0.240)\end{array}$ & $\begin{array}{c}(0.533) \\
-0.492^{* * *} \\
(0.155)\end{array}$ & $\begin{array}{l}(0.250) \\
-0.064 \\
(0.135)\end{array}$ & $\begin{array}{c}(0.280) \\
-0.441^{* *} \\
(0.158)\end{array}$ & $\begin{array}{l}(0.266) \\
-0.131 \\
(0.141)\end{array}$ & $\begin{array}{c}(0.358) \\
0.179 \\
(0.187)\end{array}$ & $\begin{array}{l}(0.246) \\
-0.185 \\
(0.136)\end{array}$ \\
\hline Slopy land & & $\begin{array}{l}0.413^{*} \\
(0.227)\end{array}$ & $\begin{array}{c}0.491 * * * \\
(0.154)\end{array}$ & $\begin{array}{c}0.988^{* * *} \\
(0.142)\end{array}$ & $\begin{array}{c}0.094 \\
(0.165)\end{array}$ & $\begin{array}{c}0.077 \\
(0.149)\end{array}$ & $\begin{array}{l}-0.041 \\
(0.194)\end{array}$ & $\begin{array}{c}0.212 \\
(0.140)\end{array}$ \\
\hline Drought & $\begin{array}{c}-0.045^{* *} \\
(0.018)\end{array}$ & $\begin{array}{c}-0.056^{* *} \\
(0.025)\end{array}$ & $\begin{array}{c}-0.099 * * * \\
(0.019)\end{array}$ & $\begin{array}{l}-0.011 \\
(0.015)\end{array}$ & $\begin{array}{l}-0.004 \\
(0.018)\end{array}$ & $\begin{array}{l}0.037^{*} \\
(0.020)\end{array}$ & $\begin{array}{c}0.009 \\
(0.021)\end{array}$ & $\begin{array}{c}-0.058 * * * \\
(0.016)\end{array}$ \\
\hline Flooding & & & $\begin{array}{c}0.059 \\
(0.059)\end{array}$ & $\begin{array}{c}0.033 \\
(0.043)\end{array}$ & $\begin{array}{l}-0.077 \\
(0.051)\end{array}$ & $\begin{array}{c}0.039 \\
(0.062)\end{array}$ & $\begin{array}{c}-0.236 * * * \\
(0.078)\end{array}$ & $\begin{array}{l}-0.017 \\
(0.042)\end{array}$ \\
\hline Dry mid-altitude & $\begin{array}{l}-0.291 \\
(0.315)\end{array}$ & $\begin{array}{l}-0.414 \\
(0.342)\end{array}$ & $\begin{array}{l}-0.548 \\
(0.336)\end{array}$ & $\begin{array}{c}1.685 * * * \\
(0.299)\end{array}$ & $\begin{array}{c}0.292 \\
(0.409)\end{array}$ & $\begin{array}{c}-2.508^{* * * *} \\
(0.381)\end{array}$ & $\begin{array}{c}-0.740^{* *} \\
(0.366)\end{array}$ & $\begin{array}{c}1.325 * * * \\
(0.290)\end{array}$ \\
\hline Dry transitional & $\begin{array}{l}0.659 * \\
(0.370)\end{array}$ & & $\begin{array}{c}1.086^{* * * *} \\
(0.329)\end{array}$ & $\begin{array}{c}2.061 * * * \\
(0.326)\end{array}$ & $\begin{array}{c}0.135 \\
(0.419)\end{array}$ & $\begin{array}{c}-2.391 * * * \\
(0.386)\end{array}$ & $\begin{array}{c}-1.073^{* *} \\
(0.418)\end{array}$ & $\begin{array}{c}1.046^{* * * *} \\
(0.303)\end{array}$ \\
\hline Moist transitional & $\begin{array}{c}1.766 * * * \\
(0.425)\end{array}$ & & $\begin{array}{c}1.952 * * * \\
(0.338)\end{array}$ & $\begin{array}{c}0.673 * * \\
(0.298)\end{array}$ & $\begin{array}{c}0.575 \\
(0.402)\end{array}$ & $\begin{array}{c}-0.934 * * \\
(0.379)\end{array}$ & $\begin{array}{l}-0.233 \\
(0.359)\end{array}$ & $\begin{array}{l}-0.400 \\
(0.278)\end{array}$ \\
\hline High tropics & $\begin{array}{c}1.083^{* * *} \\
(0.381)\end{array}$ & & $\begin{array}{c}2.416^{* * * *} \\
(0.377)\end{array}$ & $\begin{array}{l}-0.131 \\
(0.313)\end{array}$ & $\begin{array}{c}1.254 * * * \\
(0.403)\end{array}$ & $\begin{array}{c}-1.169^{* * * *} \\
(0.384)\end{array}$ & $\begin{array}{l}-0.149 \\
(0.392)\end{array}$ & $\begin{array}{c}-0.755^{* * *} \\
(0.288)\end{array}$ \\
\hline Moist mid-altitude & $\begin{array}{c}-0.884 * * * \\
(0.313)\end{array}$ & $\begin{array}{c}-1.047^{* * * *} \\
(0.341)\end{array}$ & $\begin{array}{l}0.552^{*} \\
(0.332)\end{array}$ & $\begin{array}{c}0.402 \\
(0.302)\end{array}$ & $\begin{array}{c}0.194 \\
(0.417)\end{array}$ & $\begin{array}{l}0.0767 \\
(0.409)\end{array}$ & $\begin{array}{l}-0.226 \\
(0.376)\end{array}$ & $\begin{array}{c}0.271 \\
(0.288)\end{array}$ \\
\hline Constant & $\begin{array}{l}-0.787 \\
(0.742)\end{array}$ & $\begin{array}{c}0.480 \\
(1.177)\end{array}$ & $\begin{array}{c}-1.793 * * * \\
(0.689)\end{array}$ & $\begin{array}{c}-3.018 * * * \\
(0.636)\end{array}$ & $\begin{array}{c}-1.763^{* *} \\
(0.822)\end{array}$ & $\begin{array}{c}2.547 * * * \\
(0.667)\end{array}$ & $\begin{array}{l}-1.410 \\
(0.870)\end{array}$ & $\begin{array}{l}-0.823 \\
(0.594)\end{array}$ \\
\hline Pseudo $\mathrm{R}^{2}$ & 0.225 & 0.176 & 0.274 & 0.130 & 0.051 & 0.200 & 0.118 & 0.117 \\
\hline
\end{tabular}

$* * *, * * *$ significant at $1 \%, 5 \%$, and $10 \%$ level, respectively. Figures in parentheses are standard errors. 
Table A3.2: Balancing tests before and after matching

\begin{tabular}{|c|c|c|c|c|c|c|c|c|c|}
\hline \multirow[t]{2}{*}{ Technologies } & \multicolumn{3}{|c|}{ Before matching } & \multicolumn{3}{|c|}{ After RM } & \multicolumn{3}{|c|}{ After KBM } \\
\hline & $\begin{array}{c}\text { Pseudo } \\
\mathrm{R}^{2}\end{array}$ & $\begin{array}{c}\text { Mean } \\
\text { bias }\end{array}$ & $\begin{array}{c}\text { LR } \chi^{2} \\
\text { p value }\end{array}$ & $\begin{array}{c}\text { Pseudo } \\
\mathrm{R}^{2}\end{array}$ & $\begin{array}{c}\text { Mean } \\
\text { bias }\end{array}$ & $\begin{array}{l}\mathrm{LR} \chi^{2} \\
\mathrm{P} \text { value }\end{array}$ & $\begin{array}{c}\text { Pseudo } \\
\mathrm{R}^{2}\end{array}$ & $\begin{array}{c}\text { Mean } \\
\text { bias }\end{array}$ & $\begin{array}{l}\text { LR } \chi 2 \\
\text { P value }\end{array}$ \\
\hline Improved seeds only & 0.225 & 45.2 & 0.000 & 0.008 & 3.8 & 0.065 & 0.008 & 3.8 & 0.059 \\
\hline Improved seeds for the $3 \mathrm{AEZs}$ & 0.176 & 26.3 & 0.000 & 0.008 & 3.7 & 0.986 & 0.009 & 3.6 & 0.982 \\
\hline Fertilizer only & 0.274 & 30.5 & 0.000 & 0.013 & 4.2 & 0.204 & 0.013 & 4.3 & 0.198 \\
\hline Terracing only & 0.130 & 17.7 & 0.000 & 0.006 & 2.6 & 0.981 & 0.005 & 2.6 & 0.994 \\
\hline Soil bunds only & 0.051 & 11.9 & 0.000 & 0.005 & 3.5 & 1.000 & 0.003 & 2.5 & 1.000 \\
\hline Crop residue only & 0.200 & 23.5 & 0.000 & 0.014 & 3.9 & 0.185 & 0.012 & 3.6 & 0.303 \\
\hline Zero tillage only & 0.118 & 15.3 & 0.000 & 0.006 & 3.1 & 1.000 & 0.003 & 2.1 & 1.000 \\
\hline Manure only & 0.117 & 18.6 & 0.000 & 0.007 & 3.1 & 0.775 & 0.006 & 3.0 & 0.891 \\
\hline Improved seeds+ fertilizer & 0.255 & 28.6 & 0.000 & 0.013 & 4.0 & 0.294 & 0.013 & 4.1 & 0.349 \\
\hline Improved seeds + manure & 0.097 & 16.5 & 0.000 & 0.003 & 2.5 & 1.000 & 0.002 & 2.0 & 1.000 \\
\hline Improved seeds + fertilizer + manure & 0.124 & 19.5 & 0.000 & 0.003 & 2.6 & 1.000 & 0.002 & 2.2 & 1.000 \\
\hline Improved seeds+ zero tillage & 0.115 & 17.0 & 0.000 & 0.007 & 3.5 & 1.000 & 0.006 & 3.3 & 1.000 \\
\hline Zero tillage+ crop residues & 0.136 & 18.3 & 0.000 & 0.012 & 3.9 & 1.000 & 0.009 & 3.4 & 1.000 \\
\hline Zero tillage + manure & 0.119 & 17.5 & 0.000 & 0.008 & 4.0 & 1.000 & 0.008 & 3.9 & 1.000 \\
\hline Zero tillage + fertilizers & 0.140 & 20.9 & 0.000 & 0.011 & 4.6 & 1.000 & 0.008 & 3.7 & 1.000 \\
\hline Improved seeds + zero tillage + manure & 0.123 & 18.9 & 0.000 & 0.012 & 4.9 & 1.000 & 0.123 & 4.3 & 1.000 \\
\hline Terracing + manure & 0.162 & 20.6 & 0.000 & 0.003 & 2.4 & 1.000 & 0.003 & 2.0 & 1.000 \\
\hline Improved seeds + terracing + manure & 0.157 & 21.1 & 0.000 & 0.003 & 2.3 & 1.000 & 0.002 & 1.9 & 1.000 \\
\hline Improved seeds + terracing + manure + fertilizer & 0.157 & 24.3 & 0.000 & 0.004 & 2.7 & 1.000 & 0.004 & 2.5 & 1.000 \\
\hline
\end{tabular}


Table A3.3: Differences in attributes between matched and unmatched adopters of improved seeds

\begin{tabular}{|c|c|c|c|c|c|}
\hline \multirow[t]{2}{*}{ Attribute } & \multicolumn{2}{|c|}{ Matched adopters $(n=976)$} & \multicolumn{2}{|c|}{ Unmatched $(n=156)$} & \multirow[t]{2}{*}{$\mathrm{P}$ value } \\
\hline & Mean & Std dev & Mean & Std dev & \\
\hline Household income & $237,604 * * *$ & 273,507 & 504,455 & 616,763 & 0.0000 \\
\hline Per capita income & $41,321 * * *$ & 48,712 & 96,219 & 154,012 & 0.0000 \\
\hline Propensity score & $0.863 * * *$ & 0.130 & 0.985 & 0.077 & 0.0000 \\
\hline Education & $7.49 * * *$ & 3.98 & 11.71 & 5.67 & 0.0000 \\
\hline Age & 53.78 & 13.82 & 52.77 & 12.61 & 0.4141 \\
\hline Household size & 6.50 & 2.53 & 6.28 & 2.33 & 0.3015 \\
\hline Productive assets & $30,288 * * *$ & 141,507 & 159,452 & 339,407 & 0.0000 \\
\hline Off-farm income & $0.483 * * *$ & 0.294 & 0.240 & 0.284 & 0.0000 \\
\hline Market distance & $1.695 * * *$ & 1.646 & 1.247 & 1.239 & 0.0011 \\
\hline Drought & $4.022 * * *$ & 4.299 & 2.083 & 2.170 & 0.0000 \\
\hline Dry mid-altitude & $0.163 * * *$ & 0.370 & 0.000 & 0.000 & 0.0000 \\
\hline Dry transitional & $0.178 * * *$ & 0.382 & 0.044 & 0.206 & 0.0000 \\
\hline Moist transitional & $0.225 * * *$ & 0.418 & 0.776 & 0.419 & 0.0000 \\
\hline High tropics & 0.198 & 0.399 & 0.190 & 0.393 & 0.8085 \\
\hline Moist mid-altitude & $0.166 * * *$ & 0.373 & 0.006 & 0.080 & 0.0000 \\
\hline
\end{tabular}

***, $* *, *$ significant at $1 \%, 5 \%$, and $10 \%$ level, respectively. 
Figure A 3.1: Propensity score histograms using radius matching showing common support between treated and untreated

Improved seeds

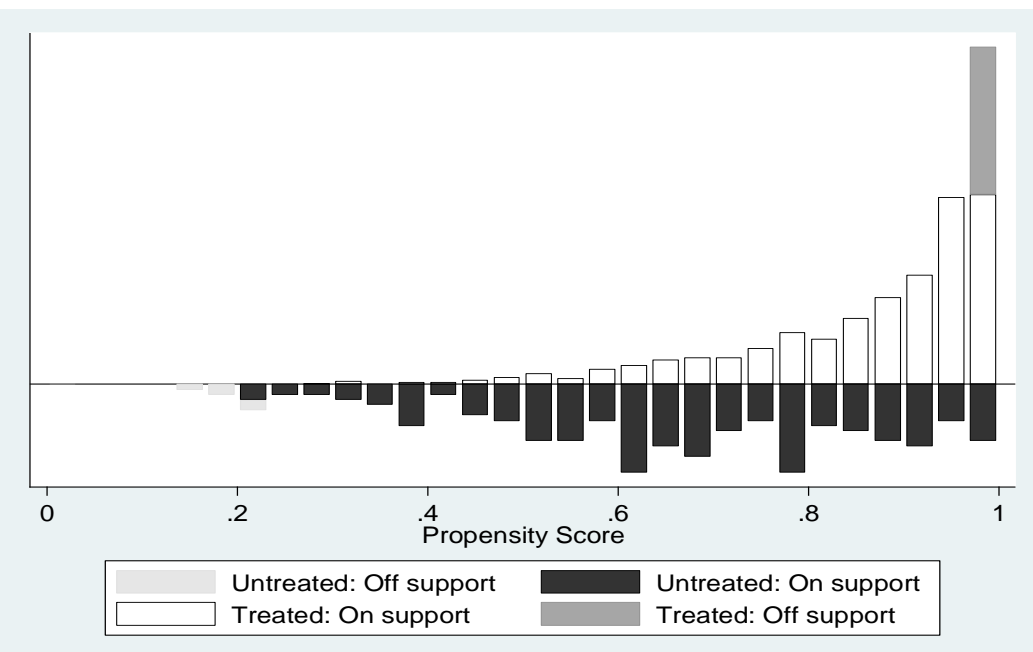

Terracing

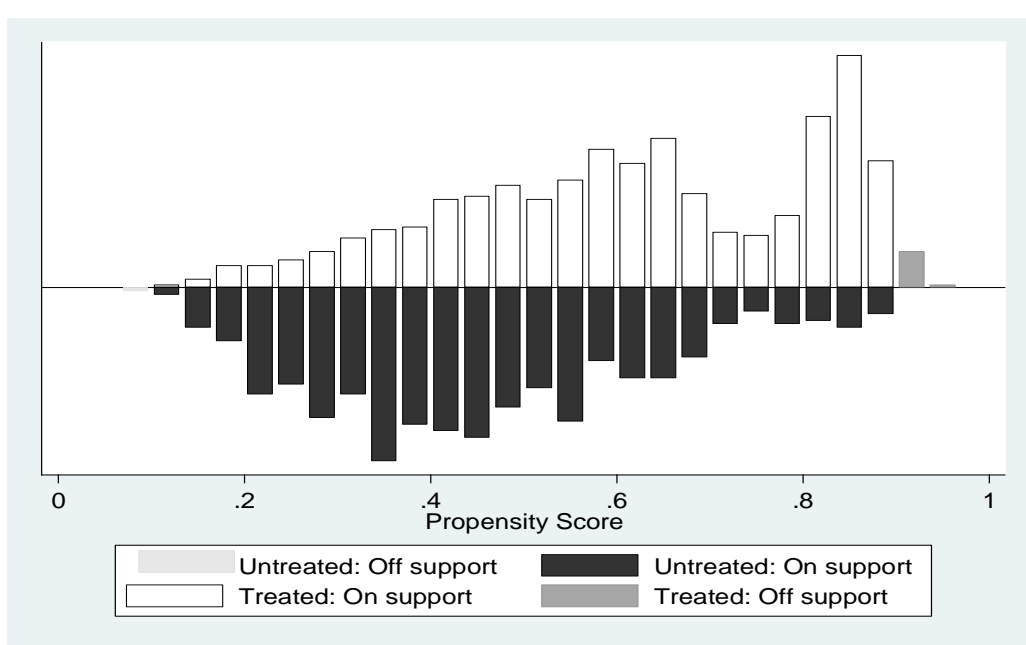

Fertilizers

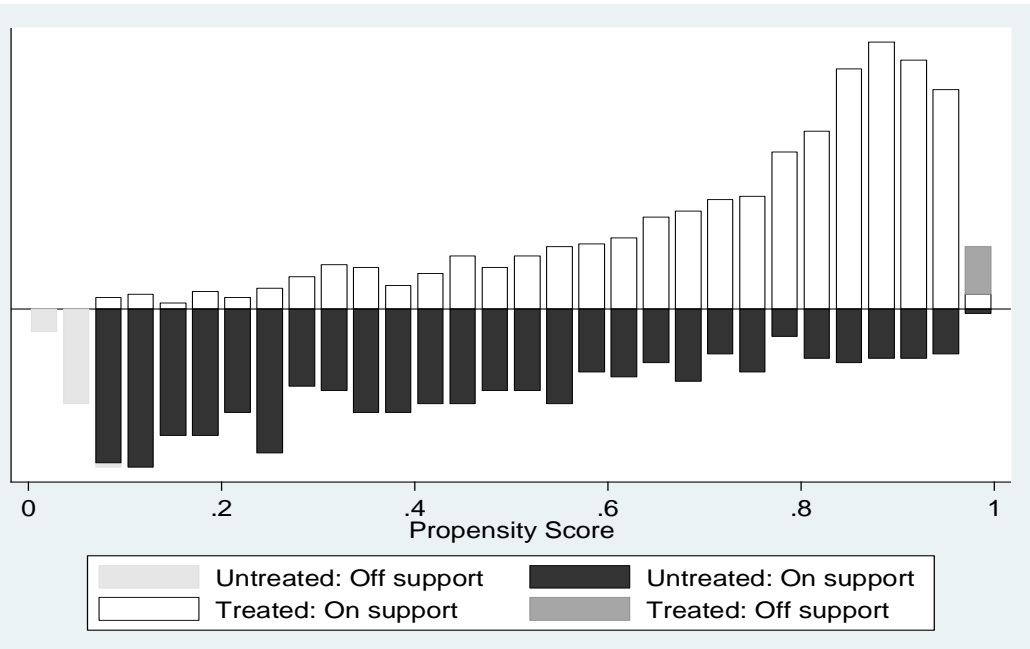

Soil bunds

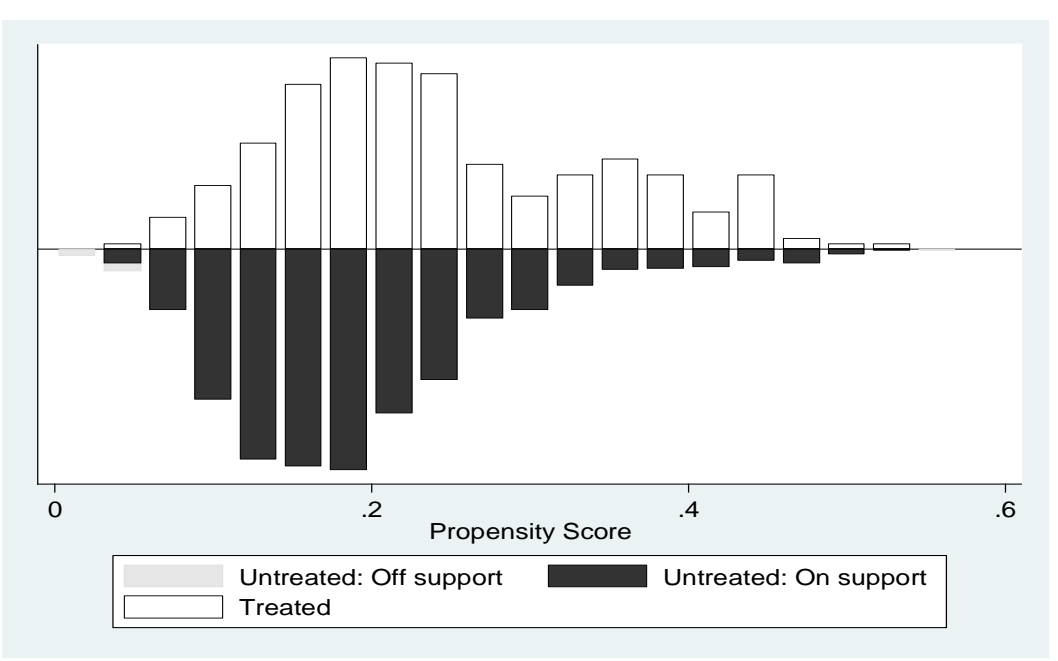


Crop residues

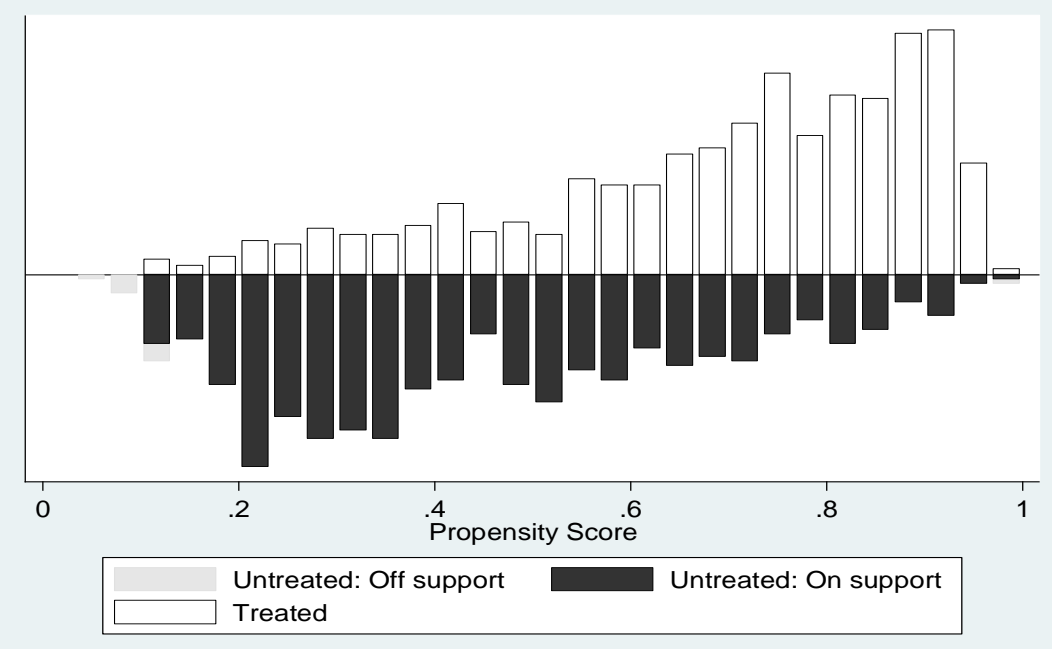

Manure

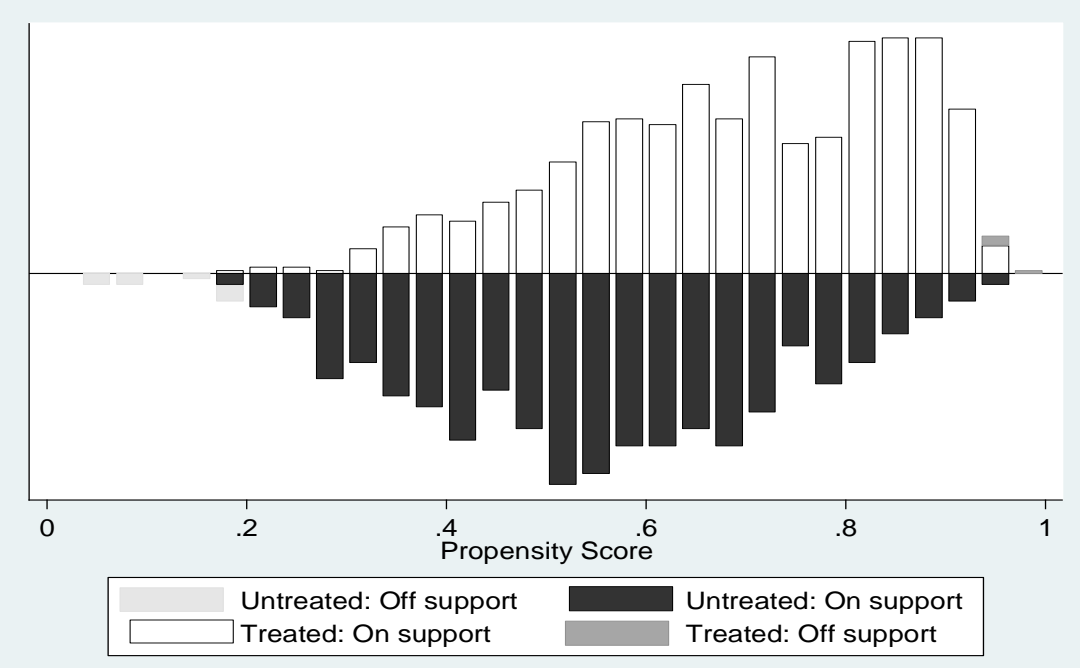

Zero tillage

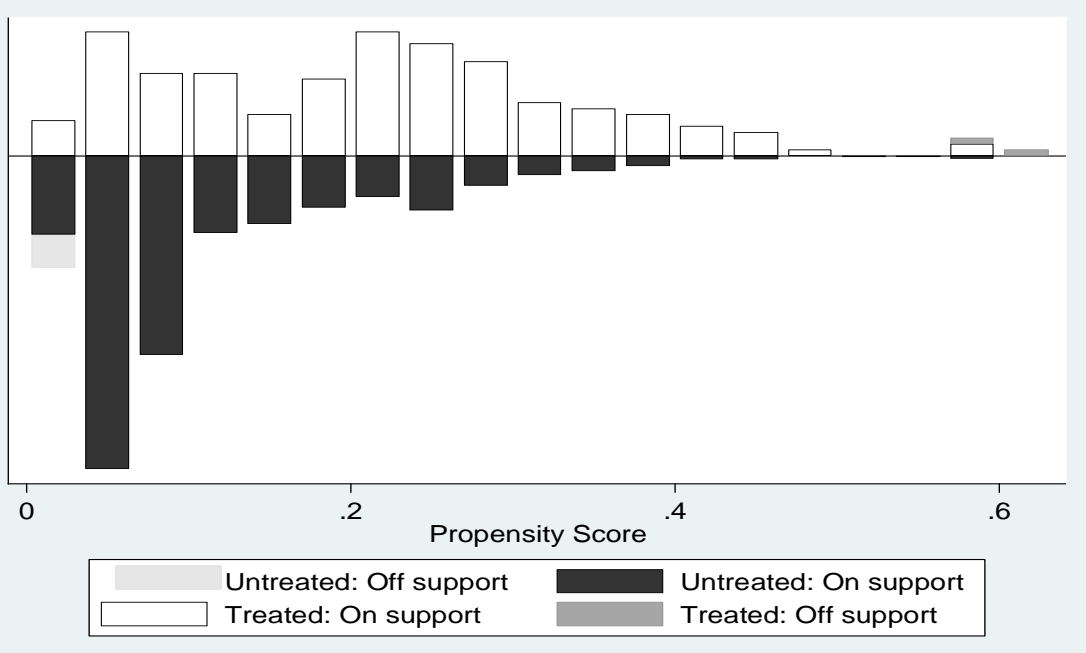




\title{
4 Technical Efficiency and Meta-technology Gap Ratios across Agroecological Zones among Maize Farmers in Kenya ${ }^{8}$
}

\begin{abstract}
Rising population and declining per capita arable land calls for increased productivity in SubSaharan Africa. Increase in production has to be met through reduction in yield gaps since cropland expansion carries high environmental costs. One way of sustainably increasing yields is by improving technical efficiency among smallholder farmers. However, while there are many studies on efficiency and productivity in SSA, limited studies make a distinction between farmers' technical inefficiencies and environmental gaps resulting from climatic differences. Not differentiating can contribute to misinformed policies, for instance when existing environmental gaps are falsely attributed to farmers' inefficiencies. The AEZs in Kenya differ substantially in their climatic conditions and other factors. We apply the stochastic meta-frontier production function framework, which allows distinguishing between TEs and meta- technology ratios (which capture environmental gaps). We also assess the factors associated with each. We find large deviations between TEs and MTRs across the AEZs. TEs relative to the group frontiers are relatively high; in some zones (mostly the drier zones) they are two to three times higher than the TEs relative to the meta-frontier. This suggests that farmers compare much more favorably with farmers in the same AEZ as opposed to the whole industry. Also, environmental gaps contribute more to observed yield differences than farmers' inefficiencies, implying that farmers have not been able to sufficiently adapt their agricultural practices to the constraints they face. This interpretation is supported by low magnitudes of MTRs coupled with wide variation across the AEZs. Efforts to narrow down environmental gaps among farmers are thus more urgent than efforts to reduce technical inefficiencies. This can be achieved through promotion of appropriate technologies necessary to adapt to environmental stresses, such as drought and heat tolerant varieties for the dry regions as well as proper infrastructure.
\end{abstract}

\footnotetext{
${ }^{8}$ This chapter is co-authored with Bernhard Brümmer and Matin Qaim.
} 


\subsection{Introduction}

Unavailability of land for cropland expansion is a major issue in Sub-Saharan Africa (SSA) particularly in countries with high rural population densities, such as Kenya (Muyanga and Jayne, 2014). The problem is predicted to become worse since SSA's population which currently stands at 949 million people is expected to double by 2050 (Population Reference Bureau, 2015). To sustainably feed this increased population there is need to improve crop productivity without ignoring significant challenges of climate change and environmental degradation. Most of the expected increase in crop production has to come from increase in yield or crop intensities in comparison to land expansion (FAO, 2009). Existing studies indicate that most countries in SSA have not yet attained their potential yield (Byerlee and Deininger, 2013) and some, such as Kenya, have declining maize yields (Ray et al., 2013). Therefore there is potential to increase productivity in SSA by reducing yield gaps through efficient use of available resources and adopting crop varieties and agricultural practices that produce same or even more under different weather conditions.

Technical efficiency (TE) provides information on the potential to improve productivity with the existing resources and technologies (Abdulai and Tietje, 2007) and assessing determinants of TE provides policy worth information on how to achieve optimal use of resources. Various studies have analyzed how different socioeconomic, institutional and technological factors affect the efficiency of farmers, the effect of some of these factors vary with the region and sometimes with the enterprise. Studies conducted among maize farmers in SSA indicate that education level, household size, credit, access to extension, group membership, experience have a positive effect on technical efficiency (Alene and Hassan, 2003; Binam et al., 2004; Aye and Mungatana, 2010). Similarly, other studies indicate a positive relationship between TE and improved seeds (Chirwa, 2007; Aye and Mungatana, 2010; Geta et al., 2010), fertilizers, insecticides (Baha, 2013), and timely availability of inputs (Alene and Hassan, 2003). Most studies show an inverse relationship between farm size and TE (Alene and Hassan, 2003; Aye and Mungatana, 2010) while others show a positive one (Geta et al., 2010; Musaba and Bwacha, 2014).

However, inasmuch as there are many studies on TE among farmers in SSA, most of these studies do not account for variations in production technologies among farmers and in some cases they attribute technological and/or environmental differences among farmers to 
inefficiencies. Such variations may include differences in input attributes, production technologies or even differences in environmental conditions and plant varieties (Villano et al., 2010). Some studies in SSA have however taken these variations in to consideration and distinguish between technology gaps and TE. For instance, Rao et al. (2012) consider differences in production systems among vegetable farmers in Kenya supplying to supermarkets and those supplying to traditional market channels and thus accounts for the technological gaps between them. Similarly, Otieno et al. (2014) differentiate production functions among beef farmers in Kenya under three diverse production systems.

However, studies taking in to account variations due to environmental and climatic differences in SSA are limited. This is in spite of the fact that climate and weather variability are increasingly becoming a major concern in SSA mostly felt through increasing frequencies of drought and changes in the distribution of rainfall resulting in floods in some areas and no rainfall in other areas (Shiferaw et al., 2014a). These weather extremes affect crop production, for example, $25 \%$ of maize which is the most important crop in SSA suffers frequent drought, with losses as high as half the harvest (CIMMYT, 2013). Similarly, Lesk et al. (2016) report significant reduction in the yield of cereal crops due to extreme weather disasters mainly droughts and extreme heat. Further still, climate change in SSA is projected to result in yield reduction of up to $12 \%$ in the 2050 s and $20 \%$ in the 2080 s (Tesfaye et al., 2015). Climatic constraints prevent farmers from making full use of certain production techniques available to them especially in rain-fed areas such as SSA.

Different geographical areas/agroecological zones (AEZs) have diverse weather characteristics and are faced with different extreme weather conditions. Some regions are more prone to droughts or extreme heat and others to floods. In literature, some production studies deal with this variability by introducing location dummy variables to account for these differences. However, in so doing they assume a uniform production function and thus attribute environmental gaps between regions to farmers' technical inefficiencies which may lead to misinformed policy decisions. Making a distinction between the two is important for policy since yield differences may result majorly from farmers' inefficiencies or from environmental gaps. If environmental gaps contribute more to yield differences then there is need for policies and/or technologies which assist farmers to adapt to the respective environmental constraints. On the other hand, if inefficiencies play a major role then policies improving farmers' TEs should be a 
priority. Thus we seek to make a distinction between TEs and environmental gaps (captured by meta-technology ratios).

We further assess factors associated with TEs across the AEZs as well those associated with meta-technology ratios (MTRs). In most cases, factors affecting TE are those within the control the farmer while those affecting the MTRs usually lie outside the control of the farmer since they capture the environment in which production takes place. We use a stochastic metafrontier production function due to (Battesse et al., 2004; O'Donnell et al., 2008) since it accounts for environmental gaps and allows comparison of TEs across heterogeneous groups such as AEZs (O’Donnell et al., 2008; Villano et al., 2010). Subsequently, we use ordinary least squares (OLS) model to assess the determinants of MTRs.

The empirical analysis is based on a survey from all maize producing areas in Kenya distributed across six diverse AEZs which differ substantially in climatic conditions among other physical conditions (Hasssan, 1998; Jaetzold, 2005). They also vary in their soil types which have different inherent soil properties such as water retention, drainage, acidity, structure and so on (Jaetzold et al., 2005). Due to climatic differences, technology adoption varies across these AEZs; with input-intensive technologies (improved seeds and fertilizers) being adopted in those AEZs with high rainfall and technologies designed to cope with water stress such as crop residue management and zero tillage being adopted in regions with lower average rainfall (Wainaina et al., 2014).

The rest of the paper is organized as follows. Section 2 outlines the analytical method, while section 3 presents the data and model specification. Section 4 presents and discusses the results, and finally section 5 concludes.

\subsection{Analytical method}

The meta-frontier estimation technique enables technology gaps to be estimated for groups under different technologies relative to the potential technology available to the industry as a whole. The meta-frontier is assumed to be a smooth function that envelopes all the frontiers of the individual groups (zones) in the industry (Battese et al., 2004). Suppose we have k groups in the industry, we can estimate the stochastic group-k frontier using the standard stochastic frontier model defined as: 


$$
Y_{i(k)} \equiv f\left(X_{i(k)} \beta_{(k)}\right) e^{v_{i(k)}-u_{i(k)}} \quad i=1,2 \ldots \ldots \ldots \mathrm{N}_{k}
$$

Where $Y_{i(k)}$ denotes the output of the $i^{t h}$ farm for group- $k ; X_{i(k)}$ denotes the inputs used by the $i^{t h}$ farm for group $k ; \beta_{(\mathrm{k})}$ is the vector of parameters to be estimated associated with group- $k ; v_{i(k)}$ represents statistical noise assumed to be independently and identically distributed as $N\left(0, \sigma_{v k}{ }^{2}\right)$ random variables; and $u_{i(k)}$ are non-negative random variables assumed to account for technical inefficiency in production and assumed to be independently distributed as truncations at zero of the $N\left(u_{i(k)}, \sigma_{u(k)}^{2}\right)$ distribution.

The technical efficiency of the $i^{t h}$ farm with respect to group- $k$ frontier can be obtained using:

$$
T E_{i}^{k}=\frac{Y_{i}}{e^{X_{i} \beta^{k}+v_{i}}}=e^{-U_{i(k)}}
$$

Equation (5) allows us to examine the performance of the $i^{\text {th }}$ farm relative to the individual group frontier. In order to examine the performance of the $i^{\text {th }}$ farm relative to the meta-frontier, the stochastic meta-frontier production approach is used. The meta-frontier is a function that envelops the stochastic frontiers of the different groups such that it is defined by all observations in the different groups in a way that is consistent with the specifications of a stochastic frontier model (Battese and Rao, 2002). Following Battese and Rao (2002) and Battese et al. (2004), a stochastic meta-frontier production function in the industry is defined as;

$$
Y_{i}^{*}=f\left(X_{i}, \beta^{*}\right) \equiv e^{X_{i} \beta^{*}}
$$

Where $i=1,2 \ldots \ldots \ldots N_{k} ; Y_{i}^{*}$ is the meta-frontier that dominates all group frontiers and $\beta^{*}$ denotes the vector of parameters satisfying the constraint:

$$
X_{i} \beta^{*} \geq X_{i} \beta^{k} \text { for all } k=1,2 \ldots ., \mathrm{K}
$$

In order to satisfy the condition in (7) an optimization problem is solved. Either the sum of absolute deviations (linear programming-LP) or the sum of squares of deviations (quadratic programming-QP) of the meta-frontier values from the values of the group frontiers are minimized; 


$$
\begin{gathered}
\min L P \equiv \sum_{n=i}^{N}\left|\ln f\left(X_{i}, \beta^{*}\right)-\ln f\left(X_{i}, \beta^{k}\right)\right| \text { or } \\
\min Q P \equiv \sum_{i=1}^{N} \ln f\left(X_{i} \beta^{*}-\ln f\left(X_{i} \beta^{k}\right)\right)^{2} \\
\text { s.t. } \ln f\left(X_{i}, \beta^{*}\right) \geq \ln f\left(X_{i}, \beta^{k}\right)
\end{gathered}
$$

The observed output defined by the stochastic frontier for the group- $k$ in equation (4) can be alternatively expressed in terms of meta-frontier function in equation (6), such that

$$
Y_{i}=e^{-U_{i(k)}} \times \frac{e^{X_{i} \beta^{(K)}}}{e^{X_{i} \beta^{*}}} \times e^{X_{i} \beta^{*}+V_{i(k)}}
$$

The first term on the right hand side of equation (9) is the same as that in equation (5), which denotes the TE of the $i^{\text {th }}$ farm relative to group- $k$ frontier. The second term is the technology gap ratio (TGR), expressed as;

$$
T G R_{i}=\frac{e^{X_{i} \beta_{(k)}}}{e^{X_{i} \beta^{*}}}
$$

The TGR measures the ratio of output for the frontier production function for the group- $k$ relative to the potential output that is defined by the meta-frontier function, given the observed inputs (Battese et al., 2014). The TGR has values between zero and one. Values of TGR closer to one imply that a farm in a given group is producing nearer to the maximum potential output given the technology available for the whole industry. For this study TGR is referred to as metatechnology ratio (MTR) to account for wider environment in which production takes place and other factors that might influence the potential productivity gains from a given technology.

The TE of the $i^{\text {th }}$ farm, relative to the metafrontier (denoted by $T E_{i}^{*}$ ) is defined similar to equation (5). It is the ratio of the observed output relative to the last term on the right hand side of equation (9), which is the metafrontier output, adjusted for the corresponding random error such that:

$$
T E_{i}^{*}=\frac{Y_{i}}{e^{X_{i} \beta^{*}+v_{i(k)}}}
$$

Following equations (5), (9) and (10),

$$
T E_{i}^{*}=T E_{i}^{k} \times M T R_{i}
$$




\subsection{Data, model specification and descriptive statistics}

\subsubsection{Data}

We use data collected through a nationally representative survey of maize-growing farms in Kenya. The data was collected at plot level from $1344^{9}$ farm households distributed across all six maize agroecological zones (AEZs), as defined by Hassan (1998). These AEZs differ in the climatic and physical characteristics among other things (Table 4.1). Households to be surveyed were selected using a stratified, two-stage random sampling procedure. In all AEZs, we selected sublocations (Kenya's smallest administrative units) as primary sampling units (PSU) and households as secondary sampling units (SSU) based on census data (KNBS, 2010). Using maps, Geographic Information System (GIS) analysis and key informants, a list of all rural sublocations in each of the six zones was established, with the number of households in each obtained from the census. For each zone, the required number of sublocations was selected proportionate to the maize area in that zone. In total, we sampled 120 sublocations distributed as follows; 15 in lowland tropics, 18 in the dry mid altitude, 17 in the dry transitional zone, 30 in the moist transitional zone and 20 in the high tropics and moist mid altitude zones, each.

In each sublocation, 12 households were randomly selected, except for the coastal lowlands where we selected six households per sublocation due to budget constraints. The survey was conducted between December 2012 and February 2013, referring to the 2012 cropping year. Data was collected on technology adoption and various other farm, farmer, household, and contextual characteristics. Maize production data was collected at plot level over two rain seasons; March-April rains and September-October rains. In addition to the household survey data, we also use community survey data. This was data collected through focus group discussions at sublocation level between April-May 2013.

\footnotetext{
${ }^{9}$ During data cleaning some of the households were dropped due to missing information on some production data. The analysis is based on 3766 maize plots distributed across 1286 households.
} 
Table 4.1: Maize agroecological zones in Kenya

\begin{tabular}{lcccccc}
\hline Attribute & $\begin{array}{c}\text { Lowland } \\
\text { tropics } \\
(\text { AEZ 1) }\end{array}$ & $\begin{array}{c}\text { Dry mid } \\
\text { altitude } \\
(\text { AEZ 2) }\end{array}$ & $\begin{array}{c}\text { Dry } \\
\text { transitional } \\
(\text { AEZ 3) }\end{array}$ & $\begin{array}{c}\text { Moist } \\
\text { transitional } \\
(\text { AEZ 4) }\end{array}$ & $\begin{array}{c}\text { High } \\
\text { tropics } \\
(\text { AEZ 5) }\end{array}$ & $\begin{array}{c}\text { Moist mid } \\
\text { altitude } \\
\text { (AEZ 6) }\end{array}$ \\
\hline Elevation (meters) & $<700$ & $700-1400$ & $1100-1700$ & $1200-2000$ & $1600-2900$ & $1100-1500$ \\
Annual rainfall(mm) & $400-1400$ & $400-800$ & $<800$ & $1000-1800$ & $>1800$ & $800-1200$ \\
Average temperature $\left({ }^{\circ} \mathrm{C}\right)$ & 25.5 & 22 & 19.7 & 19.7 & 15.2 & 22.1 \\
Maize area ('000 ha) & 33 & 118 & 118 & 461 & 307 & 118 \\
Share of national maize & 5 & 10 & 10 & 20 & 35 & 20 \\
production (\%) & 3.3 & 2.7 & 4.5 & 5.2 & 6.7 & 5.2 \\
Potential yield (t/ha) & 1.0 & 0.5 & 1.1 & 0.7 & 2.0 & 1.1 \\
$\begin{array}{l}\text { Actual yield (t/ha) } \\
\text { Share of households }\end{array}$ & 7 & 16 & 15 & 26 & 18 & 18 \\
surveyed (\%) & 7 & & & & & \\
\hline
\end{tabular}

Source: Adapted from Hassan (1998) and Jaetzold et al. (2005).

\subsubsection{Model specification}

We estimate several production functions, for pooled data (all the AEZs) and for each of the AEZs. To specify the functional form to represent the relationship between output and inputs we choose between the transcendental logarithmic (translog) and the Cobb-Douglas functional forms. We conduct likelihood ratio tests and the null hypothesis that the Cobb-Douglas is an adequate representation of the data is rejected for all the models except for the moist mid altitude zone (Table 4.2). We therefore estimate a Cobb-Douglas production function for the moist mid altitude zone and translog production function for the other AEZs. We also conduct a likelihood ratio test to test the null hypothesis of homogeneous production technology for all the AEZs and we reject it (Table 4.2); this justifies use of a meta-frontier production function (Battese et al., 2004). A test of the null hypothesis of no inefficiency component is also rejected for all the models (Table 4.2). 
Table 4.2: Hypothesis testing for stochastic production frontier model

\begin{tabular}{lccc}
\hline Null hypothesis $\mathrm{H}_{0}$ & $\begin{array}{c}\text { Likelihood } \\
\text { ratio statistic }\end{array}$ & $\begin{array}{c}\text { Degrees } \\
\text { freedom }\end{array}$ & of value \\
\hline Cobb_Douglas functional form is appropriate $\boldsymbol{\beta}_{\boldsymbol{j} k}=\mathbf{0}$ & & & \\
Pooled & 212.79 & 21 & 0.000 \\
Lowland tropics (AEZ 1) & 71.21 & 21 & 0.000 \\
Dry mid altitude (AEZ 2) & 46.21 & 21 & 0.001 \\
Dry transitional (AEZ 3) & 50.67 & 21 & 0.000 \\
Moist transitional (AEZ 4) & 64.69 & 21 & 0.000 \\
High tropics (AEZ 5) & 65.24 & 21 & 0.000 \\
Moist mid altitude (AEZ 6) & 19.36 & 21 & 0.562 \\
No technical inefficiency effects $\boldsymbol{\mu}_{\boldsymbol{i}}=\mathbf{0}$ & & & \\
Pooled & 300.43 & 20 & 0.000 \\
Lowland tropics (AEZ 1) & 87.03 & 20 & 0.000 \\
Dry mid altitude (AEZ 2) & 131.87 & 20 & 0.000 \\
Dry transitional (AEZ 3) & 116.05 & 20 & 0.000 \\
Moist Transitional (AEZ 4) & 120.01 & 20 & 0.000 \\
High tropics (AEZ 5) & 46.87 & 19 & 0.000 \\
Moist mid altitude (AEZ 6) & 116.10 & 20 & 0.000 \\
Homogeneous technology across $\boldsymbol{A E Z s}$ & 762.58 & 220 & 0.000 \\
\hline
\end{tabular}

Following Coelli et al. (2003), the translog functional form is specified as:

$$
\ln \left(Y_{i}\right)=\beta_{0} \sum_{j=1}^{n} \beta_{j} \ln X_{i j}+\frac{1}{2} \sum_{j=1}^{n} \sum_{k=1}^{n} \beta_{j k} \ln X_{i j} \ln X_{i k}+\sum_{l=1}^{m} \delta_{l} D_{l}+\sum_{t=1}^{p} \lambda_{t} W_{t}+v_{i}-\mu_{i}
$$

Where $Y_{i}$ represents the output of maize in kilograms, $X_{i}$ the quantity of the $j^{\text {th }}$ input which include; plot area under maize in acres, quantity of seeds in Kgs, labor in man days, fertilizer in Kgs, manure in Kgs and pesticide used in litres. $D_{l}$ captures the dummy variables. We follow Battese (1997) methodology to deal with zero inputs where the logarithm of the input variable with zero values is taken only if it is positive, otherwise the variable is zero and a dummy variable to take care of those zero is included in the model. The dummy variable takes the value of one if the input values are zero, and zero otherwise. In our model, some farmers did not use fertilizers, manure and pesticides, therefore we introduce three dummy variables. A season dummy is also included in the model. Maize production in Kenya takes place in two rainy seasons in a year, March-April (mostly the long rains) and September- October rains. We hypothesize that output will be lower in the short rain season therefore we introduce a dummy variable which equal one if production takes place in the September-October season. We also include plot level characteristics which capture soil fertility and the slope of the plot. 
Then $W_{t}$ captures weather variables; distribution of rains and temperature. These variables collected at sublocation level, include the number of weeks it rained and the average maximum daily temperature in the production year. Finally, $\beta, \delta$ and $\lambda$ are parameters to be estimated, $v_{i}$ is a random error term and $\mu_{i}$ is a non-negative random variable representing technical inefficiency. The technical inefficiency effects model is defined as;

$$
\mu_{i}=\alpha_{0}+\sum_{J=1}^{n} \alpha_{j} Z_{j i}+e_{i}
$$

Where $\mathrm{Z}_{\mathrm{j}}$ is a vector of observations on variable $j$ expected to influence the level of technical inefficiency. In stochastic frontiers these variables are included directly in the single-stage estimation. In our model the vector $\mathrm{Z}_{\mathrm{j}}$ include plot tenure, socioeconomic attributes of the household, frequency of weather extremes and technologies adopted by the farmers. The specification of these variables is based on relevant literature (e.g. Sherlund et al., 2002; Binam et al., 2004; Chirwa, 2007; Tchale and Sauer, 2007; Wollni and Brümmer, 2012). Socioeconomic characteristics include education level, age and gender of the farmer, total land and livestock owned by the household. We also include household size which is a measure of availability of family labor. The variable proportion of off-farm income which indicates how much of the household income comes from non-farm activities is also included.

Variables capturing frequency of weather extremes include drought, water shortages and flooding, measured in terms of the farmer-reported frequency of events during a period of 10 years prior to the survey (2003-2012). Finally, we include variables capturing the type of technology adopted in the plot. Seven technologies are included; improved seeds, fertilizers, terraces, soil bunds, zero tillage, crop residue management and manure use ${ }^{10}$.

\subsubsection{Descriptive statistics}

Table 4.3 presents summary statistics for the dependent and independent variables included in the production frontier and the inefficiency effects model by AEZs.

\footnotetext{
${ }^{10}$ These technologies serve different purposes. Improved seeds and fertilizers are input-intensive technologies while the rest are natural resource management (NRM) technologies. These NRM technologies are mainly designed to respond to soil degradation and aid in water conservation; zero tillage and crop residue are components of conservation agriculture (Hobbs et al., 2008), terracing and soil bunds mainly control soil erosion, terraces are however more permanent than the soil bunds (Gebremedhin and Swinton, 2003) and finally manure aims to improve soil fertility as well as structure.
} 
Table 4.3: Descriptive statistics of variables in the production frontier and inefficiency determinants by AEZs

\begin{tabular}{|c|c|c|c|c|c|c|c|c|}
\hline Variable & Description & $\begin{array}{l}\text { AEZ 1 a } \\
(\mathrm{N}=233)\end{array}$ & $\begin{array}{l}\text { AEZ } 2 \\
(\mathrm{~N}=715)\end{array}$ & $\begin{array}{l}\text { AEZ } 3 \\
(n=801)\end{array}$ & $\begin{array}{l}\text { AEZ } 4 \\
(n=830)\end{array}$ & $\begin{array}{l}\text { AEZ } 5 \\
(n=421)\end{array}$ & $\begin{array}{l}\text { AEZ } 6 \\
(n=766)\end{array}$ & $\begin{array}{l}\text { Pooled } \\
(n=3766)\end{array}$ \\
\hline & & $\begin{array}{l}\text { Mean } \\
\text { (Std dev) }\end{array}$ & $\begin{array}{l}\text { Mean } \\
\text { (Std dev) }\end{array}$ & $\begin{array}{l}\text { Mean } \\
\text { (Std dev) }\end{array}$ & $\begin{array}{l}\text { Mean } \\
\text { (Std dev) }\end{array}$ & $\begin{array}{l}\text { Mean } \\
\text { (Std dev) }\end{array}$ & $\begin{array}{l}\text { Mean } \\
\text { (Std dev) }\end{array}$ & $\begin{array}{l}\text { Mean } \\
\text { (Std dev) }\end{array}$ \\
\hline \multicolumn{9}{|c|}{ Output, Inputs and other variables in the production function } \\
\hline Maize output & Maize output per acre in Kgs & $\begin{array}{l}337.35 \\
(391.24)\end{array}$ & $\begin{array}{l}341.74 \\
(414.12)\end{array}$ & $\begin{array}{l}517.87 \\
(724.05)\end{array}$ & $\begin{array}{l}803.70 \\
(839.07)\end{array}$ & $\begin{array}{l}1,536.17 \\
(1446.79)\end{array}$ & $\begin{array}{l}537.18 \\
(574.96)\end{array}$ & $\begin{array}{l}654.01 \\
(855.83)\end{array}$ \\
\hline Land & Land cultivated with maize (acres) & $\begin{array}{l}1.52 \\
(1.32)\end{array}$ & $\begin{array}{l}1.84 \\
(2.48)\end{array}$ & $\begin{array}{l}1.00 \\
(1.12)\end{array}$ & $\begin{array}{l}1.01 \\
(1.34)\end{array}$ & $\begin{array}{l}1.38 \\
(2.47)\end{array}$ & $\begin{array}{l}1.00 \\
(1.11)\end{array}$ & $\begin{array}{l}1.24 \\
(1.72)\end{array}$ \\
\hline Seed & Seed quantity per acre in Kgs & $\begin{array}{l}7.66 \\
(5.63)\end{array}$ & $\begin{array}{l}8.47 \\
(6.48)\end{array}$ & $\begin{array}{l}8.84 \\
(8.12)\end{array}$ & $\begin{array}{l}10.67 \\
(7.24)\end{array}$ & $\begin{array}{l}13.00 \\
(9.46)\end{array}$ & $\begin{array}{l}10.27 \\
(6.86)\end{array}$ & $\begin{array}{l}9.85 \\
(7.56)\end{array}$ \\
\hline Labor & Labor per acre in man days & $\begin{array}{l}32.26 \\
(28.46)\end{array}$ & $\begin{array}{l}29.41 \\
(23.19)\end{array}$ & $\begin{array}{l}40.89 \\
(33.92)\end{array}$ & $\begin{array}{l}60.36 \\
(63.54)\end{array}$ & $\begin{array}{l}50.99 \\
(35.67)\end{array}$ & $\begin{array}{l}68.53 \\
(57.50)\end{array}$ & $\begin{array}{l}49.22 \\
(48.06)\end{array}$ \\
\hline Fertilizer & Fertilizer used per acre in Kgs & $\begin{array}{l}12.23 \\
(31.12)\end{array}$ & $\begin{array}{l}6.85 \\
(20.28)\end{array}$ & $\begin{array}{l}28.31 \\
(45.36)\end{array}$ & $\begin{array}{l}68.82 \\
(73.18)\end{array}$ & $\begin{array}{l}64.84 \\
(69.14)\end{array}$ & $\begin{array}{l}23.23 \\
(50.09)\end{array}$ & $\begin{array}{l}35.22 \\
(58.04)\end{array}$ \\
\hline Manure & Manure used per acre in Kgs & $\begin{array}{l}238.32 \\
(557.84)\end{array}$ & $\begin{array}{l}442.82 \\
(947.45)\end{array}$ & $\begin{array}{l}874.61 \\
(1958.5)\end{array}$ & $\begin{array}{l}849.83 \\
(2022.2)\end{array}$ & $\begin{array}{l}740.07 \\
(2205.0)\end{array}$ & $\begin{array}{l}463.56 \\
(1222.5)\end{array}$ & $\begin{array}{l}649.16 \\
(1672.5)\end{array}$ \\
\hline Pesticide & Pesticide used per acre in litres & $\begin{array}{l}0.476 \\
(0.919)\end{array}$ & $\begin{array}{l}0.050 \\
(0.311)\end{array}$ & $\begin{array}{l}0.103 \\
(0.611)\end{array}$ & $\begin{array}{l}0.190 \\
(0.712)\end{array}$ & $\begin{array}{l}0.311 \\
(1.104)\end{array}$ & $\begin{array}{l}0.045 \\
(0.286)\end{array}$ & $\begin{array}{l}0.147 \\
(0.654)\end{array}$ \\
\hline Season dummy & $\begin{array}{l}=1 \text { if production was in the Sep-Oct rains, } 0 \text { if it was } \\
\text { in the March-April rains }\end{array}$ & $\begin{array}{l}0.41 \\
(0.49)\end{array}$ & $\begin{array}{l}0.52 \\
(0.50)\end{array}$ & $\begin{array}{l}0.50 \\
(0.50)\end{array}$ & $\begin{array}{l}0.44 \\
(0.50)\end{array}$ & $\begin{array}{l}0.17 \\
(0.38)\end{array}$ & $\begin{array}{l}0.40 \\
(0.49)\end{array}$ & $\begin{array}{l}0.43 \\
(0.50)\end{array}$ \\
\hline Pesticide dummy & $=1$ if no pesticide was used, 0 otherwise & $\begin{array}{l}0.54 \\
(0.50)\end{array}$ & $\begin{array}{l}0.90 \\
(0.30)\end{array}$ & $\begin{array}{l}0.89 \\
(0.31)\end{array}$ & $\begin{array}{l}0.87 \\
(0.34)\end{array}$ & $\begin{array}{l}0.79 \\
(0.41)\end{array}$ & $\begin{array}{l}0.97 \\
(0.18)\end{array}$ & $\begin{array}{l}0.87 \\
(0.34)\end{array}$ \\
\hline Medium soil fertility ${ }^{b}$ & $=1$ if the soil fertility is medium, 0 otherwise & $\begin{array}{l}0.485 \\
(0.50)\end{array}$ & $\begin{array}{l}0.580 \\
(0.49)\end{array}$ & $\begin{array}{l}0.456 \\
(0.50)\end{array}$ & $\begin{array}{l}0.492 \\
(0.50)\end{array}$ & $\begin{array}{l}0.506 \\
(0.50)\end{array}$ & $\begin{array}{l}0.518 \\
(0.50)\end{array}$ & $\begin{array}{l}0.507 \\
(0.50)\end{array}$ \\
\hline Good soil fertility ${ }^{\mathrm{b}}$ & $=1$ if the soil fertility is good, 0 otherwise & $\begin{array}{l}0.395 \\
(0.49)\end{array}$ & $\begin{array}{l}0.330 \\
(0.47)\end{array}$ & $\begin{array}{l}0.454 \\
(0.50)\end{array}$ & $\begin{array}{l}0.381 \\
(0.49)\end{array}$ & $\begin{array}{l}0.409 \\
(0.49)\end{array}$ & $\begin{array}{l}0.285 \\
(0.45)\end{array}$ & $\begin{array}{l}0.371 \\
(0.48)\end{array}$ \\
\hline Gentle slope ${ }^{c}$ & $=1$ if the soil slope is gentle, 0 otherwise & $\begin{array}{l}0.408 \\
(0.49)\end{array}$ & $\begin{array}{l}0.484 \\
(0.50)\end{array}$ & $\begin{array}{l}0.396 \\
(0.49)\end{array}$ & $\begin{array}{l}0.420 \\
(0.49)\end{array}$ & $\begin{array}{l}0.458 \\
(0.49)\end{array}$ & $\begin{array}{l}0.436 \\
(0.50)\end{array}$ & $\begin{array}{l}0.434 \\
(0.50)\end{array}$ \\
\hline Medium slopec & $=1$ if soil slop is medium, 0 otherwise & $\begin{array}{l}0.099 \\
(0.30)\end{array}$ & $\begin{array}{l}0.189 \\
(0.39)\end{array}$ & $\begin{array}{l}0.238 \\
(0.43)\end{array}$ & $\begin{array}{l}0.225 \\
(0.42)\end{array}$ & $\begin{array}{l}0.228 \\
(0.42)\end{array}$ & $\begin{array}{l}0.175 \\
(0.38)\end{array}$ & $\begin{array}{l}0.203 \\
(0.40)\end{array}$ \\
\hline Steep slope ${ }^{c}$ & $=1$ if soil slope is steep, 0 otherwise & $\begin{array}{l}0.026 \\
(0.16)\end{array}$ & $\begin{array}{l}0.020 \\
(0.14)\end{array}$ & $\begin{array}{l}0.117 \\
(0.32)\end{array}$ & $\begin{array}{l}0.065 \\
(0.25)\end{array}$ & $\begin{array}{l}0.033 \\
(0.18)\end{array}$ & $\begin{array}{l}0.017 \\
(0.13)\end{array}$ & $\begin{array}{l}0.052 \\
(0.22)\end{array}$ \\
\hline Rainfall weeks ${ }^{\mathrm{d}}$ & Number of weeks it rained in the year & $\begin{array}{l}13.21 \\
(5.10)\end{array}$ & $\begin{array}{l}12.13 \\
(5.14)\end{array}$ & $\begin{array}{l}14.12 \\
(4.08)\end{array}$ & $\begin{array}{l}24.99 \\
(7.16)\end{array}$ & $\begin{array}{l}26.69 \\
(8.74)\end{array}$ & $\begin{array}{l}24.95 \\
(6.04)\end{array}$ & $\begin{array}{l}19.69 \\
(8.64)\end{array}$ \\
\hline Max temperature & Average max daily temperature in the year in ${ }^{\circ} \mathrm{c}$ & $\begin{array}{l}31.60 \\
(1.04)\end{array}$ & $\begin{array}{l}31.44 \\
(2.15)\end{array}$ & $\begin{array}{l}30.89 \\
(0.12)\end{array}$ & $\begin{array}{l}26.33 \\
(1.38)\end{array}$ & $\begin{array}{l}24.84 \\
(0.56)\end{array}$ & $\begin{array}{l}27.50 \\
(0.73)\end{array}$ & $\begin{array}{l}28.66 \\
(2.77)\end{array}$ \\
\hline \multicolumn{9}{|c|}{ Factors affecting inefficiency } \\
\hline Plot tenure & $=1$ if farmer owns plot, 0 if rented in & $\begin{array}{l}0.884 \\
(0.32)\end{array}$ & $\begin{array}{l}0.969 \\
(0.17)\end{array}$ & $\begin{array}{l}0.933 \\
(0.25)\end{array}$ & $\begin{array}{l}0.802 \\
(0.40)\end{array}$ & $\begin{array}{l}0.786 \\
(0.41)\end{array}$ & $\begin{array}{l}0.875 \\
(0.33)\end{array}$ & $\begin{array}{l}0.880 \\
(0.33)\end{array}$ \\
\hline
\end{tabular}


Socioeconomic factors

Education farmer

Male

Age of farmer

Household size

TLU

Land acres

Prop off-farm income

Credit

Frequency of weather extremes

Drought

Water shortages

Flooding

Technology adopted

Improved seeds

Fertilizers

Terracing

Soil bunds

Zero tillage

Crop residue

Manure
Education level of the farmers in years

$=1$ if farmer is male, 0 otherwise

Age of the farmer in years

Household size

Total livestock unit

Total land owned by household in acres

Proportion of off-farm income

$=1$ if household received credit, 0 otherwise

Frequency of drought

Frequency of water shortages

Frequency of flooding

$=1$ If used improved seeds, 0 otherwise

$=1$ If used chemical fertilizer, 0 otherwise

$=1$ If there is terracing, 0 otherwise

$=1$ If has soil bunds, 0 otherwise

$=1$ If practices zero tillage, 0 otherwise

$=1$ If practices crop residue management, 0 otherwise

$=1$ If used animal manure, 0 otherwise

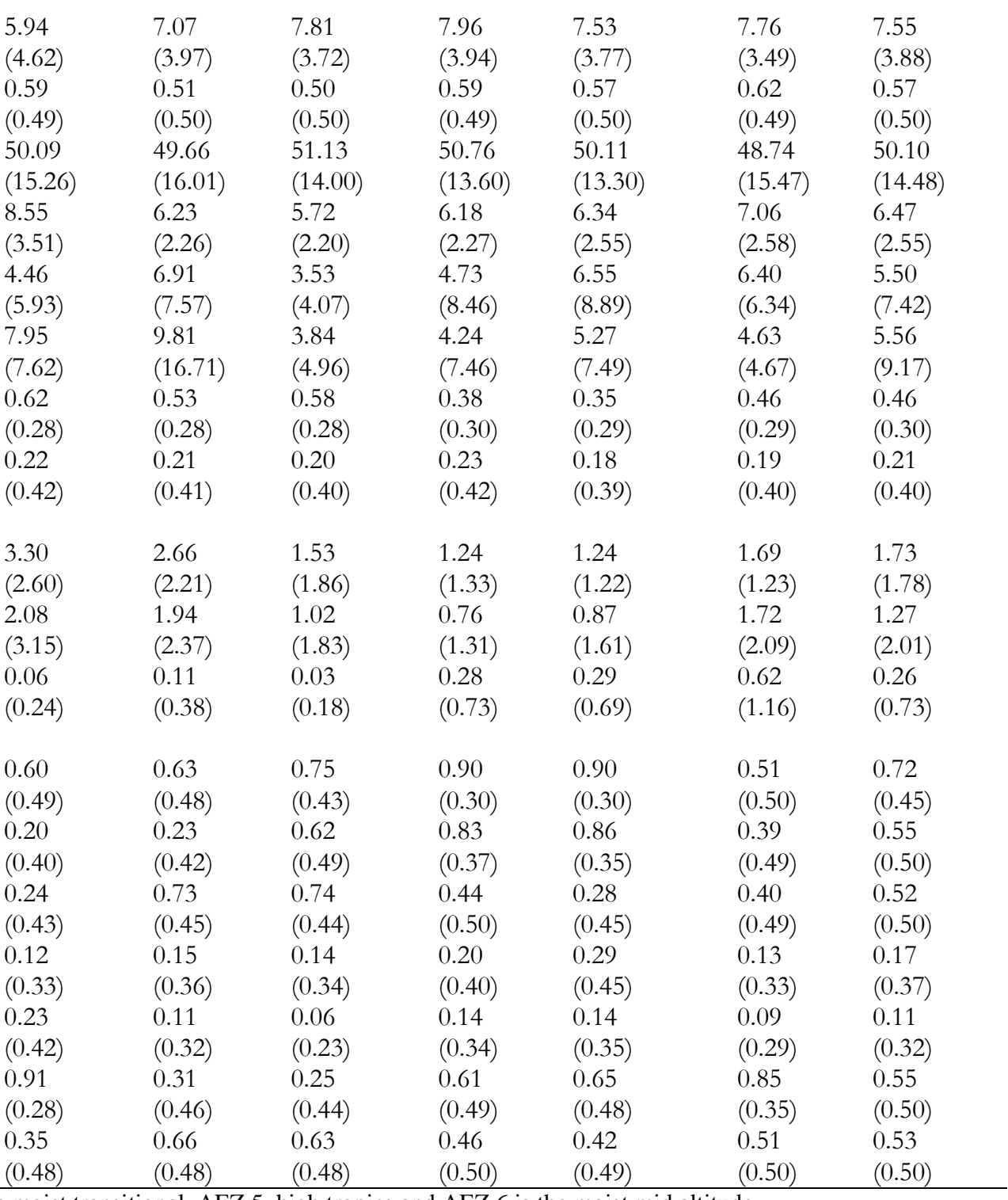

aAEZ 1 is lowland tropics, AEZ 2, dry mid altitude, AEZ 3, dry transitional , AEZ 4 the moist transitional, AEZ 5, high tropics and AEZ 6 is the moist mid altitude.

${ }^{b}$ base category is poor soil fertility ${ }^{c}$ base category is flat slope ${ }^{d}$ information on rainfall and temperature is collected at sublocation level 
There are wide variations in output and input use across the six agroecological zones. On average, farmers in the high tropics have the highest output per acre $(1,536 \mathrm{Kgs})$ while those in the lowland tropics reported the least $(337 \mathrm{Kgs})$. The high tropics and the moist transitional zones have on average substantially higher use of seeds and fertilizers compared to other AEZs. Average fertilizer use rates are particularly very low in the dry mid altitude and low tropics zones, approximately $7 \mathrm{Kgs}$ and $12 \mathrm{Kgs}$ per acre, respectively, compared to a high of $68 \mathrm{Kgs}$ in the moist transitional zone and $65 \mathrm{Kgs}$ in the high tropics.

Except for the high tropics where much of the production took place in the March-April rains (80\%), farmers in other AEZs have almost equal production plots for both seasons. Moist transitional, high tropics and moist mid altitude regions received rainfall for approximately twice the number of weeks other regions did during the production year. These three regions also recorded lower average daily maximum temperature (proxy for heat stress) compared to the lowland tropics, dry mid altitude and dry transitional zones. The difference in maximum daily temperature between these AEZs is up to $6^{\circ} \mathrm{C}$.

For farmers in the drier regions, off-farm income comprises more than half the total household income, as high as $62 \%$, for farmers in the lowland tropics compared to $38 \%$ and $35 \%$ for the moist transitional and the high tropics zones, respectively. Technology adoption also varies within these AEZs; almost all farmers use improved seeds and fertilizers in the moist transitional and high tropics while for the lowland tropics and dry mid altitudes zones only approximately $20 \%$ of the farmers use chemical fertilizers. Zero tillage and crop residue management practices are however more common in the lowland tropics region.

\subsection{Results and discussion}

\subsubsection{Results of the stochastic production function.}

Table 4.4 presents results of the stochastic translog production function for the pooled model and for the specific AEZs. Mean corrected output and input variables $\left(\log \mathrm{x}_{\mathrm{i}^{-}} \log\right.$ mean $\left.(\mathrm{x})\right)$ were used so the estimated coefficients can be directly interpreted as partial production elasticities at the sample mean. For the pooled model, the partial productivity elasticities at the sample (first order coefficients) are all positive indicating that the assumption of monotonicity i.e. marginal product increases monotonically with respect to the inputs is fulfilled. Some AEZs specific production 
function models exhibit negative point estimates for the elasticities though they are not statistically significant.

For the pooled model, all inputs except for pesticide have significant partial production elasticities: highest being from seeds (0.28), while manure has the lowest (0.06). The effect of the season dummy is negative, indicating that output levels are significantly lower in the Sep-Oct rain season (mostly the short rain season) compared to the March-April rains. As expected, interacting the inputs with the season dummy, seeds and fertilizers have lower returns during the short rains compared to the long rains. However, returns on land are significantly higher in the short rain compared to the long rains.

As expected, areas with better soil fertility have significantly higher output level while those located in steep sloped areas have significantly lower yields. In addition, areas which had more weeks of rainfall in the production year shows significantly higher outputs while those with higher maximum daily temperature have significantly lower outputs. Maize yields in Africa have been shown to reduce significantly for each day temperatures were above $30^{\circ} \mathrm{C}$, and the effect is more severe under drought conditions (Lobell et al., 2011). Areas where the farmers used no fertilizer had significantly lower output while those with no manure had significantly higher output. 
Table 4.4: Results of the stochastic production function

\begin{tabular}{|c|c|c|c|c|c|c|c|c|c|c|c|c|c|c|}
\hline & \multicolumn{2}{|c|}{ Pooled $(n=3766)$} & \multicolumn{2}{|c|}{$\operatorname{AEZ} 1^{a}(n=233)$} & \multicolumn{2}{|c|}{ AEZ $2(n=715)$} & \multicolumn{2}{|c|}{ AEZ $3(n=801)$} & \multicolumn{2}{|c|}{ AEZ $4(n=830)$} & \multicolumn{2}{|c|}{ AEZ $5(n=421)$} & \multicolumn{2}{|c|}{ AEZ $6(n=766)$} \\
\hline & Coefficient & $\begin{array}{c}\text { Std } \\
\text { error }\end{array}$ & Coefficient & $\begin{array}{c}\text { Std } \\
\text { error }\end{array}$ & Coefficient & $\begin{array}{c}\text { Std } \\
\text { error }\end{array}$ & Coefficient & $\begin{array}{c}\text { Std } \\
\text { error }\end{array}$ & Coefficient & $\begin{array}{c}\text { Std } \\
\text { error }\end{array}$ & Coefficient & $\begin{array}{c}\text { Std } \\
\text { error }\end{array}$ & Coefficient & $\begin{array}{c}\text { Std } \\
\text { error }\end{array}$ \\
\hline Log land & $0.162^{* * *}$ & 0.038 & $0.609 * * *$ & 0.146 & 0.057 & 0.073 & $0.213^{* *}$ & 0.092 & 0.124 & 0.115 & $0.358 * *$ & 0.171 & $0.294 * * *$ & 0.059 \\
\hline Log seed & $0.288^{* * *}$ & 0.036 & -0.127 & 0.133 & $0.148^{* *}$ & 0.075 & 0.001 & 0.076 & $0.490 * * *$ & 0.102 & $0.396^{* * *}$ & 0.148 & $0.330 * * *$ & 0.057 \\
\hline Log labor & $0.251 * * *$ & 0.029 & $0.620 * * *$ & 0.159 & $0.572^{* * *}$ & 0.075 & $0.388^{* * *}$ & 0.089 & 0.067 & 0.071 & $0.195 *$ & 0.103 & $0.092 * *$ & 0.042 \\
\hline Log fertilizer & $0.262^{* * *}$ & 0.022 & -0.192 & 0.135 & -0.010 & 0.103 & $0.343^{* * *}$ & 0.067 & $0.239 * * *$ & 0.052 & $0.187^{* * *}$ & 0.053 & 0.051 & 0.047 \\
\hline Log manure & $0.057 * * *$ & 0.018 & -0.072 & 0.077 & $0.082 * *$ & 0.035 & $0.143^{* * *}$ & 0.040 & 0.045 & 0.045 & 0.064 & 0.092 & $0.134 * * *$ & 0.036 \\
\hline Log pesticide & 0.048 & 0.040 & 0.133 & 0.115 & 0.020 & 0.066 & 0.154 & 0.143 & 0.010 & 0.091 & -0.115 & 0.127 & 0.181 & 0.131 \\
\hline Season dummy & $-0.094 * * *$ & 0.032 & $-0.152 *$ & 0.082 & $0.120 *$ & 0.064 & $0.113^{*}$ & 0.068 & -0.080 & 0.074 & $-0.301 * *$ & 0.130 & $-0.177 * * *$ & 0.066 \\
\hline Season* fertilizer & $-0.064 * *$ & 0.030 & 0.167 & 0.131 & 0.048 & 0.044 & $-0.193 * *$ & 0.077 & 0.008 & 0.062 & -0.053 & 0.102 & 0.042 & 0.065 \\
\hline Season*seed & $-0.104 * *$ & 0.047 & -0.195 & 0.127 & $-0.164 *$ & 0.095 & $0.204 * *$ & 0.092 & 0.008 & 0.092 & -0.076 & 0.146 & 0.045 & 0.099 \\
\hline Season*land & $0.133^{* * *}$ & 0.045 & 0.014 & 0.131 & $0.189 * *$ & 0.088 & -0.085 & 0.089 & 0.005 & 0.093 & 0.005 & 0.170 & -0.075 & 0.085 \\
\hline Fertilizer dummy & $-0.257 * * *$ & 0.056 & 0.010 & 0.162 & -0.059 & 0.133 & -0.004 & 0.138 & -0.088 & 0.108 & $-0.258^{*}$ & 0.139 & $-0.366 * * *$ & 0.084 \\
\hline Manure dummy & $0.103^{* *}$ & 0.051 & -0.073 & 0.127 & -0.020 & 0.101 & 0.085 & 0.118 & 0.072 & 0.105 & -0.127 & 0.108 & -0.050 & 0.081 \\
\hline Pesticide dummy & -0.036 & 0.050 & -0.032 & 0.112 & -0.178 & 0.118 & 0.119 & 0.134 & -0.099 & 0.138 & -0.173 & 0.113 & $-0.439 *$ & 0.262 \\
\hline Medium soil fertility & $0.148^{* * *}$ & 0.045 & -0.020 & 0.143 & $-0.205^{*}$ & 0.124 & -0.028 & 0.137 & $0.164 * *$ & 0.079 & 0.140 & 0.132 & $0.175^{* *}$ & 0.079 \\
\hline Good soil fertility & $0.286^{* * *}$ & 0.047 & 0.184 & 0.151 & 0.000 & 0.133 & 0.164 & 0.142 & $0.271 * * *$ & 0.082 & 0.081 & 0.137 & $0.267 * * *$ & 0.086 \\
\hline Gentle slope & $-0.165^{* * *}$ & 0.032 & -0.186 & 0.118 & $-0.222 * * *$ & 0.075 & -0.114 & 0.090 & $-0.119 *$ & 0.068 & $-0.177 * *$ & 0.077 & $-0.205^{* * *}$ & 0.062 \\
\hline Medium slope & $-0.176 * * *$ & 0.040 & -0.065 & 0.160 & $-0.194 * *$ & 0.081 & -0.115 & 0.096 & -0.057 & 0.092 & $-0.171 *$ & 0.100 & $-0.140 *$ & 0.082 \\
\hline Steep slope & $-0.150 * *$ & 0.070 & -0.324 & 0.281 & $-0.620 * * *$ & 0.137 & -0.018 & 0.142 & -0.026 & 0.120 & 0.070 & 0.296 & -0.233 & 0.192 \\
\hline Rain 2012 & $0.007 * * *$ & 0.002 & -0.012 & 0.010 & 0.005 & 0.009 & $0.024 * * *$ & 0.008 & $0.024 * * *$ & 0.006 & -0.003 & 0.005 & 0.004 & 0.005 \\
\hline Max daily Temp & $-0.030 * * *$ & 0.007 & $-0.346^{* * *}$ & 0.056 & $0.057 * * *$ & 0.018 & $0.939 * * *$ & 0.288 & $-0.086^{* * *}$ & 0.031 & 0.041 & 0.056 & $0.196^{* * *}$ & 0.049 \\
\hline $.5^{*} \log \operatorname{land}^{\wedge} 2$ & $-0.119 * *$ & 0.051 & 0.275 & 0.180 & $-0.354 * * *$ & 0.096 & -0.097 & 0.104 & $-0.209 *$ & 0.124 & -0.113 & 0.224 & & \\
\hline $.5^{*} \log$ seed $^{\wedge} 2$ & $-0.196 * * *$ & 0.053 & $-0.278^{*}$ & 0.157 & $-0.373 * *$ & 0.152 & $-0.412^{* * *}$ & 0.116 & -0.121 & 0.130 & $-0.236^{*}$ & 0.124 & & \\
\hline $.5^{*} \log$ labour ${ }^{\wedge} 2$ & $-0.228 * * *$ & 0.054 & $-0.517 * *$ & 0.207 & $-0.450 * * *$ & 0.145 & $-0.327 *$ & 0.179 & 0.084 & 0.139 & $-0.331 * *$ & 0.141 & & \\
\hline $.5^{*} \log$ fertilizer^ 2 & $0.076^{* * *}$ & 0.012 & 0.183 & 0.146 & 0.025 & 0.035 & 0.015 & 0.087 & 0.059 & 0.047 & 0.054 & 0.044 & & \\
\hline $.5^{*} \log$ manure ${ }^{\wedge}$ & -0.005 & 0.013 & $0.203^{*}$ & 0.118 & -0.021 & 0.021 & 0.018 & 0.020 & $-0.118^{* * *}$ & 0.034 & -0.071 & 0.085 & & \\
\hline $.5^{*} \log$ pesticide` 2 & 0.039 & 0.033 & -0.068 & 0.110 & $0.131 *$ & 0.076 & -0.090 & 0.203 & 0.010 & 0.089 & 0.028 & 0.053 & & \\
\hline
\end{tabular}


Table 4.4 (Continued)

\begin{tabular}{|c|c|c|c|c|c|c|c|c|c|c|c|c|c|c|}
\hline & \multicolumn{2}{|c|}{ Pooled $(n=3766)$} & \multicolumn{2}{|c|}{$\operatorname{AEZ} 1^{a}(n=233)$} & \multicolumn{2}{|c|}{ AEZ $2(n=715)$} & \multicolumn{2}{|c|}{ AEZ $3(n=801)$} & \multicolumn{2}{|c|}{ AEZ $4(n=830)$} & \multicolumn{2}{|c|}{ AEZ $5(n=421)$} & \multicolumn{2}{|c|}{ AEZ $6(n=766)$} \\
\hline & Coefficient & $\begin{array}{l}\text { Std } \\
\text { error }\end{array}$ & Coefficient & $\begin{array}{l}\text { Std } \\
\text { error }\end{array}$ & Coefficient & $\begin{array}{l}\text { Std } \\
\text { error }\end{array}$ & Coefficient & $\begin{array}{l}\text { Std } \\
\text { error }\end{array}$ & Coefficient & $\begin{array}{l}\text { Std } \\
\text { error }\end{array}$ & Coefficient & $\begin{array}{l}\text { Std } \\
\text { error }\end{array}$ & Coefficient & $\begin{array}{c}\text { Std } \\
\text { error }\end{array}$ \\
\hline Log land*Log seed & 0.029 & 0.043 & -0.042 & 0.148 & $0.313^{* * *}$ & 0.099 & $0.135^{*}$ & 0.081 & 0.176 & 0.107 & 0.076 & 0.156 & & \\
\hline Log land*Log labor & $0.076^{*}$ & 0.042 & -0.035 & 0.163 & 0.121 & 0.129 & -0.067 & 0.097 & -0.036 & 0.072 & 0.188 & 0.163 & & \\
\hline Log land*Log fertilizer & 0.011 & 0.026 & 0.258 & 0.204 & -0.102 & 0.085 & $-0.105^{*}$ & 0.061 & $-0.092 *$ & 0.048 & 0.038 & 0.068 & & \\
\hline Log land*Log manure & -0.020 & 0.023 & $-0.452^{* * *}$ & 0.115 & -0.043 & 0.046 & 0.016 & 0.045 & $0.100^{*}$ & 0.054 & -0.026 & 0.092 & & \\
\hline Log land*Log pesticide & 0.036 & 0.044 & $-0.428 * * *$ & 0.092 & -0.015 & 0.137 & 0.074 & 0.144 & 0.007 & 0.108 & -0.078 & 0.141 & & \\
\hline Log seed*Log labor & $0.155^{* * *}$ & 0.039 & $0.690 * * *$ & 0.149 & 0.167 & 0.104 & 0.126 & 0.114 & 0.017 & 0.099 & -0.002 & 0.154 & & \\
\hline Log seed*Log fertilizer & $0.119 * * *$ & 0.024 & $-0.604 * * *$ & 0.226 & 0.099 & 0.073 & $0.188^{* *}$ & 0.090 & $0.165^{* * *}$ & 0.059 & 0.065 & 0.069 & & \\
\hline Log seed*Log manure & $-0.048 * *$ & 0.022 & $-0.306 * * *$ & 0.113 & 0.001 & 0.039 & -0.059 & 0.037 & $-0.118^{* *}$ & 0.050 & -0.009 & 0.105 & & \\
\hline Log seed*Log pesticide & $-0.075^{* *}$ & 0.037 & $0.204 * * *$ & 0.071 & -0.167 & 0.109 & -0.007 & 0.133 & $-0.191 * * *$ & 0.062 & -0.016 & 0.128 & & \\
\hline Log labor*Log fertilizer & $-0.091 * * *$ & 0.026 & $0.475^{* *}$ & 0.193 & -0.011 & 0.104 & $0.126^{*}$ & 0.067 & $-0.118^{* *}$ & 0.056 & -0.051 & 0.056 & & \\
\hline Log labor*Log manure & $0.086^{* * *}$ & 0.024 & 0.096 & 0.116 & 0.063 & 0.054 & 0.071 & 0.051 & $0.098^{*}$ & 0.057 & $0.417 * * *$ & 0.122 & & \\
\hline Log labor*Log pesticide & 0.029 & 0.040 & 0.051 & 0.105 & 0.148 & 0.115 & -0.197 & 0.159 & $0.154^{*}$ & 0.091 & -0.029 & 0.050 & & \\
\hline Log fertilizer*Log manure & $-0.025^{*}$ & 0.014 & $0.557 * *$ & 0.218 & -0.003 & 0.025 & -0.012 & 0.024 & 0.006 & 0.040 & $-0.218^{* * *}$ & 0.064 & & \\
\hline $\begin{array}{l}\text { Log fertilizer*Log } \\
\text { pesticide }\end{array}$ & 0.009 & 0.024 & $0.211 *$ & 0.114 & 0.025 & 0.133 & 0.044 & 0.163 & $0.104 * *$ & 0.045 & 0.075 & 0.052 & & \\
\hline Log manure*Log pesticide & -0.024 & 0.019 & $0.301 * * *$ & 0.059 & $-0.077^{*}$ & 0.045 & -0.064 & 0.089 & $-0.083 * * *$ & 0.031 & 0.084 & 0.057 & & \\
\hline Constant & $0.897 * * *$ & 0.232 & $10.635^{* * *}$ & 1.826 & $-1.608^{* *}$ & 0.630 & $-29.373^{* * *}$ & 8.928 & $1.890^{* * *}$ & 0.728 & -0.127 & 1.457 & $-5.216^{* * *}$ & 1.352 \\
\hline Ln (sigma-v) & $-0.436^{* * *}$ & 0.035 & $-0.797 * * *$ & 0.073 & $-0.555^{* * *}$ & 0.069 & $-0.513^{* * *}$ & 0.111 & $-0.603^{* * *}$ & 0.075 & $-0.547 * * *$ & 0.045 & $-0.404 * * *$ & 0.037 \\
\hline gamma & 0.6644 & & 0.7605 & & 0.6936 & & 0.7365 & & 0.7361 & & 0.3321 & & 0.3879 & \\
\hline $\operatorname{Var}(\mathrm{u}) / \operatorname{Var}($ total $)$ & 0.4184 & & 0.5357 & & 0.4514 & & 0.5038 & & 0.5034 & & 0.153 & & 0.1872 & \\
\hline
\end{tabular}

aEZ 1 is the lowland tropics, AEZ 2, dry mid altitude, AEZ 3, dry transitional , AEZ 4, moist transitional, AEZ 5, high tropics and AEZ 6 is moist mid altitude.

For AEZ 6, Cobb-Douglas function was a better fit hence the squares and cross-products are not included. $*, * *, * * *$ refers to significance at $10 \%, 5 \%$ and $1 \%$ levels respectively 
Results for the specific AEZs differ from the pooled model as well as from one AEZ to another. Although there is not a very clear divide, elasticities for labor and land are notably higher in the drier zones (lowland tropics and dry mid altitude zones) while elasticities for seeds and fertilizers are higher in the high tropics and moist transitional zones. Labor elasticities are highest in the lowland tropics (0.62) and dry mid altitude (0.57) zones. Land elasticity is also highest in the lowland tropics (0.61). Seeds on the other hand have highest elasticities in the moist transitional (0.49) and high tropics (0.40) zones mainly because most farmers use improved seeds. While some farmers in the dry areas also use improved seeds, drought and heat tolerant maize varieties are not adequately used. Therefore, the seeds may not be conditioned for those areas or they are early maturing varieties which have lower yields. Several drought tolerant maize varieties have been released in SSA between 2007 and 2013 through the Drought Tolerant Maize for Africa (DTMA) project but the uptake is still very low in Kenya ${ }^{11}$ (Fisher et al., 2015). High tropics, moist transitional and dry transitional zones have relatively higher fertilizer elasticities. Compared to other inputs, elasticities for manure are relatively low in all the zones.

Farmers in the moist transitional and moist mid attitude zones have significantly higher output in areas with good soil fertility while those in the dry mid altitude zone recorded significantly lower output in steeply sloped areas. More weeks of rainfall led to significantly higher output in the dry transitional and moist transitional zones. The effect of the maximum daily temperature received is mixed across the AEZs. For the lowland tropics and the moist transitional zones, areas with high maximum temperature had lower output while for the dry mid altitude, dry transitional and the moist mid altitude zones, regions with higher maximum temperature had higher output ${ }^{12}$. For the high tropics and the moist mid altitude zones farmers who did not use fertilizers had significantly lower output.

\subsubsection{Inefficiency effects}

Table 4.5 presents the results of the inefficiency effect model for the pooled and the specific AEZs models. As expected higher education level among the farmers reduces inefficiency. This is observed for the pooled model and most of the AEZs. Total livestock owned which is a proxy

\footnotetext{
${ }^{11}$ In our sample, drought tolerant varieties were adopted in 15 plots only.

${ }^{12}$ Results on temperature within an AEZ should not be over-interpreted since the data is at sublocation level and there is not much temperature variation within an AEZ since regions in one AEZ tend to have similar temperature patterns.
} 
for wealth also have a positive effect on technical efficiency for some AEZs. Overall, household size has a negative effect on technical efficiency. This is also observed for the dry mid altitude, moist transitional and moist mid altitude zones. Imperfect labor markets are a common feature in most of rural SSA, and when workers fail to find off-farm employment excess family labor has to be absorbed in the farm resulting in a negative effect on efficiency. Proportion of off-farm income also has a negative effect on farm technical efficiency for the pooled model, dry transitional zone and moist mid altitude zone. This may be because of diversion of labor from farming to pursue other income generating activities thus resulting in delays in some activities on the maize farms. Farm size measured in terms of total land owned has an inverse relationship with TE for farmers in the high tropics zone.

Overall, higher frequencies of drought and water shortage are associated with lower technical efficiency among the farmers. Drought reduces efficiency for farmers in the lowland tropics and dry transitional zones while water shortage reduces efficiency in the dry mid altitude and moist transitional zone. However, contrary to our expectation higher frequencies of flooding are linked to higher technical efficiencies among the farmers in the dry mid altitude and moist mid altitude zones. For the pooled model, adoption of various technologies- improved seeds, soil bunds, zero tillage and manure significantly reduces inefficiencies among farmers. This pattern is however not uniform across the AEZs. For the moist transitional zones, use of fertilizers and manure as well zero tillage and crop residue management practices are associated with higher TE among the farmers. Use of improved seeds, manure and zero tillage practices also reduce in efficiencies among farmers in the moist mid altitude zone. Terracing and soil bunds reduce inefficiencies among farmers in the lowland tropics and the dry transitional zones, respectively. 
Table 4.5: Factors affecting inefficiency

\begin{tabular}{|c|c|c|c|c|c|c|c|c|c|c|c|c|c|c|}
\hline & \multicolumn{2}{|c|}{ Pooled $(n=3766)$} & \multicolumn{2}{|c|}{$\operatorname{AEZ1}^{a}(n=233)$} & \multicolumn{2}{|c|}{ AEZ $2(n=715)$} & \multicolumn{2}{|c|}{ AEZ $3(n=801)$} & \multicolumn{2}{|c|}{ AEZ $4(n=830)$} & \multicolumn{2}{|c|}{ AEZ $5(n=421)$} & \multicolumn{2}{|c|}{ AEZ $6(n=766)$} \\
\hline & Coefficient & $\begin{array}{c}\text { Std } \\
\text { error }\end{array}$ & coefficient & $\begin{array}{c}\text { Std } \\
\text { error }\end{array}$ & coefficient & $\begin{array}{c}\text { Std } \\
\text { error }\end{array}$ & coefficient & $\begin{array}{c}\text { Std } \\
\text { error }\end{array}$ & coefficient & $\begin{array}{c}\text { Std } \\
\text { error }\end{array}$ & coefficient & $\begin{array}{c}\text { Std } \\
\text { error }\end{array}$ & coefficient & $\begin{array}{c}\text { Std } \\
\text { error }\end{array}$ \\
\hline \multicolumn{15}{|l|}{ Plot level variable } \\
\hline Plot tenure & -0.012 & 0.066 & $-1.186^{* *}$ & 0.564 & -0.482 & 0.411 & 0.167 & 0.155 & 0.042 & 0.095 & $1.028^{*}$ & 0.614 & 0.097 & 0.221 \\
\hline \multicolumn{15}{|c|}{ Socioeconomic variables } \\
\hline Education farmer & $-0.027 * * *$ & 0.006 & $-0.168^{*}$ & 0.098 & -0.019 & 0.017 & -0.021 & 0.014 & $-0.063^{* * *}$ & 0.011 & $-0.251 *$ & 0.131 & $-0.078^{* * *}$ & 0.030 \\
\hline Age of farmer & 0.001 & 0.001 & -0.014 & 0.013 & -0.003 & 0.004 & $0.006^{*}$ & 0.003 & -0.004 & 0.003 & -0.060 & 0.037 & 0.005 & 0.005 \\
\hline Male & $0.071 *$ & 0.042 & 1.647 & 1.252 & $-0.218^{* *}$ & 0.111 & 0.014 & 0.095 & $0.210^{* *}$ & 0.084 & 0.855 & 0.791 & -0.091 & 0.167 \\
\hline Household size & $0.031 * * *$ & 0.009 & $-0.207^{*}$ & 0.110 & $0.059 * *$ & 0.030 & 0.003 & 0.022 & $0.054 * * *$ & 0.017 & 0.059 & 0.097 & $0.128^{* * *}$ & 0.045 \\
\hline TLU & $-0.026 * * *$ & 0.006 & 0.046 & 0.043 & $-0.048^{* *}$ & 0.020 & $-0.043 * *$ & 0.019 & $0.006^{*}$ & 0.003 & $-0.044 * *$ & 0.021 & $-0.060 * * *$ & 0.014 \\
\hline Land acres & -0.001 & 0.003 & -0.055 & 0.046 & -0.003 & 0.006 & 0.012 & 0.012 & $-0.011 *$ & 0.006 & $0.072 * *$ & 0.035 & 0.011 & 0.013 \\
\hline Prop off-farm income & $0.213^{* * *}$ & 0.078 & 1.587 & 1.321 & 0.271 & 0.221 & $0.265^{*}$ & 0.161 & -0.026 & 0.164 & -0.164 & 0.736 & $0.678^{* *}$ & 0.289 \\
\hline Credit & 0.035 & 0.053 & $-1.145^{* *}$ & 0.518 & -0.112 & 0.125 & 0.184 & 0.115 & 0.135 & 0.120 & 0.931 & 0.612 & $1.473^{* *}$ & 0.632 \\
\hline \multicolumn{15}{|c|}{ Frequency of weather extremes } \\
\hline Drought & $0.028 * *$ & 0.012 & $0.284 * * *$ & 0.088 & -0.017 & 0.025 & $0.070^{* *}$ & 0.030 & -0.013 & 0.034 & -0.119 & 0.158 & -0.017 & 0.077 \\
\hline Water shortages & $0.021 * *$ & 0.010 & 0.051 & 0.083 & $0.065^{* * *}$ & 0.023 & 0.002 & 0.029 & $0.078^{* * *}$ & 0.029 & -0.170 & 0.160 & $-0.143^{* * *}$ & 0.050 \\
\hline Flooding & -0.051 & 0.032 & 1.247 & 0.770 & $-1.009 * * *$ & 0.341 & -0.443 & 0.280 & -0.044 & 0.053 & -0.230 & 0.473 & $-0.281 * * *$ & 0.100 \\
\hline \multicolumn{15}{|c|}{ Technologies adopted in the plot } \\
\hline Improved seeds & $-0.210 * * *$ & 0.046 & $0.580^{*}$ & 0.305 & -0.150 & 0.096 & -0.105 & 0.097 & -0.120 & 0.106 & $-0.818^{*}$ & 0.451 & $-0.621 *$ & 0.346 \\
\hline Fertilizers & -0.118 & 0.083 & 0.078 & 0.339 & -0.359 & 0.234 & -0.178 & 0.186 & $-0.397 * * *$ & 0.145 & $0.747 *$ & 0.445 & -0.176 & 0.219 \\
\hline Terracing & 0.010 & 0.047 & $-2.508^{* * *}$ & 0.931 & -0.086 & 0.112 & -0.094 & 0.123 & $0.160 *$ & 0.089 & 0.536 & 0.510 & 0.021 & 0.231 \\
\hline Soil bunds & $-0.111 * *$ & 0.058 & 0.178 & 0.557 & 0.013 & 0.136 & $-0.449 * *$ & 0.227 & 0.031 & 0.105 & $1.726^{*}$ & 1.023 & 0.131 & 0.354 \\
\hline Zero tillage ${ }^{b}$ & $-0.213^{* *}$ & 0.087 & $0.868^{*}$ & 0.509 & -0.164 & 0.162 & -0.406 & 0.293 & $-0.345^{* * *}$ & 0.118 & & & $-1.637 * * *$ & 0.423 \\
\hline Crop residue & $-0.087^{*}$ & 0.045 & -0.545 & 0.824 & -0.126 & 0.119 & -0.190 & 0.123 & $-0.190 * *$ & 0.092 & 0.290 & 0.631 & -0.270 & 0.257 \\
\hline Manure & $-0.176^{* *}$ & 0.079 & -0.518 & 0.466 & 0.171 & 0.142 & -0.007 & 0.161 & $-0.341 * *$ & 0.144 & $1.793^{*}$ & 1.033 & $-0.502^{*}$ & 0.290 \\
\hline Constant & 0.085 & 0.136 & 0.791 & 1.963 & 0.130 & 0.383 & -0.181 & 0.292 & $0.581 *$ & 0.327 & -0.771 & 2.338 & $-1.704 * *$ & 0.705 \\
\hline
\end{tabular}

${ }^{\mathbf{a}}$ AEZ 1 is the lowland tropics, AEZ 2, dry mid altitude, AEZ 3, dry transitional zone, AEZ 4, moist transitional, AEZ 5, high tropics zones and AEZ 6 the moist mid altitude.

${ }^{\mathrm{b}}$ Zero tillage was omitted in the high tropics model due to multicollinearity problems. *, **, *** refers to significance at $10 \%, 5 \%$ and $1 \%$ levels respectively. 


\subsubsection{Estimates of the meta-frontier}

Owing to the fact that parameter estimates of the frontiers across the AEZs are different and the test in Table 4.2 indicate that production technologies are different across the AEZs we estimate a metafrontier. Using parameter estimates from the group frontiers, we solve for the minimization problem in (equation 8) using both linear programming (LP) and quadratic programming (QP) optimization techniques. Since for the group stochastic frontiers (except for the moist mid altitude zone) translog function was a better fit, the metafrontier also follows a translog functional form. Estimation of group frontiers and the meta-frontier was done using Ox Metrics version 6.10 (Doomik 2007).

Parameter estimates for the two meta-frontiers (LP and QP) and the simulated standard errors are shown in Table 4.6. There are only minor differences between the two meta-frontiers. Results of the metafrontier show positive and significant productivity elasticities for land (0.216), seed (0.404), labor (0.243) and fertilizer (0.219). Also farmers who used no fertilizers and pesticides have lower output and plots located on steep slopes have significantly lower output. The parameters of the meta-frontier are used in the estimation of the MTRs and TEs relative to the metafrontier as shown in equations (11) and (12). 
Table 4.6: Estimates of the meta-frontier, LP and QP

\begin{tabular}{|c|c|c|c|c|}
\hline & \multicolumn{2}{|c|}{ Linear Programming } & \multicolumn{2}{|c|}{ Quadratic Programming } \\
\hline & Coefficient & Std error & coefficient & Std error \\
\hline Log land & $0.208^{* *}$ & 0.101 & $0.216^{* *}$ & 0.104 \\
\hline Log seed & $0.416^{* * *}$ & 0.108 & $0.404 * * *$ & 0.114 \\
\hline Log labor & $0.241 * * *$ & 0.079 & $0.243^{* * *}$ & 0.080 \\
\hline Log fertilizer & $0.221 * * *$ & 0.051 & $0.219 * * *$ & 0.053 \\
\hline Log manure & $0.095^{*}$ & 0.054 & 0.096 & 0.059 \\
\hline Log pesticide & 0.042 & 0.071 & 0.044 & 0.074 \\
\hline Season dummy & -0.105 & 0.068 & -0.099 & 0.070 \\
\hline Season* fertilizer & -0.072 & 0.070 & -0.055 & 0.074 \\
\hline Season*seed & -0.077 & 0.106 & -0.078 & 0.111 \\
\hline Season*land & 0.030 & 0.102 & 0.034 & 0.105 \\
\hline Fertilizer dummy & -0.159 & 0.119 & $-0.193 *$ & 0.117 \\
\hline Manure dummy & 0.022 & 0.099 & 0.017 & 0.099 \\
\hline Pesticide dummy & $-0.247^{*}$ & 0.150 & $-0.274^{*}$ & 0.158 \\
\hline Medium soil fertility & -0.027 & 0.131 & -0.047 & 0.135 \\
\hline Good soil fertility & 0.041 & 0.129 & 0.040 & 0.131 \\
\hline Gentle slope & $-0.167 * *$ & 0.078 & $-0.169 * *$ & 0.080 \\
\hline Medium slope & $-0.207 * *$ & 0.095 & $-0.219 * *$ & 0.095 \\
\hline Steep slope & 0.007 & 0.204 & -0.012 & 0.201 \\
\hline Rain 2012 & 0.006 & 0.005 & 0.008 & 0.029 \\
\hline Max daily Temp & -0.004 & 0.013 & -0.007 & 0.043 \\
\hline $.5^{*} \log \operatorname{land}^{\wedge} 2$ & -0.030 & 0.103 & -0.030 & 0.102 \\
\hline $.5^{*} \log \operatorname{seed}^{\wedge} 2$ & 0.072 & 0.140 & 0.046 & 0.128 \\
\hline $.5^{*} \log$ labour^${ }^{\wedge}$ & 0.064 & 0.133 & 0.037 & 0.124 \\
\hline $.5^{*} \log$ fertilizer ${ }^{\wedge}$ & $0.173^{* * *}$ & 0.068 & $0.145^{* *}$ & 0.059 \\
\hline $.5^{*} \log$ manure ${ }^{\wedge} 2$ & 0.036 & 0.032 & 0.027 & 0.039 \\
\hline $.5^{*} \log$ pesticide ${ }^{\wedge} 2$ & 0.109 & 0.099 & 0.087 & 0.095 \\
\hline Log land*Log seed & -0.022 & 0.091 & -0.021 & 0.090 \\
\hline Log land*Log labor & 0.037 & 0.092 & 0.046 & 0.092 \\
\hline Log land*Log fertilizer & -0.014 & 0.053 & -0.021 & 0.057 \\
\hline Log land*Log manure & 0.007 & 0.052 & 0.006 & 0.057 \\
\hline Log land*Log pesticide & 0.036 & 0.102 & 0.055 & 0.097 \\
\hline Log seed*Log labor & 0.076 & 0.104 & 0.094 & 0.102 \\
\hline Log seed*Log fertilizer & 0.035 & 0.067 & 0.063 & 0.060 \\
\hline Log seed*Log manure & -0.086 & 0.059 & -0.074 & 0.059 \\
\hline Log seed*Log pesticide & $-0.311 * * *$ & 0.116 & $-0.305^{* * *}$ & 0.112 \\
\hline Log labor*Log fertilizer & -0.106 & 0.066 & -0.096 & 0.069 \\
\hline Log labor*Log manure & $0.178^{* * *}$ & 0.062 & $0.157^{* * *}$ & 0.062 \\
\hline Log labor*Log pesticide & 0.124 & 0.109 & 0.122 & 0.098 \\
\hline Log fertilizer*Log manure & -0.068 & 0.042 & -0.063 & 0.053 \\
\hline Log fertilizer*Log pesticide & 0.082 & 0.068 & 0.074 & 0.064 \\
\hline Log manure*Log pesticide & 0.006 & 0.066 & 0.000 & 0.058 \\
\hline Constant & $0.981 * *$ & 0.477 & 1.306 & 1.117 \\
\hline
\end{tabular}

$\mathrm{N}=3766 *, * *, * * *$ refers to significance at $10 \%, 5 \%$ and $1 \%$ levels respectively. 
4.4.4 Summary estimates of meta-technology ratios and technical efficiencies across AEZs

Table 4.7 presents a summary of descriptive statistics of TEs relative to the pooled frontier, the group frontiers and the meta-frontier. The MTRs are also presented. Overall, average TE relative to the pooled frontier is $57 \%$ implying that farmers achieve about $57 \%$ of their maximum attainable output for given input levels. The TEs varies across the AEZs with a high of $67 \%$ for the high tropics zones and a low of $51 \%$ in the lowland tropics. The mean TEs relative to the group frontiers are however higher than those from the pooled frontier except for the moist transitional and the dry transitional zones where they are approximately equal. The high tropics region especially has very high mean TE (89\%) followed by the lowland tropics and the moist mid altitude (77\%). This implies that farmers compare relatively well to those in the same AEZs.

Table 4.7: Summary statistics for the MTRs and the TEs relative to the pooled frontier, AEZs frontiers and the meta-frontier

\begin{tabular}{ccccccccc}
\hline & & $\begin{array}{c}\text { AEZ 1 } \\
\mathbf{n = 2 1 3}\end{array}$ & $\begin{array}{c}\text { AEZ 2 } \\
\mathbf{n = 7 1 5}\end{array}$ & $\begin{array}{c}\text { AEZ 3 } \\
\mathbf{n = 8 0 1}\end{array}$ & $\begin{array}{c}\text { AEZ 4 } \\
\mathbf{n = 8 3 0}\end{array}$ & $\begin{array}{c}\text { AEZ 5 } \\
\mathbf{n = 4 2 1}\end{array}$ & $\begin{array}{c}\text { AEZ 6 } \\
\mathbf{n = 7 6 6}\end{array}$ & $\begin{array}{c}\text { Pooled } \\
\mathbf{n = 3 7 6 6}\end{array}$ \\
\hline $\begin{array}{c}\text { TEs with respect to the } \\
\text { pooled frontier }\end{array}$ & Mean & 0.5109 & 0.5576 & 0.5663 & 0.5915 & 0.6745 & 0.5384 & 0.5732 \\
& Std Dev & 0.1682 & 0.1725 & 0.1638 & 0.1551 & 0.1110 & 0.1625 & 0.1640 \\
& Min & 0.0668 & 0.0499 & 0.0142 & 0.1018 & 0.2334 & 0.0493 & 0.0142 \\
& Max & 0.8149 & 0.8745 & 0.8507 & 0.9880 & 0.9482 & 0.8414 & 0.9880 \\
TEs with respect to the & Mean & 0.7723 & 0.6202 & 0.5565 & 0.5909 & 0.8935 & 0.7786 & 0.6724 \\
AEZs (group) frontiers & Std Dev & 0.2305 & 0.1967 & 0.1774 & 0.1814 & 0.1508 & 0.1737 & 0.2155 \\
& Min & 0.0624 & 0.0499 & 0.0074 & 0.0540 & 0.1340 & 0.0843 & 0.0074 \\
& Max & 0.9974 & 0.9955 & 0.8824 & 0.8974 & 0.9995 & 0.9988 & 0.9995 \\
TEs with respect to the & Mean & 0.2413 & 0.2765 & 0.3159 & 0.3515 & 0.5468 & 0.2675 & 0.3276 \\
meta-frontier (MFTEs) & Std Dev & 0.1498 & 0.1468 & 0.1445 & 0.1399 & 0.1647 & 0.0978 & 0.1625 \\
& Min & 0.0071 & 0.0162 & 0.0061 & 0.0003 & 0.0479 & 0.0104 & 0.0003 \\
& Max & 0.9117 & 0.8298 & 0.8135 & 0.7966 & 0.9717 & 0.7219 & 0.9717 \\
& & & & & & & & \\
Meta-technology ratios & Mean & 0.3226 & 0.4467 & 0.5698 & 0.6009 & 0.6198 & 0.3430 & 0.4975 \\
(MTRs) & Std Dev & 0.1910 & 0.1796 & 0.1849 & 0.1568 & 0.1703 & 0.0968 & 0.1964 \\
& Min & 0.0254 & 0.0404 & 0.0195 & 0.0007 & 0.0480 & 0.0115 & 0.0007 \\
& Max & 0.9781 & 0.9922 & 0.9844 & 0.9869 & 1.0000 & 0.8105 & 1.0000 \\
\hline
\end{tabular}

${ }^{\mathbf{a}}$ AEZ 1 is the lowland tropics, AEZ 2, dry mid altitude, AEZ 3, dry transitional zone, AEZ 4, moist transitional, AEZ 5, high tropics zones and AEZ 6, moist mid altitude

Meta-technology ratios (MTRs) and the TEs relative to the meta-frontier (MFTEs) also vary widely across the AEZs. Again, on average, high tropics zone has the highest MTRs (62\%) followed by moist transitional (60\%), while lowland tropics has the lowest (32\%). These MTRs values can be regarded as the environmental gaps faced by farmers in each AEZ when their performances are compared to the whole industry. Values closer to one imply that a farm in a given group is producing nearer to the maximum potential output given the technology available for the 
whole industry. The maximum MTR equal to one for the high tropics zone also indicates that the frontier is tangent to the metafrontier. Other AEZs' frontiers are however below the metafrontier. Distributions of the MTRs across the AEZs as shown by the histograms (Figure A4.1 in appendix A4) also differ substantially.

As expected, given the MTRs, the TEs relative to the meta-frontier (MFTEs) are lower than those relative to the group frontiers. The high tropics zone still has the highest average MFTEs, about 55\% while the lowland tropics zone has the lowest, 24\%. This means that, on average, farmers in the high tropics are able to produce $55 \%$ of the maximum attainable output in the whole industry with the same level of inputs while those in the lowland tropics are only able to attain $24 \%$ of the same. The average MFTEs of other AEZs are also very low. TEs relative to the group frontiers are considerably higher than the MFTEs; especially in the lowland tropics, dry mid altitude and moist mid altitude zones they are two to three times higher. This means that these farmers compare relatively well to farmers in the same AEZ as opposed to the whole industry indicating that environmental differences contribute more to yield differences than farmers' inefficiencies do. It also indicates that farmers have not been able to sufficiently adapt their agricultural practices to the environmental constraints they face. The low magnitudes of MTRs coupled wide variation across the AEZs further support this. This is particularly true for the lowland tropics, moist mid altitude and dry mid altitude zones hence for these farmers efforts to reduce environmental gaps may be more urgent than efforts to reduce farmers' inefficiencies.

The relatively high MTRs for the high tropics and the moist transitional zones may be attributed to the relatively high rainfall they receive and the fact that in comparison to other AEZs, they use higher levels of fertilizers as well as improved seeds. On the other hand, low MTRs for the lowland tropics can be attributed to the low rainfall, high temperatures as well as low adoption rates of technologies especially chemical fertilizers. However, for the moist mid altitude region rainfall is not a major shortcoming and the low MTRs may be due to the low adoption rates of technologies. We however, further investigate what factors may be associated with the variations in MTRs in the next section.

\subsubsection{Explaining variations in meta-technology ratios}

Owing to the wide variation in MTRs across the AEZs, we estimate an ordinary least squares regression showing how community and household factors as well as technology practices influence MTRs. They can also be interpreted as causes for the environmental gaps. The results are presented in Table 4.8. Descriptive statistics of these community and household level factors are presented in appendix A4, Table A4.1. 
Table 4.8: Ordinary least squares regression of meta-technology ratios

\begin{tabular}{|c|c|c|c|c|}
\hline & \multicolumn{2}{|c|}{ With technologies } & \multicolumn{2}{|c|}{ Without technologies } \\
\hline & Coefficient & Robust Std. error & Coefficient & Robust Std. error \\
\hline \multicolumn{5}{|l|}{ Community level characteristics $^{\text {a }}$} \\
\hline Log Annual rainfall & $0.054 *$ & 0.028 & $0.058 * *$ & 0.028 \\
\hline Maximum temperature & $-0.023^{* * *}$ & 0.003 & $-0.027 * * *$ & 0.003 \\
\hline Log population density & $-0.190 * * *$ & 0.050 & $-0.171 * * *$ & 0.048 \\
\hline Log population density squared & $0.015 * * *$ & 0.004 & $0.014 * * *$ & 0.004 \\
\hline Maize lethal necrosis & $-0.030 * *$ & 0.013 & $-0.038 * * *$ & 0.013 \\
\hline Electricity supply & $0.044 * * *$ & 0.013 & $0.051 * * *$ & 0.013 \\
\hline Number of mobile banking outlets & 0.001 & 0.001 & $0.002 *$ & 0.001 \\
\hline Number of grain buyers within & $5.14 \mathrm{e}-04$ & $3.77 \mathrm{e}-04$ & $2.24 \mathrm{e}-04$ & $4.34 \mathrm{e}-04$ \\
\hline \multicolumn{5}{|l|}{ Household level characteristics } \\
\hline Years of exposure to improved seeds & $0.001 * * *$ & $4.29 \mathrm{e}-04$ & $0.002 * * *$ & $4.42 \mathrm{e}-04$ \\
\hline Distance to main market & -0.002 & 0.004 & -0.003 & 0.004 \\
\hline Distance to inputs & $-4.76 e-04$ & 0.003 & $2.84 \mathrm{e}-04$ & 0.003 \\
\hline Frequency of flooding & $-0.016^{* * *}$ & 0.006 & $-0.017 * * *$ & 0.006 \\
\hline \multicolumn{5}{|l|}{ Technologies adopted in the plot } \\
\hline Improved seeds & $0.044 * * *$ & 0.010 & & \\
\hline Fertilizer & $0.034 * *$ & 0.014 & & \\
\hline Zero tillage & 0.014 & 0.017 & & \\
\hline Crop residue & $-0.033 * * *$ & 0.011 & & \\
\hline Soil bunds & -0.018 & 0.027 & & \\
\hline Soil bunds*slopy land & 0.046 & 0.031 & & \\
\hline Terraces & 0.018 & 0.017 & & \\
\hline Terrace*slopy land & -0.023 & 0.020 & & \\
\hline Slopy land & 0.013 & 0.014 & & \\
\hline Manure & $-0.020 * *$ & 0.008 & & \\
\hline Constant & $1.317 * * *$ & 0.219 & $1.359 * * *$ & 0.219 \\
\hline $\mathrm{R}^{2}$ & \multicolumn{2}{|c|}{0.189} & \multicolumn{2}{|c|}{0.157} \\
\hline
\end{tabular}

$\mathrm{N}=3766$, Standard errors are robust and clustered at household level.

${ }^{a}$ community characteristics are at sublocation level. Rainfall and temperature data represent averages for the years 1950-2000 and were generated from WorldClim Data. Population density data is from the latest national census in 2009 (KNBS, 2010).

We suspect that adoption of technologies in the model may be endogenous; however, we could not find suitable instruments for all the technologies to correct for possible bias. Hence, as a robustness check we estimate the model without the technologies - the effect of the other variables on MTRs is not substantially affected. As expected, areas with high amount of rainfall are associated with higher MTRs while farmers who reported higher frequencies of flooding have significantly lower MTRs. On the other hand, high maximum daily temperatures are linked to significantly lower MTRs. Areas with observed incidences of maize lethal necrosis (MLN) also have significantly low MTRs. MLN is a viral disease which severely affects maize, first incidences in Kenya were reported in 2011-2012, and by then the disease was difficult to control (Wangai et al., 2014).

At lower levels, increase in population density has a negative relationship with MTRs which may be as a result of competition for resources. However, after some point, increase in population density has a positive effect on MTRs. Probably due to the positive link between population density 
and growth of urban features which favors access to improved infrastructure and other support services thus a higher technology advantage. For the same reason, areas with electricity connection are associated with significantly higher MTRs. The role of mobile banking in providing financial services to the farmers can be attributed to the positive link with MTRs.

Improved seeds and chemical fertilizers are associated with significantly higher MTRs. Similarly, farmers with more years of exposure to improved seeds have significantly higher MTRs. However, some technologies (crop residue management and use of animal manure) are negatively associated with MTRs. This does not necessarily mean that use of these technologies should not be recommended. This may be biased since these technologies are mostly adopted in the drier regions and also by relatively poor farmers. Existing studies have in fact recommended these practices together with zero tillage and water conservation practices in the dry regions as strategies to adapt to and mitigate against climate change (Delgado et al., 2011; Di Falco and Veronesi, 2013). Adopted together with the proper seed varieties these practices ought to result in higher outputs.

\subsection{Conclusion}

Expanding crop land to feed the rising population in Sub-Saharan Africa faces restrictions due to environmental costs involved. Improving technical efficiency among smallholder farmers is one way of improving productivity sustainably. While there are many studies on efficiency and productivity in SSA, limited studies distinguish between technical efficiency and environmental gaps resulting from climatic differences. Using nationally representative data from all the maize growing areas in Kenya distributed under six diverse AEZs we apply the stochastic meta-frontier production function to distinguish between technical efficiencies (TEs) and meta-technology ratios (MTRs) among different groups of farmers.

The inputs show positive elasticities. Land and labor have substantially higher elasticities in the dry regions while seeds and fertilizer have higher elasticities in regions with more rain where most farmers use improved seeds. While some farmers in the dry areas also use improved seeds, drought and heat tolerant maize varieties are not adequately used thus the seeds may not be conditioned for those areas or they are early maturing varieties which have lower yields. We find education, ownership of livestock and adoption of various technologies to positively influence technical efficiency among the farmers. However, proportion of off-farm income, household size, frequent drought and water shortages have a negative influence on farmers' efficiency.

We also find large variations between TEs and MTRs among farmers in these AEZs. TEs relative to the group frontiers are relatively high; in some zones (mostly the drier zones) they are 
two to three times higher than TEs relative to the meta-frontier. This shows that farmers compare relatively well to farmers in the same AEZ as opposed to the whole industry, indicating that environmental gaps contribute more to yield differences than farmers' inefficiencies do. Thus while reducing farmers' inefficiencies is important, narrowing down the environmental gaps should be a priority especially for the dry and least productive regions. Farmers have not sufficiently adapted their agricultural practices and management skills to the environmental constraints they are facing. The low magnitudes of MTRs coupled wide variation across the AEZs further support this. The variations in MTRs can be explained by amount of rainfall received, maximum temperatures, population pressure, access to infrastructure, incidences of maize lethal necrosis disease and technologies adopted.

One effective way of narrowing down these environmental gaps is to adapt to the high temperatures through promotion of improved varieties conditioned for dry conditions - drought and heat tolerant varieties. However, in spite of the fact that three AEZs have average daily maximum temperature of more than $30^{\circ} \mathrm{C}$ coupled with frequent droughts, adoption rates of these varieties are very low. Several drought tolerant varieties have been released recently in SSA thus there is need for extension to promote these varieties and for more research to understand reasons for the low adoption rates. Similarly, timely control of diseases such as MLN, provision of proper infrastructure and electricity connection in these rural regions are also necessary to narrow down these environmental gaps. 


\section{Appendix A4}

Figure A 4.1: Distribution of MTRs across the AEZs

Lowland tropics

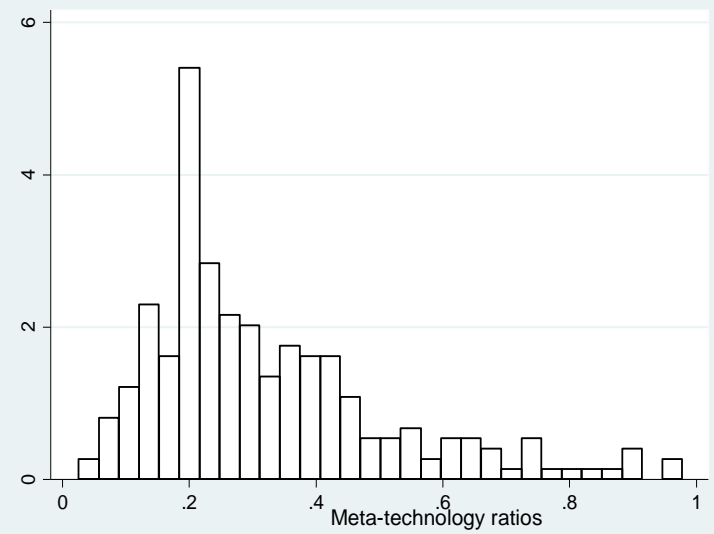

Dry transitional

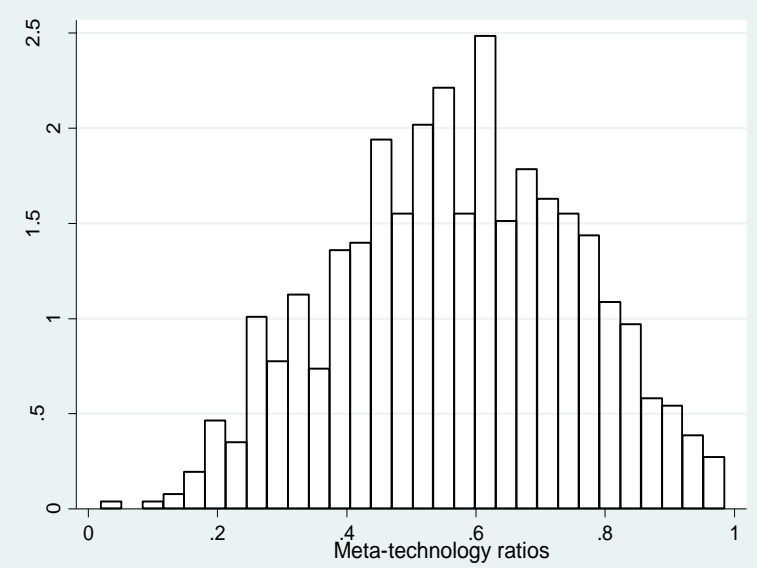

High tropics

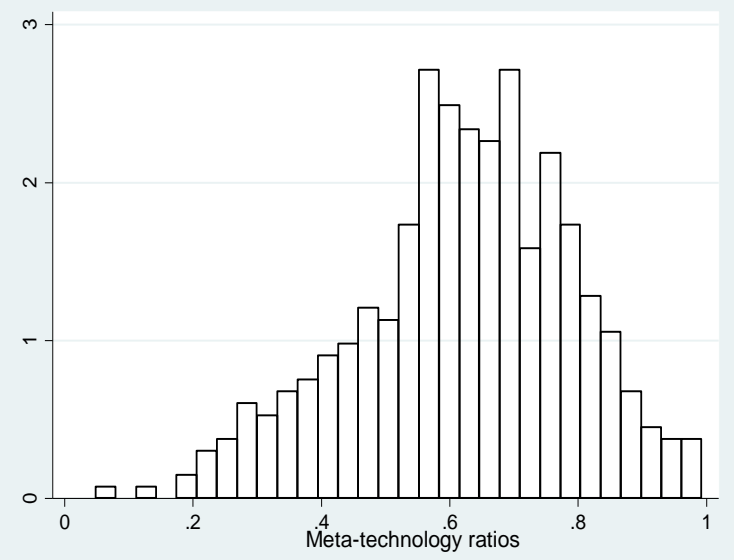

Dry mid altitude

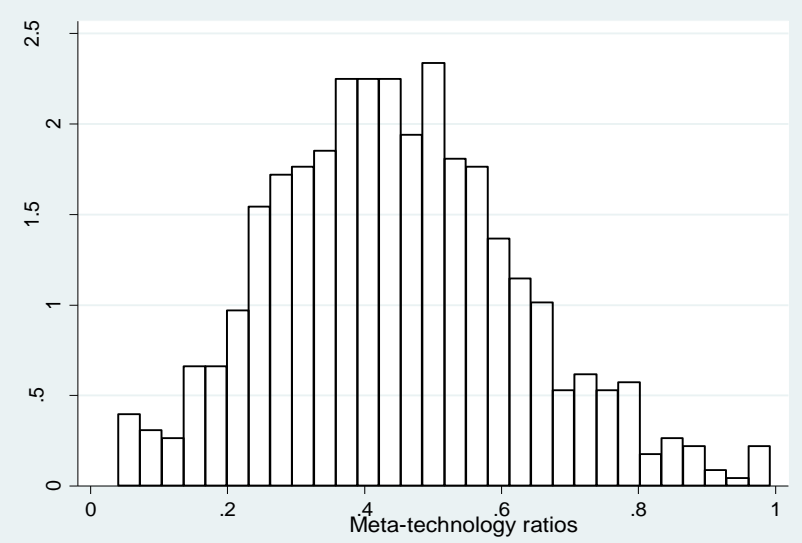

Moist transitional

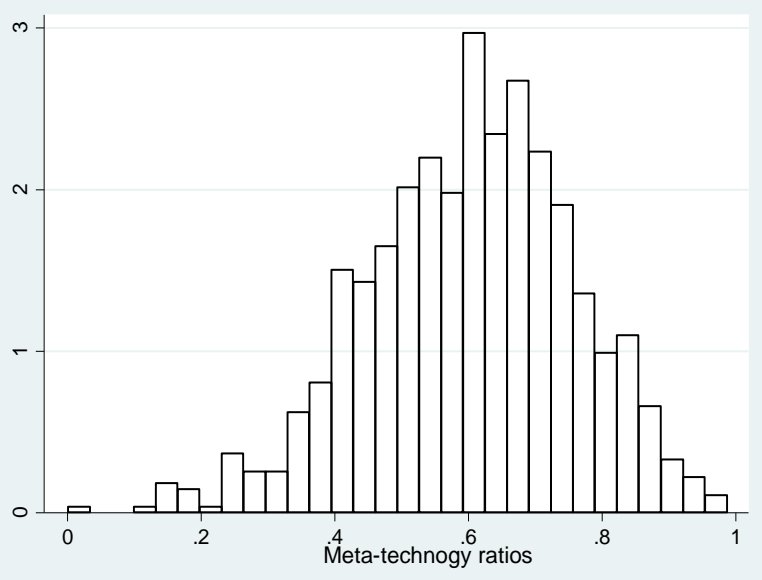

Moist mid altitude

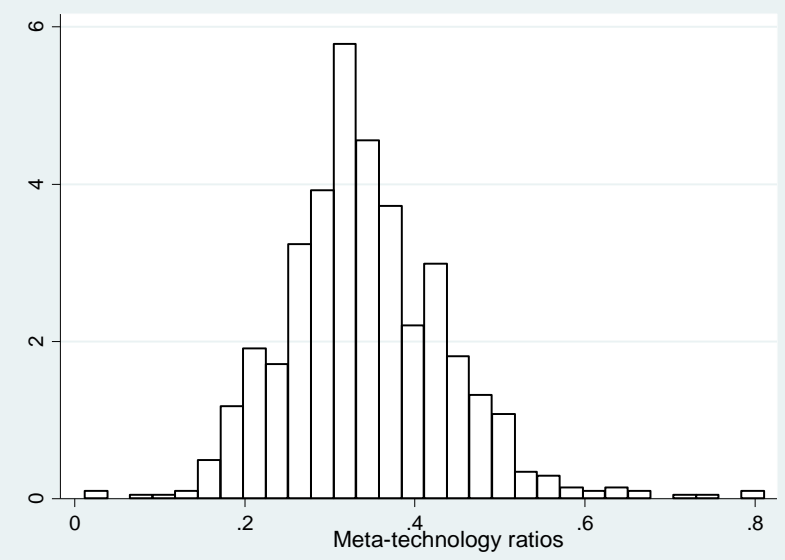


Table A 4.1: Summary statistics of variables explaining variation in MTRs

\begin{tabular}{|c|c|c|c|}
\hline Variable name & Description & Mean & Std. dev. \\
\hline \multicolumn{4}{|c|}{ Community level characteristics } \\
\hline Annual rainfall & Average annual rainfall in mm from 1950-2000 & 1174.5 & 299.1 \\
\hline Maximum temperature & Average maximum daily temperature from $1950-2000$ & 29.18 & 2.56 \\
\hline Population density & Population density in persons per KM squared & 466.8 & 682.9 \\
\hline Maize lethal necrosis & $=1$ if MLN was observed in the sublocation, 0 otherwise & 0.64 & 0.48 \\
\hline Electricity supply & $=1$ if sublocation has electricity connection, 0 otherwise & 0.80 & 0.40 \\
\hline $\begin{array}{l}\text { Number of mobile } \\
\text { banking outlets }\end{array}$ & Number of mobile banking outlets in the sublocation & 4.4 & 5.1 \\
\hline $\begin{array}{l}\text { Number of grain buyers } \\
\text { within }\end{array}$ & Number of grain buyers in the sublocation & 23.6 & 29.3 \\
\hline \multicolumn{4}{|c|}{ Household level characteristics } \\
\hline $\begin{array}{l}\text { Years of exposure to } \\
\text { improved seeds }\end{array}$ & $\begin{array}{l}\text { Number of years the farmer has been exposed to } \\
\text { improved maize varieties }\end{array}$ & 17.13 & 11.9 \\
\hline Distance to main market & Distance to the main market in walking hours & 1.67 & 1.65 \\
\hline Distance to inputs & Distance to the input markets in walking hours & 1.58 & 1.94 \\
\hline Frequency of flooding & Frequency of floods in the last 10 years & 0.26 & 0.73 \\
\hline
\end{tabular}




\section{Conclusion and Policy Recommendations}

\subsection{Main findings}

We have analyzed the adoption and impact of different input-intensive and NRM technologies among maize farmers in Kenya using data from a nationally representative survey. We have also assessed what associations in form of tradeoffs and complementarities exist between these technologies. Synergy effects arising from various technology combinations have also been assessed. This study adds to the existing literature since most previous adoption and/or impact studies have either looked at input-intensive technologies or at NRM techniques, using different data and methodologies, so that comparisons were not easily possible. The input-intensive technologies considered in this study were improved maize seeds and mineral fertilizer while NRM technologies were zero tillage, management of crop residues, use of organic manure, and the construction of terraces and soil bunds.

In analyzing adoption of these technologies, we employed a multivariate probit model, which allows for correlation of the error term between equations, thus enabling us to analyze the adoption of different technologies simultaneously. As covariates we included plot level, farm level, farmer, and household characteristics, as well as contextual factors characterizing infrastructure, institutional, and agroecological conditions. The estimation results show that the adoption covariates differ between technologies. For instance, improved seeds, mineral fertilizer, manure, and stone terraces are more adopted in regions with higher rainfalls, whereas zero tillage and crop residue management are more adopted under drier conditions. Education, farm size, market distance, credit, and several other variables also play significant roles, partly with differing signs across technologies. However, we did not find a clear divide in terms of adoption covariates between input-intensive and NRM technologies, suggesting that the two types of technologies can often be suitable in the same settings.

These technologies are not mutually exclusive. The correlation matrix from the MVP model shows negative correlations (tradeoffs) as well as positive correlations (complementarities) between these technologies. Tradeoffs are observed for some technologies that serve the same purpose hence farmers consider them as substitutes such as terracing and soil bunds or manure and mineral fertilizers. In certain cases, negative correlation simply indicates that different technologies are suitable for different conditions for example manure and crop residue management. Manure application is more common in crop-livestock systems, where crop residues are mostly used as livestock fodder. Positive correlations are also observed although most of them occur either among input-intensive or among NRM technologies. Many other combinations between input-intensive 
and NRM technologies that were shown to be beneficial elsewhere are rarely observed among maize farmers in Kenya. This is due to the fact that input-intensive and NRM technologies are partly promoted by different organizations. NRM technologies are more promoted by the public extension service and NGOs, whereas for improved seeds and mineral fertilizer the private sector plays a larger role. Some organizations that promote NRM technologies would not promote the use of external inputs at the same time, because of the perceived incompatibility. Getting information from different sources and then making informed decisions would not be a problem if farmers really had access to the different types of information. However, this is often not the case because of high transaction costs involved in obtaining information. When farmers happen to have access to only one type of information, the picture they get is incomplete, and synergies between different types of technologies cannot be fully exploited.

Owing to the finding that these technologies are not mutually exclusive, we assessed synergy impacts arising from existing combinations. In particular, we assessed the impact of each of the technologies and of some of their respective combinations on total household income and per capita income. We consider income as a measure of welfare since agricultural technologies can affect income through various pathways, such as higher yields, lower production costs, or changes in household labor requirements that may entail time reallocation and higher or lower incomes from alternative economic activities. We used propensity score matching methods to correct for selection bias that may be present. The estimation results show that - when adopted alone - some technologies produce positive income effects, while other technologies do not. Improved seeds and use of organic manure in particular lead to positive income effects. However, contrary to our expectation use of mineral fertilizers show negative income effects. We suspect that the reason is because many farmers use fertilizers that only contain macronutrients (NPK fertilizers) while in reality most African soils are also micronutrient deficient. In fact, when we confine fertilizer adopters to those that used fertilizers with micronutrients the negative income effect turns positive (though it is not significant due to large standard errors). At the same time, some of the technology combinations lead to higher positive impacts. The largest positive income effects are observed when improved seeds are adopted together with organic manure and zero tillage practices. This clearly underlines that there are important synergies between input-intensive and NRM technologies. On the other hand, the number of farmers adopting such promising technology combinations is relatively low, suggesting that the synergies are not yet fully exploited.

Finally, using plot level maize production data from farmers distributed across six AEZs in Kenya, which are diverse in their climatic conditions among other attributes, we made a distinction between farmers' technical efficiency and meta-technology ratios and assessed their determinants 
thereof. We employed the stochastic meta-frontier production function. We find that farmers in these regions have significantly different production functions and by estimating a uniform production function we could have attributed environmental gaps to farmers' inefficiencies. We find large variations between technical efficiencies and meta-technology ratios between farmers in these AEZs. The high tropics and the moist transitional zones have the highest MTRs while the lowland tropics have the lowest. However, TEs relative to the group frontiers are quite high; in some zones, mainly the drier ones, they are two to three times higher than TEs relative to the metafrontier. This shows that farmers compare relatively well to farmers in the same AEZ compared to the whole industry indicating that environmental gaps contribute more to yield differences than farmers' inefficiencies do. Low magnitudes of MTRs coupled with wide variation across the AEZs further support this interpretation. This implies that farmers have not sufficiently adapted their agricultural practices and management skills to the environmental constraints they face. The variations in MTRs can be explained by amount of rainfall received, maximum temperatures, population pressure, access to infrastructure, incidences of maize lethal necrosis disease and technologies adopted.

\subsection{Policy implications}

The study finds that there are synergy effects arising from combination of input-intensive technologies and NRM technologies with the highest impact being from combining improved seeds, zero tillage and manure. The adoption rate of this combination is however relatively low and also other combinations between input-intensive and NRM technologies that were shown to be beneficial elsewhere are rarely observed among maize farmers in Kenya. This may be attributed to the finding that different organizations promote different types of technologies. Some tend to focus on promoting specific seed varieties or techniques, rather than more holistic approaches to increasing yields while protecting the environment. Some, particularly NGOs, tend to promote only NRM technologies which they equate with sustainable agriculture. This influences development programs and prevents more widespread implementation of combined approaches that can bring about important synergies. NRM technologies can reduce the use of external inputs in situations where such inputs are excessively used. But this does not imply that optimal external input use is zero when NRM technologies are adopted. Especially in the African small farm sector, where little external inputs are used, a combination of improved NRM techniques, better seeds, and increased levels of other inputs could significantly contribute to sustainable productivity growth. To fully 
realize synergy effects from these technologies there is need to adopt more integrated extension approaches among different information sources.

We also find that environmental gaps contribute more to yield differences than farmers' inefficiencies do, particularly for the less productive regions. Thus policies geared towards narrowing down environmental gaps should be a priority more so for farmers in drier zones and those with low adoption of agricultural technologies. This can be done through provision of enabling infrastructure as well as technologies that help these farmers adapt to their environmental constraints. One effective way of narrowing down these environmental gaps is to help farmers adapt to the higher temperatures through promotion of improved varieties conditioned for such conditions - drought and heat tolerant varieties. However, in spite of the fact that three AEZs have average daily maximum temperature of more than $30^{\circ} \mathrm{C}$ coupled with frequent droughts, adoption rates of these varieties are very low. Several drought tolerant maize varieties have been released recently in SSA thus there is need for extension to promote use of these varieties and for more research to understand reasons for the low adoption rates. Also, for agricultural practices intended to conserve water and reduce soil degradation to result in better yields they will have to be used together with seeds designed to adapt to the dry conditions. Similarly, timely control of diseases such as maize lethal necrosis, provision of proper infrastructure and electricity connection in these rural regions are also necessary to narrow down these environmental gaps.

\subsection{Limitations of the study}

This study is not without limitations. First, whereas agricultural technologies can be associated with various environmental benefits and costs, this study did not assess environmental benefits and costs accruing from the adoption of these technologies. Some of the environmental benefits may include reduction in top soil erosion or improved structure of the soil accruing from technologies such as use of animal manure and crop residue management. Costs may include emission of green-house gases such as methane, carbon dioxide and nitrous oxide or pollution of ground water due to leaching resulting from use of certain technologies. Further studies should capture environmental synergies in addition to the economic ones analyzed in this study. Although these environmental costs and benefits are difficult to monitor and quantify, it would be interesting to see how such synergies unfold when both economic and environmental impacts are considered.

Second, this study uses cross-sectional data hence we might not be able to control for heterogeneity over time. Some results may have been influenced by prevailing weather conditions in the study year. Future studies applying panel data could help reduce unobserved heterogeneity caused by time invariant factors. Third, endogeneity problems hinder us from implying causality for 
some of the results. For instance, in chapter 2, some variables in the MVP, such as access to information, are not fully exogenous in the adoption model. Thus we cannot fully imply causality and hence we interpret the relationships as associations and not cause-effect. This may hinder us from making strong policy recommendations. Similarly, in chapter 3 while assessing the impact of various technologies we apply propensity score matching which is only able to control for selection bias due to observables although there may be bias due to unobservables too. An alternative for this would have been to use an instrumental variable approach but we could not find appropriate instruments for each of seven technologies and the several combinations thereof. Fixed effects models would also have been appropriate but we were limited by the fact that we did not have panel data. Future research where the impact is assessed using a method which addresses both unobservable and observable bias may be relevant for further policy decisions. 


\section{References}

Aakvix, A., 2001. Bounding a matching estimator; the case of a Norwegian training program, Oxford Bulletin of Economics and Statistics 63(1), 115-143.

Abadie, A., Imbens, G. W., 2006. Large Sample Properties of Matching Estimators for Average Treatment Effects. Econometrica, 74(1), 235-267.

Abdulai, A., Tietje, H., 2007. Estimating technical efficiency under unobserved heterogeneity with stochastic frontier models: application to northern German dairy farms. European Review of Agricultural Economics, 34(3), 393-416.

Alene, A. D., Hassan, R. M., 2003. The determinants of farm-level technical efficiency among adopters of improved maize production technology in western Ethiopia. Agrekon, 42(1), 114

Altieri, M. A., Toledo, V. M., 2011. The agroecological revolution in Latin America: rescuing nature, ensuring food sovereignty and empowering peasants. Journal of Peasant Studies 38, 587-612.

Altieri, M.A., 2002. Agroecology: the science of natural resource management for poor farmers in marginal environments. Agriculture, Ecosystems and Environment 93, 1-24.

Amsalu, A., De Graaff, J., 2006. Determinants of adoption and continued use of stone terraces for soil and water conservation in an Ethiopian highland watershed. Ecological Economics 61, 294-302.

Asfaw, S., Shiferaw, B., Simtowe, F., Lipper, L., 2012. Impact of modern agricultural technologies on small holder welfare: Evidence from Tanzania and Ethiopia. Food Policy 37, 283-295.

Aye, G. C., Mungatana, E. D., 2010. Technical efficiency of traditional and hybrid maize farmers in Nigeria: Comparison of alternative approaches. African Journal of Agricultural Research, $5(21), 2909-2917$

Baha, M. R., 2013. Sources of Technical Efficiency Among Smallholder Maize Farmers in Babati District, Tanzania. International Journal of African and Asian Studies, 1, 34-41.

Baker, J., 2000. Evaluating the Impact of Development Projects on Poverty. A Handbook for Practitioners. The World Bank Washington, D.C.

Battese, G. E., Rao, D. P., O'Donnell, C. J., 2004. A metafrontier production function for estimation of technical efficiencies and technology gaps for firms operating under different technologies. Journal of Productivity Analysis, 21(1), 91-103.

Battese, G. E., Rao, D. P., 2002. Technology gap, efficiency, and a stochastic metafrontier function. International Journal of Business and Economics, 1(2), 87-93. 
Battese, G. E., 1997. A note on the estimation of Cobb-Douglas production functions when some explanatory variables have zero values. Journal of Agricultural Economics, 48(1-3), 250252.

Becerril, J., Abdulai, A., 2010. The impact of improved maize varieties on poverty in Mexico: A propensity score matching approach. World Development 38, 1024-1035.

Berazneva, J., 2013. Economic value of crop residues in African smallholder agriculture. Paper presented at the Annual Meeting of the Agricultural and Applied Economics Association, 46 August 2013, Washington, DC

Binam, J. N., Tonye, J., Wandji, N., Nyambi, G., Akoa, M., 2004. Factors affecting the technical efficiency among smallholder farmers in the slash and burn agriculture zone of Cameroon. Food Policy, 29(5), 531-545.

Binswanger, H. P., 1980. Attitudes toward risk: Experimental measurement in rural India. American Journal of Agricultural Economics 62, 395-407.

Borlaug, N., 2007. Feeding a hungry world. Science 318, 359-359.

Byerlee, D., Deininger, K., 2013. Growing resource scarcity and global farmland investment. Annual Review of Resource Economics 5(1), 13-34.

Caliendo, M., Kopeinig, S., 2008. Some practical guidance for the implementation of propensity score matching. Journal of Economic Surveys 22, 31-72.

Cappellari, L., Jenkins, S.P., 2003. Multivariate probit regression using simulated maximum likelihood. Stata Journal 3(3), 278-294.

Chamberlin, J., Jayne, T. S., Headey, D., 2014. Scarcity amidst abundance? Reassessing the potential for cropland expansion in Africa. Food Policy, 48, 51-65.

Chianu, J. N., Chianu, J. N., Mairura, F., 2012. Mineral fertilizers in the farming systems of subSaharan Africa. A review. Agronomy for Sustainable Development, 32(2), 545-566.

Chirwa, E. W., 2007. Sources of technical efficiency among smallholder maize farmers in Southern Malawi. The African Economic Research Consortium.

CIMMYT, 2013. The Drought Tolerant Maize for Africa project. DTMA Brief, September http://dtma.cimmyt.org/index.php/about/background

Coelli, T., 2003. A primer on efficiency measurement for utilities and transport regulators (Vol. 953). World Bank Publications. Washington, D.C.

Dehejia, R.H., Wahba, S., 2002. Propensity score matching methods for non-experimental causal studies. Review of Economics and Statistics 84(1), 151-161. 
Deininger, K. W., Byerlee, D., Lindsay, J., Norton, A., Selod, H., Stickler, M., 2011. Rising global interest in farmland: can it yield sustainable and equitable benefits? World Bank Publications. Washington, D.C.

Delgado, J.A., Groffman, P.M., Nearing, M.A., Goddard, T., Reicosky, D., Lal, R., Kitchen, N.R., Rice, C.W., Towery, D., Salon, P., 2011. Conservation practices to mitigate and adapt to climate change. Journal of Soil and Water Conservation, 66(4), 118A-129A.

De Groote, H., 1996. Optimal survey design in rural data collection in developing countries. Quarterly Journal of International Agriculture 35(2), 163-175.

De Janvry, A., Sadoulet, E., 2001. World poverty and the role of agricultural technology: Direct and indirect effects. Journal of Development Studies 38(4), 1-26.

De Schutter, O., 2010. Report submitted by the Special Rapporteur on the right to food. A/HRC/16/49, United Nations General Assembly, New York.

De Schutter, O., Vanloqueren, G., 2011. The new green revolution: How twenty-first-century science can feed the world. Solutions 2(4), 33-44.

DFID, 2009. Building Our Common Future in Sub-Saharan Africa. Department for International Development, London

Di Falco, S., Veronesi, M., 2013. How can African agriculture adapt to climate change? A counterfactual analysis from Ethiopia. Land Economics 89 (4), 743-766.

Doomik, J. 2007. Object-Oriented Matrix Programming Using Ox, 3rd ed. London: Timberlake Consultants Press and Oxford.

Dorfman, J.H., 1996. Modelling multiple adoption decisions in a joint framework. American Journal of Agricultural Economics 78, 547-557.

Evenson, R.E., Gollin D., 2003. Assessing the impact of the green revolution, 1960-2000. Science $300,758-762$.

FAO, 2016. Save and grow in practice. Maize, rice and wheat. A guide to sustainable cereal production. Rome, Food and Agriculture Organization of the United Nations.

FAO, 2015. Status of the World's Soil Resources. Rome, Italy: Food and Agriculture Organization of the United Nations.

FAO, 2013. Climate-smart agriculture Sourcebook. FAO, Rome.

FAO, 2011a. Save and grow: a policymaker's guide to sustainable intensification of smallholder crop production. Rome, Food and Agriculture Organization of the United Nations.

FAO, 2011b. The State of Food and Agriculture 2010-2011. Women in Agriculture, Closing the Gender Gap for Development. FAO, Rome.

FAO, 2009. Global agriculture towards 2050. How to feed the world in 2050. FAO, Rome. 
FAOSTAT, 2015. Statistical databases and data-sets of the Food and Agriculture Organization of the United Nations. http://faostat.fao.org/site/291/default.aspx Accessed on 24th Aug 2015.

FAOSTAT, 2012. Crop production statistics. Food and Agriculture Organization: Rome. http://faostat.fao.org/site/291/default.aspx

FAO and Biodiversity International, 2007. SARD and Agroecology. Sustainable Agriculture and Rural Development Policy Brief 11, FAO and Biodiversity International, Rome.

Feder, G., Just, R.E., Zilberman, D., 1985. Adoption of agricultural innovations in developing countries: A survey. Economic Development and Cultural Change 33(2), 255-298.

Fisher, M., Abate, T., Lunduka, R.W., Asnake, W., Alemayehu, Y., Madulu, R.B., 2015. Drought tolerant maize for farmer adaptation to drought in sub-Saharan Africa: Determinants of adoption in eastern and southern Africa. Climatic Change, 133(2), 283-299.

Foresight, 2011.The Future of Food and Farming. The Government Office for Science, London.

Garnett, T., Appleby, M. C., Balmford, A., Bateman, I. J., Benton, T. G., Bloomer, P., Burlingame, B., Dawkins, M., Dolan, L., Fraser, D., Herrero, M., Hoffmann, I., Smith, P., Thornton, P.K., Toulmin, C., Vermeulen, S.J., Godfray, H. C. J., 2013. Sustainable intensification in agriculture: premises and policies. Science, 341(6141), 33-34.

Gebremedhin B., Swinton, S.M., 2003. Investment in soil conservation in northern Ethiopia: the role of land tenure security and public programs. Agricultural Economics 29, 69-84.

Geta, E., Bogale, A., Kassa, B., Elias, E., 2013. Productivity and efficiency analysis of smallholder maize producers in Southern Ethiopia. Journal of Human Ecology, 41(1), 67-75.

Geweke, J., Keane, M., Runkle, D., 1997. Statistical inference in the multinomial multiperiod probit model. Journal of Econometrics 80, 125- 165.

Gibbon, D., Dixon, J., Flores Velazquez, D., 2007. Beyond drought tolerant maize: study of additional priorities in maize. Report to Generation Challenge Program. Impacts, Targeting and Assessment Unit. CIMMYT.

Giller, K.E., Witter, E., Corbeels, M., Tittonell, P., 2009. Conservation agriculture and smallholder farming in Africa: The heretics' view. Field Crops Research 114, 23-34.

Godfray, H. C. J., Beddington, J. R., Crute, I. R., Haddad, L., Lawrence, D., Muir, J. F., Pretty, J., Robinson, S., Thomas, S.M., Toulmin, C. , 2010 . Food security: the challenge of feeding 9 billion people. Science, 327(5967), 812-818.

Gollin, D., Morris, M., Byerlee, D., 2005. Technology adoption in intensive post-green revolution systems. American Journal of Agricultural Economics 87(5), 1310-1316.

Greenpeace Africa, 2015. Fostering economic resilience: The financial benefits of ecological farming in Kenya and Malawi. Greenpeace Africa, Johannesburg. 
Hajivassiliou, V., McFadden, D., Ruud, P., 1996. Simulation of multivariate normal rectangle probabilities and their derivatives: Theoretical and computational results. Journal of Econometrics 72, 85-134.

Hassan, R.M., ed., 1998. Maize Technology Development and Transfer: A GIS Application for Research Planning in Kenya. CAB International, Wallingford.

Heckman, J., Vytlacil, E., 2005. Structural equations, treatment effects, and econometric policy evaluation. Econometrica 73, 669-738

Hertel, T., 2015. The challenges of sustainably feeding a growing planet. Food Security 7, 185-198.

Hintze, L.H., Renkow, M., Sain, G., 2003.Variety characteristics and maize adoption in Honduras. Journal of Agricultural Economics 29, 307-317.

Hobbs, P.R., Sayre, K., Gupta, R., 2008. The role of conservation agriculture in sustainable agriculture. Philosophical Transactions of the Royal Society B 363, 543-555.

Holt-Gimenez, E., Shattuck, A., Altieri, M., Herren, H., Gliessman, S., 2012. We already grow enough food for 10 billion people... and still can't end hunger. Journal of Sustainable Agriculture 36, 595-598.

IAASTD, 2009. Executive Summary of the Synthesis Report. International Assessment of Agricultural Knowledge, Science and Technology for Development, Washington, DC.

Imbens, G.W., Woodridge, J.M., 2009. Recent developments in the econometrics of program evaluation. Journal of Economic Literature 47(1), 5-86.

Jaetzold, R., Schmidt, H., Hornetz, B., Shisanya, C., 2005. Farm Management Handbook of Kenya; Second Edition. Ministry of Agriculture, Nairobi.

Jhamtani, H., 2010. The green revolution in Asia: lessons for Africa. FAO Paper.

Juma, C., 2011. The New Harvest: Agricultural Innovation in Africa, Oxford University Press, Oxford.

Kabunga, N.S., Dubois, T., Qaim, M., 2014. Impact of tissue culture banana technology on farm household income and food security in Kenya. Food Policy 45, 25-34.

Kabunga, N.S., Dubois, T., Qaim, M., 2012. Heterogeneous information exposure and technology adoption: The case of tissue culture bananas in Kenya. Agricultural Economics 43(5), 473486.

Kassie, M., Teklewold, H., Jaleta, M., Marenya, P., Erenstein, O., 2015a. Understanding the adoption of a portfolio of sustainable intensification practices in eastern and southern Africa. Land Use Policy 42, 400-411. 
Kassie, M., Teklewold, H., Marenya, P., Jaleta, M., Erenstein, O., 2015b. Production risks and food security under alternative technology choices in Malawi: application of a multinomial endogenous switching regression. Journal of Agricultural Economics 66, 640-659.

Kassie, M., Jaleta, M., Shiferaw, B., Mmbando, F., Mekuria, M., 2013. Adoption of interrelated sustainable agricultural practices in smallholder systems: Evidence from rural Tanzania. Technological Forecasting and Social Change 80, 525-540.

Kassie, M., Zikhali, P., Pender, J., Kohlin, G., 2010. The economics of sustainable land management practices in the Ethiopian highlands. Journal of Agricultural Economics 61, 605-627.

Kathage, J., Kassie, M., Shiferaw, B., Qaim, M., 2016. Big constraints or small returns? Explaining nonadoption of hybrid maize in Tanzania. Applied Economic Perspectives and Policy 38, 113-131.

Kirimi, L., Sitko, N., Jayne, T.S., Karin, F., Muyanga, M., Sheahan, M., Flock, J., Bor, G., 2011. A farm gate-to-consumer value chain analysis of Kenya's maize marketing system. Tegemeo Institute of Agricultural Policy and Development Working Paper, (44).

KNBS, 2010. Population Census. Kenya National Bureau of Statistics, Nairobi.

Lambrecht, I., Vanlauwe, B., Merckx, R., Maertens, M., 2014. Understanding the process of agricultural technology adoption: Mineral fertilizer in Eastern DR Congo. World Development 59, 132-146.

Lobell, D. B., Bänziger, M., Magorokosho, C., Vivek, B. (2011). Nonlinear heat effects on African maize as evidenced by historical yield trials. Nature Climate Change, 1(1), 42-45.

Lunt, M., 2014. Selecting an appropriate caliper can be essential for achieving good balance with propensity score matching. American Journal of Epidemiology 179(2), 226-235.

Lee, D.R., 2005. Agricultural sustainability and technology adoption: Issues and policies for developing countries. American Journal of Agricultural Economics 87(5), 1325-1334.

Lesk, C., Rowhani, P., Ramankutty, N., 2016. Influence of extreme weather disasters on global crop production. Nature, 529, 84-87.

Magnan, N., Larson, D. M., Taylor, J. E., 2012. Stuck on stubble? The non-market value of agricultural byproducts for diversified farmers in Morocco. American Journal of Agricultural Economics 94, 1055-1069.

Marenya, P. P., Barrett, C. B., 2009. Soil quality and fertilizer use rates among smallholder farmers in western Kenya. Agricultural Economics, 40(5), 561-572. 
Marenya, P.P., Barrett, C.B., 2007. Household level determinants of adoption of improved natural resources management practices among smallholder farmers in western Kenya. Food Policy $32,515-536$.

Mathenge, M.K., Smale, M., Olwande, J., 2014. The impacts of hybrid maize on the welfare of farming households in Kenya. Food Policy 44, 262-171.

Mendola, M., 2007. Agricultural technology adoption and poverty reduction: A propensity score matching analysis for rural Bangladesh. Food Policy 32, 372-393.

Minten, B., Barrett, C.B., 2008. Agricultural technology, productivity, and poverty in Madagascar. World Development, 36(5), 797-822.

Mohajan, H.K., 2014. Food and Nutrition Scenario of Kenya. American Journal of Food and Nutrition, 2(2), 28-38.

Morris, M., Kelly, V.A., Kopicki, R. J., Byerlee, D., 2007. Fertilizer use in African agriculture. Lessons learned and good practice guidelines. The World Bank.

Musaba, E., Bwacha, I., 2014. Technical Efficiency of Small Scale Maize Production in Masaiti District, Zambia: A Stochastic Frontier Approach. Journal of Economics and Sustainable Development, 5(4), 104-111.

Muyanga, M., Jayne, T. S., 2014. Effects of rising rural population density on smallholder agriculture in Kenya. Food Policy, 48, 98-113.

Nkonya, E., Koo, J., Marenya, P., Licker, R., 2011. Land degradation: land under pressure. Global food policy report. IFPRI.

Nkonya, E., Schroeder, T., Norman, D., 1997. Factors affecting adoption of improved maize seed and fertilizer in Northern Tanzania. Journal of Agricultural Economics 48(1), 1-12.

Noltze, M., Schwarze, S., Qaim, M., 2013. Impacts of natural resource management technologies on agricultural yield and household income: The system of rice intensification in Timor Leste. Ecological Economics 85(1), 59-68.

Noltze, M., Schwarze, S., Qaim, M., 2012. Understanding the adoption of system technologies in smallholder agriculture: The system of rice intensification (SRI) in Timor Leste. Agricultural Systems 108, 64-73.

O’Donnell, C.J., Rao, D.P. and Battese, G.E., 2008. Metafrontier frameworks for the study of firmlevel efficiencies and technology ratios. Empirical Economics, 34(2), 231-255.

Otieno, D. J., Hyubbard, L., Ruto, E., 2014. Assessment of technical efficiency and its determinants in beef cattle production in Kenya. Journal of Development and Agricultural Economics, 6(6), 267-278. 
Oxfam, 2011. Who Will Feed the World? The Production Challenge. Oxfam Research Report, Oxfam International, Oxford, UK.

Paarlberg, R., 2008. Starved for Science: How Biotechnology is Being Kept out of Africa. Harvard University Press, Cambridge, MA.

Pender, J., Gebremedhin, B., 2007. Determinants of agricultural and land management practices and impacts of crop production and household income in the highlands of Tigray Ethiopia. Journal of African Economies 3, 395-450.

Pingali, P., 2007. Agricultural growth and economic development: A view through the globalization lens. Agricultural Economics 37(S1), 1-12.

Population Reference Bureau, Data Finder, 2015. http://www.prb.org

Pretty, J., Toulmin, C., Williams, S., 2011. Sustainable intensification in African agriculture. International Journal of Agricultural Sustainability 9(1), 5-24.

Rao, E. J., Brümmer, B., Qaim, M., 2012. Farmer participation in supermarket channels, production technology, and efficiency: the case of vegetables in Kenya. American Journal of Agricultural Economics, 94(4), 891-912.

Ravallion, M., 2001. The mystery of the vanishing benefits: an introduction to impact evaluation, The World Bank Economic Review 15(1), 115-140.

Ray, D.K., Mueller, N.D., West, P.C., Foley, J.A., 2013. Yield trends are insufficient to double global crop production by 2050. PLoS ONE 8(6), e66428.

Reij, C. P., Smaling, E.M.A., 2008. Analyzing successes in agriculture and land management in Sub-Saharan Africa: Is macro-level gloom obscuring positive micro-level change? Land Use Policy, 25(3), 410-420.

Rosenbaum, P., Rubin, D. B., 1983. The Central Role of the Propensity Score in Observational Studies for Causal Effects. Biometrika, 70, 41-55.

Royal Society, 2009. Reaping the Benefits: Science and the Sustainable Intensification of Global Agriculture. Royal Society, London

Ryan, J., Rashid, A., Torrent, J., Kwong Yau, S., Ibrikci, H., Sommer, R., Bulent Erenoglu, E., 2013. Micronutrient constraints to crop production in the middle East-West Asia Region. significance, research, and management. Advances in Agronomy 122, 1-84.

Sanchez P. A., 2002. Soil fertility and hunger in Africa. Science 295, 2019-2020.

Sheahan, M., Black, R., Jayne, T. S., 2013. Are Kenyan farmers under-utilizing fertilizer? Implications for input intensification strategies and research. Food Policy, 41, 39-52. 
Sherlund, S.M., Barrett, C.B. and Adesina, A.A., 2002. Smallholder technical efficiency controlling for environmental production conditions. Journal of Development Economics, 69(1), 85101.

Shiferaw, B., Tesfaye, K., Kassie, M., Abate, T., Prasanna, B. M., Menkir, A., 2014a. Managing vulnerability to drought and enhancing livelihood resilience in sub-Saharan Africa: Technological, institutional and policy options. Weather and Climate Extremes, 3, 67-79.

Shiferaw, B., Kassie, M., Jaleta, M., Yirga, C., 2014b. Adoption of improved wheat varieties and impacts on household food security in Ethiopia. Food Policy 44, 272-284.

Smale, M., Olwande, J., 2014. Demand for maize hybrids and hybrid change on smallholder farms in Kenya. Agricultural Economics 45, 409-420.

Stevenson, J. R., Villoria, N., Byerlee, D., Kelley, T., Maredia, M., 2013. Green Revolution research saved an estimated 18 to 27 million hectares from being brought into agricultural production. Proceedings of the National Academy of Sciences USA 110, 8363-8368.

Stokstad, E., 2008. Dueling visions for a hungry world. Science 319, 1474-1476.

Tchale, H., Sauer, J., 2007. The efficiency of maize farming in Malawi: A bootstrapped translog frontier. Cahiers d'économie et sociologie rurales, 82-83.

Tesfaye, K., Gbegbelegbe, S., Cairns, J.E., Shiferaw, B., Prasanna, B.M., Sonder, K., Boote, K., Makumbi, D., Robertson, R., 2015. Maize systems under climate change in sub-Saharan Africa: Potential impacts on production and food security. International Journal of Climate Change Strategies and Management, 7(3), 247-271.

The Montpellier panel, 2014. No ordinary matter: conserving, restoring and enhancing Africa's soils. London

The Montpellier panel, 2013. Sustainable intensification: A new paradigm for African agriculture. London

Train, K., 2002. Discrete Choice Methods with Simulation. Cambridge University Press, Cambridge.

Tubiello, F.N., Salvatore, M., Cóndor Golec, R.D., Ferrara, A.F., Rossi, S., Biancalani, R., Federici, S., Jacobs, H., Flammini, A., 2014. Agriculture, forestry and other land use emissions by sources and removals by sinks.1990-2011 Analysis. Statistics Division, Food and Agriculture Organization, Rome.

Valbuena, D., Erenstein, O., Tui, S. H. K., Abdoulaye, T., Claessens, L., Duncan, A. J., Gérald, B., Rufino, M.C., Teufel, N., van Rooyen, A., van Wijk, M. T., 2012. Conservation agriculture in mixed crop-livestock systems: Scoping crop residue trade-offs in SubSaharan Africa and South Asia. Field Crops Research, 132, 175-184. 
Via Campesina, 2015. The International's Peasant Voice. http://viacampesina.org (retrieved on 14 July 2015).

Villano, R., Mehrabi Boshrabadi, H., Fleming, E., 2010. When is metafrontier analysis appropriate? An example of varietal differences in Pistachio production in Iran. Journal of Agricultural Science and Technology, 12, 379-389.

Wainaina, P., Tongruksawattana, S., Qaim, M., 2014. Tradeoffs and complementarities in the adoption of improved seeds, fertilizer, and natural resource management technologies in Kenya. GlobalFood Discussion Paper 51, Georg-August-University of Goettingen, Goettingen.

Wangai, A.W., Redinbaugh, M.G., Kinyua, Z.M., Miano, D.W., Leley, P.K., Kasina, M., Mahuku, G., Scheets, K., Jeffers, D., 2014. First report of maize chlorotic mottle virus and maize lethal necrosis in Kenya. Phytopathology, 104(12), 1360-1369.

Winters, P., De Janvry, A., Saudolet, E., Stamoulis, K., 1998. The role of agriculture in economic development: Visible and invisible surplus transfers. Journal of Development Studies 345, 71-97.

Wollni, M., Brümmer, B., 2012. Productive efficiency of specialty and conventional coffee farmers in Costa Rica: Accounting for technological heterogeneity and self-selection. Food Policy, 37(1), 67-76.

Wollni, M., Lee, D.R., Janice L.T., 2010. Conservation agriculture, organic marketing, and collective action in the Honduran hillsides. Agricultural Economics 41, 373-384.

World Bank, 2007. World Development Report 2008: Agriculture for Development. World Bank, Washington, DC 


\section{Appendix B}

Appendix B1: Map of Kenya, showing the study areas by AEZ

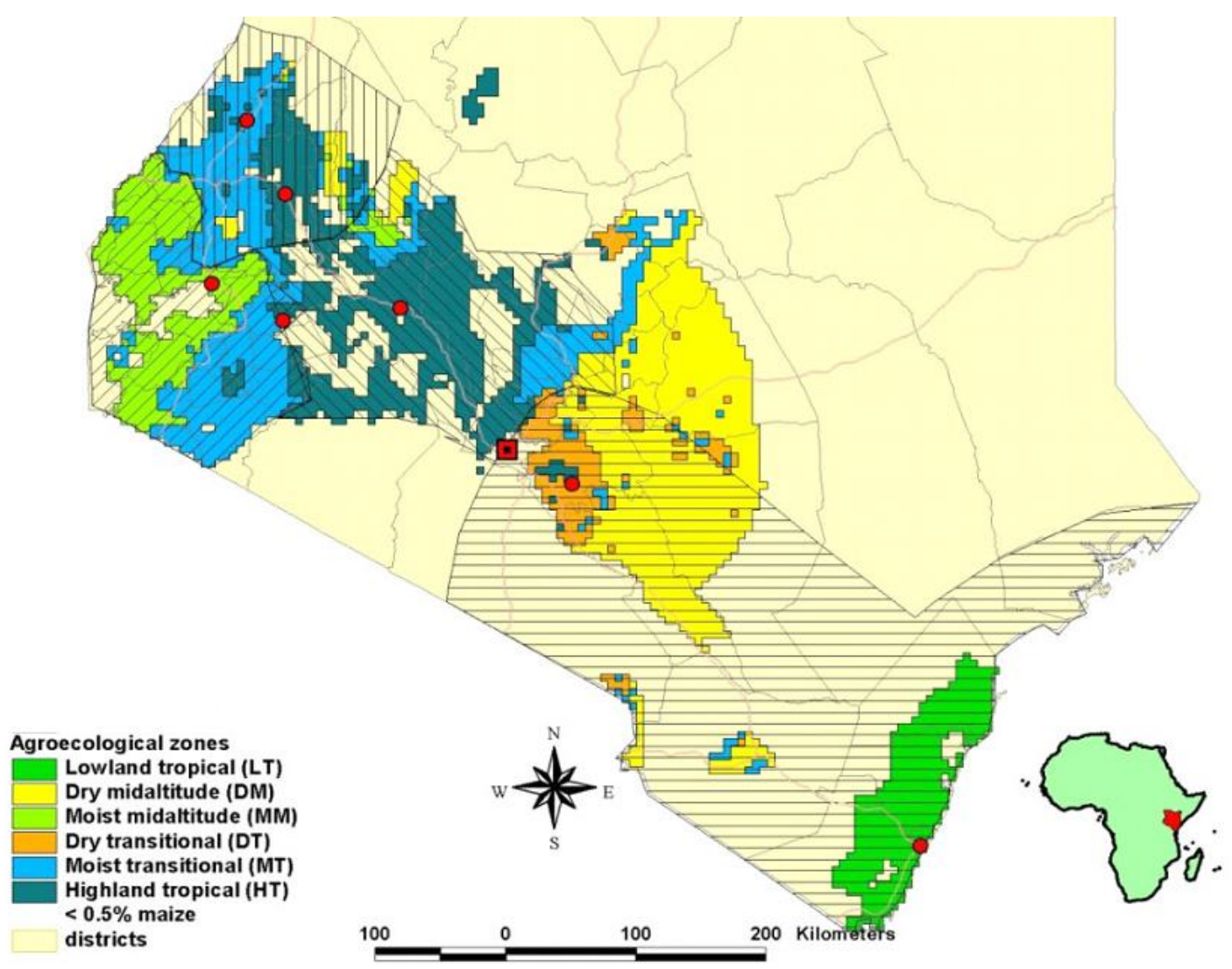


Appendix B2: List of surveyed sublocations by AEZs

\begin{tabular}{|c|c|c|c|c|c|}
\hline Lowland tropics & $\begin{array}{l}\text { Dry mid } \\
\text { altitude }\end{array}$ & $\begin{array}{l}\text { Dry } \\
\text { transitional }\end{array}$ & $\begin{array}{l}\text { Moist } \\
\text { transitional }\end{array}$ & $\begin{array}{l}\text { High } \\
\text { tropics }\end{array}$ & Moist mid altitude \\
\hline Bongwe & Athi River North & Iveti & Boikanga & Bartera & Aуweyo \\
\hline Dabaso & Katangi & Kangii & Buyangu & Gatei & Bala \\
\hline Ganze/ Tsangalaweni & Kathungi & Kangungi & Chepwostuiyet & Gikingi & Bar B \\
\hline Gongoni / Vipingo & Kawongo & Kasinga & Egetonto & Kachibora & Budonga \\
\hline Kikoma/ Mbwaka & Kithimani & Kikambuani & Embaro & Kanyenyaini & Central Kawere Rateng \\
\hline Kinondo & Kivaa & Kilala & Emesa & Kapkechir & Gen Nam \\
\hline Kundutsi & Mangelete & Kivutini & Gacharage & Karandi & Kachuth \\
\hline Mazeras & Mbuvu & Kyamuoso & Gesangero & Kipkeigei & Kaila \\
\hline Mere & Muusini & Maiuni & Kahuti & Kondabilet & Kakapel \\
\hline Mkondoni & Mwatati & Mathatani & Kapchemogung & Kyogong & Kakumu \\
\hline Mnyenzeni & Mwingi & Mbee & Kapchumbe & Lolkinyei & Kambare \\
\hline Mzizima & Nduluku & Misakwani & Kapng'etuny & Mabroukie & Kasugunga Central \\
\hline Tiribe & Ngaaie & Miumbuni & Kapomboi & Melwa & Kobuya West \\
\hline Vyemani & Ngungi & Muthwani & Karai & Merewet & Lunao \\
\hline \multirow[t]{16}{*}{ Ziani } & Ngwani & Nduu & Kaurine & Moricho & Malanga \\
\hline & Nziu & Utangwa & Kinyaga & Olorropil & Masumbi \\
\hline & Utithi & Uthiuni & Kiribwet & Silibwet & Namaduru \\
\hline & Wathini & & Maitharui & Tetu & Nyagoko \\
\hline & & & Masana & Tulaga & Ogwedhi \\
\hline & & & Matulo & Tulwet & Wamono \\
\hline & & & Mentera & & \\
\hline & & & Mukore & & \\
\hline & & & Mwera & & \\
\hline & & & Njuku & & \\
\hline & & & Nyakongo & & \\
\hline & & & Nyangoge & & \\
\hline & & & Owaga & & \\
\hline & & & Rwanderi & & \\
\hline & & & Tongaren & & \\
\hline & & & Vinyenya & & \\
\hline
\end{tabular}


Appendix B3: Household Questionnaire for Kenya - 2012/2013

MODULE 1: IDENTIFICATION AND INTERVIEW BACKGROUND

\begin{tabular}{|c|c|c|c|}
\hline & Zone & Sub-location & HH No \\
\hline HHID & & & \\
\hline
\end{tabular}

5-digit code: zone (1digit), sub-location (02 digit) and household number (2 digits)

\begin{tabular}{|l|l|l|l|l|}
\hline & DD/MM/YYYY & Name & Code \\
\hline Date $1^{\text {st }}$ visit & & Interviewer & & \\
\hline Time started $24 \mathrm{hr}$ & & Time ended 24 hr & & \\
\hline Date checked & & Checked by: & & \\
\hline Date entered & & Entered by: & & \\
\hline
\end{tabular}

\begin{tabular}{|l|l|l|}
\hline Variable & Response & $\begin{array}{l}\text { Code } \\
\text { (provided) }\end{array}$ \\
\hline AEZ & & \\
\hline County & & \\
\hline District & & \\
\hline Division & & \\
\hline Location & & \\
\hline Sub-location & & \\
\hline Village & & \\
\hline GPS readings & & \\
\hline Elevation (meters) & \\
\hline $\begin{array}{l}\text { Latitude in decimal degrees (dd.dddd) } \\
\text { S/N }\end{array}$ & & \\
\hline $\begin{array}{l}\text { Longitude in decimal degrees (dd.ddddd) } \\
\text { E/W }\end{array}$ & & \\
\hline Waypoint number save HHID & & \\
\hline GPS unit number (as labelled) & & \\
\hline
\end{tabular}

\begin{tabular}{|l|l|}
\hline Respondent's name & \\
\hline Mobile phone No. & \\
\hline Tribe & \\
\hline Respondent's years of farming experience & \\
\hline
\end{tabular}

\section{General remarks :}


MODULE 2: CURRENT HOUSEHOLD COMPOSITION AND CHARACTERISTICS

Household members =Persons who live together and eat together from the same pot (share food), including hired labour, students and spouse living and working in another location but excluding visitors

\begin{tabular}{|c|c|c|c|c|c|c|c|c|c|c|c|}
\hline \multirow{2}{*}{ 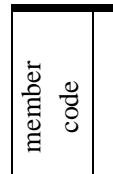 } & \multirow{2}{*}{\multicolumn{2}{|c|}{$\begin{array}{l}\text { Name of household member } \\
\text { (start with respondent) }\end{array}$}} & \multirow{2}{*}{$\begin{array}{c}\text { Sex } \\
\text { Codes } \\
\text { A }\end{array}$} & \multirow{2}{*}{$\begin{array}{c}\text { Marital } \\
\text { status } \\
\text { Codes B }\end{array}$} & \multirow{2}{*}{$\begin{array}{c}\text { Age } \\
\text { (years) }\end{array}$} & \multirow{2}{*}{$\begin{array}{l}\text { Education } \\
\text { (years) } \\
\text { Codes C }\end{array}$} & \multirow{2}{*}{$\begin{array}{c}\text { Relation to } \\
\text { HH Head } \\
\text { Codes D }\end{array}$} & \multirow{2}{*}{$\begin{array}{l}\text { Number of months member } \\
\text { has lived in the household } \\
\text { in the last } 12 \text { months }\end{array}$} & \multicolumn{2}{|c|}{$\begin{array}{c}\text { Occupation } \\
\text { Codes } \mathbf{E} \text { (time spent) }\end{array}$} & \multirow{2}{*}{$\begin{array}{l}\text { Household farm } \\
\text { labour contribution } \\
\text { Codes F }\end{array}$} \\
\hline & & & & & & & & & Main & Secondary & \\
\hline \multicolumn{12}{|c|}{1} \\
\hline \multicolumn{12}{|l|}{2} \\
\hline \multicolumn{12}{|l|}{3} \\
\hline \multicolumn{12}{|l|}{4} \\
\hline \multicolumn{12}{|l|}{5} \\
\hline \multicolumn{12}{|l|}{6} \\
\hline \multicolumn{12}{|l|}{7} \\
\hline \multicolumn{12}{|l|}{8} \\
\hline \multicolumn{12}{|l|}{9} \\
\hline \multicolumn{12}{|l|}{10} \\
\hline \multicolumn{12}{|l|}{11} \\
\hline \multicolumn{12}{|l|}{12} \\
\hline $\begin{array}{l}\text { Codes A } \\
\text { 0. Femal } \\
\text { 1. Male }\end{array}$ & $\begin{array}{l}\text { 1. Married living with spouse } \\
\text { 2. Married but spouse away } \\
\text { 3. Divorced/separated } \\
\text { 4. Widow/widower } \\
\text { 5. Single } \\
\text { 6. Other, specify...... }\end{array}$ & $\begin{array}{l}\text { Codes Cone/llliterate } \\
\text { 1. Adult education o } \\
\text { year of education } \\
\text { * Give other educati } \\
\text { in years }\end{array}$ & & $\begin{array}{l}\text { Codes D } \\
\text { 1.Household he } \\
\text { 2. Spouse } \\
\text { 3. Son/daughter } \\
\text { 4. Son/daughter } \\
\text { 5. Parent } \\
\text { 6. Broth/sister } \\
\text { 7. Broth/sister }\end{array}$ & $\begin{array}{l}\text { In law } \\
\text {-law }\end{array}$ & $\begin{array}{l}\text { 8. Mother/'father in } \\
\text { 9. Grand child } \\
\text { 10. grand parent } \\
\text { 11. Aunt/Uncle } \\
\text { 12. Nephew/niece } \\
\text { 13. Hired worker } \\
\text { 14. Other, specify... }\end{array}$ & & $\begin{array}{l}\text { Codes } \\
\text { 1. Farming (crop + livesto } \\
\text { 2. Salaried employment } \\
\text { 3. Self-employed off-farm } \\
\text { 4. Casual labourer on-farn } \\
\text { 5. Casual labourer off-farn }\end{array}$ & & $\begin{array}{l}\text { 6. School/college child } \\
\text { 7. Non-school child } \\
\text { 8. Herding } \\
\text { 9. Household chores. } \\
\text { 10.Other specify, }\end{array}$ & $\begin{array}{l}\text { Codes } \mathbf{F} \\
\text { 1. } 100 \% \\
2.75 \% \\
3.50 \% \\
4.25 \% \\
\text { 5. } 10 \% \\
\text { 6. Not a worker }\end{array}$ \\
\hline
\end{tabular}


MODULE 4: SOCIAL CAPITAL AND NETWORKING

Does any member of the household currently belong to any group? 1=Yes $\mathbf{0 = N o}$; If Yes, fill the table below

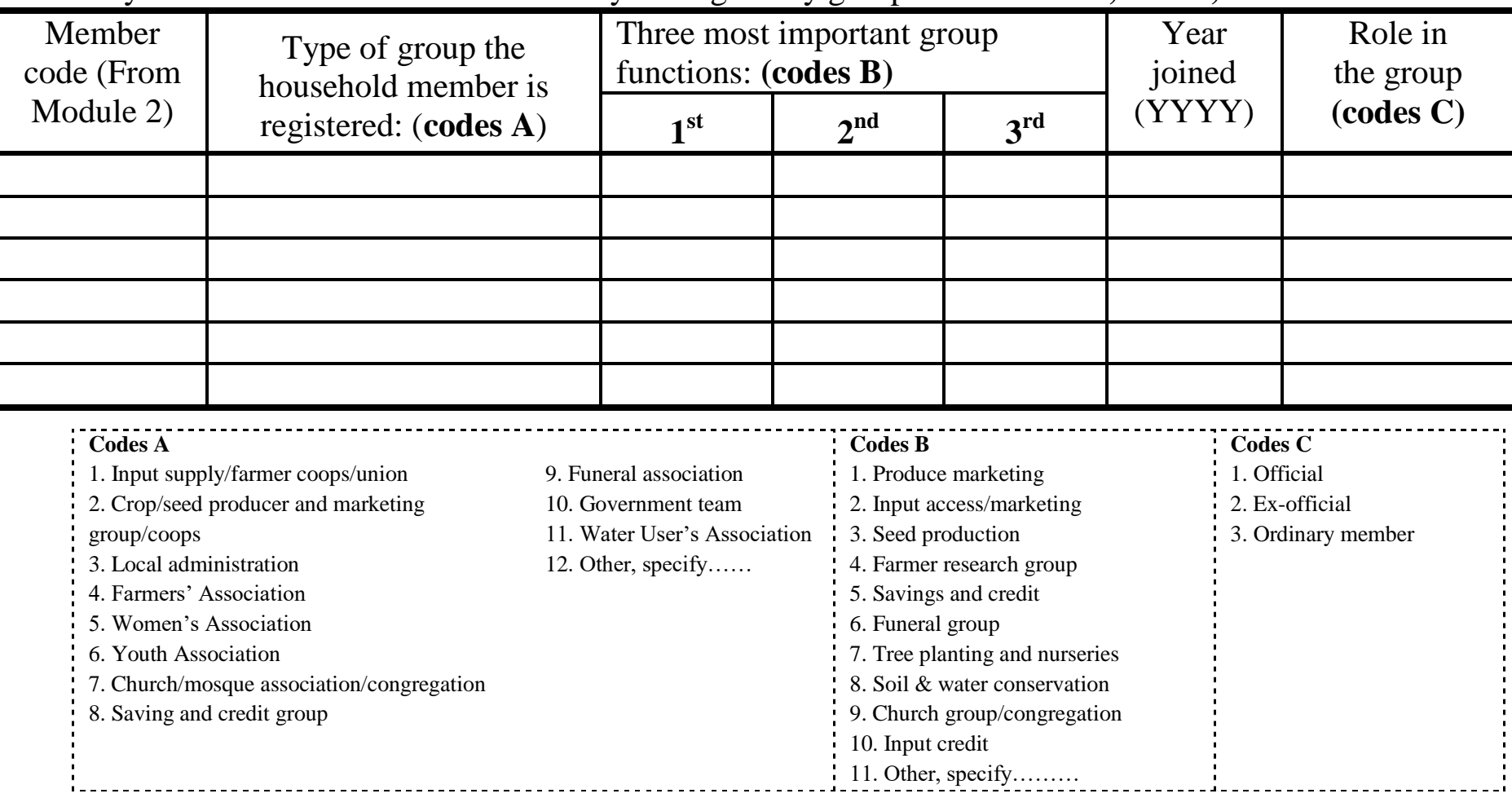

\section{MODULE 5: LAND HOLDING (ACRES) DURING THE 2011/2012 CROPPING YEAR}

\begin{tabular}{|l|l|l|l|l|}
\hline \multirow{2}{*}{ Land category } & \multicolumn{2}{|c|}{ Oct-Nov rain season (2011) } & \multicolumn{2}{c|}{ Mar-Apr rain season (2012) } \\
\cline { 2 - 5 } & $\begin{array}{c}\text { Cultivated } \\
\text { (annual + } \\
\text { permanent crops) }\end{array}$ & $\begin{array}{c}\text { Uncultivated (e.g. } \\
\text { grazing, } \\
\text { homestead etc) }\end{array}$ & $\begin{array}{c}\text { Cultivated } \\
\text { (annual + } \\
\text { permanent } \\
\text { crops) }\end{array}$ & $\begin{array}{c}\text { Uncultivated } \\
\text { (e.g. grazing, } \\
\text { homestead etc) }\end{array}$ \\
\hline 1. Own land used & & & & \\
\hline 2. Rented in land & & & & \\
\hline 3. Rented out land & & & & \\
\hline 4. Borrowed in land & & & & \\
\hline 5. Borrowed out land & & & & \\
\hline
\end{tabular}

\section{MODULE 6: HOUSING}

\begin{tabular}{|c|c|c|c|c|c|}
\hline & Issue & \multicolumn{3}{|l|}{ Codes } & Response \\
\hline 1 & $\begin{array}{l}\text { What is the roofing material } \\
\text { of the main house? }\end{array}$ & \multicolumn{3}{|c|}{$\begin{array}{l}1=\text { Grass/makuti } 2=\text { Iron sheets } 3=\text { Tiles } \quad 4=\text { other specify } \\
(\ldots \ldots \ldots \ldots \ldots \ldots\end{array}$} & \\
\hline 2 & $\begin{array}{l}\text { What is the main wall } \\
\text { material of the main house? }\end{array}$ & 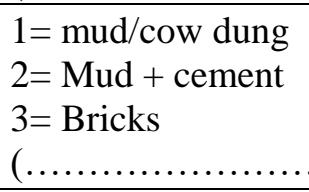 & $\begin{aligned} & 4=\text { Stones } \\
& 5=\text { wood } \\
& 6=\text { other specify } \\
& \ldots \ldots \ldots \ldots \ldots \ldots \ldots \ldots \ldots \ldots \ldots\end{aligned}$ & $\ldots \ldots \ldots \ldots \ldots \ldots)$ & \\
\hline 3 & $\begin{array}{l}\text { What is the floor material of } \\
\text { the main house? }\end{array}$ & $\begin{array}{l}1=\text { Earth } \\
2=\text { Cement } \\
3=\text { Wood }\end{array}$ & $\begin{array}{l}4=\text { Tiles } \\
5=\text { Other specify }\end{array}$ & & \\
\hline 4 & Main source of drinking water & $\begin{array}{l}1=\text { Piped } \\
2=\text { Stream } \\
3=\text { Well } \\
4=\text { River } \\
5=\text { Rain water harvest }\end{array}$ & $\begin{array}{l}6=\text { Borehole protected (private) } \\
7=\text { Borehole unprotected (private) } \\
8=\text { Borehole protected (shared) } \\
9=\text { Borehole unprotected (shared) } \\
10=\text { Lake }\end{array}$ & $\begin{array}{l}11=\text { Ponds/dams } \\
12=\text { Spring }\end{array}$ & \\
\hline
\end{tabular}


MODULE 7: MARKET AND DISTANCE TO SERVICES

Issue

\begin{tabular}{c|c|c}
$\mathrm{km}$ & $\begin{array}{c}\text { Walking } \\
\text { (minutes }\end{array}$ & $\begin{array}{c}\text { Cost } \\
\text { (KES) }\end{array}$
\end{tabular}

$1 \quad$ Distance to the village market from residence

2 What means of transport do you use mainly to get to the village market Refer to codes question 13 above (Code A below)

3 Average single trip transport cost per person to village market using this means of transport (KSh/person)

4 Distance to the nearest main market from residence

5 Distance to the nearest source of inputs (seeds, fertilizers) from residence

6 Distance to the nearest farmer cooperative from residence

7 Distance to the nearest agricultural extension office from residence

8 Distance to the nearest health centre from residence 13 Others specify ...........

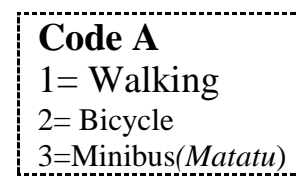

\section{MODULE 8: HOUSEHOLD ASSETS}

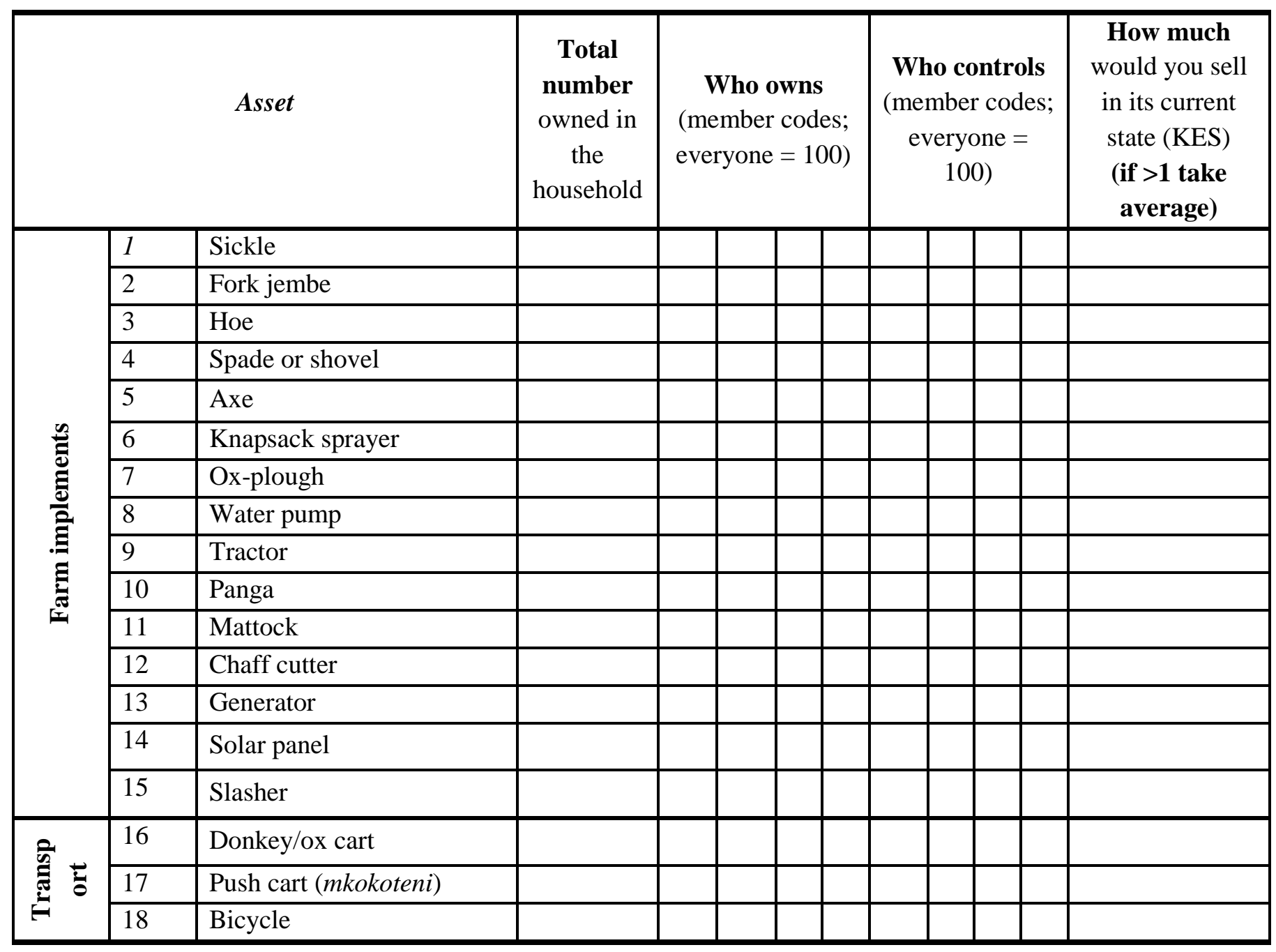




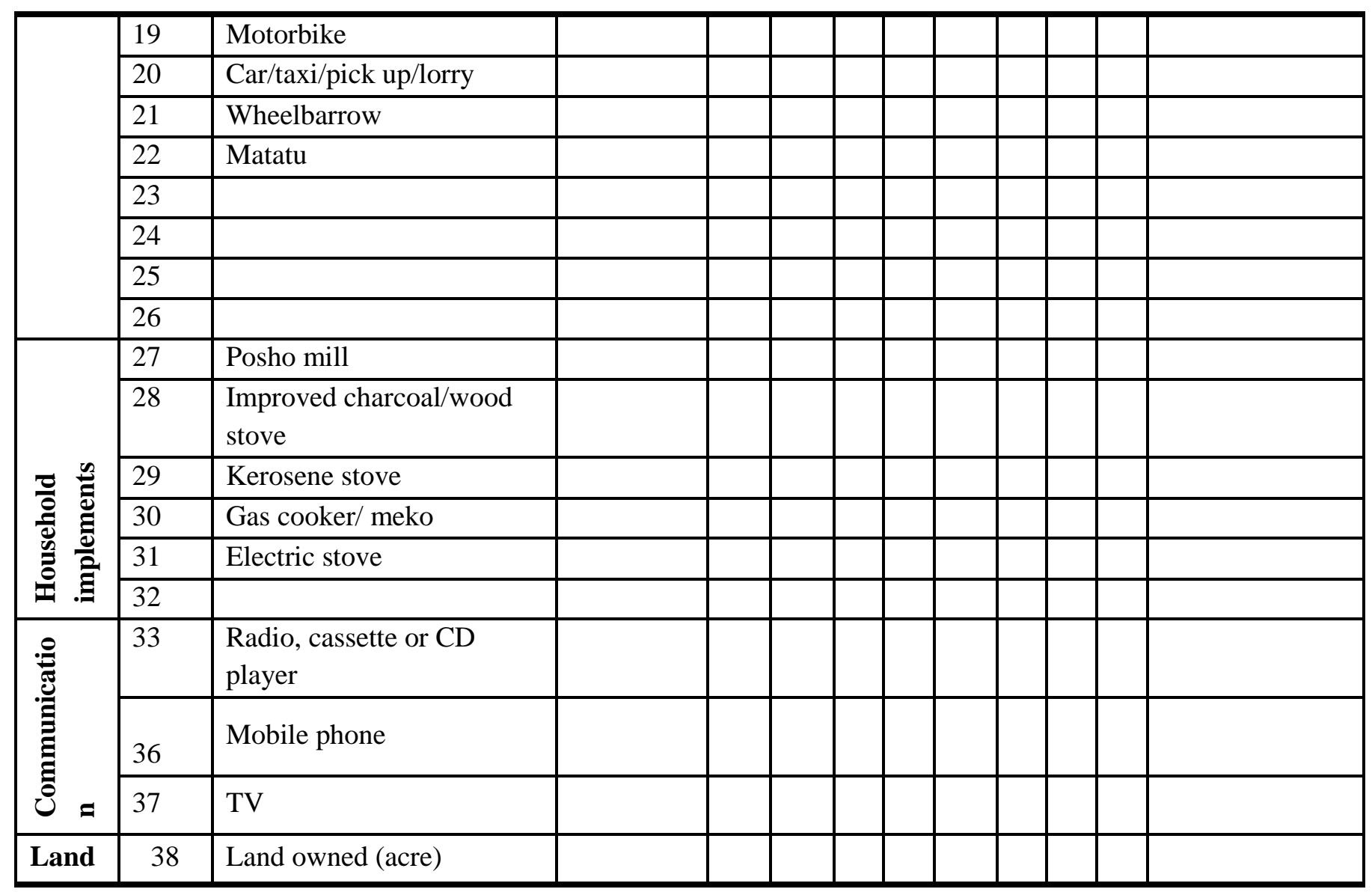


MODULE 9: IMPROVED MAIZE VARIETY KNOWLEDGE AND ADOPTION

\begin{tabular}{|c|c|c|c|c|c|c|c|c|c|c|c|c|c|c|}
\hline \multirow{2}{*}{\multicolumn{3}{|c|}{$\begin{array}{c}\text { Improved maize } \\
\text { varieties aware/heard }\end{array}$}} & \multirow[b]{3}{*}{$\begin{array}{c}\text { Year variety } \\
\text { known/heard } \\
\text { YYYY }\end{array}$} & \multirow[b]{3}{*}{$\begin{array}{c}\text { Sources of } \\
\text { variety } \\
\text { informatio } \\
\text { n } \\
\text { Codes A, } \\
\text { Rank 3 }\end{array}$} & \multirow[b]{3}{*}{$\begin{array}{c}\text { Ever } \\
\text { planted } \\
? \\
\text { 0=No } \\
\text { 1=Yes }\end{array}$} & \multirow[b]{3}{*}{$\begin{array}{l}\text { If NO in } \\
\text { Column } \\
5 \text {, Why? } \\
\text { Codes B } \\
\text { Rank } 3\end{array}$} & \multirow[b]{3}{*}{$\begin{array}{c}\text { If YES } \\
\text { in } \\
\text { column } \\
\text { 5, year } \\
\text { first } \\
\text { planted } \\
\text { YYYY }\end{array}$} & \multicolumn{6}{|c|}{ If Yes in column 5} & \\
\hline & & & & & & & & \multicolumn{3}{|c|}{ First seed } & \multicolumn{3}{|c|}{ Current and future planting } & \\
\hline \multirow{2}{*}{\multicolumn{2}{|c|}{$\begin{array}{c}\text { Maize variety name } \\
\text { Annex } 2\end{array}$}} & $\begin{array}{c}\text { Maize } \\
\text { variety } \\
\text { code } \\
\text { Annex 2 }\end{array}$ & & & & & & $\begin{array}{l}\text { Main } \\
\text { source } \\
\text { of first } \\
\text { seed } \\
\text { Codes } \\
\text { C }\end{array}$ & $\begin{array}{c}\text { Means } \\
\text { of } \\
\text { acquirin } \\
\text { g first } \\
\text { seed } \\
\text { Codes } \\
\text { D, Rank } \\
\mathbf{3}\end{array}$ & $\begin{array}{l}\text { No. of } \\
\text { seasons } \\
\text { variety } \\
\text { has } \\
\text { been } \\
\text { planted }\end{array}$ & $\begin{array}{l}\text { Planted } \\
\text { variety in } \\
\text { last } 2 \\
\text { seasons } \\
\quad \mathbf{0 = N o} \\
\quad \mathbf{1 = Y e s}\end{array}$ & $\begin{array}{c}\text { Will } \\
\text { plant } \\
\text { variety } \\
\text { in } \\
\text { future } \\
\mathbf{0 = N o} \\
\mathbf{1 = Y e s}\end{array}$ & $\begin{array}{c}\text { If No in } \\
\text { Column } \\
\text { 12, why } \\
\text { not, } \\
\text { Codes B } \\
\text { Rank 3 }\end{array}$ & \\
\hline & & 2 & 3 & 4 & 5 & 6 & 7 & 8 & 9 & 10 & 11 & 12 & 13 & \\
\hline & & & & & & & & & & & & & & \\
\hline & & & & & & & & & & & & & & \\
\hline & & & & & & & & & & & & & & \\
\hline & & & & & & & & & & & & & & \\
\hline & & & & & & & & & & & & & & \\
\hline & & & & & & & & & & & & & & \\
\hline & & & & & & & & & & & & & & \\
\hline & & & & & & & & & & & & & & \\
\hline & & & & & & & & & & & & & & \\
\hline & & & & & & & & & & & & & & \\
\hline & & & & & & & & & & & & & & \\
\hline $\begin{array}{l}\text { ment extension } \\
\text { Coop/Union } \\
\text { group } \\
\text { BO } \\
\text { h Centre } \\
\text { nos/field days) }\end{array}$ & $\begin{array}{l}\text { 6. Seed/grai } \\
\text { 7. Another } \\
\text { 8. Another } 1 \\
\text { 9. Radio/ne } \\
\text { 10. Other, S }\end{array}$ & $\begin{array}{l}\text { ockist } \\
\text { ner relative } \\
\text { ner neighbour } \\
\text { aper/TV } \\
\text { ify............ }\end{array}$ & $\begin{array}{l}\text { Codes B } \\
\text { 1. Seed not avail } \\
\text { 2. Lack of cash } t \\
3=\text { seed expensiv } \\
4=. \text { Susceptible to } \\
\text { field diseases/pe } \\
5=\text { Susceptible to } \\
\text { Storage pests } \\
6=\text { requires mor } \\
7=\text { Poor taste }\end{array}$ & $\begin{array}{l}\text { lable } \\
\text { o buy seed (credit } \\
\text { sts } \\
\text { rainfall }\end{array}$ & $\begin{array}{l}8=\mathrm{I} \\
9=\mathrm{I} \\
10= \\
11= \\
12= \\
13 . \\
14 .\end{array}$ & $\begin{array}{l}\text { ow yielding var } \\
\text { ow grain prices } \\
\text { No market } \\
\text { Theft during gre } \\
\text { Lack of enough } \\
\text { lequires high sk } \\
\text { ther, specify... }\end{array}$ & $\begin{array}{l}\text { n stage } \\
\text { and } \\
\text { ls } \\
\ldots \ldots\end{array}$ & $\begin{array}{l}\text { Codes C } \\
1=\text { On-farm tria } \\
2=\text { Extension d } \\
\text { plots } \\
3=\text { Farmer } \\
\text { groups/Coops } \\
4=\text { seed compa } \\
5=\text { Local trader } \\
6=\text { Agro- } \\
\text { dealers/Agrove }\end{array}$ & $\begin{array}{l}\text { als } \\
\text { lemo } \\
\text { nies } \\
\text { ts }\end{array}$ & $\begin{array}{l}\text { armer to farme } \\
\text { ovided free by } \\
\text { ovt subsidy pr } \\
\text { cal seed prodı } \\
\text { Dther (specify) }\end{array}$ & $\begin{array}{l}\text { r seed exchange } \\
\text { NGOs/govt } \\
\text { ogram } \\
\text { ucer } \\
. . . \ldots \ldots \ldots \ldots\end{array}$ & $\begin{array}{l}\text { Codes D } \\
\text { 1. Gift/free } \\
\text { 2. Borrowe } \\
\text { 3. Bought } \\
\text { 4. Payment } \\
\text { 5. Exchang } \\
\text { other seed }\end{array}$ & $\begin{array}{l}\text { seed } \\
\text { ith cash } \\
\text { in kind } \\
\text { with }\end{array}$ & $\begin{array}{l}\text { 6. Subsidy and } \\
\text { cash } \\
\text { 7. Advance } \\
\text { pay from coop } \\
\text { 8. Other, } \\
\text { specify...... }\end{array}$ \\
\hline
\end{tabular}


MODULE 10: CHARACTERISTICS OF MAIZE VARIETIES GROWN DURING 2012 and/or in the past three years [main local variety first]

\section{Characteristics}

\section{Name of the}

Name of the
Variety

Code

\section{Agronomic}

1. Grain yield

2. Stover (crop residue) yield

3. Palatability of stover to livestock

4. Drought tolerance

5. Water-logging tolerance

6. Disease tolerance

7. Insect pest tolerance

8. Early maturity

9. Uniformity in maturity

10. Grain size

11. Cob size

12. Saving on fertilizer

13.Striga weed tolerance

Market and economics

14. Marketability (demand)

15. Grain colour

16. Grain price

Cooking \& utilization

17. Storability

18. Milling percentage

19. Taste

22. Overall variety score

\section{Maize varieties (use maize variety codes in Annex 2 for improved varieties)}

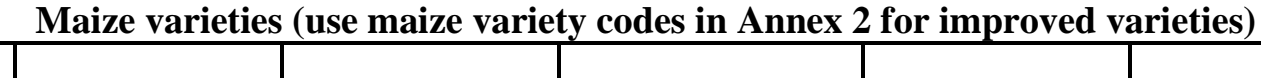

\begin{tabular}{|c|c|c|c|}
\hline $\begin{array}{c}\text { Main local } \\
\text { variety } \\
\text {................ }\end{array}$ & $1 \ldots \ldots \ldots \ldots$ & $2 \ldots \ldots \ldots \ldots \ldots$ & $3 \ldots \ldots \ldots \ldots \ldots$ \\
\hline & & & \\
\hline & & & \\
\hline & & & \\
\hline & & & \\
\hline & & & \\
\hline & & & \\
\hline & & & \\
\hline & & & \\
\hline & & & \\
\hline & & & \\
\hline & & & \\
\hline & & & \\
\hline & & & \\
\hline & & & \\
\hline & & & \\
\hline & & & \\
\hline & & & \\
\hline & & & \\
\hline & & & \\
\hline & & & \\
\hline & & & \\
\hline & & & \\
\hline & & & \\
\hline & & & \\
\hline
\end{tabular}

\begin{tabular}{|c|c|c|c|}
\hline $4 \ldots \ldots \ldots \ldots \ldots$ & $5 \ldots . . . \ldots \ldots . . .$. & 6............... & $7 \ldots \ldots \ldots \ldots \ldots . . .$. \\
\hline & & & \\
\hline & & & \\
\hline & & & \\
\hline & & & \\
\hline & & & \\
\hline & & & \\
\hline & & & \\
\hline & & & \\
\hline & & & \\
\hline & & & \\
\hline & & & \\
\hline & & & \\
\hline & & & \\
\hline & & & \\
\hline & & & \\
\hline & & & \\
\hline & & & \\
\hline & & & \\
\hline & & & \\
\hline & & & \\
\hline & & & \\
\hline & & & \\
\hline & & & \\
\hline 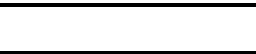 & $-2+2+2+25$ & 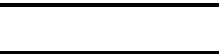 & 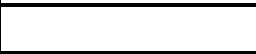 \\
\hline
\end{tabular}

Codes A:

1. Very poor, 2. Poor, 3. Average 4. Good, 5. Very Good 
MODULE 11: MAIZE PRODUCTION (LAST TWO SEASONS): Start with Mar-Apr 2012 rain season

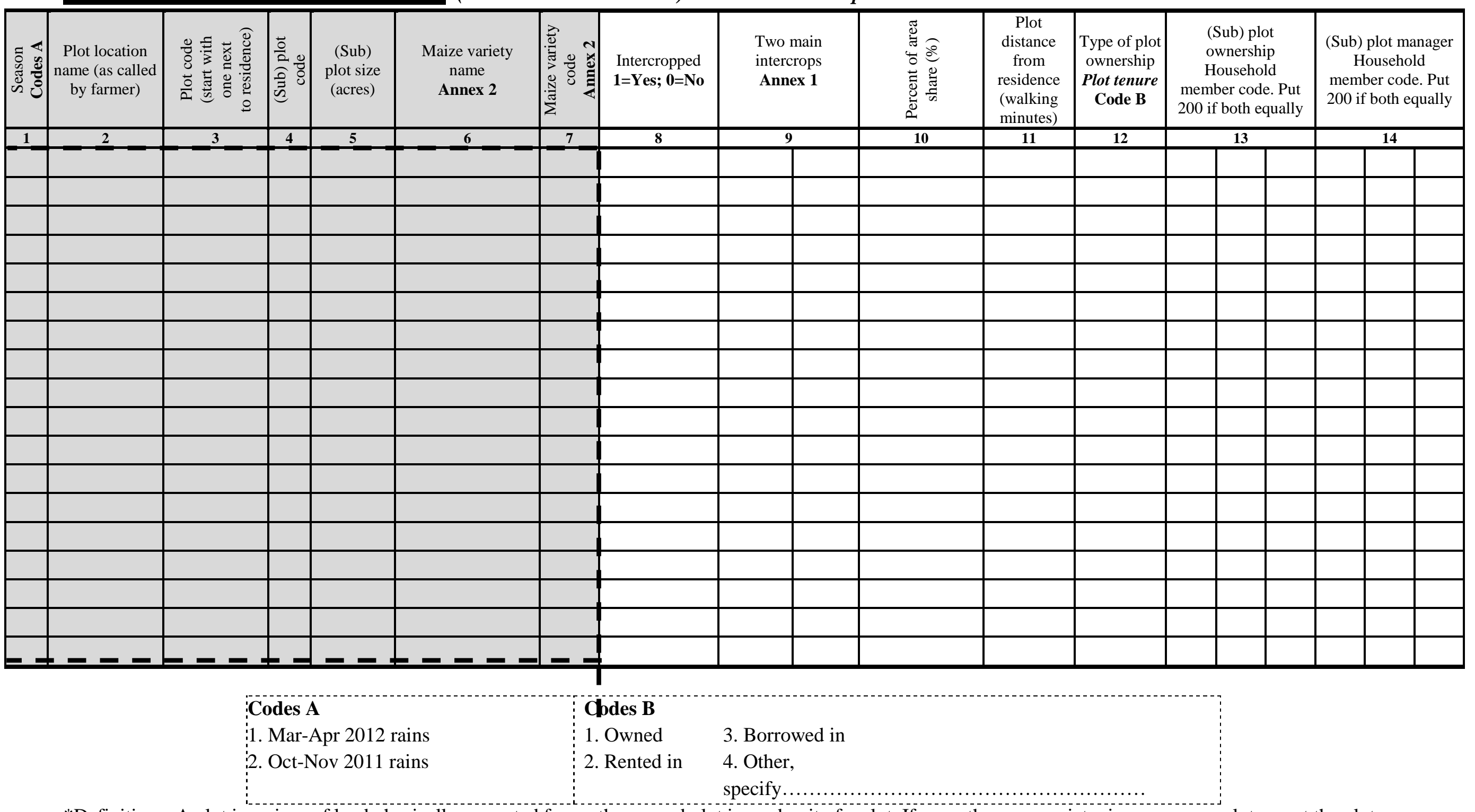

*Definitions: A plot is a piece of land physically separated from others; a subplot is a subunit of a plot. If more than one variety is grown on a plot repeat the plot code in next row and use subplot code. 
MODULE 11: MAIZE PRODUCTION (Cont'd)

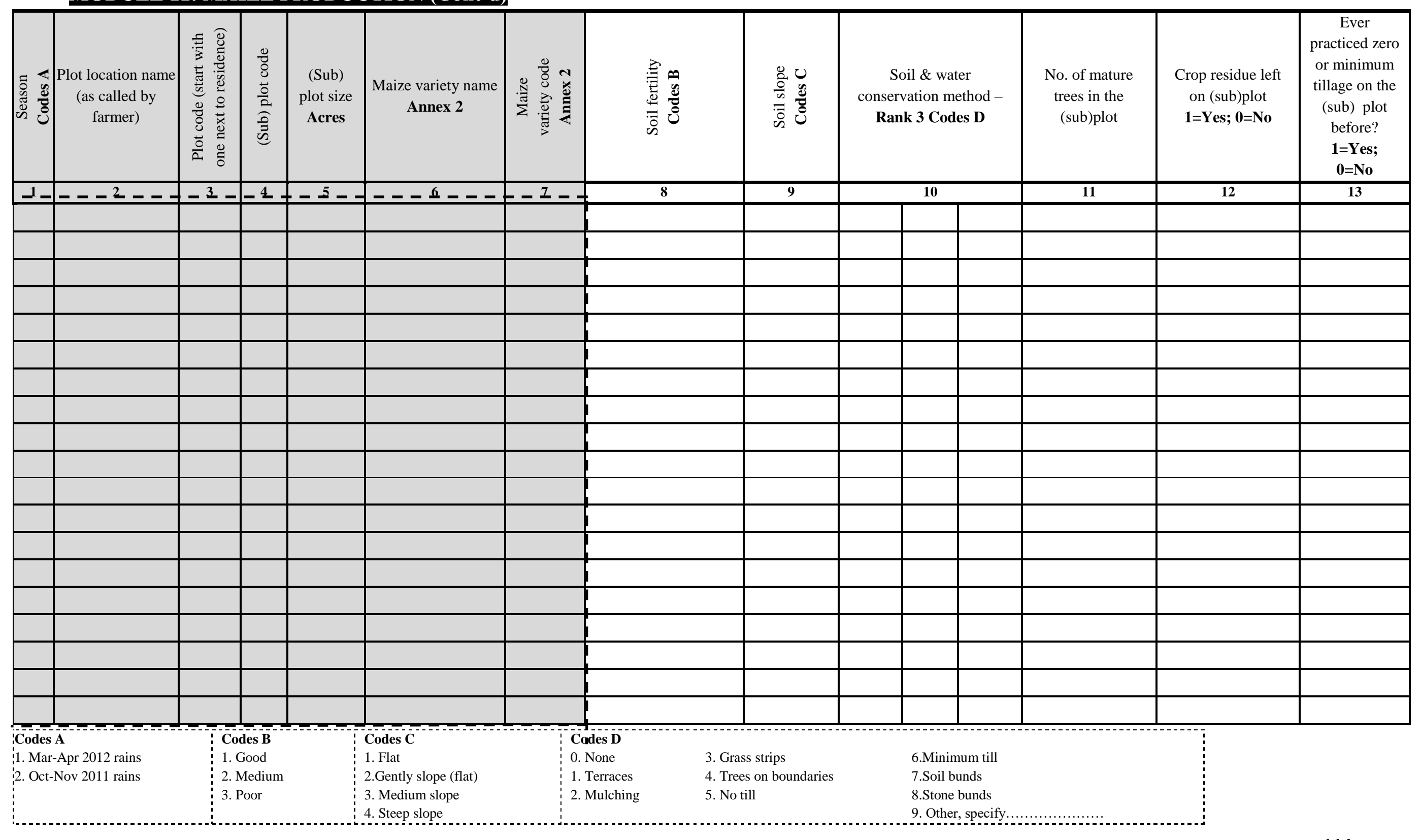




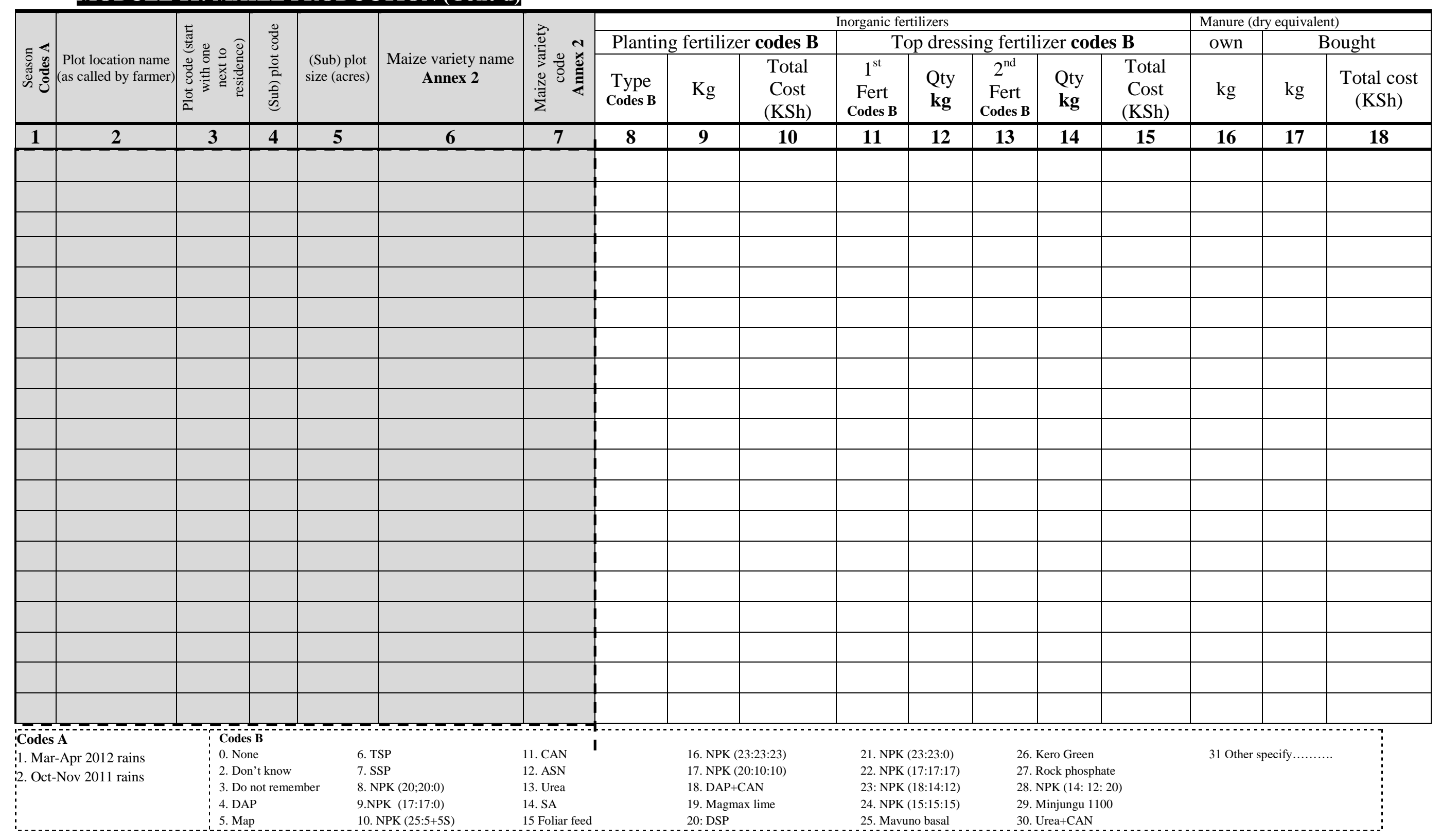




\section{MODULE 11: MAIZE PRODUCTION (Cont'd)}

\begin{tabular}{|c|c|c|c|c|c|c|c|c|c|c|c|c|c|c|c|c|}
\hline \multirow{3}{*}{ 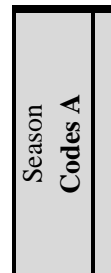 } & \multirow{3}{*}{ 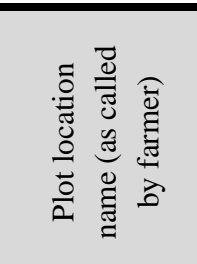 } & \multirow{3}{*}{ 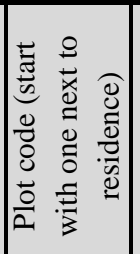 } & \multirow{3}{*}{ 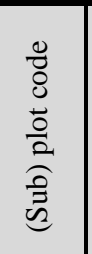 } & \multirow{3}{*}{$\begin{array}{c}\text { (Sub) } \\
\text { plot size } \\
\text { Acres }\end{array}$} & \multirow{3}{*}{$\begin{array}{c}\text { Maize variety name } \\
\text { Annex 2 }\end{array}$} & \multirow{3}{*}{ 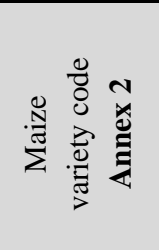 } & \multicolumn{6}{|c|}{ Main seed source Codes B } & \multirow{3}{*}{$\mid \begin{array}{c}\text { Main seed } \\
\text { type Code } \\
\text { C }\end{array}$} & \multirow{3}{*}{$\begin{array}{l}\text { Who decided } \\
\text { on the seed } \\
\text { variety } \\
\text { Hh member } \\
\text { code }\end{array}$} & \multirow{3}{*}{$\begin{array}{l}\text { Number } \\
\text { of } \\
\text { Seasons } \\
\text { recycled }\end{array}$} & \multirow{3}{*}{$\begin{array}{c}\text { Total cost } \\
\text { (bought seed } \\
\text { only) } \\
\text { KSh }\end{array}$} \\
\hline & & & & & & & \multicolumn{2}{|c|}{ Source 1 } & \multicolumn{2}{|c|}{ Source2 } & \multicolumn{2}{|c|}{ Source3 } & & & & \\
\hline & & & & & & & $\begin{array}{l}\text { हूँ } \\
\text { z̆ }\end{array}$ & $\mathrm{kg}$ & 芩 & $\mathrm{kg}$ & $\begin{array}{l}\text { छ్ } \\
\text { Zूँ }\end{array}$ & $\mathrm{kg}$ & & & & \\
\hline 1 & $-2-$ & $\underline{3}$ & 4 & -5 & $-6-1$ & $-7=$ & 8 & 9 & 10 & 11 & 12 & 13 & 14 & 15 & 16 & $\overline{17}$ \\
\hline & & & & & & & & & & & & & & & & \\
\hline & & & & & & & & & & & & & & & & \\
\hline & & & & & & & & & & & & & & & & \\
\hline & & & & & & & & & & & & & & & & \\
\hline & & & & & & & & & & & & & & & & \\
\hline & & & & & & & & & & & & & & & & \\
\hline & & & & & & & & & & & & & & & & \\
\hline & & & & & & & & & & & & & & & & \\
\hline & & & & & & & & & & & & & & & & \\
\hline & & & & & & & & & & & & & & & & \\
\hline & & & & & & & & & & & & & & & & \\
\hline & & & & & & & & & & & & & & & & \\
\hline & & & & & & & & & & & & & & & & \\
\hline & & & & & & & & & & & & & & & & \\
\hline & & & & & & & & & & & & & & & & \\
\hline & & & & & & & & & & & & & & & & \\
\hline & & & & & & & & & & & & & & & & \\
\hline & & & & & & & & & & & & & & & & \\
\hline- & $1--=$ & $1-$ & - & -- & $1---c$ & -- & & & & & & & & & & \\
\hline & $\begin{array}{l}\text { Codes A } \\
\text { 1. Mar-App } 2012 \text { ra } \\
\text { 2. Oct-Nov } 2011 \text { ra }\end{array}$ & & $\begin{array}{l}\text { Code } \\
\text { 1. Own } \\
\text { 2. Gift fit } \\
\text { 3. Farme } \\
\text { exchang } \\
\text { 4. On-fa }\end{array}$ & $\begin{array}{l}\text { B } \\
\text { aved } \\
\text { om family/neigl } \\
\text { rto farmer seed } \\
\text { s trials }\end{array}$ & 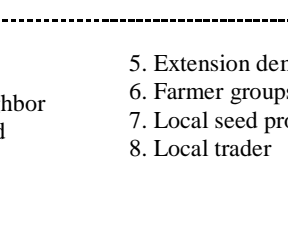 & $\begin{array}{l}\text { enom plots } \\
\text { proclops } \\
\text { roducers }\end{array}$ & & $\begin{array}{l}\text { alerslagre } \\
\text { from see } \\
\text { drtee } \\
\text { bisidy pry }\end{array}$ & $\begin{array}{l}\text { ppany } \\
\text { plovt }\end{array}$ & & & $\begin{array}{l}3 . \\
4 . \\
8 .\end{array}$ & $\begin{array}{l}\text { les } \mathbf{C} \\
\text { chased/ new hybrid } \\
\text { cycled hybrid } \\
\text { v } \\
\text { al variety } \\
\text { ter specify................ }\end{array}$ & & & 16 \\
\hline
\end{tabular}




\section{MODULE 11: MAIZE PRODUCTION (Cont'd)}

\begin{tabular}{|c|c|c|c|c|c|c|c|c|c|c|c|c|c|c|c|c|}
\hline \multirow{3}{*}{ 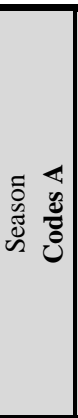 } & \multirow{3}{*}{ 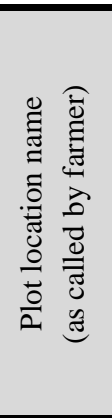 } & \multirow{3}{*}{ 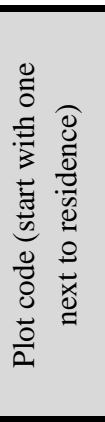 } & \multirow{3}{*}{ 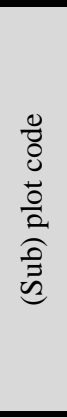 } & \multirow{3}{*}{$\begin{array}{c}\text { (Sub) plot } \\
\text { size (acres) }\end{array} \mid$} & \multirow{3}{*}{$\begin{array}{c}\text { Maize variety name } \\
\text { Annex } 2\end{array}$} & \multirow{3}{*}{ 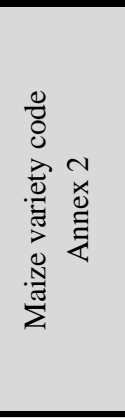 } & \multirow{2}{*}{\multicolumn{3}{|c|}{ Oxen/donkey use }} & \multicolumn{7}{|c|}{ Total labour (family and hired) use in person days } \\
\hline & & & & & & & & & & \multicolumn{2}{|c|}{$\begin{array}{c}\text { Land } \\
\text { preparation }\end{array}$} & \multicolumn{2}{|c|}{ Planting } & \multicolumn{3}{|c|}{ Weed control } \\
\hline & & & & & & & Plowing Freq & $\begin{array}{c}\text { Total Plowing } \\
\text { days }\end{array}$ & $\begin{array}{c}\text { Cost of } \\
\text { oxen/donkey hired } \\
\text { (KSh) }\end{array}$ & Male & Female & Male & Female & $\begin{array}{l}\text { Weeding } \\
\text { freq }\end{array}$ & Male & Female \\
\hline 1 & 2 & 3 & 4 & 5 & 6 & 7 & 8 & 9 & 10 & 11 & 12 & 13 & 14 & 15 & 16 & 17 \\
\hline 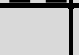 & & & & & & & & & & & & & & & & \\
\hline & & & & & & & & & & & & & & & & \\
\hline & & & & & & & & & & & & & & & & \\
\hline & & & & & & & & & & & & & & & & \\
\hline & & & & & & & & & & & & & & & & \\
\hline & & & & & & & & & & & & & & & & \\
\hline & & & & & & & & & & & & & & & & \\
\hline & & & & & & & & & & & & & & & & \\
\hline & & & & & & & & & & & & & & & & \\
\hline & & & & & & & & & & & & & & & & \\
\hline & & & & & & & & & & & & & & & & \\
\hline & & & & & & & & & & & & & & & & \\
\hline & & & & & & & & & & & & & & & & \\
\hline & & & & & & & & & & & & & & & & \\
\hline & & & & & & & & & & & & & & & & \\
\hline & & & & & & & & & & & & & & & & \\
\hline & & & & & & & & & & & & & & & & \\
\hline & & & & & & & & & & & & & & & & \\
\hline - & -- & - & 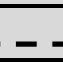 & ---- & $------t$ & --- & & & & & & & & & & \\
\hline
\end{tabular}

Codes A : 1. Mar-Apr 2012 rains $\quad$ 2. Oct-Nov 2011 rains 


\section{MODULE 11: MAIZE PRODUCTION (Cont'd)}

\begin{tabular}{|c|c|c|c|c|c|c|c|c|c|c|c|c|c|c|c|}
\hline \multirow{3}{*}{ 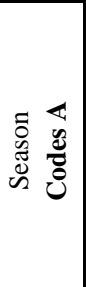 } & \multirow{3}{*}{ 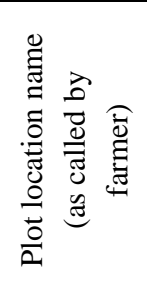 } & \multirow{3}{*}{ 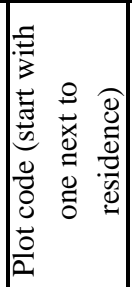 } & \multirow{3}{*}{ 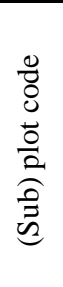 } & \multirow{3}{*}{$\begin{array}{c}\text { (Sub) plot } \\
\text { size (acres) }\end{array}$} & \multirow{3}{*}{$\begin{array}{l}\text { Maize variety name } \\
\text { Annex } 2\end{array}$} & \multirow{3}{*}{ 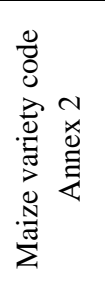 } & \multicolumn{4}{|c|}{ Labour for harvesting and threshing } & \multicolumn{2}{|c|}{ Field pesticides } & \multirow{3}{*}{$\begin{array}{l}\text { Cost of } \\
\text { hired } \\
\text { labor } \\
\text { (KSh) }\end{array}$} & \multicolumn{2}{|c|}{$\begin{array}{l}\text { Total harvested per } \\
\text { (sub)plot }\end{array}$} \\
\hline & & & & & & & \multicolumn{2}{|c|}{ Harvesting } & \multicolumn{2}{|c|}{ Threshing or shelling } & \multirow[b]{2}{*}{$\begin{array}{l}\text { Qty } \\
\text { litres }\end{array}$} & \multirow[b]{2}{*}{$\begin{array}{c}\text { Total cost } \\
\text { (KSh) }\end{array}$} & & \multirow[b]{2}{*}{$\begin{array}{l}\text { Fresh or } \\
\text { green }(\mathrm{kg})\end{array}$} & \multirow[b]{2}{*}{ Dry $(\mathrm{kg})$} \\
\hline & & & & & & & Male & Female & Male & Female & & & & & \\
\hline 1 & 2 & 3 & 4 & 5 & 6 & 7 & 8 & 9 & 10 & 11 & 12 & 13 & 14 & 15 & 16 \\
\hline & & & & & & & & & & & & & & & \\
\hline & & & & & & & & & & & & & & & \\
\hline & & & & & & & & & & & & & & & \\
\hline & & & & & & & & & & & & & & & \\
\hline & & & & & & & & & & & & & & & \\
\hline & & & & & & & & & & & & & & & \\
\hline & & & & & & & & & & & & & & & \\
\hline & & & & & & & & & & & & & & & \\
\hline & & & & & & & & & & & & & & & \\
\hline & & & & & & & & & & & & & & & \\
\hline & & & & & & & & & & & & & & & \\
\hline & & & & & & & & & & & & & & & \\
\hline & & & & & & & & & & & & & & & \\
\hline & & & & & & & & & & & & & & & \\
\hline & & & & & & & & & & & & & & & \\
\hline & & & & & & & & & & & & & & & \\
\hline & & & & & & & & & & & & & & & \\
\hline & & & & & & & & & & & & & & & \\
\hline & & & & & & & & & & & & & & & \\
\hline
\end{tabular}




\section{MODULE 12: MARKETING OF OTHER CROPS APART FROM MAIZE}

one row per sale (different months, different buyers), per crop

\begin{tabular}{|c|c|c|c|c|c|c|c|c|c|c|c|c|c|c|}
\hline 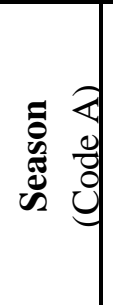 & $\begin{array}{c}\text { Crops } \\
\text { code } \\
(\text { Annex 1) }\end{array}$ & $\begin{array}{c}\text { Crops } \\
\text { variety } \\
\text { Code B }\end{array}$ & $\begin{array}{c}\text { Market } \\
\text { type } \\
\text { Codes C }\end{array}$ & $\begin{array}{c}\text { Month } \\
\text { sold } \\
\text { Codes D }\end{array}$ & $\begin{array}{l}\text { Quantit } \\
\text { y sold } \\
(\mathrm{kg})\end{array}$ & $\begin{array}{c}\text { Who } \\
\text { sold } \\
(\mathrm{HH} \\
\text { member } \\
\text { code })\end{array}$ & $\begin{array}{c}\text { Price } \\
(\mathrm{KSh} / \mathrm{kg})\end{array}$ & $\begin{array}{c}\text { Buyer } \\
\text { Codes E }\end{array}$ & $\begin{array}{l}\text { Peri } \\
\text { payn } \\
\text { after } \\
\text { in wo } \\
(\text { if in } \\
=0)\end{array}$ & $\begin{array}{l}\text { to } \\
\text { elling } \\
\text { elling } \\
\text { ks } \\
\text { nediate }\end{array}$ & $\begin{array}{l}\text { Relation } \\
\text { to buyer } \\
\text { Codes F }\end{array}$ & $\begin{array}{l}\text { Sales } \\
\text { tax or } \\
\text { charges } \\
\text { (KSh.) }\end{array}$ & $\begin{array}{c}\text { Mode of } \\
\text { transpor } \\
\mathbf{t} \\
\text { Codes } G\end{array}$ & $\begin{array}{c}\text { Actual } \\
\text { transpor } \\
\text { t cost } \\
\text { (KSh.) }\end{array}$ \\
\hline 1 & 2 & 3 & 4 & 5 & 6 & 7 & 8 & 9 & & & 11 & 12 & 13 & 14 \\
\hline & & & & & & & & & & & & & & \\
\hline & & & & & & & & & & & & & & \\
\hline & & & & & & & & & & & & & & \\
\hline & & & & & & & & & & & & & & \\
\hline & & & & & & & & & & & & & & \\
\hline & & & & & & & & & & & & & & \\
\hline & & & & & & & & & & & & & & \\
\hline & & & & & & & & & & & & & & \\
\hline & & & & & & & & & & & & & & \\
\hline & & & & & & & & & & & & & & \\
\hline & & & & & & & & & & & & & & \\
\hline & & & & & & & & & & & & & & \\
\hline & & & & & & & & & & & & & & \\
\hline & & & & & & & & & & & & & & \\
\hline & & & & & & & & & & & & & & \\
\hline Codes A & 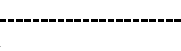 & \multirow{4}{*}{\multicolumn{2}{|c|}{$\begin{array}{l}\text { Codes C } \\
\text { 1. Farmgate } \\
\text { 2. Village market } \\
\text { 3. Main/district market }\end{array}$}} & \multirow{4}{*}{$\begin{array}{l}\text { Codes D } \\
\text { 1. January } \\
\text { 2. February } \\
\text { 3. March } \\
\text { 4. April } \\
\text { 5. May } \\
\text { 6. June }\end{array}$} & \multirow{4}{*}{$\begin{array}{l}\text { 7. July } \\
\text { 8. August } \\
\text { 9. September } \\
\text { 10. October } \\
\text { 11. November } \\
\text { 12. December }\end{array}$} & \multirow{4}{*}{\multicolumn{2}{|c|}{$\begin{array}{l}\text { Codes } \mathbf{E} \\
\text { 1. Farmer group } \\
\text { 2. Farmer Union or Coop } \\
\text { 3. Consumer or other farmer } \\
\text { 4. Rural assembler } \\
\text { 5. Broker/middlemen } \\
\text { 6. Rural grain trader }\end{array}$}} & \multirow{4}{*}{\multicolumn{2}{|c|}{$\begin{array}{l}\text { 7. Rural wholesaler } \\
\text { 8. Urban wholesaler } \\
\text { 9. Urban grain trader } \\
\text { 10. Exporter, } \\
\text { 11. Other, specify....... }\end{array}$}} & \multirow{4}{*}{\multicolumn{3}{|c|}{$\begin{array}{l}\text { Codes } \mathbf{F} \\
\text { 1. No relation but not a long time buyer } \\
\text { 2. No relation but a long term buyer } \\
\text { 3. Relative } \\
\text { 4. Friend } \\
\text { 5. Money lender } \\
\text { 6. Other, specify...... }\end{array}$}} & \multirow{4}{*}{\multicolumn{2}{|c|}{$\begin{array}{l}\text { Codes } \mathbf{~} \\
\text { 1. Bicycle } \\
\text { 2. Hired truck } \\
\text { 3. Public transport } \\
\text { 4. Donkey } \\
\text { 5. Oxen/horse cart } \\
\text { 6. Back/head load } \\
\text { 7. Other, specify.... }\end{array}$}} \\
\hline 1. Mar-A & pr 2012 rains & & & & & & & & & & & & & \\
\hline 2. Oct-Nc & ov 2011 rains & & & & & & & & & & & & & \\
\hline $\begin{array}{l}\text { Codes B } \\
\text { 1. Improy } \\
\text { 2. Local }\end{array}$ & & & & & & & & & & & & & & \\
\hline
\end{tabular}




\section{MODULE 13: PERCENT UTILIZATION OF CROP RESIDUES FROM MAIN CROPPING}

\section{SEASON (\%)}

Note that percentages need to add up to $100 \%$ for every row.

\begin{tabular}{|c|c|c|c|c|c|c|c|c|}
\hline $\begin{array}{c}\text { Crops code } \\
\text { Annex 1 }\end{array}$ & $\begin{array}{c}\text { Burnt in } \\
\text { the field } \\
(\%)\end{array}$ & $\begin{array}{c}\text { Used as } \\
\text { firewood } \\
(\%)\end{array}$ & $\begin{array}{c}\text { Left on } \\
\text { land for } \\
\text { soil } \\
\text { fertility } \\
(\%)\end{array}$ & $\begin{array}{c}\text { Feed for } \\
\text { livestock } \\
(\%)\end{array}$ & $\begin{array}{c}\text { Used for } \\
\text { construct } \\
\text { ion (\%) }\end{array}$ & Sold (\%) & $\begin{array}{c}\text { Used to } \\
\text { make } \\
\text { compost } \\
(\%)\end{array}$ & $\begin{array}{c}\text { Other } \\
\text { uses } \\
(\%)\end{array}$ \\
\hline & & & & & & & & \\
\hline & & & & & & & & \\
\hline & & & & & & & & \\
\hline & & & & & & & & \\
\hline & & & & & & & & \\
\hline
\end{tabular}

\section{MODULE 14: PRE-STORAGE HANDLING AND MAIZE STORAGE}

\section{FACILITIES INVENTORY}

Please indicate if you do the following before storing your maize

\begin{tabular}{|c|c|c|c|c|c|c|}
\hline \multirow{3}{*}{1} & \multicolumn{2}{|l|}{ Activity } & \multicolumn{3}{|c|}{ Practice } & code \\
\hline & \multirow{2}{*}{$\begin{array}{l}\text { Harvesting methods } \\
\text { 1= Always } \\
\text { 2=Sometimes } \\
\text { Know }\end{array}$} & \multirow[t]{2}{*}{$\begin{array}{l}\text { 3=Never . } \\
\text { 4=Don't }\end{array}$} & \multicolumn{3}{|c|}{$\begin{array}{l}\text { i) Stooking (leaving cob on stalk after harvesting to dry in the } \\
\text { field) }\end{array}$} & \\
\hline & & & \multicolumn{3}{|c|}{ ii) Early removal of crop from field } & \\
\hline \multirow[t]{2}{*}{2} & \multirow{2}{*}{$\begin{array}{l}\text { Drying on homestead } \\
\text { 1= Always } \\
\text { 2=Sometimes } \\
\text { Know }\end{array}$} & \multirow{2}{*}{$\begin{array}{l}3=\text { Never } \\
4=\text { Don't }\end{array}$} & i) & \multicolumn{2}{|c|}{$\begin{array}{l}\text { Placing cobs (in husks or de-husked) in crib for further } \\
\text { drying }\end{array}$} & \\
\hline & & & ii) & \multicolumn{2}{|l|}{ drying cobs on the ground } & \\
\hline \multirow[t]{3}{*}{3} & \multirow{3}{*}{$\begin{array}{l}\text { Shelling } \\
\text { 1= Always } \\
\text { 2=Sometimes } \\
\text { Know }\end{array}$} & \multirow{3}{*}{$\begin{array}{l}\text { 3=Never } \\
\text { 4=Don't }\end{array}$} & i) & \multicolumn{2}{|c|}{$\begin{array}{l}\text { Shelling immediately when grain is dry enough for } \\
\text { posho mill or grain storage }\end{array}$} & \\
\hline & & & ii) & \multicolumn{2}{|c|}{$\begin{array}{l}\text { Shelling by hand to reduce kernel damage and easy } \\
\text { exposure to infestation }\end{array}$} & \\
\hline & & & iii) & \multicolumn{2}{|c|}{ Cleaning and sorting grain } & \\
\hline \multirow[t]{5}{*}{4} & \multirow{5}{*}{\multicolumn{2}{|c|}{$\begin{array}{ll}\text { Treatment of grain for storage } \\
\text { 1= Always } & \text { 3=Never } \text {. } \\
\text { 2=Sometimes } & \text { 4=Don't } \\
\text { Know } & \end{array}$}} & \multicolumn{3}{|c|}{ i) no treatment } & \\
\hline & & & \multicolumn{3}{|c|}{ ii) Chemical treatment, product name: $\ldots \ldots \ldots \ldots \ldots \ldots \ldots \ldots \ldots$} & \\
\hline & & & \multicolumn{3}{|c|}{ iii) ash } & \\
\hline & & & \multicolumn{3}{|c|}{ iv), botanical control } & \\
\hline & & & \multicolumn{3}{|c|}{ v) other: please specifiy: .............. } & \\
\hline \multirow[t]{5}{*}{5} & \multirow{2}{*}{\multicolumn{2}{|c|}{$\begin{array}{l}\text { Storage of treated and untreated } \\
\text { grain }\end{array}$}} & i) & Storing shelled grain in bulk (without baggi & & \\
\hline & & & & Bagging of shelled grain & & \\
\hline & \multirow{2}{*}{$\begin{array}{l}\text { 1= Always } \\
\text { 2=Sometimes } \\
\text { Know }\end{array}$} & \multirow{2}{*}{$\begin{array}{l}\text { 3=Never } . \\
\text { 4=Don't }\end{array}$} & iii) & Placing bagged grain on raised platform & & \\
\hline & & & iv) & $\begin{array}{l}\text { How many bags did you buy last season to } \\
\text { store grain? }\end{array}$ & & \\
\hline & & & v) & What was the cost per bag & & \\
\hline
\end{tabular}


MODULE 15: PRE-STORAGE HANDLING AND MAIZE STORAGE FACILITIES INVENTORY

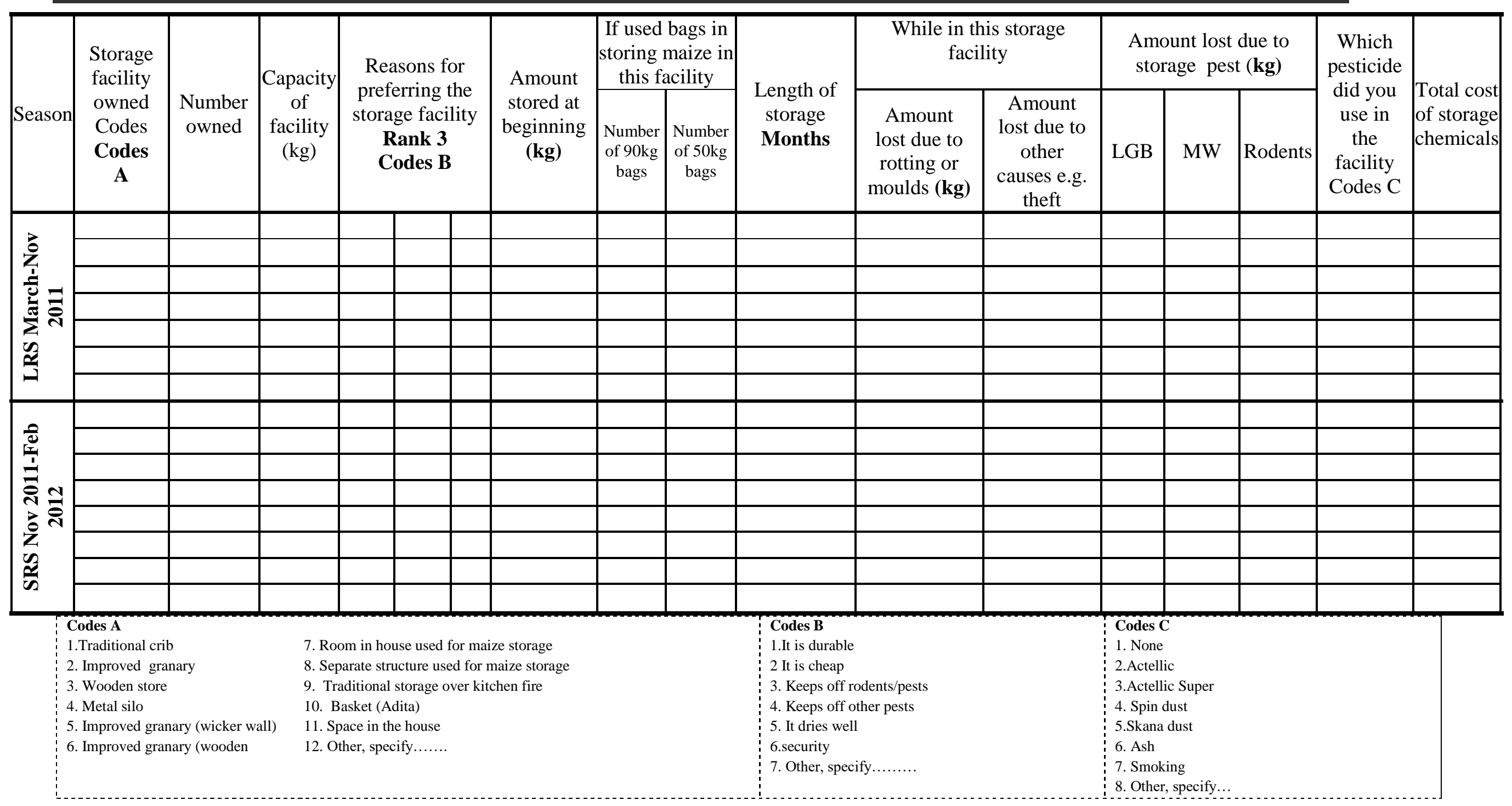


MODULE 16A: MAIZE POSTHARVEST AND STORAGE AND MARKETING LONG RAIN SEASON MARCH -AUGUST, 2011 (ask for maize

harvested between June-Nov, 2011)

***Note: FOR J.08, START WITH THE MONTH RECORDED IN J.03 AND RECORD FOR EACH MONTH UNTILL MONTH RECORDED IN J.06

\begin{tabular}{|c|c|c|c|c|c|c|c|c|c|c|c|c|c|}
\hline \multirow{3}{*}{\begin{tabular}{l}
\multicolumn{1}{c}{$\mathbf{J . 0 0}$} \\
In \\
which \\
month \\
did you \\
harvest
\end{tabular}} & & \multicolumn{2}{|c|}{ J.02 } & \multicolumn{5}{|c|}{ J.02a } & \multirow{3}{*}{\begin{tabular}{l}
\multicolumn{1}{c}{$\mathbf{J . 0 3}$} \\
Which month \\
did you put \\
maize in \\
storage?
\end{tabular}} & \multirow{3}{*}{\begin{tabular}{l}
\multicolumn{1}{c|}{$\mathbf{J . 0 4}$} \\
Number of \\
month maize \\
stayed in \\
storage
\end{tabular}} & \multirow{3}{*}{\begin{tabular}{|l|}
\multicolumn{1}{|c|}{$\mathbf{J . 0 5}$} \\
At what month did \\
you take the first \\
batch of maize out \\
from storage?
\end{tabular}} & \multirow{3}{*}{\begin{tabular}{l}
\multicolumn{1}{c}{ J.06 } \\
At what month did \\
you take the last \\
batch of maize out \\
from storage?
\end{tabular}} & \multirow{3}{*}{$\begin{array}{l}\text { J.06a } \\
\text { If you still have maize } \\
\text { in storage facility, } \\
\text { which month do you } \\
\text { anticipate to finish? }\end{array}$} \\
\hline & \multirow[t]{2}{*}{$\begin{array}{l}\text { Qty put aside in } \\
\text { cobs }(90 \mathrm{~kg} \text { bags }) \\
\text { because of rotting }\end{array}$} & $\begin{array}{l}\text { How many bags } \\
\text { after shelling (bas } \\
\text { months in number }\end{array}$ & $\begin{array}{l}\text { d you have } \\
\text { record } \\
\text { e.g. } 01=\text { jan }\end{array}$ & Qty sol & imme & iately after sh & ling before st & & & & & & \\
\hline & & Shelling Month s & Qty & Month & Qty & Price per kg & $\begin{array}{l}\text { Main buyer } \\
\text { Codes B }\end{array}$ & \begin{tabular}{|l} 
Point of sale \\
Codes A
\end{tabular} & & & & & \\
\hline
\end{tabular}

\begin{tabular}{|c|c|c|c|c|c|c|c|c|c|c|c|c|c|c|c|c|}
\hline J.09 & J.10 & $\mathrm{J} .11$ & $\mathrm{~J} .12$ & \multicolumn{2}{|c|}{$\mathrm{J} .13$} & J.14 & J15 & J16 & J17 & J18 & J19 & $\mathrm{J} 20$ & J.21 & J.22 & J.23 & J.24 \\
\hline $\begin{array}{l}\text { Mont } \\
\text { h ID }\end{array}$ & $\begin{array}{l}\text { Month ID } \\
\text { starting from } \\
\text { month } \\
\text { recorded in } \\
\mathrm{J} .05^{* * * *}\end{array}$ & \begin{tabular}{|l} 
Amount of \\
maize given \\
to livestock \\
e.g. poultry \\
(kgs)
\end{tabular} & $\begin{array}{l}\text { How much maize } \\
\text { was taken from } \\
\text { storage for home } \\
\text { consumption } \\
\text { (kgs) (githeri \& } \\
\text { posho)? } \\
\text { If } \text { " }^{\prime \prime}=>\text { J.14a } \\
\end{array}$ & \multicolumn{2}{|c|}{$\begin{array}{l}\text { During that } \\
\text { month, how much } \\
\text { maize was taken } \\
\text { from storage to be } \\
\text { sold? (kg) } \\
\text { If "0" go to J19 }\end{array}$} & $\begin{array}{l}\text { where } \\
\text { sold } \\
\text { codes } \\
\text { A }\end{array}$ & $\begin{array}{l}\text { Who got the } \\
\text { money from } \\
\text { sales } \\
\text { (see hh } \\
\text { codes } \\
100 \text { if more } \\
\text { than one) }\end{array}$ & $\begin{array}{l}\text { What was the } \\
\text { average price that } \\
\text { you received for } \\
\text { sold grain during } \\
\text { that month? } \\
\text { KSh/KG }\end{array}$ & $\begin{array}{l}\text { Who was the } \\
\text { buyer for the } \\
\text { largest sale } \\
\text { in [month]? } \\
\text { CODE B }\end{array}$ & $\begin{array}{c}\text { Relation } \\
\text { to the } \\
\text { buyer } \\
\text { Codes C }\end{array}$ & $\begin{array}{c}\text { Market } \\
\text { fee } \\
\text { (KES) }\end{array}$ & $\begin{array}{c}\text { Time taken } \\
\text { to sell } \\
\text { (minutes) }\end{array}$ & \begin{tabular}{|c|} 
Time taken \\
to get to the \\
market \\
(minutes)
\end{tabular} & $\begin{array}{c}\text { Mode of } \\
\text { transport to } \\
\text { the market } \\
\text { Codes D }\end{array}$ & $\begin{array}{c}\text { Transport } \\
\text { cost to the } \\
\text { market } \\
\text { (KES) }\end{array}$ & $\begin{array}{l}\text { During that month, } \\
\text { how much maize was } \\
\text { taken from storage to } \\
\text { be donated? kg } \\
\text { QTY }\end{array}$ \\
\hline \multicolumn{17}{|l|}{1} \\
\hline \multicolumn{17}{|l|}{2} \\
\hline \multicolumn{17}{|l|}{3} \\
\hline \multicolumn{17}{|l|}{4} \\
\hline \multicolumn{17}{|l|}{5} \\
\hline \multicolumn{17}{|l|}{6} \\
\hline \multicolumn{17}{|l|}{7} \\
\hline \multicolumn{17}{|l|}{8} \\
\hline \multicolumn{17}{|l|}{9} \\
\hline \multicolumn{17}{|l|}{10} \\
\hline \multicolumn{17}{|l|}{11} \\
\hline \multicolumn{17}{|l|}{12} \\
\hline \multicolumn{17}{|l|}{13} \\
\hline \multicolumn{3}{|c|}{$\begin{array}{l}\text { Codes A } \\
\text { 1. Farm gate } \\
\text { 2. Village market } \\
\text { 3. Main market } \\
\text { 4. other, specify... }\end{array}$} & \multicolumn{6}{|c|}{$\begin{array}{l}\text { Codes B } \\
\text { 1= Farmer group } \\
2=\text { Farmer Union or Coop } \\
3=\text { Consumer or other farmer } \\
\text { 4= Rural assembler } \\
5=\text { Broker/middlemen }\end{array}$} & \multicolumn{5}{|c|}{$\begin{array}{l}\text { Codes C } \\
1=\text { No relation but not a long term buyer } \\
2=\text { No relation but a long term buyer } \\
\text { lender } \\
3=\text { Relative } \\
\text { specify...... }\end{array}$} & \multicolumn{3}{|c|}{$\begin{array}{ll}\text { Codes D } & \\
\text { 1= Bicycle } & \text { 5=Oxen/horse cart } \\
\text { 2= Hired truck. } & \text { 6= Back } / \text { head load } \\
\text { 3= Public transport } & 7=\text { Other, specify.... } \\
\text { 4= Donkey } & \end{array}$} \\
\hline
\end{tabular}


MODULE 16B: MAIZE POSTHARVEST AND STORAGE AND MARKETING SHORT RAIN SEASON NOV. 2011-FEB 2012 (ask for maize

harvested between Feb-March, 2012)

***Note: FOR J.08, START WITH THE MONTH RECORDED IN J.03 AND RECORD FOR EACH MONTH UNTILL MONTH RECORDED IN J.06

\begin{tabular}{|c|c|c|c|c|c|c|c|c|c|c|c|c|c|}
\hline $\mathbf{J . 0 0}$ & & \multicolumn{2}{|c|}{$\mathbf{J . 0 2}$} & \multicolumn{5}{|c|}{ J.02a } & $\mathbf{J . 0 3}$ & J.04 & $\mathbf{J . 0 5}$ & J.06 & J.06a \\
\hline \multirow{2}{*}{$\begin{array}{l}\text { In } \\
\text { which } \\
\text { month } \\
\text { did you } \\
\text { harvest }\end{array}$} & \multirow[t]{2}{*}{$\begin{array}{l}\text { Qty put aside in } \\
\text { cobs ( } 90 \mathrm{~kg} \text { bags) } \\
\text { because of rotting }\end{array}$} & \multicolumn{2}{|c|}{$\begin{array}{l}\text { How many bags did you have } \\
\text { after shelling (bags) record } \\
\text { months in numbers e.g. } 01=\text { jan }\end{array}$} & \multicolumn{5}{|c|}{ Qty sold immediately after shelling before storage } & \multirow{2}{*}{$\begin{array}{l}\text { Which month } \\
\text { did you put } \\
\text { maize in } \\
\text { storage? }\end{array}$} & \multirow{2}{*}{$\begin{array}{l}\text { Number of } \\
\text { month maize } \\
\text { stayed in } \\
\text { storage }\end{array}$} & \multirow{2}{*}{$\begin{array}{l}\text { At what month did } \\
\text { you take the first } \\
\text { batch of maize out } \\
\text { from storage? }\end{array}$} & \multirow{2}{*}{$\begin{array}{l}\text { At what month did } \\
\text { you take the last } \\
\text { batch of maize out } \\
\text { from storage? }\end{array}$} & \multirow{2}{*}{$\begin{array}{l}\text { If you still have maize } \\
\text { in storage facility, } \\
\text { which month do you } \\
\text { anticipate to finish? }\end{array}$} \\
\hline & & Shelling Month s & Qty & Month & Qty & Price per $\mathrm{kg}$ & $\begin{array}{l}\text { Main buyer } \\
\text { Codes B }\end{array}$ & \begin{tabular}{|l|} 
Point of sale \\
Codes A
\end{tabular} & & & & & \\
\hline
\end{tabular}

\begin{tabular}{|c|c|c|c|c|c|c|c|c|c|c|c|c|c|c|c|c|}
\hline J.09 & J.10 & $\mathrm{J} .11$ & J.12 & \multicolumn{2}{|c|}{ J.13 } & J.14 & J15 & J16 & J17 & J18 & J19 & $\mathrm{J} 20$ & J.21 & J.22 & J.23 & J.24 \\
\hline $\begin{array}{l}\text { Mont } \\
\text { h ID }\end{array}$ & $\begin{array}{l}\text { Month ID } \\
\text { starting from } \\
\text { month } \\
\text { recorded in } \\
\mathrm{J} .05^{* * *}\end{array}$ & $\begin{array}{l}\text { Amount of } \\
\text { maize given } \\
\text { to livestock } \\
\text { e.g. poultry } \\
\text { (kgs) }\end{array}$ & $\begin{array}{l}\text { How much maize } \\
\text { was taken from } \\
\text { storage for home } \\
\text { consumption } \\
\text { (kgs) (githeri \& } \\
\text { posho)? } \\
\text { If } \text { " }^{\prime \prime}=>\text { J.14a } \\
\end{array}$ & \multicolumn{2}{|c|}{$\begin{array}{l}\text { During that } \\
\text { month, how much } \\
\text { maize was taken } \\
\text { from storage to be } \\
\text { sold? }(\mathrm{kg}) \\
\text { If "0" } \\
\text { " } 0 \text { o to J19 }\end{array}$} & $\begin{array}{l}\text { where } \\
\text { sold } \\
\text { codes } \\
\text { A }\end{array}$ & $\begin{array}{l}\text { Who got the } \\
\text { money from } \\
\text { sales } \\
\text { (see hh } \\
\text { codes } \\
100 \text { if more } \\
\text { than one) } \\
\end{array}$ & $\begin{array}{l}\text { What was the } \\
\text { average price that } \\
\text { you received for } \\
\text { sold grain during } \\
\text { that month? } \\
\text { KSh/KG }\end{array}$ & $\begin{array}{l}\text { Who was the } \\
\text { buyer for the } \\
\text { largest sale } \\
\text { in [month]? } \\
\text { CODE B }\end{array}$ & $\begin{array}{c}\text { Relation } \\
\text { to the } \\
\text { buyer } \\
\text { Codes C }\end{array}$ & \begin{tabular}{|c|} 
Market \\
fee \\
(KES)
\end{tabular} & $\begin{array}{c}\text { Time taken } \\
\text { to sell } \\
\text { (minutes) }\end{array}$ & $\begin{array}{l}\text { Time taken } \\
\text { to get to the } \\
\text { market } \\
\text { (minutes) }\end{array}$ & $\begin{array}{l}\text { Mode of } \\
\text { transport to } \\
\text { the market } \\
\text { Codes D }\end{array}$ & $\begin{array}{c}\text { Transport } \\
\text { cost to the } \\
\text { market } \\
\text { (KES) }\end{array}$ & $\begin{array}{l}\text { During that month, } \\
\text { how much maize } \\
\text { was taken from } \\
\text { storage to be } \\
\text { donated? kg } \\
\text { QTY }\end{array}$ \\
\hline \multicolumn{17}{|l|}{1} \\
\hline \multicolumn{17}{|l|}{2} \\
\hline \multicolumn{17}{|l|}{3} \\
\hline \multicolumn{17}{|l|}{4} \\
\hline \multicolumn{17}{|l|}{5} \\
\hline \multicolumn{17}{|l|}{6} \\
\hline \multicolumn{17}{|l|}{7} \\
\hline \multicolumn{17}{|l|}{8} \\
\hline \multicolumn{17}{|l|}{9} \\
\hline \multicolumn{17}{|l|}{10} \\
\hline \multicolumn{17}{|l|}{11} \\
\hline \multicolumn{17}{|l|}{12} \\
\hline \multicolumn{17}{|l|}{13} \\
\hline \multicolumn{3}{|c|}{$\begin{array}{l}\text { Codes A } \\
\text { 1. Farm gate } \\
\text { 2. Village market } \\
\text { 3. Main market } \\
\text { 4. other, specify... }\end{array}$} & \multicolumn{6}{|c|}{$\begin{array}{l}\text { Codes B } \\
\text { 1= Farmer group } \\
\text { 2= Farmer Union or Coop } \\
3=\text { Consumer or other farmer } \\
\text { 4= Rural assembler } \\
\text { 5= Broker/middlemen }\end{array}$} & \multicolumn{5}{|c|}{$\begin{array}{l}\text { Codes C } \\
1=\text { No relation but not a long term buyer } \\
2=\text { No relation but a long term buyer } \\
\text { lender } \\
3=\text { Relative } \\
\text { specify...... }\end{array}$} & \multicolumn{3}{|c|}{$\begin{array}{ll}\text { Codes D } & \\
\text { 1= Bicycle } & 5=\text { Oxen/horse cart } \\
\text { 2= Hired truck. } & 6=\text { Back/head load } \\
\text { 3= Public transport } & 7=\text { Other, specify } \ldots . \\
\text { 4= Donkey } & \end{array}$} \\
\hline
\end{tabular}




\section{MODULE 17: LIVESTOCK PRODUCTION AND MARKETING in the last 12 months}

Section 17A: Livestock: Please describe your household's livestock assets:

\begin{tabular}{|c|c|c|c|c|c|c|c|c|c|c|c|}
\hline & \multirow[t]{2}{*}{ Animal type } & \multirow{2}{*}{$\begin{array}{c}\text { Number owned } \\
\text { in the } \\
\text { household }\end{array}$} & \multicolumn{4}{|c|}{$\begin{array}{l}\text { Number owned by: } \\
\text { (total needs to add up) }\end{array}$} & \multirow{2}{*}{$\begin{array}{l}\text { How } \\
\text { many did } \\
\text { you sell }\end{array}$} & \multirow{2}{*}{$\begin{array}{l}\text { Average } \\
\text { selling } \\
\text { price } \\
\text { Ksh/unit }\end{array}$} & \multirow{2}{*}{$\begin{array}{c}\text { How } \\
\text { many } \\
\text { did you } \\
\text { consume }\end{array}$} & \multirow{2}{*}{$\begin{array}{l}\text { Who makes decision } \\
\text { to sell? } \\
\text { Household member } \\
\text { code. Put } 200 \text { if } \\
\text { both equally }\end{array}$} & \multirow{2}{*}{$\begin{array}{l}\text { Who decides how to use } \\
\text { the money from the sale? } \\
\text { Household member code. } \\
\text { Put } 200 \text { if both equally }\end{array}$} \\
\hline & & & Head & Spouse & Both & Other & & & & & \\
\hline 1 & Improved milking cow & & & & & & & & & & \\
\hline 2 & Other cows & & & & & & & & & & \\
\hline 3 & Trained oxen for ploughing & & & & & & & & & & \\
\hline 4 & Bulls & & & & & & & & & & \\
\hline 5 & Heifers & & & & & & & & & & \\
\hline 6 & Calves & & & & & & & & & & \\
\hline 7 & Goats & & & & & & & & & & \\
\hline 8 & Sheep & & & & & & & & & & \\
\hline 9 & Chicken & & & & & & & & & & \\
\hline 10 & Other poultry & & & & & & & & & & \\
\hline 11 & Donkey & & & & & & & & & & \\
\hline 12 & Pigs & & & & & & & & & & \\
\hline 13 & Camel & & & & & & & & & & \\
\hline 14 & Bee hives & & & & & & & & & & \\
\hline 15 & Rabbit & & & & & & & & & & \\
\hline 16 & & & & & & & & & & & \\
\hline
\end{tabular}

Section 17B: Livestock products: Please describe your household's livestock products:

\begin{tabular}{|c|c|c|c|c|}
\hline & Product & $\begin{array}{c}\text { Who manages the production? } \\
\text { Household member code. Put } 200 \text { if both } \\
\text { equally }\end{array}$ & $\begin{array}{l}\text { Who makes decision to sell? } \\
\text { Household member code. Put } 200 \text { if both } \\
\text { equally }\end{array}$ & $\begin{array}{l}\text { Who decides how to use the money from the sale? } \\
\text { Household member code. Put } 200 \text { if both equally }\end{array}$ \\
\hline 1 & Cow milk & & & \\
\hline 2 & Goat milk & & & \\
\hline 3 & Fermented milk (mala) & & & \\
\hline 4 & Eggs & & & \\
\hline 5 & Honey & & & \\
\hline
\end{tabular}


Please tell me about your sources of income that your household received in the last 12 months.

\begin{tabular}{|c|c|c|c|c|c|c|c|}
\hline & & \multirow[t]{2}{*}{ Type of income received } & \multirow{2}{*}{$\begin{array}{l}\text { Did you or any } \\
\text { household } \\
\text { member earn } \\
\text { income from } \\
\text { this last year? } \\
(\text { No }=0, \text { Yes }=1)\end{array}$} & \multirow{2}{*}{$\begin{array}{l}\text { Number of } \\
\text { units } \\
\text { (days, } \\
\text { weeks, ...) } \\
\text { worked per } \\
\text { year }\end{array}$} & \multicolumn{2}{|c|}{$\begin{array}{l}\text { Average income per } \\
\text { unit }\end{array}$} & \multirow{2}{*}{$\begin{array}{l}\text { Total } \\
\text { income } \\
\text { earned } \\
\text { (KShs) }\end{array}$} \\
\hline & & & & & $\begin{array}{l}\text { Cash } \\
\text { (Ksh) }\end{array}$ & $\begin{array}{c}\text { Payment in } \\
\text { kind - cash } \\
\text { equivalent } \\
\text { (Kshs) }\end{array}$ & \\
\hline \multirow[t]{4}{*}{ Labor } & 1 & Agricultural labor & & & & & \\
\hline & 2 & Casual labor & & & & & \\
\hline & 3 & Salary & & & & & \\
\hline & 4 & Pension & & & & & \\
\hline \multirow[t]{2}{*}{ Remittances } & 5 & Food aid & & & & & \\
\hline & 6 & Remittance income, gifts & & & & & \\
\hline Rent & 7 & Rent & & & & & \\
\hline \multirow{5}{*}{$\begin{array}{c}\text { Small } \\
\text { business }\end{array}$} & 8 & Brick making & & & & & \\
\hline & 9 & Carpentry & & & & & \\
\hline & 10 & Construction & & & & & \\
\hline & 11 & Grain mill & & & & & \\
\hline & 12 & Other: & & & & & \\
\hline \multirow{2}{*}{$\begin{array}{l}\text { Sales of } \\
\text { forest } \\
\text { products } \\
\text { Trade }\end{array}$} & 13 & Sale of wood and charcoal, & & & & & \\
\hline & 14 & Sale of wild nuts/fruits & & & & & \\
\hline \multirow[t]{5}{*}{ Petty trade } & 15 & Handicrafts & & & & & \\
\hline & 16 & Food & & & & & \\
\hline & 17 & Beverages, local brew & & & & & \\
\hline & 18 & Sales in shop, petty trade and & & & & & \\
\hline & 19 & Transport & & & & & \\
\hline \multirow{12}{*}{$\begin{array}{l}\text { Sales of } \\
\text { farm } \\
\text { products }\end{array}$} & 20 & Crops & & & & & \\
\hline & 21 & Animal manure & & & & & \\
\hline & 22 & Crop residues & & & & & \\
\hline & 23 & Hay, grass or fodder & & & & & \\
\hline & 24 & Cattle & & & & & \\
\hline & 25 & Milk & & & & & \\
\hline & 26 & Mala & & & & & \\
\hline & 27 & Skins, wool & & & & & \\
\hline & 28 & Poultry & & & & & \\
\hline & 29 & Eggs & & & & & \\
\hline & 30 & Other: & & & & & \\
\hline & 31 & Other: & & & & & \\
\hline
\end{tabular}


MODULE 19: ACCESS TO FINANCIAL CAPITAL, INFORMATION AND INSTITUTIONS

Section 19A: Household credit need and sources during 2011/12 cropping year

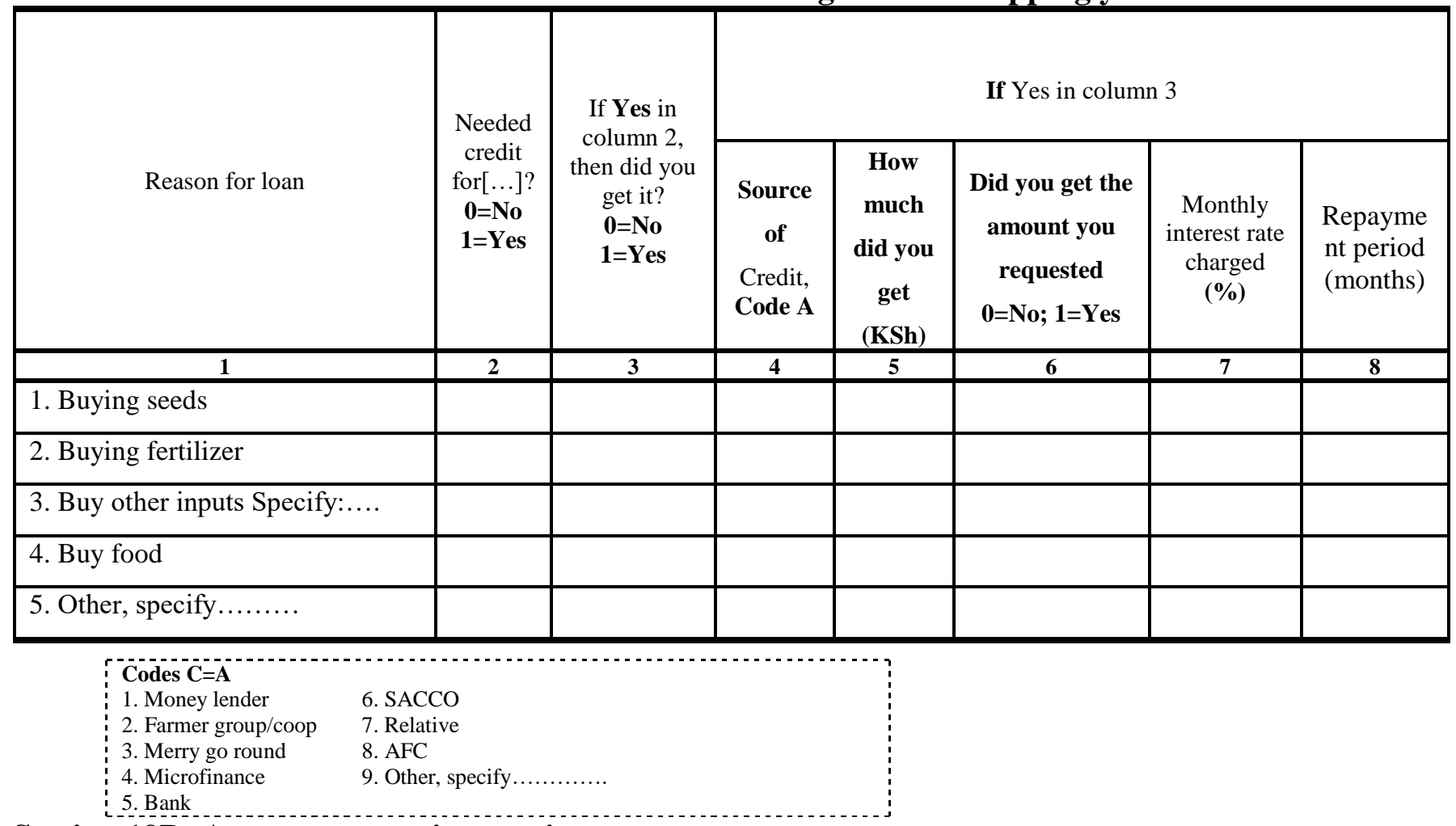

\section{Section 19B: Access to extension services}

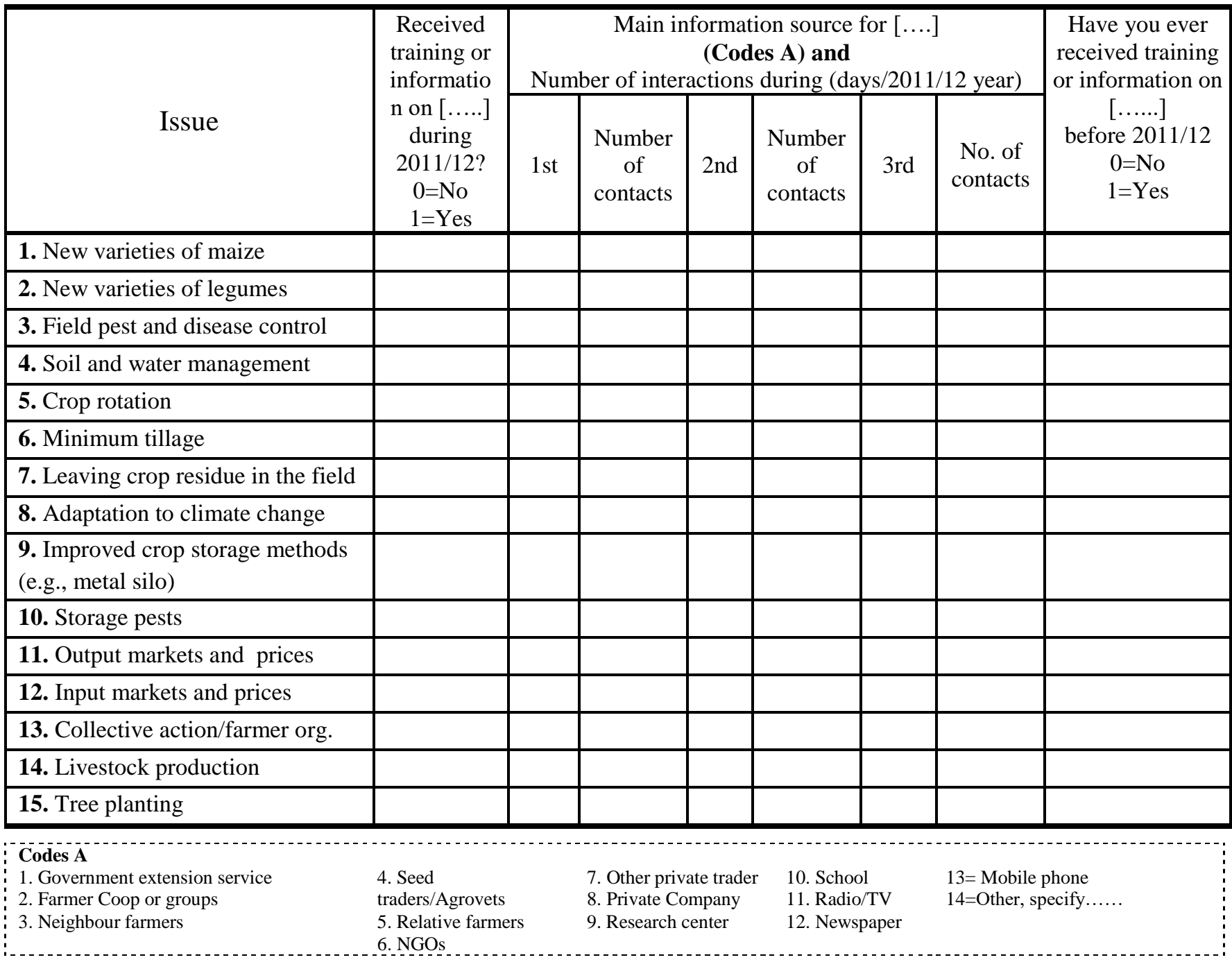




\section{MODULE 20: HOUSEHOLD FOOD AND NON-FOOD EXPENDITURE}

Section 20A: Food expenditure (Here, wife and/or the person involved in purchases should be the principal respondent/s).

\begin{tabular}{|c|c|c|c|}
\hline \multirow{2}{*}{$\begin{array}{l}\text { Item } \\
\text { ID }\end{array}$} & \multirow[t]{2}{*}{ Item name } & \multicolumn{2}{|c|}{$\begin{array}{c}\text { In the last } 7 \text { days did your household spend } \\
\text { money on [item]? If } 0=>\text { next[item] }\end{array}$} \\
\hline & & $1=$ Yes $0=\mathrm{No}$ & Ksh \\
\hline 1 & Maize & & \\
\hline 2 & Other cereals (sorghum, millet, wheat, rice) & & \\
\hline 2 & Legumes (beans, pigeon pea, cow pea, green grams) & & \\
\hline 3 & Maize flour & & \\
\hline 4 & Wheat flour & & \\
\hline 5 & Bread & & \\
\hline 6 & $\begin{array}{l}\text { Roots and tubers (potatoes/ sweet potatoes/ arrow } \\
\text { roots/cassava) }\end{array}$ & & \\
\hline 7 & Vegetables & & \\
\hline 8 & Fruits & & \\
\hline 9 & Meat and animal products & & \\
\hline 10 & Milk and dairy products & & \\
\hline 11 & Beverages and drinks (non-alcohol) & & \\
\hline 12 & Fruits (mangoes, pawpaws, bananas,avocadoes.) & & \\
\hline 14 & Oils and spices (sugar, salt, seasoning) & & \\
\hline 15 & Meals eaten away from home & & \\
\hline 16 & Alcohol and cigarettes & & \\
\hline 17 & Other 1 , specify & & \\
\hline 18 & Other 2, specify & & \\
\hline 19 & Other 3, specify & & \\
\hline
\end{tabular}

\section{Section 20B: Non-food expenditure}

\begin{tabular}{|c|c|c|c|}
\hline $\begin{array}{c}\text { Item } \\
\text { No }\end{array}$ & Item name & $\begin{array}{c}\text { In the past } \mathbf{1 2} \\
\text { months, did your } \\
\text { household spend } \\
\text { money on [item]? if } \\
\text { 0=> next [item] }\end{array}$ & $\begin{array}{c}\text { What was your } \\
\text { household's total } \\
\text { expenditure on [item] } \\
\text { over the last } 12 \\
\text { months? }\end{array}$ \\
\hline & & $1=$ Yes $\quad 0=$ No & KSh \\
\hline 1 & Fuel (firewood, charcoal, kerosene, gas) & & \\
\hline 2 & Transport & & \\
\hline 3 & Communication (cell phone, calling) & & \\
\hline 4 & Electronics (TV, Radio) & & \\
\hline 5 & Entertainment (cinema/ movies, TV subscription) & & \\
\hline 6 & Utilities and taxes (electricity bill, water) & & \\
\hline 6 & Clothes and shoes (including school uniforms) & & \\
\hline 8 & School fees and other educational expenses & & \\
\hline 9 & Social events (wedding, funeral, harambee, etc) & & \\
\hline 10 & Housing improvement (latrine, new roof, etc) & & \\
\hline 11 & $\begin{array}{l}\text { Human health expenses (medication, consultation, } \\
\text { hospitalization) }\end{array}$ & & \\
\hline 12 & Vacation & & \\
\hline 13 & Livestock & & \\
\hline 14 & Other 1, specify & & \\
\hline 15 & Other 2, specify & & \\
\hline 16 & Other 3, specify & & \\
\hline
\end{tabular}




\section{MODULE 21 - HOUSEHOLD FOOD INSECURITY ACCESS SCALE}

Taking into consideration ALL your food sources (own food production + food purchase + help from different sources + food hunted from forest and lakes, etc.), how would you define your family's food consumption last year? (Codes E). /

Codes E: $\quad 1=$ Food shortage throughout the year $3=$ No food shortage but no surplus

$$
2=\text { Occasional food shortage } \quad 4=\text { Food surplus. }
$$

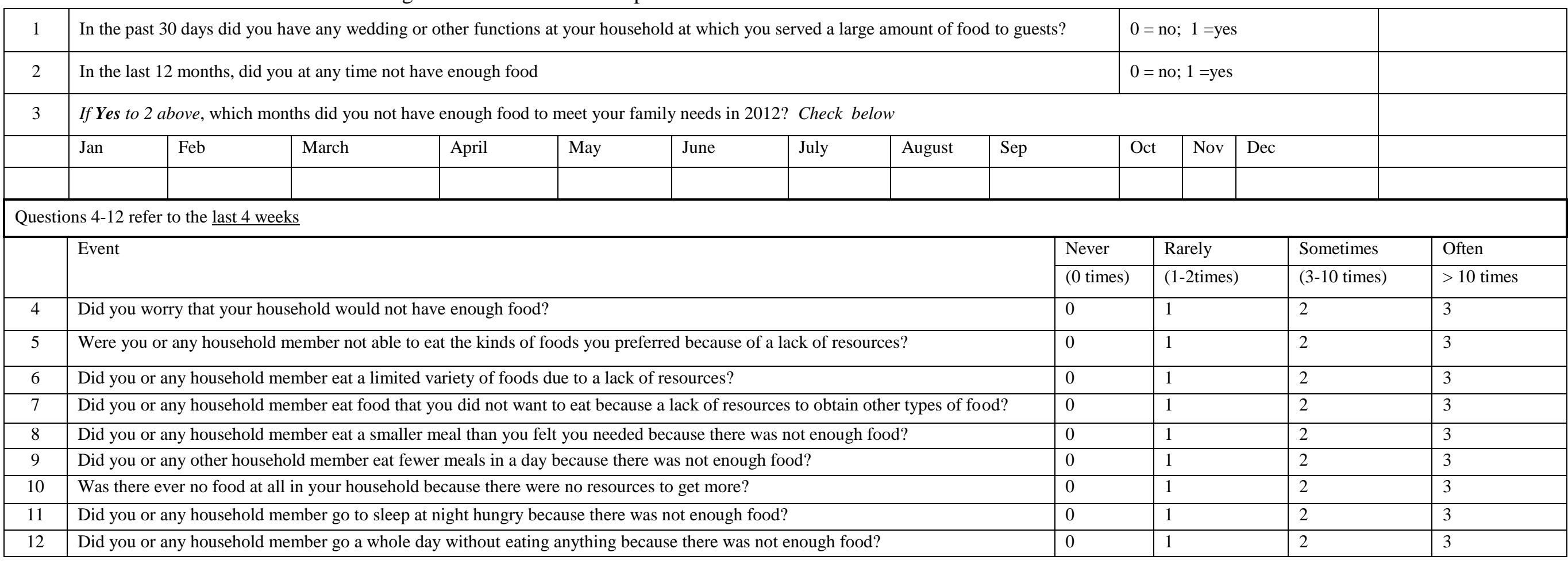




\section{RISK GAME}

\section{TEST GAME}

Interviewer - Step 1: Before starting the real game, ask the respondent to try a test-game using candy. In this test-game, there are only 2 choices:

\begin{tabular}{|l|l|l|l|l|}
\hline Choice & $\begin{array}{l}\text { Event A } \\
\text { Blue stone } \\
\text { Probability 50\% }\end{array}$ & $\begin{array}{l}\text { Event B } \\
\text { Yellow stone } \\
\text { Probability 50\% }\end{array}$ & $\begin{array}{l}\text { Respondent's } \\
\text { selection } \\
\text { (Mark } \boldsymbol{X} \text { ) }\end{array}$ & Give reason \\
\hline 1 & 1 candy & 5 candies & & \\
\hline 2 & 3 candies & 2 candies & & \\
\hline 3 & None of the above choices & & \\
\hline
\end{tabular}

Interviewer - Step 2: After the respondent has made a selection of his/her preferred gamble choice, ask him/her to draw a coloured stone.

1. What is the colour of the drawn coloured stone? Blue Yellow

Interviewer - Step 3: Decide on the amount based on the gamble choice selected above.

2. Total candy received (pieces).

\section{REAL GAME}

Interviewer - Step 4: Once the respondent completely understands the game, give the respondent 50 KSH endowment and show all 5 choice cards to the respondent in any random order. Ask the respondent for his/her most preferred choice lottery and mark the selection $(\boldsymbol{X})$ in given box below and ask for reason.

Mark the respondent's choice selection with an $X$ in the last column across from his/her preferred choice.

\begin{tabular}{|l|l|l|l|l|}
\hline Choice & $\begin{array}{l}\text { Event A } \\
\text { Blue stone } \\
\text { Probability 50\% }\end{array}$ & $\begin{array}{l}\text { Event B } \\
\text { Yellow stone } \\
\text { Probability 50\% }\end{array}$ & $\begin{array}{l}\text { Respondent's } \\
\text { selection } \\
\text { (Mark } \boldsymbol{X} \text { ) }\end{array}$ & Give reason \\
\hline 1 & 50 & 50 & & \\
\hline 2 & 80 & 30 & & \\
\hline 3 & 100 & 20 & & \\
\hline 4 & 120 & 10 & & \\
\hline 5 & 150 & -20 & & \\
\hline 6 & None of the above choice & & \\
\hline
\end{tabular}

Interviewer - Step 5: After the respondent has made a selection of his/her preferred gamble choice, ask him/her to draw a coloured stone.

What is the colour of the drawn coloured stone? Blue
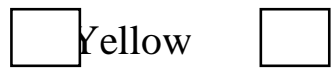

Interviewer - Step 7: Decide on the amount to be paid or deducted based on the gamble choice selected above.

Total amount received: $50 \mathrm{KSH}+$ $\mathrm{KSH}=$ KSH

(Respondent signature 